Portland State University

PDXScholar

$12-2008$

\title{
Using Archived ITS Data to Measure the Operational Benefits of a System-wide Adaptive Ramp Metering System
}

\author{
Robert L. Bertini \\ Portland State University \\ Christopher Monsere \\ Portland State University, monsere@pdx.edu \\ Oren Eshel \\ Portland State University \\ Soyoung Ahn \\ Arizona State University
}

Follow this and additional works at: https://pdxscholar.library.pdx.edu/cengin_fac

Part of the Civil and Environmental Engineering Commons, and the Transportation Commons Let us know how access to this document benefits you.

\section{Citation Details}

Bertini, Robert L., Christopher Monsere, Oren Eshel, and Soyoung Ahn. Using Archived ITS Data to Measure the Operational Benefits of a System-wide Adaptive Ramp Metering System. SPR 645 OTRECRR-08-04. Portland, OR: Transportation Research and Education Center (TREC), 2008. http://dx.doi.org/ 10.15760/trec.152

This Report is brought to you for free and open access. It has been accepted for inclusion in Civil and Environmental Engineering Faculty Publications and Presentations by an authorized administrator of PDXScholar. Please contact us if we can make this document more accessible: pdxscholar@pdx.edu. 

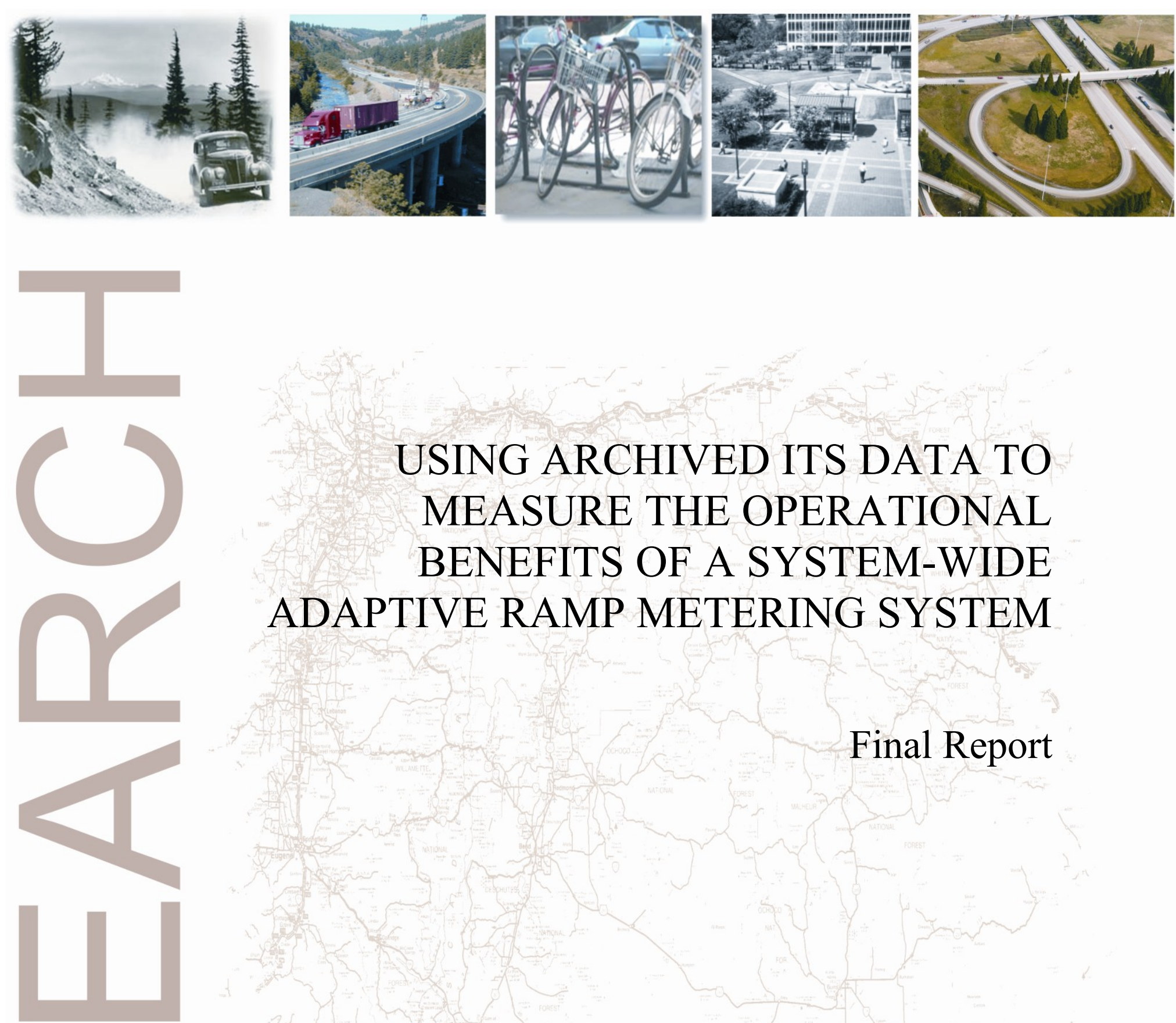

\section{USING ARCHIVED ITS DATA TO MEASURE THE OPERATIONAL BENEFITS OF A SYSTEM-WIDE BENEFITS OF A SYSTEM-WIDE
ADAPTIVE RAMP METERING SYSTEM}

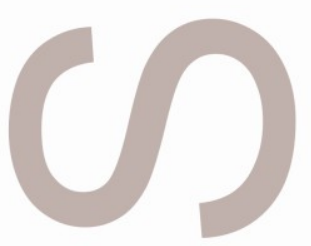

Final Report
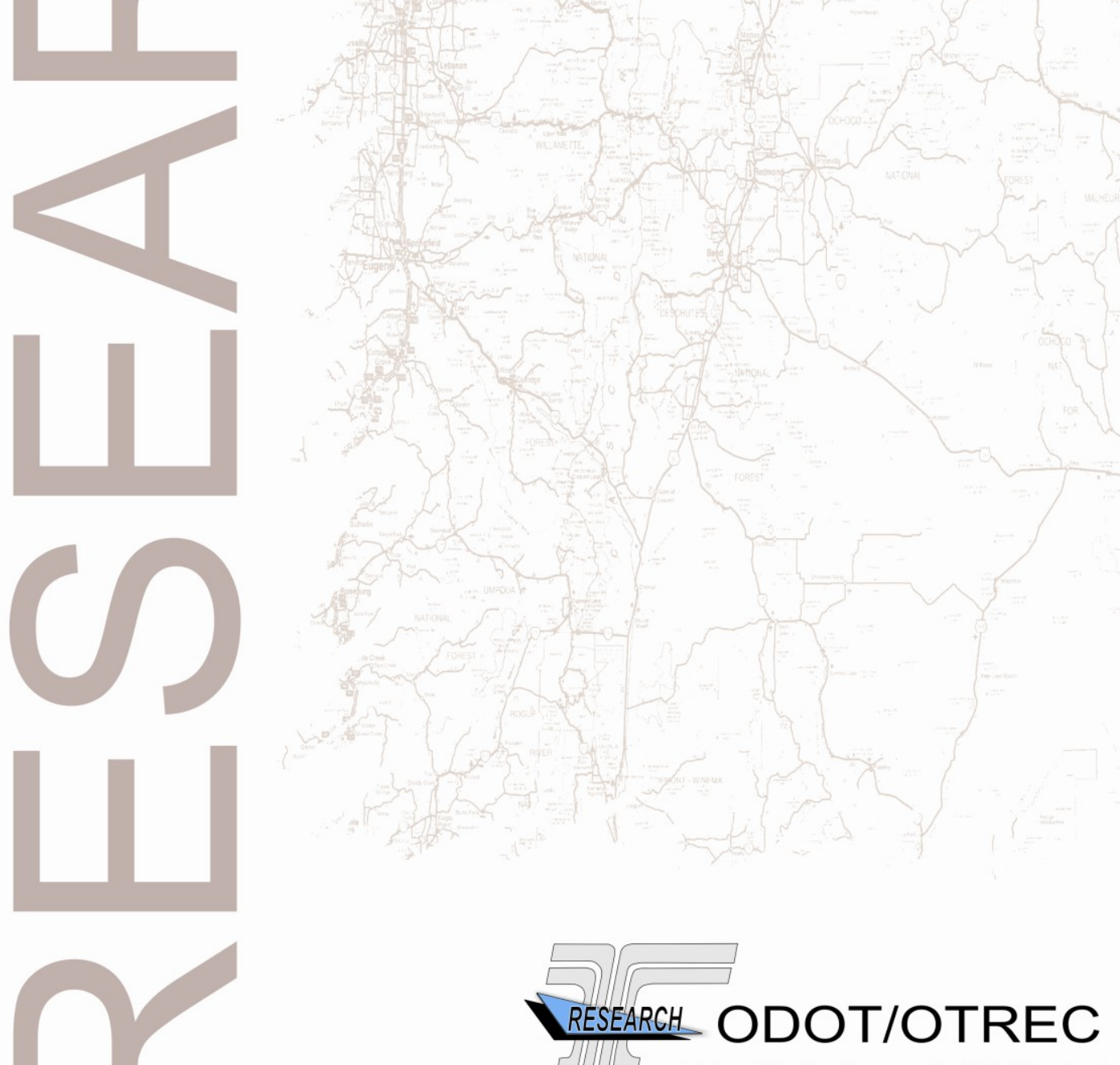

This publication is a result of joint funding by Oregon Department of Transportation (ODOT) and Oregon Transportation Research and Education Consortium (OTREC) 



\title{
USING ARCHIVED ITS DATA TO MEASURE THE OPERATIONAL BENEFITS OF A SYSTEM-WIDE ADAPTIVE RAMP METERING SYSTEM
}

\author{
Final Report \\ SPR 645 \\ OTREC-RR-08-04
}

\author{
by \\ Christopher M. Monsere, Assistant Professor \\ Robert L. Bertini, Associate Professor \\ Oren Eshel, Graduate Student \\ Portland State University \\ PO Box 751 \\ Portland OR 97207 \\ and \\ Soyoung Ahn, Assistant Professor \\ Arizona State University \\ Tempe, AZ 85287-5306 \\ for \\ Oregon Department of Transportation \\ Research Unit \\ 200 Hawthorne Avenue SE, Suite B-240 \\ Salem OR 97301-5192 \\ Oregon Transportation Research \\ and Education Consortium \\ P.O. Box 751 \\ Portland, OR 97207 \\ and \\ Federal Highway Administration \\ 400 Seventh Street, SW \\ Washington, DC 20590-0003
}

December 2008 



\begin{tabular}{|c|c|c|}
\hline $\begin{array}{l}\text { 1. Report No. } \\
\text { FHWA-OR-RD-09-10 } \\
\text { OTREC-RR-08-04 }\end{array}$ & 2. Government Accession No. & 3. Recipient's Catalog No. \\
\hline \multicolumn{2}{|l|}{ 4. Title and Subtitle } & 5. Report Date \\
\hline \multicolumn{2}{|c|}{$\begin{array}{l}\text { Using Archived Data to Measure Operational Benefits of a System-wide Adaptive Ramp Metering } \\
\text { (SWARM) System }\end{array}$} & December 2008 \\
\hline 7. Author(s) & & 8. Performing Organization Report No. \\
\hline \multicolumn{3}{|c|}{ Christopher M. Monsere, Ph.D., PE; Robert L. Bertini, Ph.D., PE; Soyoung Ahn, Ph.D. Oren Eshel } \\
\hline \multicolumn{2}{|c|}{ 9. Performing Organization Name and Address } & 10. Work Unit No. (TRAIS) \\
\hline \multicolumn{2}{|c|}{$\begin{array}{l}\text { Portland State University } \\
\text { Department of Civil and Environmental Engineering } \\
\text { P.O. Box } 751 \\
\text { Portland, OR 97207-0751 }\end{array}$} & $\begin{array}{l}\text { 11. Contract or Grant No. } \\
\text { SPR } 645 \\
\text { OTREC RR-08-190 }\end{array}$ \\
\hline \multicolumn{2}{|c|}{ 12. Sponsoring Agency's Names and Addresses } & 13. Type of Report and Period Covered \\
\hline $\begin{array}{l}\text { Oregon Department of Transportation } \\
\text { Research Unit }\end{array}$ & $\begin{array}{l}\text { Oregon Transportation Research } \\
\text { and Education Consortium (OTREC) }\end{array}$ & Final Report \\
\hline $\begin{array}{l}200 \text { Hawthorne Ave. SE, Suite B-240 } \\
\text { Salem, Oregon 97301-5192 }\end{array}$ & $\begin{array}{l}\text { P.O. Box } 751 \\
\text { Portland, Oregon } 97207\end{array}$ & 14. Sponsoring Agency Code \\
\hline \multicolumn{3}{|l|}{$\begin{array}{l}\text { Federal Highway Administration } \\
400 \text { Seventh Street SW } \\
\text { Washington, DC 20590-0003 }\end{array}$} \\
\hline
\end{tabular}

15. Supplementary Notes

16. Abstract

A System-Wide Adaptive Ramp Metering (SWARM) system has been implemented in the Portland, Oregon metropolitan area, replacing the previous pre-timed ramp-metering system that had been in operation since 1981. SWARM has been deployed on six major corridors and operates during the morning and afternoon peak hours. This report presents results of a "before" and "after" evaluation of the performance of two freeway corridors as part of ongoing efforts to measure the benefits of the new SWARM system, as compared to the pre-timed system. The study benefited from using the existing regional data, surveillance and communications infrastructure in addition to a regional data archive system. The evaluation revealed that the operation of the SWARM system, as currently configured in the Portland metropolitan region, produced mixed results when comparing the selected performance metrics to pre-timed operation. For the I-205 corridor, the results were generally positive. In the morning peak period, SWARM operation resulted in an $18.1 \%$ decrease in mainline delay and decreased variability in the delay. For the afternoon peak period, improvements were also found (a $7.9 \%$ decrease in mainline delay) with the exception of moderately congested days which saw an $4.7 \%$ increase in mainline delay. On the OR-217, however, significant increases were found in overall average delay. In the morning peak period, delay increased $34.9 \%$ while in the afternoon period delay increased $55.0 \%$. These conclusions, however, must be tempered because of lack of ramp demand data. If an assumption is made that ramp demand changes correspond with the measured freeway VMT changes, it is likely that ramp delay decreased under SWARM operation (i.e. more vehicles were allowed on the freeway which would equate to lower delay for vehicles on the ramps). Another important finding of this evaluation was that implementation of the SWARM algorithm resulted in significantly more data communication failures in the traffic management system. While this outcome is specific to the ODOT communication infrastructure and hardware, it was not anticipated. These communication failures have the potential to impact other traveler information programs that depend on the freeway surveillance data as well as the SWARM algorithm. Finally, one of the intentions of this research project was to encourage ongoing evaluation and continuous improvement of the ramp metering system and, in general, the overall freeway management system. It is clear from the analysis that meter activation times and rates are necessary to evaluate system performance. Incorporating additional logging capabilities into the SWARM system would make it easier to evaluate system operations on an on-going automated basis.

17. Key Words

RAMP METERING;FREEWAY OPERATIONS; DATA ARCHIVE

18. Distribution Statement Copies available from NTIS, and online at http://www.oregon.gov/ODOT/TD/TP_RES/ and http://www.otrec.us

\begin{tabular}{l|l|l|l|}
\hline $\begin{array}{l}\text { 19. Security Classification (of this report) } \\
\text { Unclassified }\end{array}$ & $\begin{array}{l}\text { 20. Security Classification (of this page) } \\
\text { Unclassified }\end{array}$ & $\begin{array}{l}21 . \text { No. of Pages } \\
132\end{array}$ & 22. Price \\
\hline
\end{tabular}




\begin{tabular}{|c|c|c|c|c|c|c|c|c|c|}
\hline \multicolumn{10}{|c|}{ SI* (MODERN METRIC) CONVERSION FACTORS } \\
\hline \multicolumn{5}{|c|}{ APPROXIMATE CONVERSIONS TO SI UNITS } & \multicolumn{5}{|c|}{ APPROXIMATE CONVERSIONS FROM SI UNITS } \\
\hline Symbol & When You Know & Multiply By & To Find & Symbol & Symbol & When You Know & Multiply By & To Find & Symbol \\
\hline \multicolumn{5}{|c|}{$\underline{\text { LENGTH }}$} & \multicolumn{5}{|c|}{$\underline{\text { LENGTH }}$} \\
\hline in & inches & 25.4 & millimeters & $\mathrm{mm}$ & $\mathrm{mm}$ & millimeters & 0.039 & inches & in \\
\hline $\mathrm{ft}$ & feet & 0.305 & meters & $\mathrm{m}$ & $\mathrm{m}$ & meters & 3.28 & feet & $\mathrm{ft}$ \\
\hline yd & yards & 0.914 & meters & $\mathrm{m}$ & $\mathrm{m}$ & meters & 1.09 & yards & yd \\
\hline $\mathrm{mi}$ & miles & 1.61 & kilometers & $\mathrm{km}$ & $\mathrm{km}$ & kilometers & 0.621 & miles & $\mathrm{mi}$ \\
\hline \multicolumn{5}{|c|}{ AREA } & \multicolumn{5}{|c|}{ AREA } \\
\hline in $^{2}$ & square inches & 645.2 & millimeters squared & $\mathrm{mm}^{2}$ & $\mathrm{~mm}^{2}$ & millimeters squared & 0.0016 & square inches & in $^{2}$ \\
\hline $\mathrm{ft}^{2}$ & square feet & 0.093 & meters squared & $\mathrm{m}^{2}$ & $\mathrm{~m}^{2}$ & meters squared & 10.764 & square feet & $\mathrm{ft}^{2}$ \\
\hline $\mathrm{yd}^{2}$ & square yards & 0.836 & meters squared & $\mathrm{m}^{2}$ & ha & hectares & 2.47 & acres & $\mathrm{ac}$ \\
\hline $\mathrm{ac}$ & acres & 0.405 & hectares & ha & $\mathrm{km}^{2}$ & kilometers squared & 0.386 & square miles & $\mathrm{mi}^{2}$ \\
\hline \multirow[t]{2}{*}{$\mathrm{mi}^{2}$} & square miles & 2.59 & kilometers squared & $\mathrm{km}^{2}$ & \multicolumn{5}{|c|}{ VOLUME } \\
\hline & & VOLUME & & & $\mathrm{mL}$ & milliliters & 0.034 & fluid ounces & $\mathrm{fl} \mathrm{oz}$ \\
\hline $\mathrm{fl} \mathrm{oz}$ & fluid ounces & 29.57 & milliliters & $\mathrm{mL}$ & $\mathrm{L}$ & liters & 0.264 & gallons & gal \\
\hline gal & gallons & 3.785 & liters & $\mathrm{L}$ & $\mathrm{m}^{3}$ & meters cubed & 35.315 & cubic feet & $\mathrm{ft}^{3}$ \\
\hline $\mathrm{ft}^{3}$ & cubic feet & 0.028 & meters cubed & $\mathrm{m}^{3}$ & $\mathrm{~m}^{3}$ & meters cubed & 1.308 & cubic yards & $\mathrm{yd}^{3}$ \\
\hline $\mathrm{yd}^{3}$ & cubic yards & 0.765 & meters cubed & $\mathrm{m}^{3}$ & & & MASS & & \\
\hline \multicolumn{5}{|c|}{ NOTE: Volumes greater than $1000 \mathrm{~L}$ shall be shown in $\mathrm{m}^{3}$. } & g & grams & 0.035 & ounces & $\mathrm{oz}$ \\
\hline & & $\underline{\text { MASS }}$ & & & $\mathrm{kg}$ & kilograms & 2.205 & pounds & $\mathrm{lb}$ \\
\hline $\mathrm{oz}$ & ounces & 28.35 & grams & $\mathrm{g}$ & $\mathrm{Mg}$ & megagrams & 1.102 & short tons $(2000 \mathrm{lb})$ & $\mathrm{T}$ \\
\hline $\mathrm{lb}$ & pounds & 0.454 & kilograms & $\mathrm{kg}$ & \multicolumn{5}{|c|}{ TEMPERATURE (exact) } \\
\hline $\mathrm{T}$ & short tons (2000 lb) & 0.907 & megagrams & $\mathrm{Mg}$ & ${ }^{\circ} \mathrm{C}$ & Celsius temperature & $1.8+32$ & Fahrenheit & ${ }^{\circ} \mathrm{F}$ \\
\hline \multicolumn{10}{|c|}{ TEMPERATURE (exact) } \\
\hline${ }^{\circ} \mathrm{F}$ & $\begin{array}{l}\text { Fahrenheit } \\
\text { temperature }\end{array}$ & $5(\mathrm{~F}-32) / 9$ & Celsius temperature & ${ }^{\circ} \mathrm{C}$ & & $\begin{array}{ccc}-40 & -20 \\
{ }^{\circ} \mathrm{C} & -20\end{array}$ & $20 \begin{array}{ccc}1 & 11 \\
20 & 40 \\
& 37\end{array}$ & 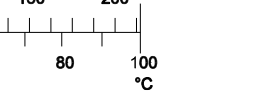 & \\
\hline * SI is the sy & bol for the International s & em of Measurem & & & & & & & (4-7-94 jbp) \\
\hline
\end{tabular}




\section{ACKNOWLEDGEMENTS}

The authors thank the Oregon Department of Transportation (ODOT), Federal Highway Administration (FHWA), Oregon Transportation Research and Education Consortium (OTREC) and the National Science Foundation for providing the data and/or for funding this research. Portland State University's Department of Civil and Environmental Engineering and the Oregon Engineering and Technology Industry Council also supported this work. The Technical Advisory Committee has provided valuable input throughout the project, members of the committee include: Jack Marchant, Galen McGill, Dennis Mitchell, Phuong Nguyen, Amy Mastraccio and June Ross - ODOT; Bill Kloos and Paul Zebell, City of Portland; Nathaniel Price - FHWA. The contents of this report reflect the views and opinions of the authors, who are responsible for the facts and the accuracy of the data presented here.

\section{DISCLAIMER}

The contents of this report reflect the views of the authors, who are solely responsible for the facts and the accuracy of the material and information presented herein. This document is disseminated under the sponsorship of the United States. Department of Transportation University Transportation Centers Program, the United States Department of Transportation, and Oregon Department of Transportation in the interest of information exchange. The U.S. Government and the Oregon Department of Transportation assume no liability for the contents or use thereof. The contents do not necessarily reflect the official views of the U.S. Government or Oregon Department of Transportation. This report does not constitute a standard, specification, or regulation. 


\section{USING ARCHIVED ITS DATA TO MEASURE THE OPERATIONAL BENEFITS OF A SYSTEM-WIDE ADAPTIVE RAMP METERING SYSTEM}

\section{TABLE OF CONTENTS}

EXECUTIVE SUMMARY XIII

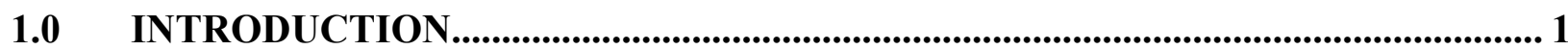

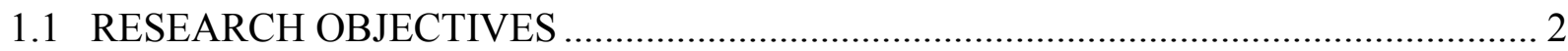

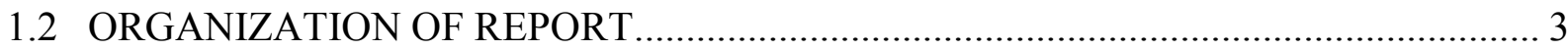

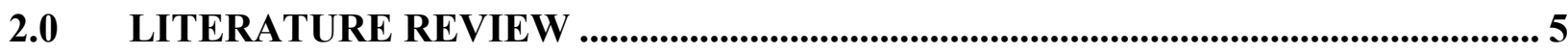

2.1 SYSTEM-WIDE AREA RAMP METERING (SWARM) ………............................... 6

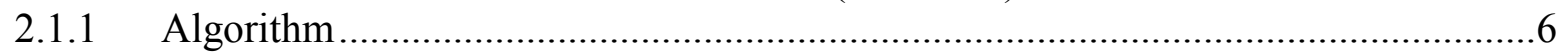

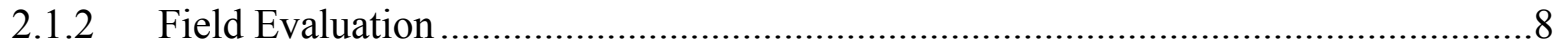

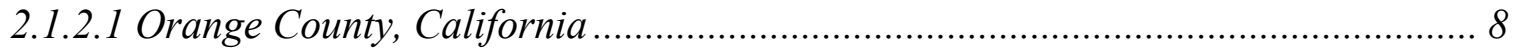

2.1.2.2 Los Angeles and Ventura Counties, California ................................................. 8

2.2 OTHER TRAFFIC-RESPONSIVE RAMP METERING ………….............................. 8

2.2.1 Zone Algorithm - Minneapolis/St. Paul, Minnesota ................................................. 9

2.2.2 Helper Algorithm - Denver, Colorado ……….................................................. 10

2.2.3 Bottleneck Algorithm - Seattle, Washington .............................................................10

2.2.4 Fuzzy Logic Algorithm - Seattle, Washington and Zoetermeer,

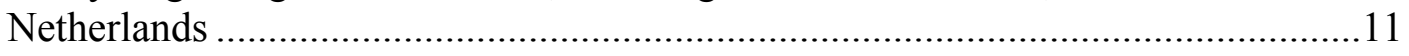

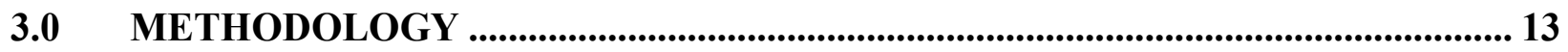

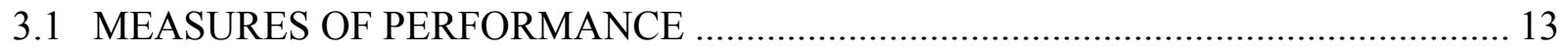

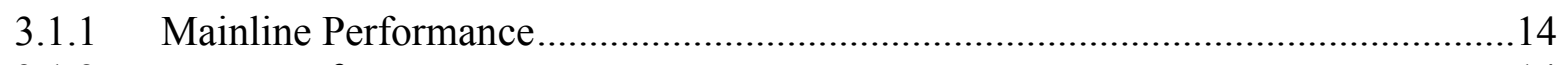

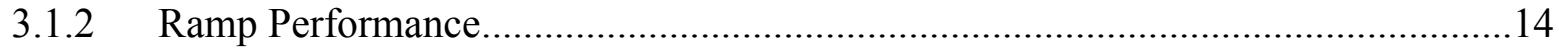

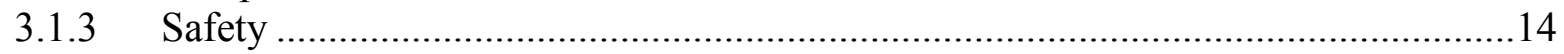

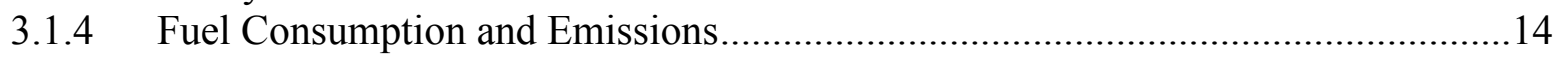

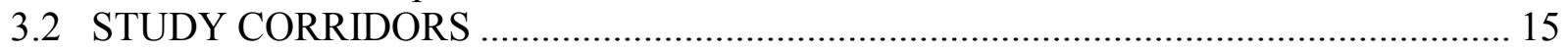

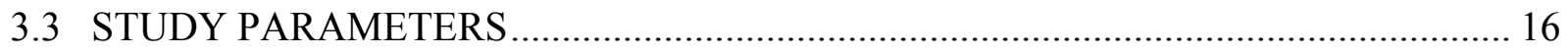

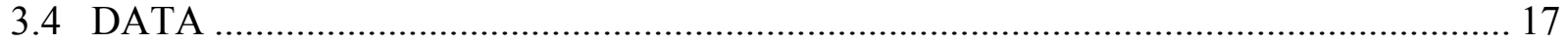

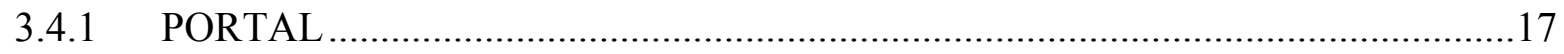

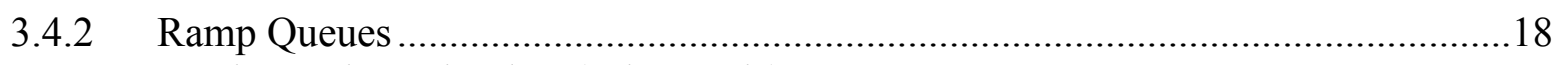

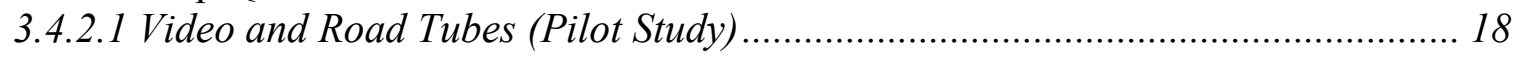

3.4.2.2 Programmable Logic Controllers (Regional Study).......................................... 20

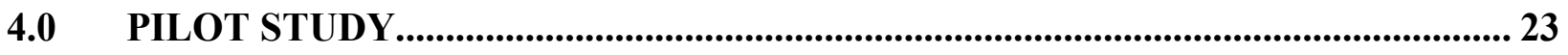

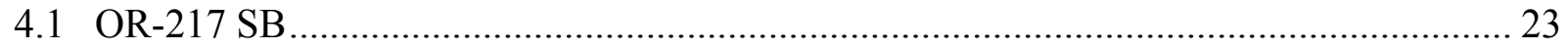

4.1.1 Typical Congestion Pattern........................................................................24

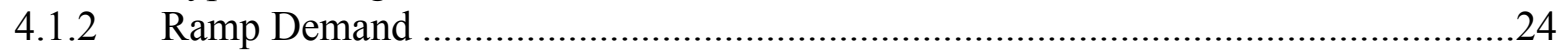

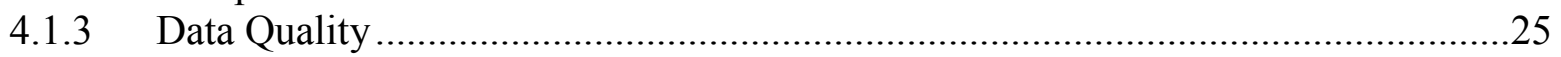

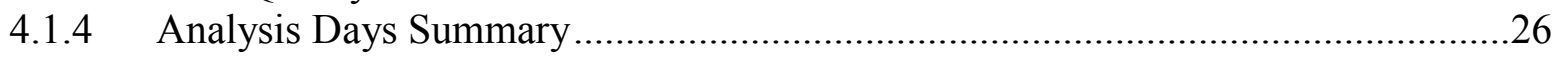

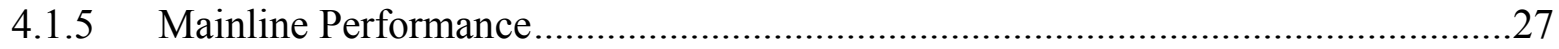

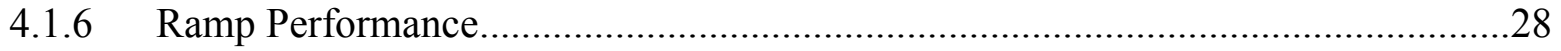




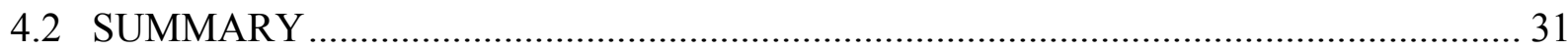

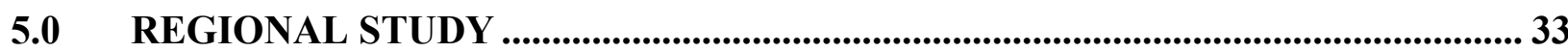

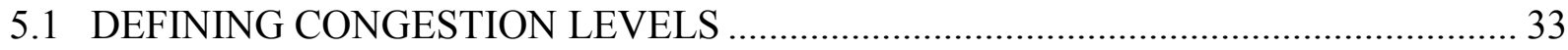

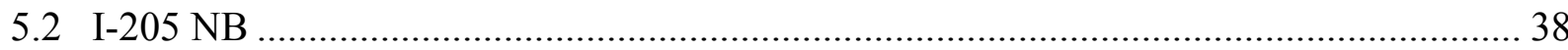

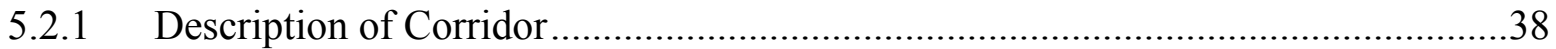

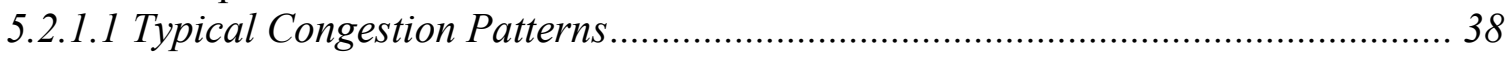

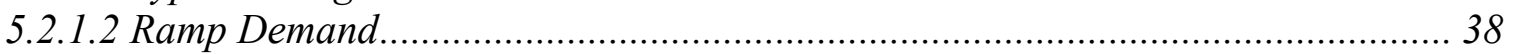

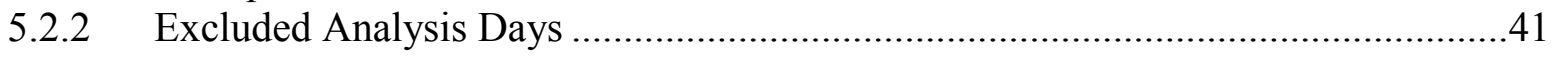

5.2.2.1 Communication Failures ............................................................................... 41

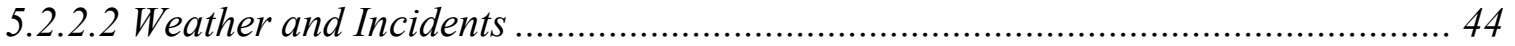

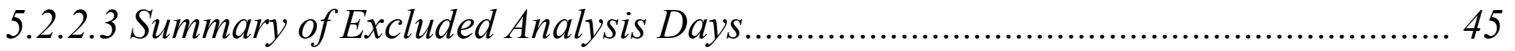

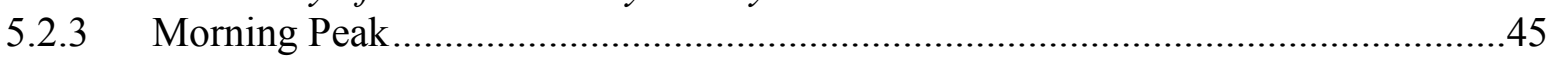

5.2.3.1 Mainline Performance …………………………........................................ 45

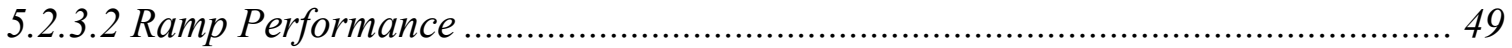

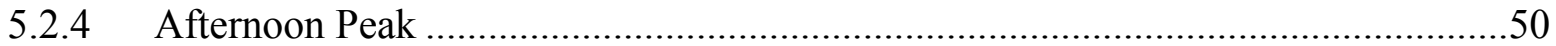

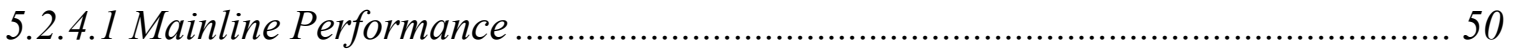

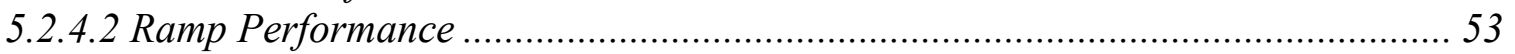

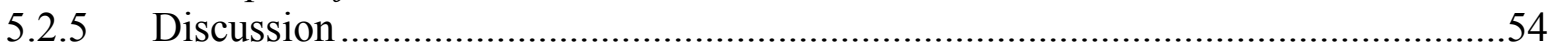

5.2.5.1 SWARM Performance on Moderately Congested Days...................................... 55

5.2.5.1.1 Johnson Creek to Powell..................................................................... 57

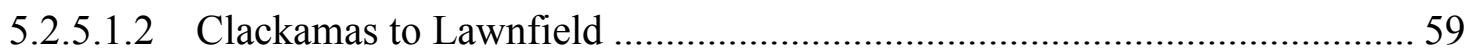

5.2.5.1 SWARM Performance on Very Highly Congested Days....................................... 60

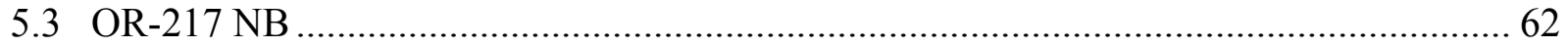

5.3.1 Description of Corridor .............................................................................62

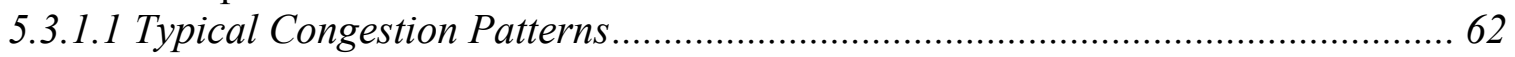

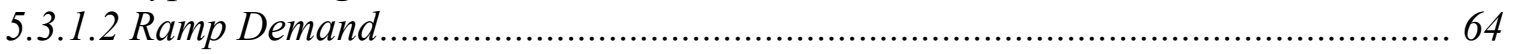

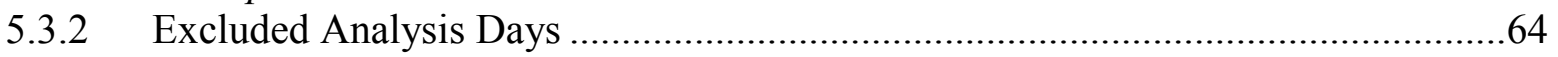

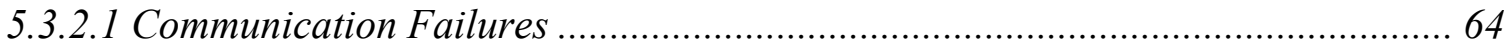

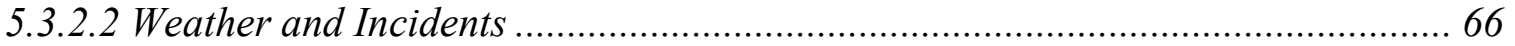

5.3.2.3 Summary of Excluded Analysis Days.............................................................. 67

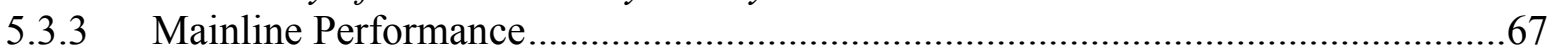

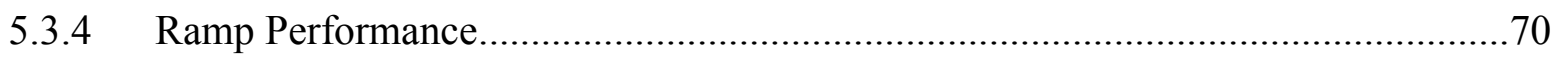

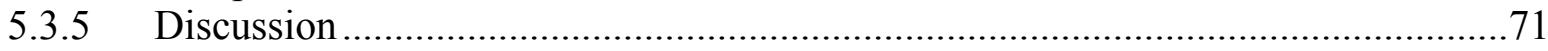

5.3.5.1 SWARM Performance on Very Highly Congested Days...................................... 71

6.0 CONCLUSIONS AND RECOMMENDATIONS......................................................... 75

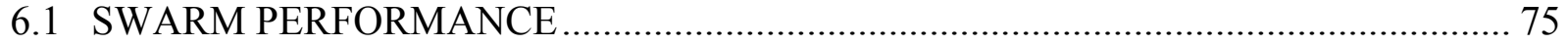

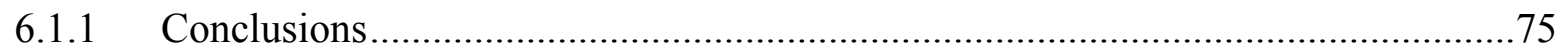

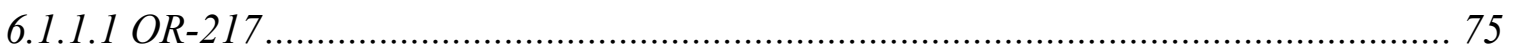

6.1.1.2 I-205

6.1.1.3 Comparison of Results ................................................................................. 77

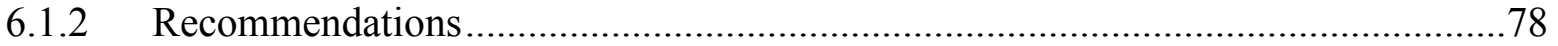

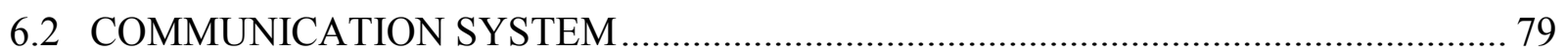

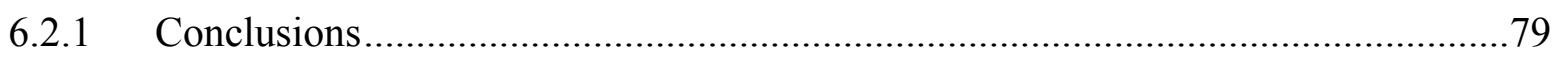

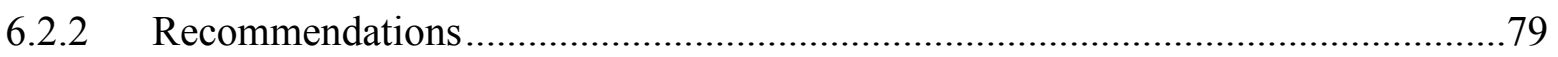

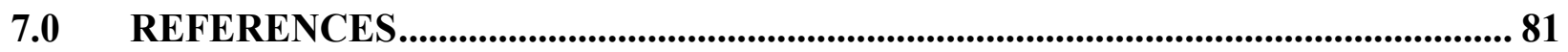




\author{
APPENDICES \\ APPENDIX A: SELECTED TIME-SPACE SPEED CONTOUR \\ APPENDIX B: USING PORTAL DATA TO MONITOR THE RAMP METERING \\ SYSTEM \\ APPENDIX ONLINE-1: I-205 NB TIME- SPACE SPEED CONTOUR PLOTS WITH \\ METER ACTIVATIONS \\ APPENDIX ONLINE-2: I-205 NB SPEED-FLOW PLOTS \\ APPENDIX ONLINE-3: I-205 NB SPEED-OCCUPANCY PLOTS \\ APPENDIX ONLINE-4: I-205 NB FLOW-OCCUPANCY PLOTS \\ APPENDIX ONLINE-5: I-205 NB ON-RAMP FLOW - MAINLINE SPEED/FLOW \\ PLOTS \\ APPENDIX ONLINE-6: OR-217 NB SPACE SPEED CONTOUR PLOTS WITH METER \\ ACTIVATIONS \\ APPENDIX ONLINE-7: OR-217 NB SPEED-FLOW PLOTS \\ APPENDIX ONLINE-8: OR-217 NB SPEED-OCCUPANCY PLOTS \\ APPENDIX ONLINE-9: OR-217 NB FLOW-OCCUPANCY PLOTS \\ APPENDIX ONLINE-10: OR-217 NB ON-RAMP FLOW - MAINLINE SPEED/FLOW \\ PLOTS
}

The online appendices can be found on the ODOT Research Unit website at: http://www.oregon.gov/ODOT/TD/TP RES/ResearchReports.shtml

\title{
LIST OF TABLES
}

Table 3.1: Potential measures for evaluations and data sources..................................................13

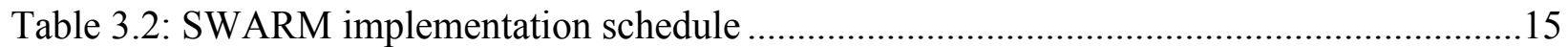

Table 3.3: Dates of study, pre-timed metering times, and SWARM study times..........................17

Table 3.4: Pilot study data collection methods .......................................................................19

Table 4.1: Summary of evaluation results of the mainline freeway, 6:00 to 9:00 AM ................27

Table 5.1: Criteria for levels of congestion for corridor..............................................................35

Table 5.2: Summary of congestion levels for pre-timed and SWARM study days.........................37

Table 5.3: Percent communication failures under pre-timed and SWARM by day and station, I-205 NB, 6-10 AM

Table 5.4: Percent communication failures under pre-timed and SWARM by day and station, I-205 NB, 1-7 PM

Table 5.5 Observed weather during study period for I-205 NB

Table 5.6 Inventory of potentially significant incidents occurring during study period for I$205 \mathrm{NB}$

Table 5.7: Summary of Excluded Analysis Days for I-205 NB 
Table 5.8: Performance measures overall and by level of congestion, I-205 NB, 6:00-10:00

AM

Table 5.9: Performance measures overall and by level of congestion, I-205 NB, 1-7 PM. .........51

Table 5.10: Communication Failures, OR-217 NB ..........................................................65

Table 5.11: Observed weather during study period for OR-217 NB ......................................66

Table 5.12: Inventory of potentially significant incidents occurring during study period for OR-217 NB

Table 5.13: Summary of Exclusion Analysis Days, OR-217 NB.

Table 5.14: Performance measures overall and by level of congestion, OR-217 NB, 1:007:00 PM. .68

Table 6.1: Summary of Performance Measures. .76

\section{LIST OF FIGURES}

Figure 1.1: Freeway network in the Portland metropolitan area ............................................2

Figure 2.1: Categories of ramp metering (Source: Zhang et al., 2001) .......................................6

Figure 2.2: SWARM 1 (Global Mode) forecasting theory (Source: Bogenberger and

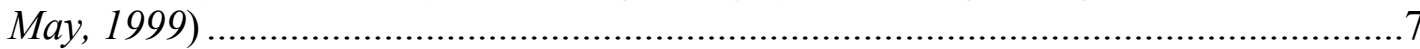

Figure 3.1: Sample video image from Beaverton Hillsdale on-ramp, OR-217 SB ..................19

Figure 3.2: Ramp Meter Plan, Lawnfield Rd, I-205 NB, MP 13.58 .........................................20

Figure 3.3: Maximum ramp inflows/outflows, Scholl's Ferry Road, 3/22/07, 6:00 to

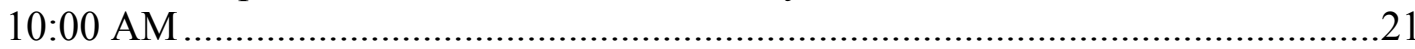

Figure 3.4: Cumulative ramp inflows/outflows and queue length, Scholls-Ferry Road, 3/22/07, 8:40 AM to 8:55 AM. ...22

Figure 4.1: Schematic of OR-217 southbound and sample CCTV camera views ......................23

Figure 4.2: On-ramp queue storage and average hourly volumes (6:00-9:00 AM)..................25

Figure 4.3: On-ramp queue storage and average hourly volumes (3:00-6:00 PM) ...................25

Figure 4.4: Percent communication failures under SWARM vs. pre-timed by station,

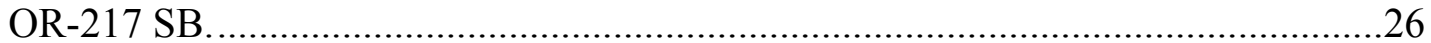

Figure 4.5: Changes in delay under SWARM in time-space plane, OR-217 SB ......................28

Figure 4.6: Cumulative on-ramp vehicle counts ..............................................................29

Figure 4.7. On-ramp volumes between 6:30 AM and 8:30 AM ...........................................29

Figure 4.8: Travel time on OR-217 SB on-ramps: Beaverton-Hillsdale Hwy. ...........................30

Figure 4.9: Travel time on OR-217 SB on-ramps: Scholls-Ferry Rd.........................................30

Figure 5.1: Traffic flow fundamental diagram (Source: Mannering and Kilareski, 2004). Individual fundamental diagrams are from OR-217 NB, Scholls-

Ferry Road station

Figure 5.2: Plots of mainline occupancy (\%) vs mainline flow (vph) for all stations (a), and time-space speed contour plot (b), OR-217 NB, December 6, 2007 1:00-7:00 PM.....

Figure 5.3: Schematic of I-205 NB.

Figure 5.4: Average hourly volume and queue storage on I-205 NB, AM peak, March 2007

Figure 5.5: Average hourly volume and queue storage on I-205 NB, PM peak, March 2007. 
Figure 5.6: Percent communication failures under SWARM and pre-timed operation by station, I-205 NB, AM peak.

Figure 5.7: Percent communication failures under SWARM and pre-timed operation by station, I-205 NB, PM peak

Figure 5.8: Mainline Delay, overall average and average by level of congestion for I205 NB, Morning Peak, (a) pre-timed (top) and (b) SWARM (bottom).

Figure 5.9: Cumulative on-ramp vehicle counts, I-205 NB, 6:30-9:00 AM.

Figure 5.10: Average hourly on-ramp flow, I-205 NB, morning peak, 6:00-10:00 AM.

Figure 5.11: Mainline delay showing overall average and averages by level of congestion for I-205 NB during the afternoon peak for (a) pre-timed (top) and (b) SWARM (bottom).

Figure 5.12: Cumulative on-ramp vehicle counts, I-205 NB, 14:30/2:30-18:30/6:30 PM..........53

Figure 5.13: Average hourly on-ramp flow, I-205 NB, afternoon peak, 1:00-7:00 PM..............54

Figure 5.14: Changes in delay under SWARM in time-space plane, I-205 NB, AM peak

Figure 5.15: Plots for Foster Road showing mainline flow (vph), ramp flow (vph) and mainline speed (mph) over time with meter activations....

Figure 5.16: Changes in moderately congested delay under SWARM in time-space plane, I-205NB, 1:00-7:00 PM

Figure 5.17. Annotated plots of mainline flow (vph), ramp flow (vph) and mainline speed (mph) over time with meter activations, Sunnyside, Johnson Creek, Foster, 9/17/2007 and 10/1/2007....

Figure 5.18: Plots of mainline flow (vph), ramp flow (vph) and mainline speed (mph) over time with meter activations, Clackamas Hwy

Figure 5.19: Changes in highly and very highly congested delay days under SWARM in time-space plane, I-205NB, PM peak

Figure 5.20: Plots of mainline flow (vph), ramp flow (vph) and mainline speed (mph) over time with meter activations, Sunnyside, Johnson Creek, Foster, 9/28/2007 and 9/21/2007

Figure 5.21: Schematic of OR-217 NB

Figure 5.22: Average hourly volume and queue storage on OR-217 NB, March 2007, PM peak

Figure 5.23: Percent communication failures under SWARM and pre-timed operation by station, OR-217 NB, PM peak.

Figure 5.24: Mainline Delay, overall average and average by level of congestion for OR-217 NB, Afternoon Peak, (a) Pre-Timed (top) and (b) SWARM (bottom).

Figure 5.25: Cumulative on-ramp vehicle counts, OR-217 NB, afternoon peak

Figure 5.26: Average hourly on-ramp flow, OR-217 NB, afternoon period, 1:00-7:00 PM .70

Figure 5.27: Changes in delay under SWARM in time-space plane, OR-217NB, PM peak

Figure 5.28: Plots of mainline flow (vph), ramp flow (vph) and mainline speed (mph) over time with meter activations, $11 / 15 / 2007$ and 12/7/2007. 


\section{EXECUTIVE SUMMARY}

Ramp metering, one of the most common freeway management techniques, has been implemented in many cities around the world. At their most fundamental level, ramp meters are traffic signals located at on-ramps to control the flow of vehicles from the ramp onto the freeway. As one of the few freeway corridor management tools available, ramp meters are usually implemented to achieve two main goals: 1) limit the amount of traffic entering a freeway in an attempt to prevent freeway flows from reaching capacity or breakdown levels, and 2) break up the platoons of vehicles discharged from a traffic signal upstream. Effective ramp metering has the potential to improve traffic flow and traffic safety; reduce congestion and fuel consumption; improve air quality; and manage demand by discouraging short trips.

Ramp meters were first implemented in the Portland metropolitan area by the Oregon Department of Transportation (ODOT) in January 1981, along a 6-mile stretch of Interstate 5 (I5). Portland's original ramp metering strategy employed a pre-timed approach that determined the days and times that the meters were active as well as each ramp's metering rate, based on limited analysis of historical patterns. With the development of a robust freeway surveillance and communication system, the deployment of a traffic-responsive metering approach became possible. In May 2005, the System-Wide Adaptive Ramp Metering (SWARM) system was implemented in stages in the Portland metropolitan area and is currently operational on all corridors except for I-405. SWARM uses a mathematical algorithm to select optimized metering rates. SWARM was developed by the National Engineering Technology (NET) Corporation, now known as Delcan, under a contract with the California Department of Transportation (Caltrans). The algorithm was first implemented in Orange County (District 12) and later in Los Angeles and Ventura Counties (District 7) in the late 1990s.

\section{OBJECTIVES}

The objective of this research was to compare selected freeway and ramp performance metrics between the existing pre-timed operation and the SWARM operating mode. To accomplish this, data were obtained from the existing surveillance and communications infrastructures (and supplemental sources) while the ramp meters were operated in consecutive weeks, under the different operating strategies, and the results were compared.

\section{METHODOLOGY}

Archived traffic sensor data was the primary data source used to evaluate the system-wide impact of the SWARM system. These data were available via the Portland Oregon Regional Transportation Archive Listing (PORTAL). The primary measures of mainline freeway performance used are flow and speed; the other measures are derived from these measures. In this evaluation, vehicle miles traveled (VMT), vehicle hours traveled (VHT), and delay were used to evaluate mainline performance. Delay is defined as the difference between the actual travel times and the free flow travel times. Any ramp metering approach attempts to balance 
increased ramp delay and mainline performance; thus any change in ramp delay is an important metric. Enforcement of ramp metering is an important issue; however, no data were collected onramp meter compliance. Finally, the data intensive nature of the adaptive metering system requires consistent and accurate data from the system in order to compute an appropriate metering rate (local and global). The system must also send new commands to the controllers frequently. Without data, and the ability to communicate in both directions without any time lag, the adaptive nature of the system is lost. The ability of the Advanced Traffic Management System (ATMS) to handle the additional data needs of the adaptive system was considered. As described in the body of the report, the communications failure rate is apparent when the archived data was compared for the pre-timed and adaptive systems.

\section{RESULTS AND CONCLUSIONS}

A pilot study on the OR-217 southbound corridor during the morning peak was followed by a regional study which evaluated three additional corridors: I- 205 northbound, morning peak; I205 northbound, afternoon peak; and OR-217 northbound, afternoon peak. For each peak period, the average of each performance metric (VHT, VMT, delay, and communication failures) was calculated and compared. In addition to these metrics, the standard deviation of delay was calculated. This metric was used to compare mainline reliability (less variability was assumed to imply more reliable performance). Where there were sufficient numbers of days, results were tested using a t-test of means on the delay metric (significance was assumed at the 95th percentile). This evaluation revealed that the operation of the SWARM system, as currently configured in the Portland, Oregon metropolitan region, produced mixed results.

For the I-205 corridor, the results were generally positive. Overall, in the morning peak period the average VMT increased by only 0.87 percent, indicating that the amount of travel remained fairly constant between the SWARM and pre-timed periods. At the same time, mainline VHT decreased by $3.7 \%$ between the two periods which corresponded to an $18.1 \%$ improvement in mainline delay under SWARM. This decrease in delay, however, was not statistically significant $(p=0.435)$. The standard deviation of delay was less under the SWARM operation (overall and for all congestion categories). This indicates that the delay under SWARM was less variable and overall freeway performance was more reliable - a valuable benefit of the SWARM system. In the afternoon peak, the corridor VMT increased by about $1.6 \%$ while mainline VHT remained nearly unchanged and average mainline delay decreased by $7.9 \%$. This decrease was not statistically significant $(p=0.896)$. SWARM operation resulted in higher average communication failures $(14 \%)$ as compared to the pre-timed period $(1.5 \%)$ in the afternoon peak.

On OR-217, significant increases were found in overall average delay. The pilot study on OR217 found that while VMT exhibited a marginal increase $(+0.4 \%)$ under the SWARM operation, total delay on the freeway increased $34.9 \%$. This increase was not statistically significant $(p=0.421)$. In the regional study, the northbound afternoon VMT marginally decreased $(-3.08 \%)$ while delay increased by $55 \%$ (375 vehicle-hours). This increase was statistically significant $(p=0.02)$. In addition, the standard deviation of the average delay increased $(+8.4 \%)$. In the regional study, the afternoon VMT decreased $3.1 \%$ while mainline VHT increased by $10.6 \%$ in the SWARM period as compared to the pre-timed period. The average mainline delay increased by $54.95 \%$; this increase was statistically significant $(p=0.02)$. Communication failures were generally lower on the OR-217 corridor than on the I-205 corridor. Pre-timed period failures 
averaged $0.6 \%$ of all readings. Under SWARM the communication failure rate increased to $3.9 \%$.

The contrasting results for SWARM performance between the two freeway corridors can be partially explained by the general differences between the two facilities. OR-217 is a relatively short freeway ( 7 miles) bounded on both ends by freeway-to-freeway (system) interchanges. The ramp spacing is generally short ( 0.75 mile average) and the freeway contains numerous auxiliary lane drops and adds. In the afternoon, the unmetered merge with Kruse Way and I-5 northbound (NB) traffic results in recurrent congestion. In contrast, the I-205 corridor is unbounded, has greater ramp spacing (1.07 mile average), and maintains three through lanes. Only one auxiliary lane is present. Peak-per-mainline lane flows are generally higher on OR-217 than I-205. With SWARM allowing more vehicles to enter the freeway mainline than in pre-timed operation, the impact of higher per lane flows was more significant on OR-217 than on I-205. This, combined with less desirable geometry on OR-217 may explain why higher metering rates on OR-217 produced a more significant increase in mainline delay. To improve system operations, tunable SWARM parameters that distribute the volume reduction (or volume excess, if local density is smaller than the required density) to upstream on-ramps based on demand, and the available queue storage of each on-ramp should be revaluated.

These conclusions, however, must be tempered because of the lack of ramp demand data. If an assumption is made that ramp demand changes correspond with the measured freeway VMT changes, it is likely that ramp delay would decrease under SWARM operation (i.e. more vehicles would be allowed on the freeway which would equate to lower delay for vehicles on the ramps).

Another important finding of this evaluation was that implementation of the SWARM algorithm resulted in significantly more data communication failures. While this outcome is specific to the ODOT communication infrastructure and hardware, it was not anticipated. These communication failures have the potential to impact other traveler information programs that depend on the freeway surveillance data as well as the SWARM algorithm. Following the completion of this study ODOT has investigated and implemented measures to improve communications.

Finally, one of the intentions of this research project was to encourage ongoing evaluation and continuous improvement of the ramp metering system, and in general the overall freeway management system. It is clear from the analysis that meter activations times and rates are necessary to evaluate system performance. Incorporating additional data logging capabilities into the SWARM system would make it easier to evaluate system operations on an on-going automated basis. In addition, the freeway surveillance system should be modified to incorporate vehicle counts from the ramp queue loop detectors. For an on-going evaluation of the ramp meter system, these data are critical. 



\subsection{INTRODUCTION}

Ramp metering is one of the most common freeway management techniques and has been implemented in many cities around the world. At their most fundamental level, ramp meters are traffic signals located at on-ramps to control the flow of vehicles from the ramp onto the freeway. Based on a pre-defined or variable signal cycle, vehicles are allowed to enter the freeway at a rate of one vehicle per green signal. Ramp meters are usually implemented to achieve two main goals: 1) limit the amount of traffic entering a freeway in an attempt to prevent freeway flows from reaching capacity or breakdown levels, and 2) break up the platoons of vehicles discharged from a traffic signal upstream. Effective ramp metering has the potential to improve traffic flow and traffic safety; reduce congestion and fuel consumption; improve air quality; and manage demand by discouraging short trips.

The freeway system in the Portland metropolitan region (see Figure 1.1) consists of seven major freeway corridors consisting of Interstates, U.S. Highways and State Routes, that serve local commuters and through traffic, as well as freight trucks to and from the Portland International Airport and the Port of Portland. Ramp meters were first implemented in the Portland metropolitan area by the Oregon Department of Transportation (ODOT) in January 1981, on a 6mile section of Interstate 5 (I-5). As part of the original ramp metering deployment, a surveillance system, including inductive loop detectors and a closed circuit television (CCTV) system was installed. This original ramp metering strategy was expanded throughout Portland's freeway network (Bertini et al., 2004).

Optimal ramp metering strategies are often debated, but all involve tradeoffs between imposing delay on those vehicles already on the freeway and those attempting to enter. Delays imposed on vehicles at on-ramps are often constrained by spatial limitations for queue storage. Early ramp metering systems in the United States were installed as pre-timed (or fixed-rate) systems, whereby the activation and deactivation times of the ramp meters and the daily metering rates were pre-determined based on the analysis of historical data. This kind of metering strategy was designed to cope with "typical" traffic conditions and was not able to incorporate real-time freeway conditions. Consequently, the effectiveness of the fixed-time system deteriorated substantially with large variations in freeway conditions or when non-recurrent conditions (e.g. incidents) occurred on freeways. With the enhancement of sensing and communication technologies, this strategy has been replaced by more sophisticated algorithms that account for real-time traffic conditions.

Portland's original ramp metering strategy employed a pre-timed approach that determined the times that the meters were active as well as each ramp's metering rate based on historical patterns. With the development of a robust freeway surveillance system, the deployment of a traffic-responsive metering approach became possible. In May 2005, the System-Wide Adaptive Ramp Metering (SWARM) system was implemented in stages in the Portland metropolitan area and is currently operational on all corridors except for I-405. SWARM was developed by the National Engineering Technology (NET) Corporation, now known as Delcan (Paesani et al., 
1997), under a contract with the California Department of Transportation (Caltrans). The SWARM algorithm was first implemented in Orange County (District 12) and later in Los Angeles and Ventura Counties (District 7) in the late 1990s.

The comparison of these two operations is the focus of this evaluation.

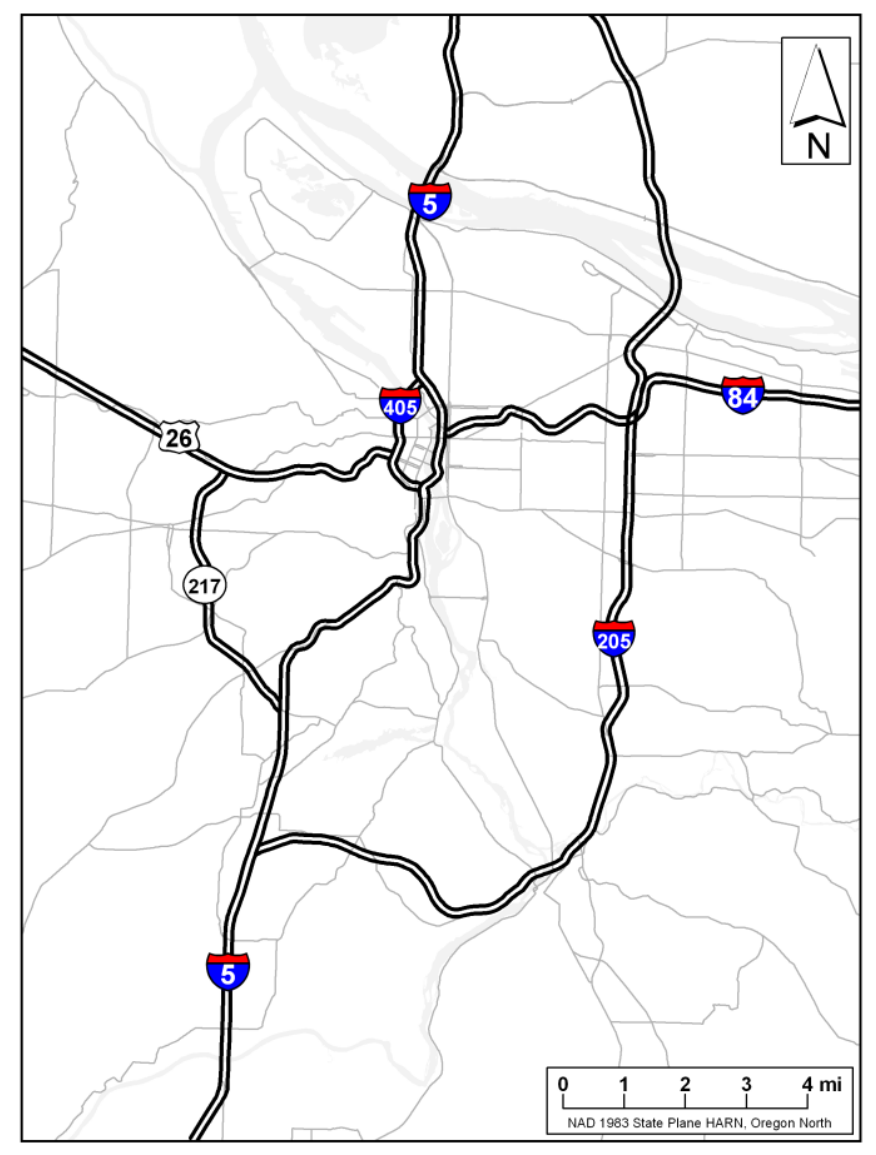

Figure 1.1: Freeway network in the Portland metropolitan area

\subsection{RESEARCH OBJECTIVES}

While the SWARM system is designed to be more effective than the current ramp metering strategy, the true benefits of the new system had not yet been quantified for Oregon. The objective of this research was to compare selected freeway and ramp performance metrics between the original pre-timed operation and the new SWARM operating mode. To accomplish this, data were obtained from the existing surveillance and communications infrastructure (and supplemental sources) while the ramp meters were operated in consecutive weeks, under the different operating strategies, and the results were compared. 


\subsection{ORGANIZATION OF REPORT}

The report is organized into seven chapters. A review of traffic responsive algorithms and corresponding field results are presented in Chapter 2 - Literature Review. The methodology, including measures of performance, study corridors, and data collection are described in Chapter 3- Methodology. Prior to a large scale evaluation, a pilot study was conducted on OR-217 southbound (SB); the results are presented in Chapter 4- Pilot Study. Chapter 5- Regional Study, contains the results of a more detailed evaluation of two additional corridors, I-205 northbound (NB) and OR-217 NB. Conclusions and recommendations are presented in Chapter 6 Conclusions, and references are listed in Chapter 7 - References. 


\subsection{LITERATURE REVIEW}

Traffic responsive ramp-metering algorithms were developed in an effort to cope with daily fluctuations and non-recurrent freeway conditions. In these algorithms, metering rates and activation/deactivation times at individual ramps are determined proactively in response to realtime freeway conditions along corridors. Many traffic-responsive ramp-metering algorithms have been developed, and some of them have been evaluated for their benefits via field-testing (e.g. Cambridge Systematics, 2001; Hourdakis and Michalopoulos, 2002; Levinson and Zhang, 2006) or simulations (e.g. Zhang et al., 2001). Various traffic-responsive ramp-metering strategies and their test results are described in numerous publications (e.g. Zhang et al., 2001; Bogenberger and May, 1999). Zhang et al., (2001) categorized the existing traffic-responsive ramp metering algorithms, as shown in Figure 2.1, by the extent of freeway conditions considered (system-wide vs. local) and by the way in which measured conditions are incorporated in deploying metering rates.

Traffic responsive algorithms are largely divided into two groups, local (or isolated) and coordinated. In local strategies, metering rates at each on-ramp are controlled based solely on local conditions around the ramp, while in coordinated strategies, both local and system-wide (e.g. a bottleneck and its influence zone upstream) freeway conditions are considered. In both groups, freeway conditions are measured in terms of flow, occupancy, and speed from mainline loop detectors and detectors installed in the vicinities of controlled on-ramps. Both groups also measure on-ramp conditions to avoid excessive queue build-up and/or spill-over to nearby city arterials.

Coordinated algorithms consist of three types:

- cooperative: if metering rates are computed based on local conditions and then adjusted according to system-wide conditions;

- competitive: if two metering rates are computed locally and system-wide for each ramp, with the more restrictive of the two deployed; and

- integral: if both local and system-wide conditions are incorporated to determine optimal rates that achieve an objective (e.g. minimum travel time or maximum throughput). 


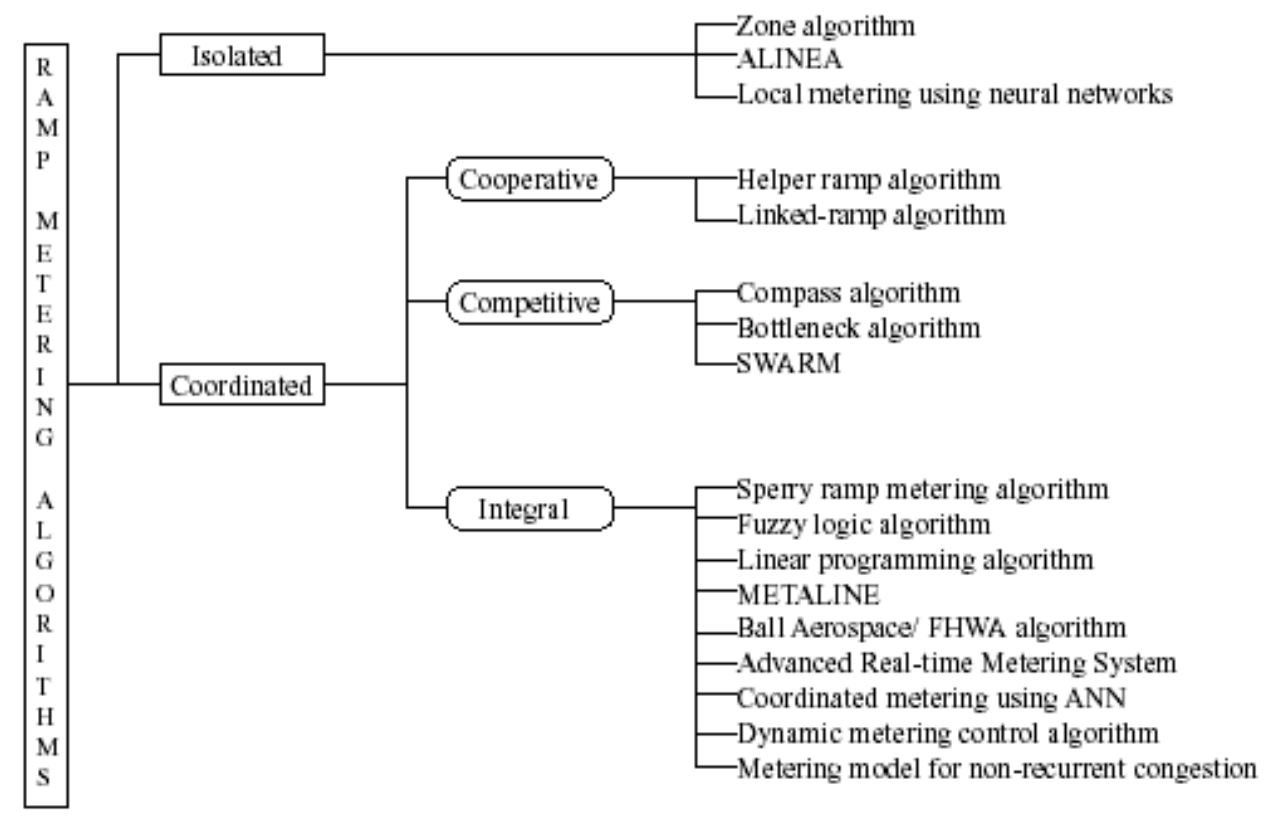

Figure 2.1: Categories of ramp metering (Source: Zhang et al., 2001)

\subsection{SYSTEM-WIDE AREA RAMP METERING (SWARM)}

\subsubsection{Algorithm}

The SWARM algorithm is a comprehensive, traffic-responsive ramp metering algorithm. In this metering strategy, a freeway network is divided into contiguous freeway systems (sections), whereby each freeway system is bounded by the location of two bottlenecks (identified by loop detectors) and contains multiple on- and off-ramp.

For each system, there are two "competing" modes of SWARM operations: global (SWARM 1), and local (SWARM 2). The global mode operates on an entire system, based on forecasted densities at the system's bottleneck location. The local mode operates with respect to (real-time) local traffic conditions near each ramp. The local metering system could utilize any existing local traffic-responsive algorithm. Metering rates are computed from both global and local modes, and the more restrictive rate is deployed in the field.

In SWARM 1 mode, density at the bottleneck is forecasted into the future by performing linear regression on a set of data collected from the immediate past and applying a Kalman filtering process (to incorporate a non-linear term in the forecasting model). A tunable parameter $\left(T_{\text {crit }}\right)$ is the forecasting time horizon into the future (labeled in Figure 2.2), which is usually several minutes. The excess density (also labeled in Figure 2.2) is then the difference between the forecasted density and a pre-determined threshold density that represents the saturation level at 
the bottleneck. This excess density is converted to the (current) required density to avoid congestion in $T_{\text {crit }}$ (Equation 2-1 and 2-2).

\section{Required density $=$ current density $-\left(\right.$ excess density $\left./ T_{\text {crit }}\right)$}

The corresponding volume reduction at each detector station is computed as:

\section{Volume reduction $=($ local density - required density $) *($ No. of lanes $) *($ distance to next station $)$}

The volume reduction (or excess, if local density is smaller than the required density) is distributed to upstream on-ramps within the system according to the distribution (or weighting) factors pre-determined based on demand, queue storage, etc., of each on-ramp.

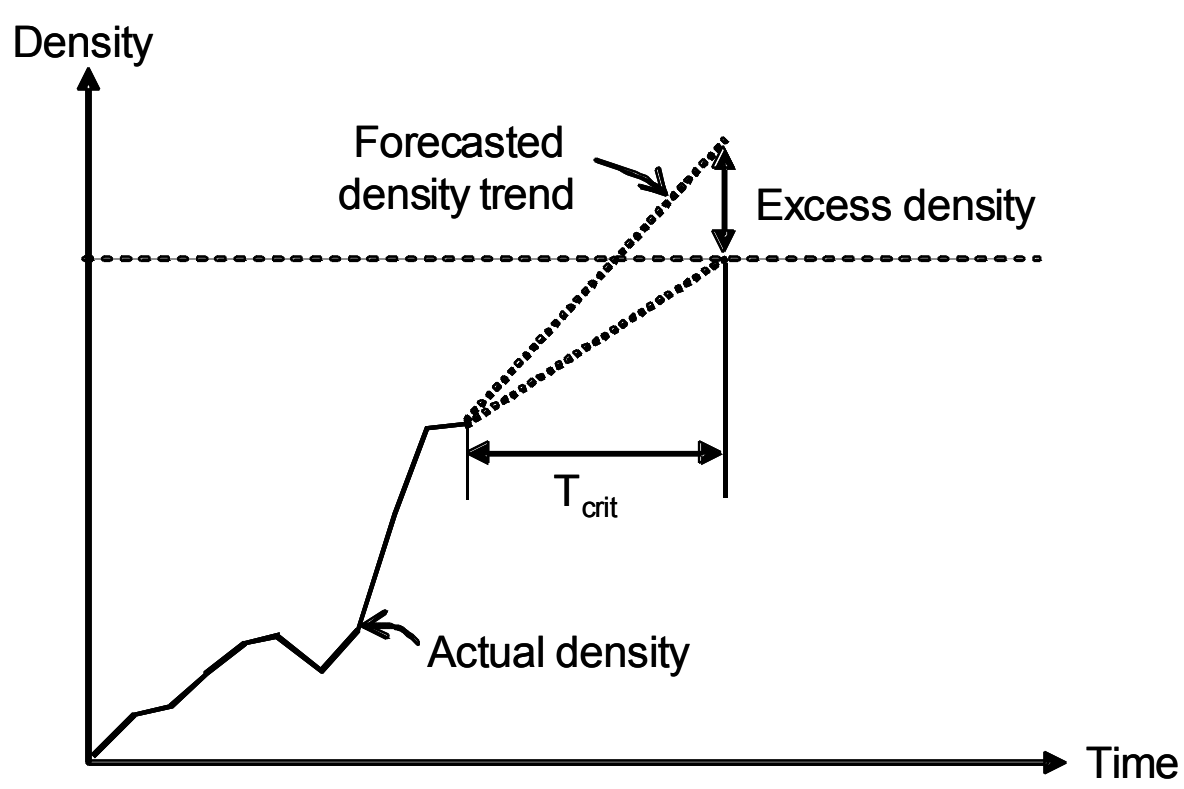

Figure 2.2: SWARM 1 (Global Mode) forecasting theory (Source: Bogenberger and May, 1999)

The SWARM 2 mode is a traditional local metering system. The specific algorithm used varies by location, and can actually be any existing local traffic-responsive system. For instance, SWARM 2a and SWARM 2b were used in Southern California. SWARM 2a uses headways observed at the detector station upstream of an on-ramp. The measured headways are then converted to densities that determine local metering rates. SWARM $2 \mathrm{~b}$, on the other hand, keeps track of available storage near each on-ramp using the detectors both upstream and downstream. SWARM 2c was written for use in Portland, which does not have off-ramp detection. It averages occupancy data from the mainline detectors near the metered on-ramp and the ones downstream, and looks up the metering rate from a local table. 
SWARM has a built-in capability to clean the defective data in case of loop failures, which improves the robustness of the algorithm. With this feature and accurate prediction models, SWARM is able to accurately detect and avoid potential congestion in advance. However, if the prediction models are poor or if supporting loop data are not accurate, it can generate limited benefits (Zhang et al., 2001).

\subsubsection{Field Evaluation}

SWARM was implemented in parts of southern California and is expected to be deployed on the majority of California's freeway network (Caltrans, 2005). In the following sections, results of initial implementation and evaluation efforts are briefly described. As a result of this Oregon evaluation project, the research team is now in close communication with the California ramp metering team, which will be useful for future evaluations and coordination. As of mid-2008, there are further evaluations on-going with possible results to be available in early 2009.

\subsubsection{Orange County, California}

The SWARM system implemented in Orange County could not be evaluated for a number of reasons. MacCarley et al. (2002) noted that Caltrans did not receive proper training nor documentation related to SWARM operations. Moreover, the algorithm itself did not seem to operate properly when tested in the field over a six week period.

\subsubsection{Los Angeles and Ventura Counties, California}

The implementation and evaluation of SWARM was more successful in Los Angeles and Ventura Counties in California. There are over 1,200 ramp meters in that network. Before the implementation of the SWARM system, Caltrans District 7 operated pre-timed and local trafficresponsive ramp metering throughout their freeway network in Los Angeles and Ventura Counties. The benefits of the new SWARM algorithm, as compared to the previous rampmetering operations, were evaluated during the morning peak periods on a freeway corridor (westbound Route 210) that contained 20 controlled on-ramps (detailed descriptions of the evaluation methods and results are included in Pham et al. (2002)). Caltrans tested three operational strategies: global mode only, local mode only, and a combined strategy. Each strategy was evaluated for several days between September, 2001 and January, 2002.

Caltrans found that the combined strategy generated the most benefits in terms of traffic conditions on the mainline freeway. In particular, it increased the mainline speed by $11 \%$ during the morning rush, decreased the travel time by $14 \%$, and reduced the freeway delay by $17 \%$. Furthermore, on-ramp queue lengths at the nine busiest on-ramps increased by over $40 \%$.

\subsection{OTHER TRAFFIC-RESPONSIVE RAMP METERING}

In the following sections, the descriptions of several other traffic responsive ramp-metering algorithms (one for each category shown in Figure 2.1), that have been implemented and tested in the field, are presented. 


\subsubsection{Zone Algorithm - Minneapolis/St. Paul, Minnesota}

The ramp metering system in the Minneapolis/St. Paul metropolitan area was first implemented on a freeway corridor in 1970. The initial system was operated based on pre-timed metering rates and was converted later to a local traffic responsive system. In 1974, ramp meters were deployed on another freeway corridor along with closed-circuit television (CCTV) cameras and loop detectors as supporting tools.

The Minnesota Department of Transportation (MnDOT) carried out comprehensive evaluations of the ramp metering system after 10 years of operation. The study showed that the system was beneficial in terms of delays, air quality, and safety on the freeways. Based on these results, the ramp metering system was implemented in stages to cover the entire Twin Cities freeway network.

In the Zone algorithm (Stephanedes, 1994), freeways are divided into multiple zones (with length of three to six miles). Typically, the upstream end of each zone exhibits freely-flowing conditions, and the downstream end is at the location of a bottleneck. Each zone is comprised of the freeway mainline, off-ramps, metered freeway-to-freeway connectors, and un-metered and metered on-ramps. For each zone, the algorithm is designed to maintain the condition on the mainline below certain density levels by balancing the inflows (from upstream end, on-ramps, and freeway connectors) and outflows (through the bottleneck and off-ramps). Based on the measured flows on the mainline and uncontrolled ramps, the algorithm determines the collective metering rate for all the controlled on-ramps and freeway connectors. The collective metering rate is then divided into individual metering rates using the pre-defined ramp factors. If nonrecurrent conditions arise locally (e.g. local queues due to incidents, construction, etc.), the algorithm takes that into consideration and adjusts the metering rates accordingly.

In March of 2000, MnDOT conducted an evaluation study on two selected highways (Highway 169 and I-394). The study showed that the ramp metering system resulted in $6-16 \%$ improvement in travel time on the highways and $2-47 \%$ savings in fuel consumption and engine emission (Hourdakis and Michaelopoulos, 2002).

In the following fall of 2000, the ramp meters were shut off for eight weeks in order to conduct a true before and after study. Several seminal evaluation studies (Cambridge Systematics, 2001; Kwon et al., 2001; Hourdakis and Michalopoulos, 2002; and Levinson and Zhang, 2006) were conducted, and they showed that the ramp-meter shut-off resulted in an increase in congestion and crash rates as well as changes in travel patterns. They also showed that although rampmetering incurred more delay for on-ramp traffic, it resulted in benefits at the system-wide level.

Levinson and Zhang (2006) evaluated the system according to seven performance measures: mobility, accessibility, equity, consumers' surplus, travel time variation, productivity, and travel demand responses. The results from the evaluation of the seven measures demonstrated overall benefits of the ramp metering system, consistent with the other studies. However, their analysis on equity revealed that the benefits occurred at the expense of short trips such that ramp metering actually increased travel time for short trips while it decreased travel time for longer trips. 


\subsubsection{Helper Algorithm - Denver, Colorado}

In the Denver area, ramp meters were first deployed on five on-ramps on I-25 in 1981. These onramps were initially controlled in response to real-time local traffic conditions. This initial implementation was shown to be beneficial, and as a result, more ramp meters were deployed throughout the freeway network in the Denver area by 1984. Along with this second-stage implementation, centralized control was enabled to monitor and override locally-determined metering rates when necessary. In a comprehensive evaluation study that followed in 1988 and 1989 , the central override was shown to be effective in mitigating congestion on the mainline if the speeds were less than $90 \mathrm{~km} / \mathrm{hr}$ ( $\sim 55 \mathrm{miles}$ per hour (mph)) (Lipp et al., 1991).

The Helper algorithm (Lipp et al., 1991) is comprised of a local traffic-responsive algorithm with the added feature of central override control. Within a freeway corridor, controlled on-ramps are divided into six location groups, with each group containing one to seven controlled on-ramps. With a local traffic-responsive component, one of six pre-set metering rates is selected at each on-ramp, based on local conditions near the ramp. The local conditions are measured by mainline occupancy reported from the detector station upstream of the on-ramp.

The algorithm also monitors on-ramp queues by keeping track of occupancies on queue detectors and adjusts metering rates in case of any excess queue development. If an on-ramp is operating at the minimum metering rate, and occupancy on the queue detector exceeds a pre-determined threshold value, the on-ramp is categorized as critical and the central override feature becomes active. The centralized algorithm increases the rate at the critical on-ramp by one level and reduces the rate for the upstream on-ramp by one level. The distribution continues one level at a time to other upstream on-ramps, until no on-ramp is categorized as critical.

\subsubsection{Bottleneck Algorithm - Seattle, Washington}

The Bottleneck Algorithm (Jacobsen et al., 1989) was developed by Washington State Department of Transportation (WsDOT) and was implemented on I-5, north of the Seattle Central Business District, starting in 1981. A six-year evaluation study was conducted on a 7mile corridor on I-5 during the morning (southbound) and afternoon (northbound) rush. The evaluation showed that the mainline volume increased significantly ( $86 \%$ northbound and $62 \%$ southbound) with ramp-metering. The mainline travel time, nonetheless, decreased by $48 \%$, and delays on the on-ramps were less than 3 minutes. Moreover, ramp metering resulted in improved safety on the mainline, such that the crash rate decreased by $39 \%$.

The Bottleneck Algorithm is a competitive, traffic-responsive ramp metering algorithm. Just as in SWARM, the Bottleneck Algorithm computes two metering rates for each on-ramp, one based on local conditions and the other based on system-wide condition, and selects whichever is more restrictive. A local metering rate is computed as the difference between demand (in volume) and capacity near an on-ramp. The capacity is estimated from volume-occupancy relationships established using historical data. Also, based on the relations, occupancy measured from the detector(s) upstream of the on-ramp is converted to demand (in volume units).

At the global level, the location of a bottleneck and its influence area (with multiple on-ramps) are identified. The global algorithm takes effect when two conditions are met: 1) occupancies in 
the influence area exceed a pre-determined threshold value, indicating that the area is operating beyond capacity, and 2) the influence area is storing vehicles (inflow to the influence area is greater than exiting flow from it). Then, the excess inflow is distributed to the on-ramps in the influence area according to the pre-determined weighting factors. The final metering rates can undergo further adjustments if excessive ramp queues are detected.

\subsubsection{Fuzzy Logic Algorithm - Seattle, Washington and Zoetermeer, Netherlands}

Fuzzy Logic ramp metering (Taylor and Meldrum, 1998) is an integrated, traffic-responsive ramp metering algorithm. This algorithm was developed at the University of Washington and was first deployed in 1999 by WsDOT. It was initially implemented on fifteen on-ramps on I405 and then was deployed on the entire I-405 in the Seattle area, after an evaluation study demonstrated improved operations in comparison with the existing Bottleneck Algorithm.

In Zoetermeer, Netherlands, implementation of Fuzzy Logic ramp metering began in 1989, and nine on-ramps were metered by 1995 . Evaluation results showed improvements in mainline conditions in terms of speeds and travel time.

In the Fuzzy Logic Algorithm, traffic conditions measured from loop detectors are categorized into finite textual classes, such as very small, small, ... , big, and very big. Within each class, measurements are also given degrees of membership based on their values. Then, a set of rules is run on these "fuzzified" inputs and textual metering levels are determined. For example, IF occupancy is small AND ramp queue is small, THEN there is a high metering rate. The textual metering levels are then "defuzzified" and converted to numeric metering rates.

Although the model implemented in Seattle demonstrated benefits (via field-testing and simulation tool FRESIM) in terms of freeway performance, Zhang and et al. (2001) noted that the robustness of this algorithm heavily relies on proper selection of rules, which can be quite complex for global-level control. Moreover, calibrating parameters associated with fuzzification and defuzzification requires a great amount of effort. Finally, these rules and parameters may not work well if traffic conditions change over time. 


\subsection{METHODOLOGY}

In this chapter, the methodology used to compare freeway and ramp performance metrics between the existing pre-timed and SWARM operations is described. The chapter begins with a summary of the selected performance metrics. In the sections that follow, the criteria used to select corridors, the study duration and time periods, and descriptions of the various data sources used in the evaluation are presented. As part of the research plan, a pilot study was first conducted which was followed by a more detailed evaluation of two additional corridors (termed the "regional study"). For simplicity, the methodologies for both of these studies are presented in this chapter.

\subsection{MEASURES OF PERFORMANCE}

The potential measures of performance and required data sources to evaluate the ramp metering systems are shown in Table 3.1. Archived traffic data was the primary data source used to evaluate the system-wide impact of the SWARM system. This data source, the Portland Oregon Regional Transportation Archive Listing (PORTAL), is described in Section 3.4, Data.

Table 3.1: Potential measures for evaluations and data sources.

\begin{tabular}{l|l|l}
\hline $\begin{array}{l}\text { EVALUATION } \\
\text { OBJECTIVES }\end{array}$ & MEASURES & DATA SOURCES \\
\hline Freeway Performance & $\begin{array}{l}\text { Flow } \\
\text { Speed } \\
\text { Travel Time } \\
\text { Delay } \\
\text { Vehicle-Miles-Traveled } \\
\text { Vehicle-Hours-Traveled }\end{array}$ & \\
& $\begin{array}{l}\text { Outflow } \\
\text { Demand } \\
\text { Travel Time } \\
\text { Queue Length } \\
\text { Delay } \\
\text { Compliance }\end{array}$ & $\begin{array}{l}\text { CCTV Cameras } \\
\text { PLC/Road Tubes } \\
\text { PORTAL }\end{array}$ \\
\hline Ramp Performance & Communication failures & \\
\hline ATMS Performance & $\begin{array}{l}\text { Incidents or Crashes in Study } \\
\text { Area }\end{array}$ & $\begin{array}{l}\text { PORTAL or } \\
\text { ODOT Statewide Crash Data System }\end{array}$ \\
\hline Safety & $\begin{array}{l}\text { Fuel Consumption } \\
\text { Engine Emissions }\end{array}$ & \\
\hline Air Quality & PORTAL \\
\hline Note: The &
\end{tabular}

Note: The measures selected for this evaluation are italicized. 


\subsubsection{Mainline Performance}

The primary measures of mainline freeway performance are flow and speed; the other performance indicators are derived from these basic measures. In this evaluation, vehicle miles traveled (VMT), vehicle hours traveled (VHT), and delay were used to evaluate mainline performance. Delay is defined as the difference between the actual travel times and the free flow travel times.

\subsubsection{Ramp Performance}

Any ramp metering approach attempts to balance increased ramp delay and mainline performance; ramp delay is therefore an important metric. In order to measure ramp delay, two important pieces of data are needed 1) on-ramp demand; and 2) ramp outflow. When ramp meters are not operational, the demand (vehicles entering the ramp) is equal to the ramp outflow and can usually be extracted from the archived data. While the Advanced Traffic Management System (ATMS) does not log metering rates, often they can be approximated from the ramp outflow volumes. However, when the meters are operational, the demand generally exceeds the ramp outflow, which result in queues and delays for the vehicles on the ramp. Without supplemental data collection, the demand is not known and ramp delay cannot be estimated.

In the pilot study, ramp delay was estimated from a sample of video-based observations of ramp travel times. In the regional study, an attempt was made to use the existing infrastructure to measure ramp queues and delays using simple queuing theory. Ramp meter enforcement is an important issue, however for this study no data were collected on meter compliance.

The data intensive nature of the adaptive system requires consistent and accurate data to compute an appropriate metering rate (local and global) and to send new commands to the controllers. Without data and a robust communication network, the adaptive nature of the system is lost. The ability of the ATMS to handle the additional data needs of the adaptive system was considered. The communications failure rate apparent from the archived data was compared for the pretimed and adaptive systems.

\subsubsection{Safety}

While other studies have shown improved safety to be a benefit of ramp metering, this evaluation did not have sufficient before-and-after time periods to make that comparison. In addition, the marginal changes in ramp meter operation implemented would make it extremely difficult to accurately detect safety changes in this study (other evaluations compared ramp metering to no ramp metering). As a result, safety benefits were not considered. These data are, however, available from the ODOT Statewide Crash Data System and ATMS incident logs.

\subsubsection{Fuel Consumption and Emissions}

The impact of the SWARM system on air quality could also be evaluated in terms of the changes in fuel consumption and engine emissions. These measures could be quantified using wellknown models that require input data (e.g. traffic speed, volume, etc.). Additional data on vehicle types was needed as was detailed information on ramp queue. In some respects, delay was a 
suitable, but not perfect, measure for air quality metrics. As a result of study constraints, no air quality metrics were calculated.

\subsection{STUDY CORRIDORS}

The first step in the evaluation was to identify potential corridors for evaluation, both for the pilot study and the regional study. As mentioned, the SWARM system was implemented in stages from May 2005 to March 2006 as shown in Table 3.2. All freeway corridors were candidates for evaluation with the exception of I-405, where SWARM was not implemented.

Table 3.2: SWARM implementation schedule

\begin{tabular}{l|l}
\hline CORRIDOR & $\begin{array}{l}\text { SWARM } \\
\text { IMPLEMENTATION }\end{array}$ \\
\hline I-205 NB & December 2005 \\
\hline I-205 SB & December 2005 \\
\hline I-405 NB & Not implemented \\
\hline I-405 SB & Not implemented \\
\hline I-5 Lower (NB and SB) & February 2006 \\
\hline I-5 Upper (NB and SB) & January 2006 \\
\hline I-84EB & May 2005 \\
\hline I-84WB & May 2005 \\
\hline OR 217 NB & November 2005 \\
\hline OR 217 SB & November 2005 \\
\hline US26 EB & March 2006 \\
\hline
\end{tabular}

Prior to selection of corridors, a set of desirable criteria was developed. The criteria are:

- Level of congestion - Duration and spatial extent of congestion should be reasonably large (i.e., no localized queues). This allows for an assessment of the SWARM performance while the global control interacts with the local controls at multiple onramps.

- Spatial extent of queues - If queue(s) are present they should be isolated within a corridor; i.e., the location of a recurrent bottleneck (the head of a queue) and the tail of the resulting queue should reside within the same corridor. This criterion allows a comprehensive evaluation of the SWARM system on a single freeway corridor without having to evaluate other intersecting freeways simultaneously.

- Detector spacing - The spacing between detectors should be reasonably small so that the data from detectors reflect actual conditions prevailing on the freeway as closely as possible.

- Data quality - The accuracy of evaluation results will depend on the quality of loop detector data. The selected corridor should have a recent history of good data quality. Individual 20 -second readings from loop detectors were reviewed to identify poor performing detectors and stations. 
- Stability of the SWARM system - The SWARM system implemented in the field should be stable; i.e., all ramp meters should be working properly, and the actual metering rates deployed should match the theoretical rates determined from the SWARM algorithm.

- Construction schedule- The corridor should not include any active construction projects.

- Alternative routes - The presence of alternative routes is needed to measure the impact of traffic diversion on local arterials.

Of the available corridors for study, none could completely satisfy all of the desirable criteria. The alternate route criterion was dropped after it was determined there was not sufficient project resources to evaluate this metric. After detailed analysis, the following corridors and ramps were selected for detailed study:

- Pilot Study Corridor: OR-217 Southbound, AM peak (6 - 9 AM )

○ US-26 to I-5 southbound.

○ Study ramps: Beaverton-Hillsdale Highway and Scholls-Ferry.

- Regional Study Corridor: I-205 Northbound, AM (6 - 10 AM ) and PM peak (1 - 7 PM )

- Gladstone to Division.

- Study ramps: Sunnyside, Johnson Creek, and Powell.

- Regional Study Corridor: OR-217 Northbound, PM peak (1 - 7 PM).

- I-5 to US-26 (opposite corridor of the pilot study).

- Study ramps: 99W (WB), Greenburg, and Scholls-Ferry.

Information and details about the selected corridors is presented in the following chapters.

\subsection{STUDY PARAMETERS}

The evaluation was conducted by operating the meters in pre-timed operation for a defined period followed immediately by SWARM operation (except for I-205 NB where this was reversed). ODOT's ramp metering system uses Type 170E controllers running W4LRM Waipiti firmware/software. No adjustment period was incorporated since it was believed that the difference between the two operations is not large enough to require driver adjustment. The pretimed metering rates used were the last operational rates used. ODOT Region 1 Traffic staff periodically reviews and updates meter rates and times.

Table 3.3 presents the dates of each meter operation, the general window of the pre-timed metering, and the analysis time period for each corridor. Note that the pilot study used one week before and after while the regional study used two weeks before and after. Also, the analysis time periods were expanded beyond the pilot study hours to match SWARM's potential activation times. 
Table 3.3: Dates of study, pre-timed metering times, and SWARM study times

\begin{tabular}{l|l|l|l|l}
\hline CORRIDOR & PRE-TIMED & $\begin{array}{l}\text { PRE-TIMED METER } \\
\text { ACTIVATION }\end{array}$ & SWARM & STUDY TIMES \\
\hline $\begin{array}{l}\text { OR 217 SB } \\
\text { PILOT }\end{array}$ & $6 / 19-6 / 232006$ & $6: 15-9: 30 \mathrm{AM}^{1}$ & $6 / 26-6 / 302006$ & $6-9 \mathrm{AM}^{2}$ \\
\hline I-205 NB & $9 / 24-9 / 282007 \&$ & $6: 15-8: 30 \mathrm{AM}^{1}$ & $\begin{array}{l}9 / 10-9 / 142007 \& \\
9 / 17-9 / 212007\end{array}$ & $\begin{array}{l}6-10 \mathrm{AM}^{2} \\
1-7 \mathrm{PM}^{2}\end{array}$ \\
\hline OR 217 NB & $10 / 1-10 / 52007$ & $2: 30-6: 30 \mathrm{PM}^{1}$ & $\begin{array}{l}11 / 26-11 / 302007 \\
\& 1-12 / 3-12 / 72007\end{array}$ & $1-7 \mathrm{PM}^{2}$ \\
\hline
\end{tabular}

${ }^{1}$ Varies by on-ramp and corridor.

${ }^{2}$ SWARM may be active in these time windows.

\subsection{DATA}

The following subsections describe the data collected and used to support this evaluation.

\subsubsection{PORTAL}

The Portland Oregon Regional Transportation Archive Listing (PORTAL) (http://portal.its.pdx.edu) is the official Intelligent Transportation Systems (ITS) data archive for the Portland metropolitan region. PORTAL has been archiving 20 -second speed, count, and occupancy ${ }^{1}$ data from inductive loop detectors on Portland-area freeways since July 2004. These data are stored in a PostgreSQL relational database management system (RDBMS) and are accessed through PORTAL's web-based front end (Bertini et al., 2005). Dual loop detectors typically positioned in each mainline lane just upstream from on-ramp locations allow capture of count and speed data Ramp loop detectors only report counts. In addition to the raw data collected, other measures were derived from these data (Equations 3-1, 3-2, and 3-3):

\section{Vehicle Miles Traveled $($ VMT $)=($ Count, veh $) *($ Distance between stations, mi $)$}

Vehicle Hours Traveled $($ VHT $)=($ Count, veh $) *($ Distance between stations, $\mathrm{mi}) /($ Speed, $\mathbf{m p h})$

$$
\text { Delay }=\text { VHT }-(\text { Count, veh }) *(\text { Distance between stations, mi }) /(\text { Free Flow Speed, mph) }
$$

The free flow speed was assumed to be $55 \mathrm{mph}$ for this evaluation. For the ramp traffic, only the count data are reported. A typical ramp detector layout is shown in Figure 3.2. When the ramp metering system is active, ramp outflow is reported from each passage loop (detectors 6 and 9 in detail A). On all ramps, queued traffic is instructed to form two lanes. When metering is not active, traffic operates in a single lane and the passage loops are function as a single detector.

\footnotetext{
${ }^{1}$ Occupancy $=$ percent of unit time detector is occupied. Occupancy is generally assumed to be a good proxy for density which is defined as the number of vehicles per mile.
} 
PORTAL also includes information about weather and incidents (which was used to exclude some analysis days):

- Weather - PORTAL currently obtains daily weather information from National Oceanic and Atmospheric Administration (NOAA) http://cdo.ncdc.noaa.gov/ulcd/ULCD) and from the Portland Bureau of Environmental Services, Hydrologic Data and Acquisition (HYDRA) (http://or.water.usgs.gov/non-usgs/bes). Automated scripts collect these data bi-hourly and nightly from these sites respectively. These sites store data collected from the Portland, Hillsboro and Troutdale airports. The hydra table includes hourly precipitation data from 19 HYDRA stations. Data stored include wind speed in knots, temperature, humidity percentage, visibility (in miles), general sky condition in text (e.g. clear, partly cloudy) and precipitation information. In the database, each highway segment is associated with the nearest weather station.

- Incidents - The incident data incorporated into PORTAL are based on incident data from the ODOT Advanced Transportation Management System (ATMS) database. Incident data is entered into the ATMS database by operators at the ODOT Traffic Management Operations Center (TMOC). The TMOC operators work closely with emergency responders and the ODOT COrridor ManagEmenT (COMET) teams who are the incident responders patrolling the freeways. For each incident, operators create several entries in the database; entries are created when the incident is reported, when the status of the incident changes, and finally when the incident is cleared. PORTAL combines these entries into a single incident record providing location, duration and other important parameters for that incident.

PORTAL also logs data returned from the ATMS about communication failures:

- Communication Failure - A series of codes is used to indicate the status of the data; whether the detector is disabled or active, whether a communication failure occurred or not, and a quality status of the detector reading. Details of these codes can be found in the SWARM manual.

\subsubsection{Ramp Queues}

One key performance measure to be captured was the length and duration of ramp queues. In general, more restrictive metering will result in an increase in delay for ramp traffic. Both measures of demand and delay are needed to accurately characterize ramp performance. In the pilot study, surveillance video was used to sample ramp travel times (surrogate for delay). Some ramp inflows were measured with road tubes while the remainder were determined by the review of video footage. In the regional study, the ramp detection infrastructure was used to capture these data at key ramps. These methods are described below.

\subsubsection{Video and Road Tubes (Pilot Study)}

In the study of SWARM operation on OR-217 in June 2006, road tubes and portable cameras supplemented the existing loop detectors and CCTV cameras at the ramps, detailed in Table 3.4. Video of key ramps was recorded and vehicle counts were recorded at 20 -second intervals. Using basic queuing theory, this allowed delay at the 
ramps to be quantified, however the process was labor-intensive and relied on cameras being properly pointed throughout the time interval (in the case of existing CCTV cameras) and the video recording successfully. In addition, travel times were measured from video at 5-minute intervals at the Beaverton-Hillsdale (B-H) Highway and SchollsFerry Road on-ramps. A sample of a video image is shown in Figure 3.1. This method was used to estimate ramp delay (as discussed later in the pilot study documentation), but proved to be labor intensive.

Table 3.4: Pilot study data collection methods

\begin{tabular}{l|l|l}
\hline LOCATION OF ON-RAMPS & METER: OUTFLOWS & ENTRANCE: INFLOWS \\
\hline Barnes Rd. / US 26W & Loop & \\
\hline US 26E & Road tube & CCTV camera \\
\hline Wilshire Rd. & Loop & Road tube, Portable camera \\
\hline Walker Rd. & Loop & CCTV camera \\
\hline B-H Hwy & Loop & CCTV camera, Portable camera \\
\hline Allen Blvd. & Loop & CCTV camera \\
\hline Denney Rd. & Loop & CCTV camera \\
\hline Hall Blvd. & Loop & Road tube, Portable camera \\
\hline Scholls-Ferry Rd. & Loop & CCTV camera, Portable camera \\
\hline Greenburg Rd. & Loop & CCTV camera \\
\hline Pacific Hwy & Loop & CCTV camera \\
\hline 72nd Ave. & Loop & CCTV camera \\
\hline
\end{tabular}

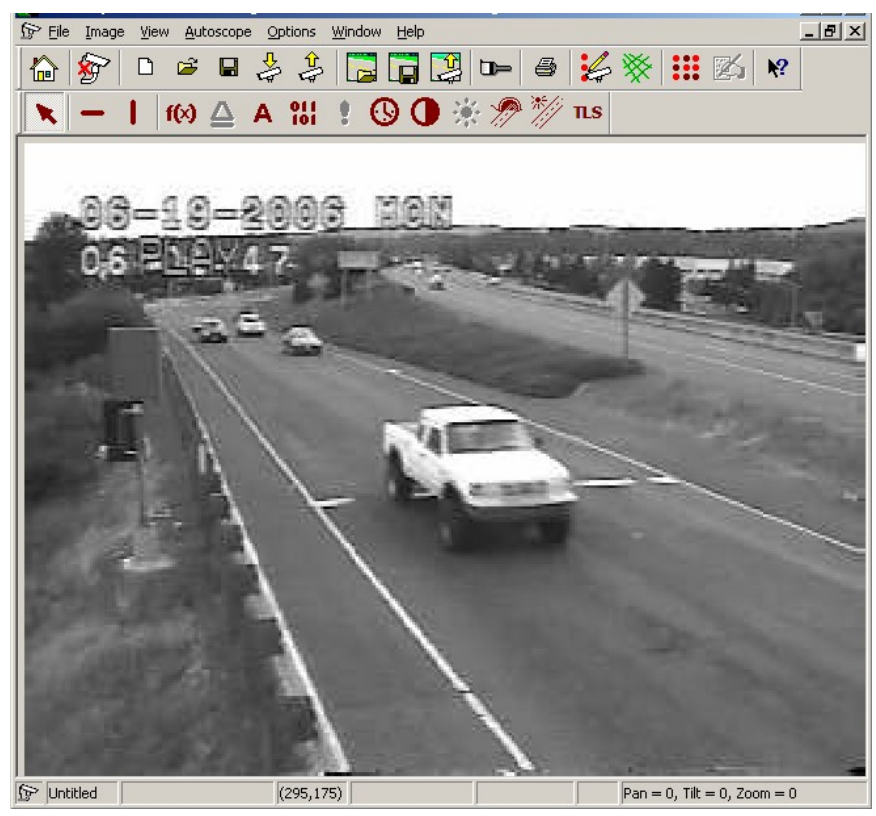

Figure 3.1: Sample video image from Beaverton Hillsdale on-ramp, OR-217 SB 


\subsubsection{Programmable Logic Controllers (Regional Study)}

Following the video-based analysis, an effort was made to use the existing ramp detection infrastructure to estimate queue length. Nearly all of the ramps in the study corridors have detectors placed near the ramp entrance to capture entering volumes. At the meter signal, the loop configuration is such that vehicle departures can be captured. Figure 3.2 shows a sample ramp meter plan for the Lawnfield Rd. entrance to I-205 NB, with the location of the back loops highlighted. The typical design of the loop detection at the ramp meter signal is also shown in the figure (Detail A). If these data could be collected simultaneously with outflow volumes, simple queuing theory (vehicles in vehicles out) per time period could be used to estimate queue length and total ramp delay.

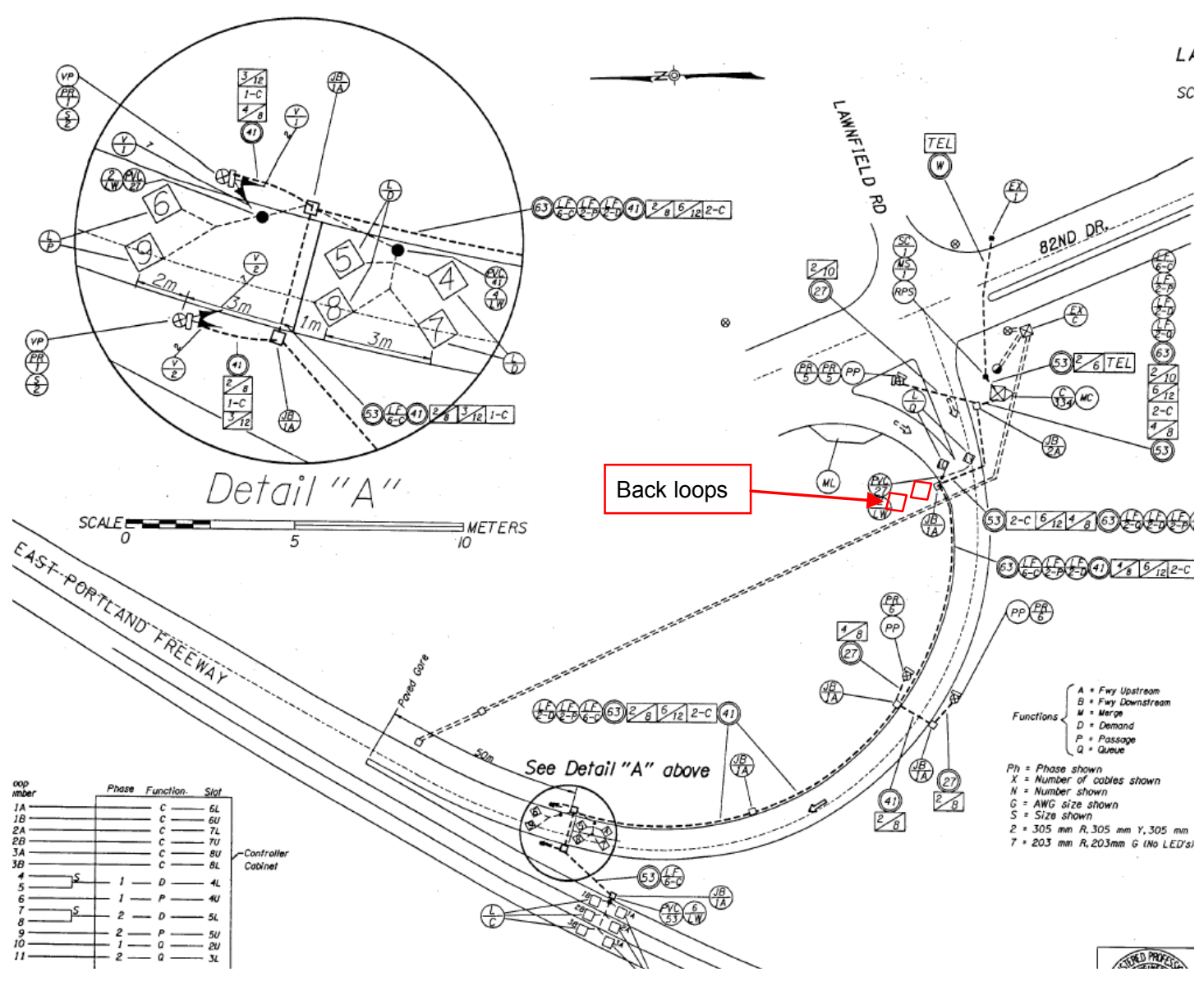

Figure 3.2: Ramp Meter Plan, Lawnfield Rd, I-205 NB, MP 13.58

A preliminary test of the concept was conducted at the southbound Scholls-Ferry Road on-ramp of OR-217. The City of Portland staff assisted the research team to program Programmable Logic Controllers (PLCs) to collect back loop individual vehicle activations (with a time stamp). Because of data storage limitations of the PLC, only one 
morning peak was used for the preliminary test (Thursday March 22, 2007). For validation and verification, video of the ramp was recorded. The discharge count was obtained from PORTAL (20 second aggregation). The PLC clock was manually synchronized with the controller time in the field.

Matching these data to a common time reference was challenging. However, after some data manipulations, the plot in Figure 3.3 was produced.

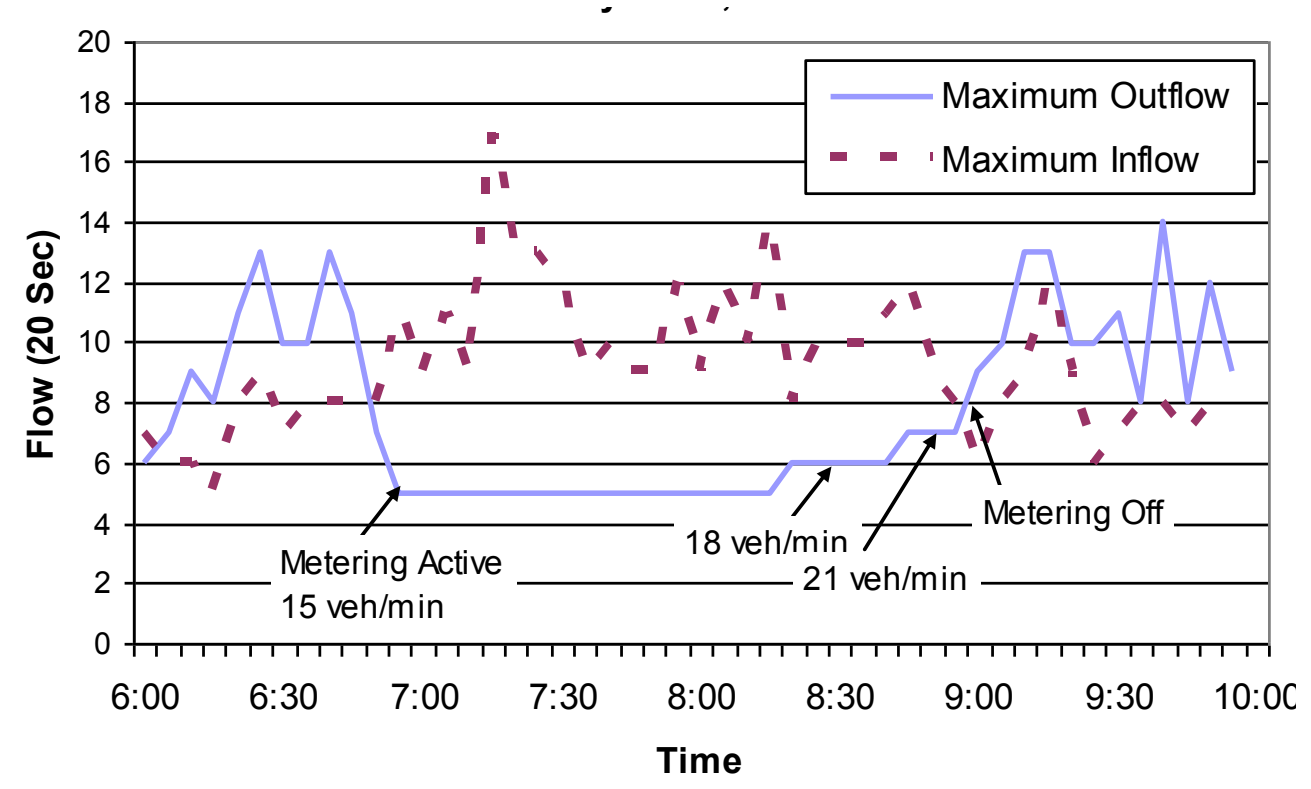

Figure 3.3: Maximum ramp inflows/outflows, Scholl's Ferry Road, 3/22/07, 6:00 to 10:00 AM

The plot shows the maximum vehicle outflow per 20 second period to more clearly show when metering was active. Where the line is flat, it represents the metering rate per 20 second period. The corresponding maximum ramp inflow per 20 second period is shown in the dashed line, which lies above the outflow line when metering was active. Inspection of the figure reveals that when the meter was not active, outflows are in excess of inflows, indicating that there is possibly an over count of vehicles entering the mainline from the ramp in the time periods when the metering is not active.

By focusing on the time when the meter was active, simple queuing theory can be used to estimate the number of vehicles in the queue and estimate total delay. The dashed line in Figure 3.4 shows cumulative vehicle outflows and the solid line shows cumulative inflows. The vertical bars represent the difference between inflows and outflows, or the number of vehicles queued at any particular time plotted on the second $y$-axis. The area between the two curves is equivalent to the total delay for the ramp. Note that after 8:54 AM, there were few, if any, vehicles queued.

Validation of queue length was only possible for part of the analysis period since an incident required the ODOT Traffic Management Operations Center (TMOC) to move the camera. However, for the times when video confirming queue length was available 
the estimated queue length from the PLC method was reasonable. Other parameters were also within expected ranges. The Scholls-Ferry southbound ramp has approximately $1,400 \mathrm{ft}$ available for vehicle storage ( $\sim 50$ vehicles) and an average hourly demand of approximately 750 vehicles per hour (see section 4.1.2). Values in this test study at the peak demand were in line with those values $(\sim 250$ vehicles in 15 minutes). Observation of the queue was also consistent with the data in the figure (a maximum of 25 vehicles).

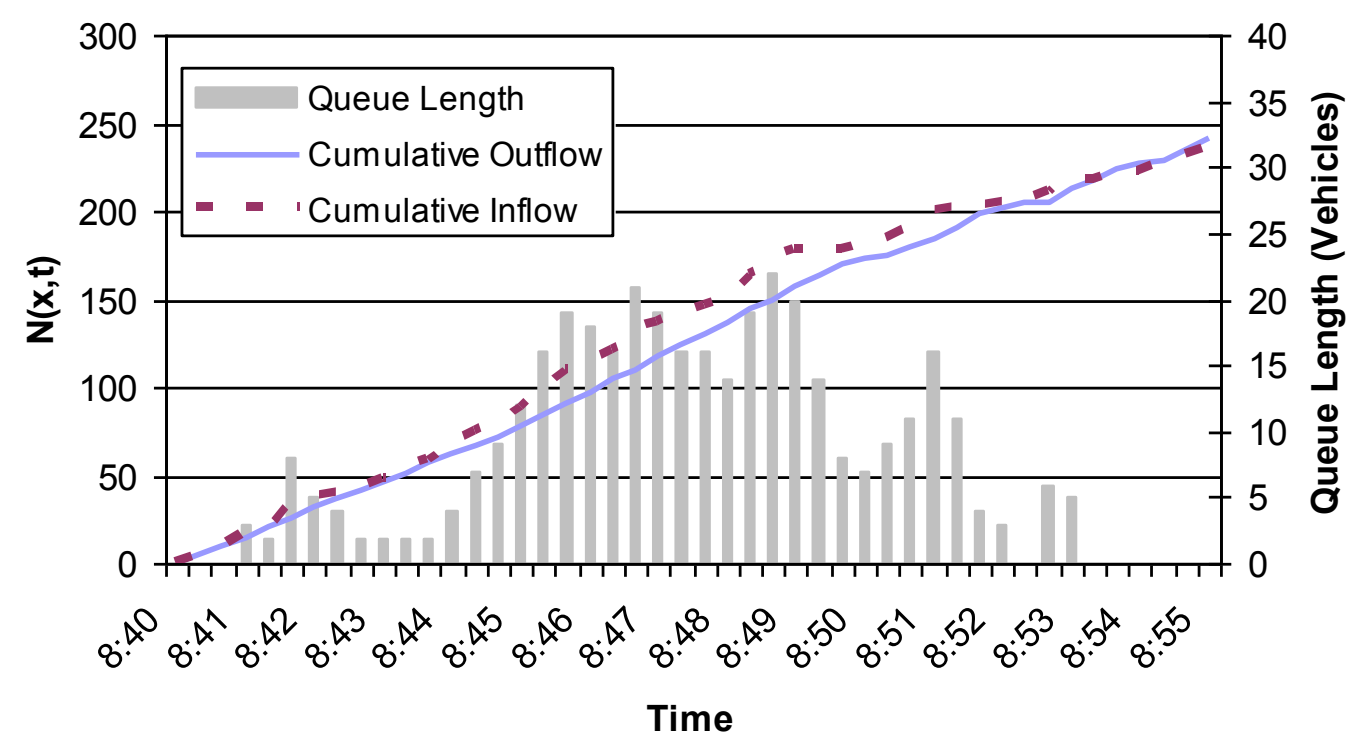

Figure 3.4: Cumulative ramp inflows/outflows and queue length, Scholls-Ferry Road, 3/22/07, 8:40 AM to 8:55 AM

This preliminary test of this approach was deemed successful and a decision was made to use the Programmable Logic Controllers (PLCs) at several key ramps in the regional study. Field visits were conducted at all ramps in the study corridors and the operation of the back and discharge loops were verified. The PLC program was rewritten to capture both the arriving and departing vehicles which would eliminate the need to synchronize time between PORTAL (front loop) and PLC (back loop) data. This would eliminate any need to synchronize PORTAL and PLC times and improve accuracy of the counting. The program was also changed to store 5-minute aggregations because the PLC's memory was insufficient to allow individual vehicle activations to be stored for an extended period. The PLC was also connected to the dynamic sign that indicates to motorists that ramp metering is active. In this manner, the regional study was able to capture meter activation times (which are not currently stored in the ATMS).

The methodology described above is demonstrated in the next two chapters to compare freeway and ramp performance metrics between the existing pre-timed and SWARM operations. 


\subsection{PILOT STUDY}

Prior to engaging in a detailed regional evaluation, a pilot study was conducted to verify experimental design and inform the large scale evaluation. This chapter reports on the evaluation completed to compare pre-timed metering to SWARM on OR-217 SB in June 2006.

\subsection{OR-217 SB}

OR-217 southbound is a seven-mile corridor that serves commuters during peak periods between downtown Portland and suburban areas in Beaverton, Tigard, Lake Oswego, and other communities. This freeway diverges from US-26, intersects with Highways 8 (Canyon Rd./ Tualatin Valley Hwy.), 10 (Beaverton-Hillsdale (B-H) Hwy.), 210 (Scholls-Ferry Rd.), and 99W (Pacific Hwy.), and finally merges onto I-5 SB (see Figure 4.1). This freeway corridor contains 12 on-ramps, 10 of which are controlled by ramp meters. The ramp-metering system on this freeway is supported by 36 loop detectors and nine CCTV cameras. The locations of loop detectors are 0.75 miles apart on average (minimum of 0.31 miles and maximum of 1.23 miles). SWARM was implemented on this corridor in early November 2005.
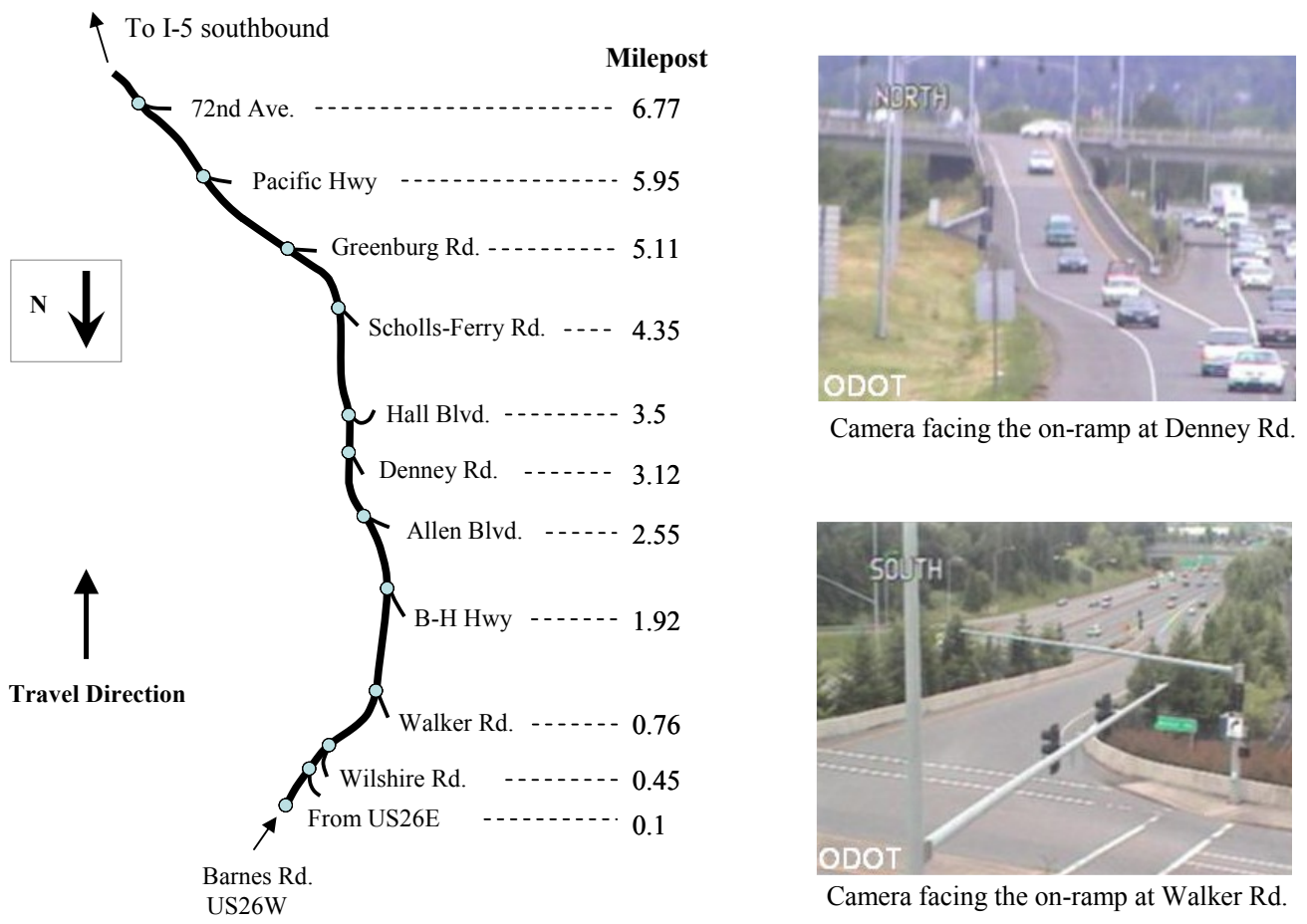

Camera facing the on-ramp at Denney Rd.

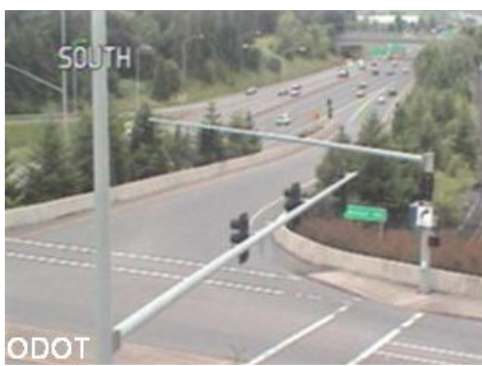

Camera facing the on-ramp at Walker Rd.

Figure 4.1: Schematic of OR-217 southbound and sample CCTV camera views 


\subsubsection{Typical Congestion Pattern}

Queues typically form on this corridor during each morning and evening peak. In the morning peak period, a recurrent bottleneck is located between Scholls-Ferry Rd. and Greenburg Rd., and the resulting queue propagates four to five miles upstream. The bottleneck activates due to large inflow from the on-ramp at Scholls-Ferry Rd. and remains active for a couple of hours (7:009:00 AM). During this period, traffic speeds can drop as low as 20-30 $\mathrm{mph}$ in some parts of the freeway (e.g. near B-H Highway).

During the afternoon peak, a queue forms between Denney Rd. and Allen Blvd. and propagates several miles upstream to Barnes Rd. However, a queue from this active bottleneck is often overridden by another queue that forms on I-5 southbound and spills over to OR-217 southbound. The duration of congestion is typically longer in the afternoon, and the condition can become severe (especially when the queue from I-5 southbound reaches this corridor), such that traffic speed can fall below $20 \mathrm{mph}$ for extended periods.

\subsubsection{Ramp Demand}

For each of the 12 on-ramps, volumes during the peak hours and a queue storage space (in feet) were measured in order to assess if on-ramp traffic is adequately accommodated without causing additional delays to local traffic during the rush. In particular, the average hourly volume during each peak was computed based on the total peak-hour volume. The queue storage space was provided by the Oregon Department of Transportation (ODOT). The number of lanes on the ramp was taken into consideration in estimating the storage space.

The bar chart in Figure 4.2 corresponds to average hourly volumes during the morning rush (6:00-9:00 AM), and the storage spaces are shown as a line chart. The average hourly volumes were measured using archived data from PORTAL for April 3 through April 7, 2006, which were the most recent weekdays at the time of analysis. The traffic conditions on these days were typical for this corridor. Figure 4.3 presents the results for the afternoon hours (3:00-6:00 PM) on the same days. There are 10 on-ramps in this plot; the freeway connector from US-26E to OR-217 and the on-ramp at Barnes Rd. are not shown in the plot. The data for the freeway-tofreeway connector are not available since the ramp is not controlled by a ramp meter. Data at the Barnes Rd. on-ramp are available but were omitted in this analysis since the ramp is located where the freeway begins and is regarded more as a mainline detector.

The figures show that the spatial distributions of the demand during morning and afternoon peaks show some similarities, such that the on-ramps at B-H Highway and Scholls-Ferry Rd. carried large volumes. However, the volumes were larger in general in the afternoon, and some of them exhibited a large increase in volume (e.g. Greenburg Rd.). Based on this observation, the B-H Highway and the Scholls-Ferry on-ramps were closely observed during the pilot study so that delays on these on-ramps as well as queue length could be analyzed adequately. 


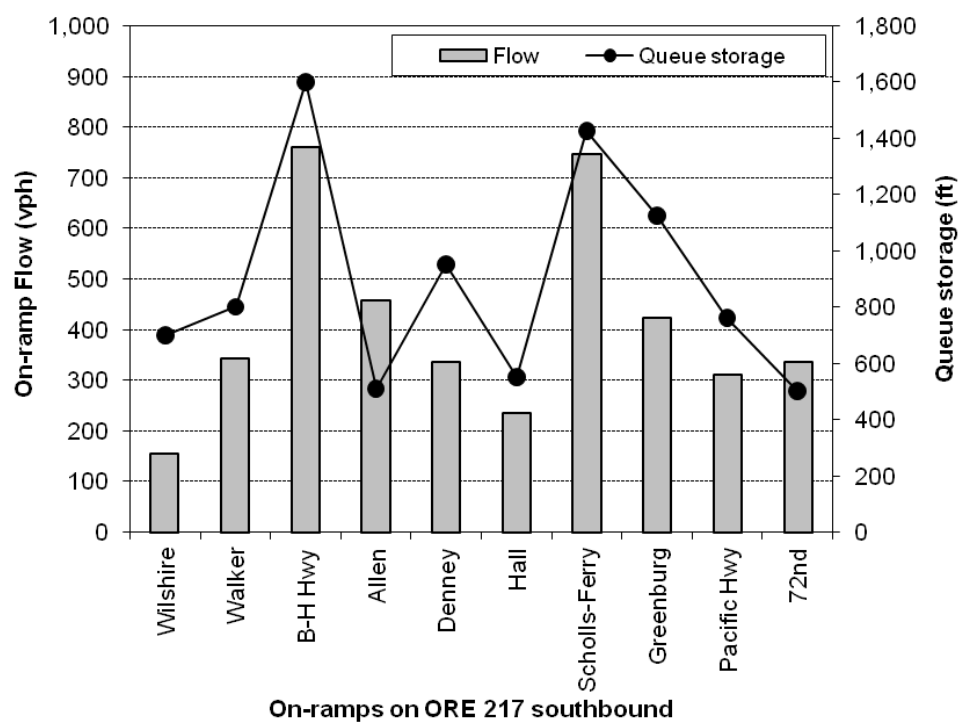

Figure 4.2: On-ramp queue storage and average hourly volumes (6:00-9:00 AM)

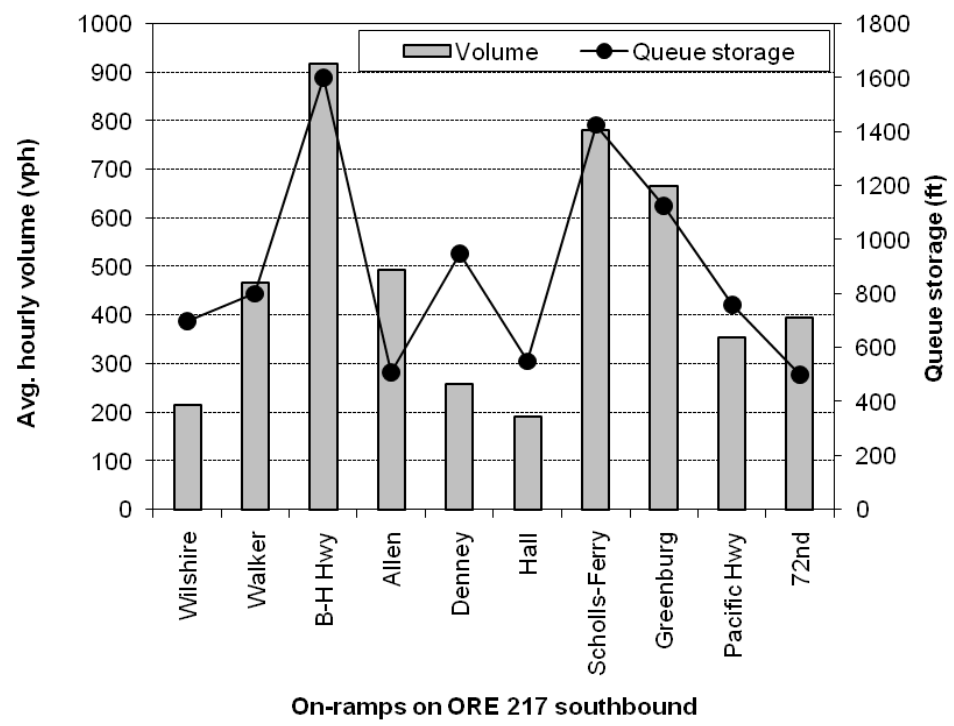

Figure 4.3: On-ramp queue storage and average hourly volumes (3:00-6:00 PM)

\subsubsection{Data Quality}

One of the major concerns with implementing the SWARM system (or any sophisticated trafficresponsive system) is communication failures between loop detector stations and the traffic management center, as the performance of SWARM largely depends on the availability of accurate data. In order to compute metering rates in response to the real-time traffic conditions, the SWARM algorithm requires a large amount of data from multiple freeway locations and onramps. A large amount of (simultaneous) data streams can cause communication failures and loss of data if the communication network is not established to accommodate them. 
Figure 4.4 was constructed by computing the percentage of 20 -second readings that corresponded to communication failures during the morning peak hours (6:00-9:00 AM) under the pre-timed ramp metering (white bars) and the SWARM operations (shaded bars).

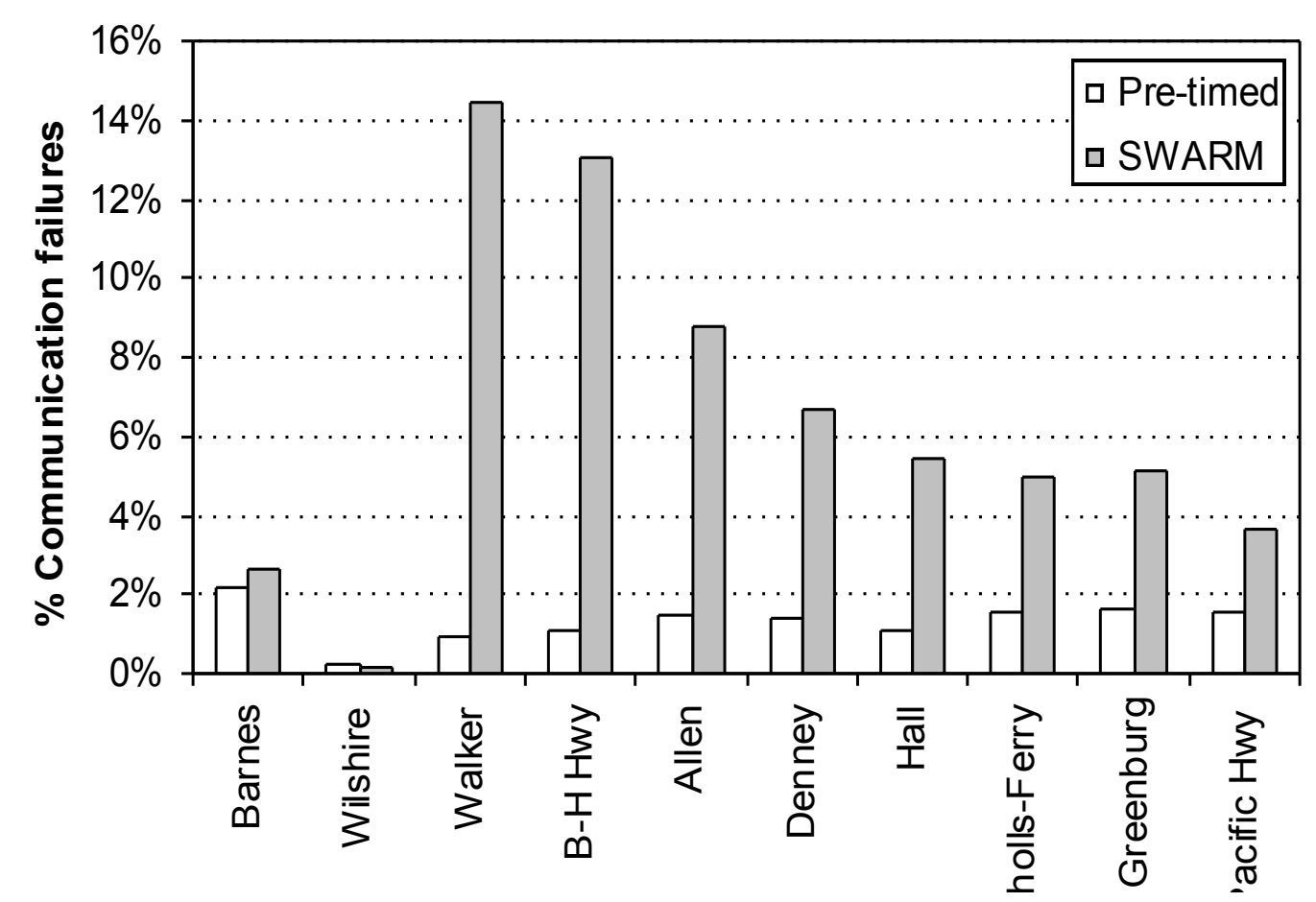

Figure 4.4: Percent communication failures under SWARM vs. pre-timed by station, OR-217 SB.

The figure shows that the percentages of communication failures were below $2 \%$ at most locations with the pre-timed strategy, while the percentages under SWARM were much larger. At some freeway locations, such as near Walker Rd. and B-H Hwy, the communication failures exceeded $10 \%$. At $72 \mathrm{nd}$ Ave. the percentages of communication failures were larger than $60 \%$ (64\% for pre-timed and $69 \%$ for SWARM), indicating that there may be other factors causing the communication failures at the location. For small amounts of missing data due to communication failures interpolated values were used.

\subsubsection{Analysis Days Summary}

As a first step, the quality of the loop detector data was investigated to ensure that there was no significant change in quality during the study period. Then, some basic performance measures such as VMT, VHT, and total delay were computed and compared.

During the data collection period for the pilot study, there were no adverse weather conditions that could potentially affect the driving behavior. However, there was a significant incident on June 21 during the morning peak hours, which resulted in unusual traffic patterns. The data from 
this day was excluded in the comparative analysis. Thus, the data from nine days (four days under the pre-timed and five days under the SWARM operations) were analyzed to report preliminary findings and make recommendations for the future regional-level study.

\subsubsection{Mainline Performance}

This section presents results of the evaluation of freeway conditions before and after the SWARM implementation. Table 4.1 summarizes the basic measures computed from the loop detector data from 6:00 to 9:00 AM. This time window was just large enough to capture the morning congestion over the two study weeks. It shows that the VMT increased marginally $(0.4 \%)$ under the SWARM operation, indicating that the morning demand for this freeway corridor remained nearly independent of the ramp metering control deployed in the field (at least for the short term). However, the VHT increased by $8.6 \%$ under SWARM, corresponding to a significant increase of $34.9 \%$ in total freeway delay. This change in delay, however, was not statistically significant $(p=0.421)$.

Table 4.1: Summary of evaluation results of the mainline freeway, 6:00 to 9:00 AM

\begin{tabular}{rccccc}
\hline & $\begin{array}{c}\text { NUMBER } \\
\text { OF } \\
\text { DAYS }\end{array}$ & $\begin{array}{c}\text { VMT } \\
\text { (AVG } \\
\text { DAILY) }\end{array}$ & $\begin{array}{c}\text { VHT } \\
\text { (AVG } \\
\text { DAILY) }\end{array}$ & $\begin{array}{c}\text { AVG DELAY } \\
\text { (VEH- } \\
\text { HOURS) }\end{array}$ & $\begin{array}{c}\text { DELAY } \\
\text { STANDARD } \\
\text { DEVIATION }\end{array}$ \\
\hline Pre-Timed & 4 & 65,157 & 1,308 & 209 & 115 \\
SWARM & 5 & 65,444 & 1,421 & 282 & 135 \\
$\%$ Change & - & $0.4 \%$ & $8.6 \%$ & $34.9 \%$ & $18.0 \%$ \\
\hline
\end{tabular}

In an attempt to understand the reason for the increase in average delay, the temporal and spatial changes in freeway delay were plotted as shown in Figure 4.5. The darker time-space regions correspond to the increases in delay under SWARM, as indicated by the gray scale on the right side of the figure. The figure illustrates that most increases were observed between 6:30 and 8:30 AM. 


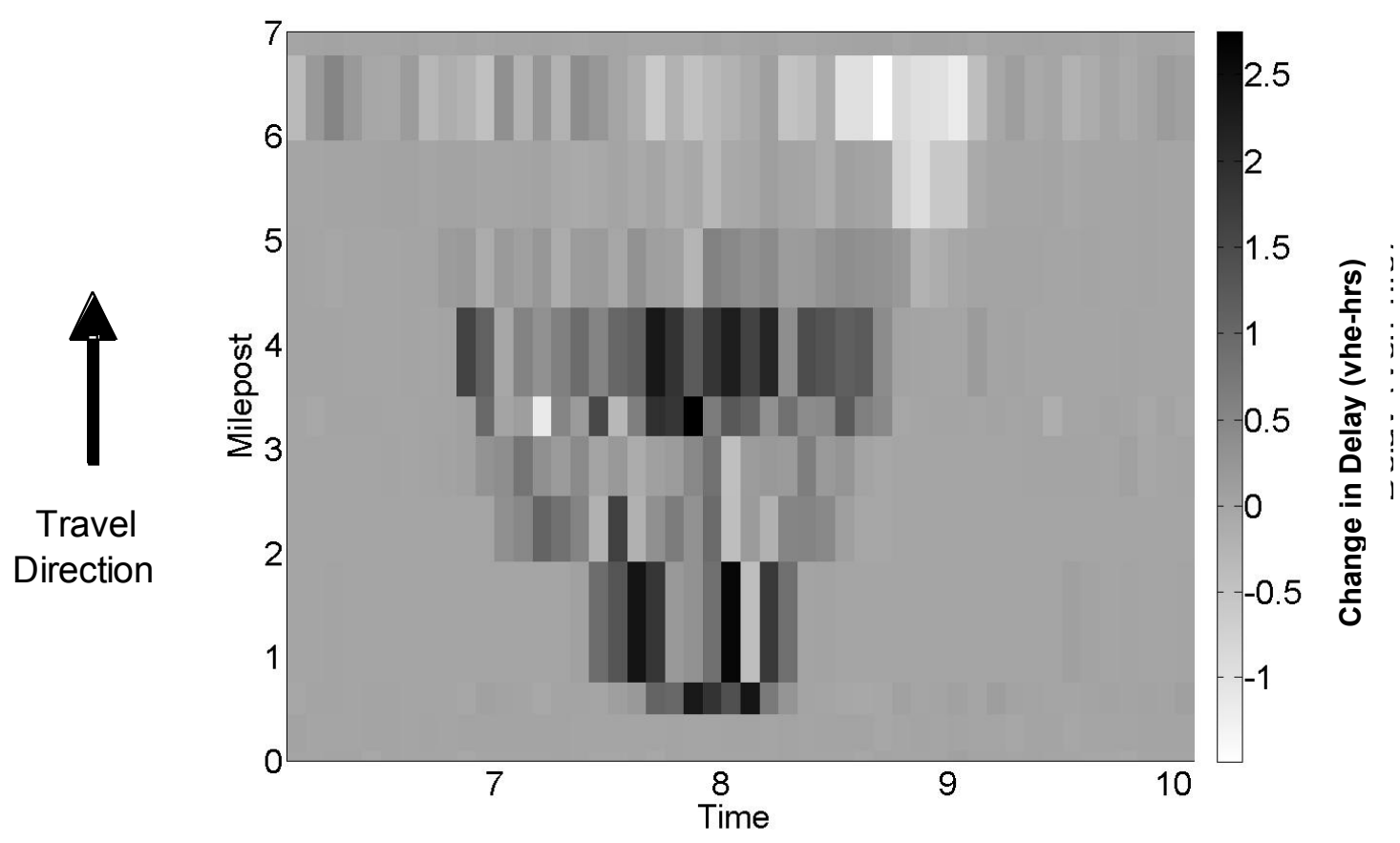

Figure 4.5: Changes in delay under SWARM in time-space plane, OR-217 SB

\subsubsection{Ramp Performance}

The increase in freeway delay with the SWARM operation is attributable to either higher metering rates at the on-ramps or diminished flow through the bottleneck (i.e. bottleneck discharge rate). Unfortunately, we could not verify the latter since the bottleneck discharge rate cannot be estimated solely from the current configuration of the loop detectors.

Higher metering rates seem to play a role in the increase in the freeway delay as illustrated in Figure 4.6. The figure shows the cumulative vehicle counts at all on-ramps, $N$, plotted on an oblique time axis. (In other words, the curves shown in the figure correspond to the quantities, $N$ $q_{0} *\left(t-t_{0}\right)$, where $q_{0}$ is a background flow (3,600 vehicles per hour (vph) in this case), $t$ is time, and $t_{0}$ is the start time of 6:30 AM).) This data processing technique was used to better reveal the changes in traffic flows over time, as described in detail in numerous references (e.g., Cassidy and Windover 1995; Munoz and Daganzo 2002).

Figure 4.6 shows that the cumulative curve for SWARM lies above the one for the pre-timed strategy, and the vertical separation between the two curves increases over time. This indicates that the SWARM strategy consistently admitted higher flows to the freeway throughout the twohour morning peak period. 


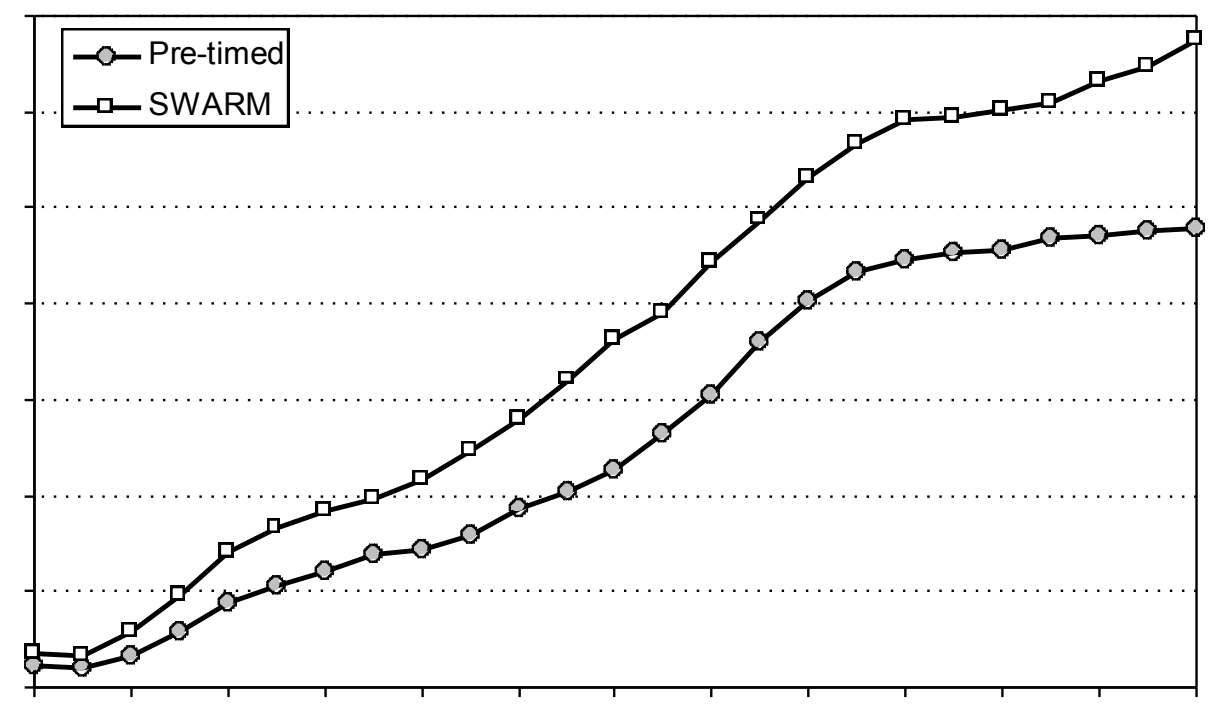

Figure 4.6: Cumulative on-ramp vehicle counts

Figure 4.7 displays the on-ramp flows at the meters between 6:30 and 8:30 AM under the pretimed and the SWARM operations. It shows that the flows were slightly larger at most on-ramps when SWARM was in operation. The increases in flow (except at Hall Blvd.) were in the range between $3 \%$ and $9 \%$.

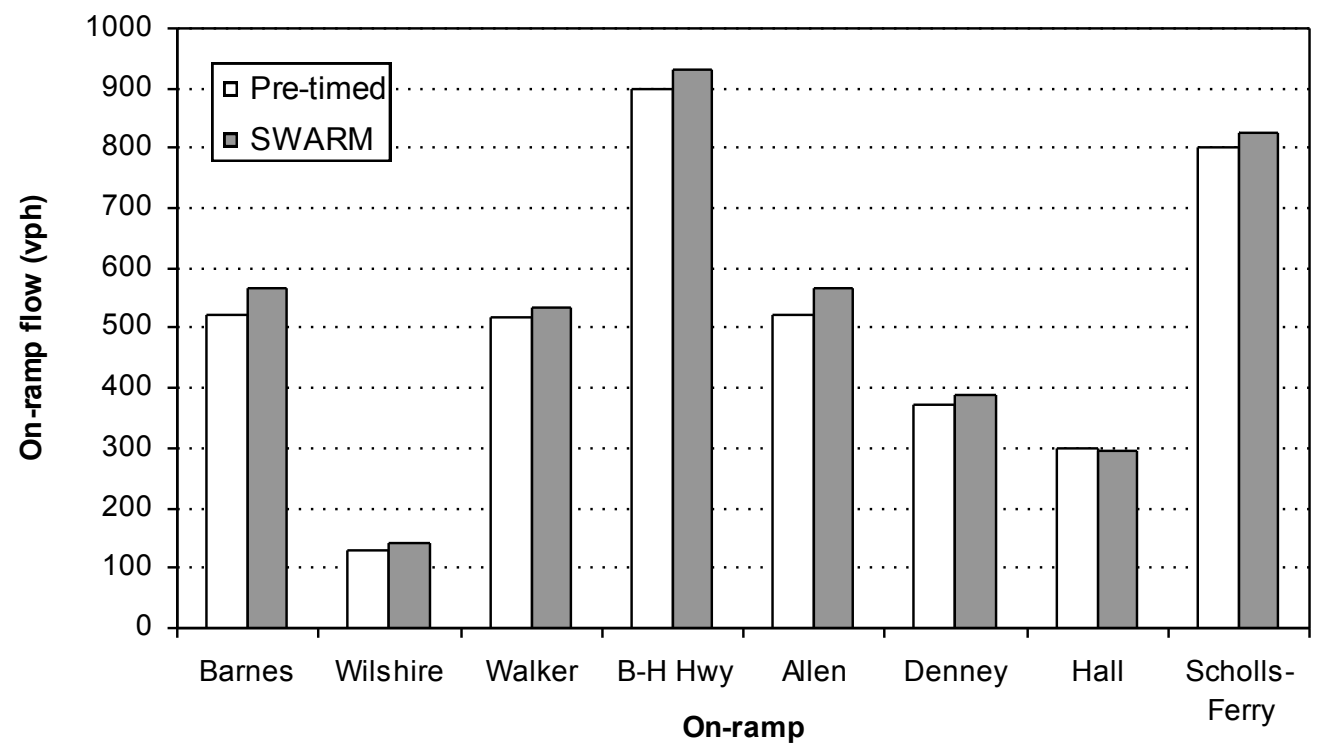

Figure 4.7. On-ramp volumes between 6:30 AM and 8:30 AM 
These moderate increases in flow resulted in decreases in travel time on the ramps, as indicated in Figure 4.8 and Figure 4.9. For these figures, video was used to sample vehicle travel times once every five minutes at the B-H Highway and Scholls-Ferry Rd. on-ramps.

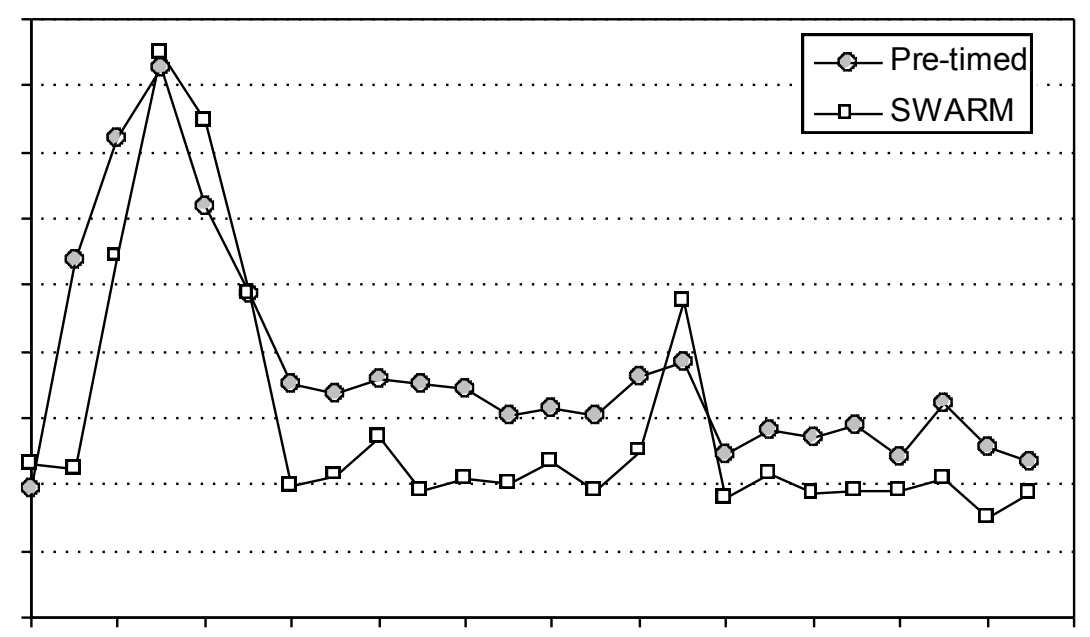

Figure 4.8: Travel time on OR-217 SB on-ramps: Beaverton-Hillsdale Hwy.

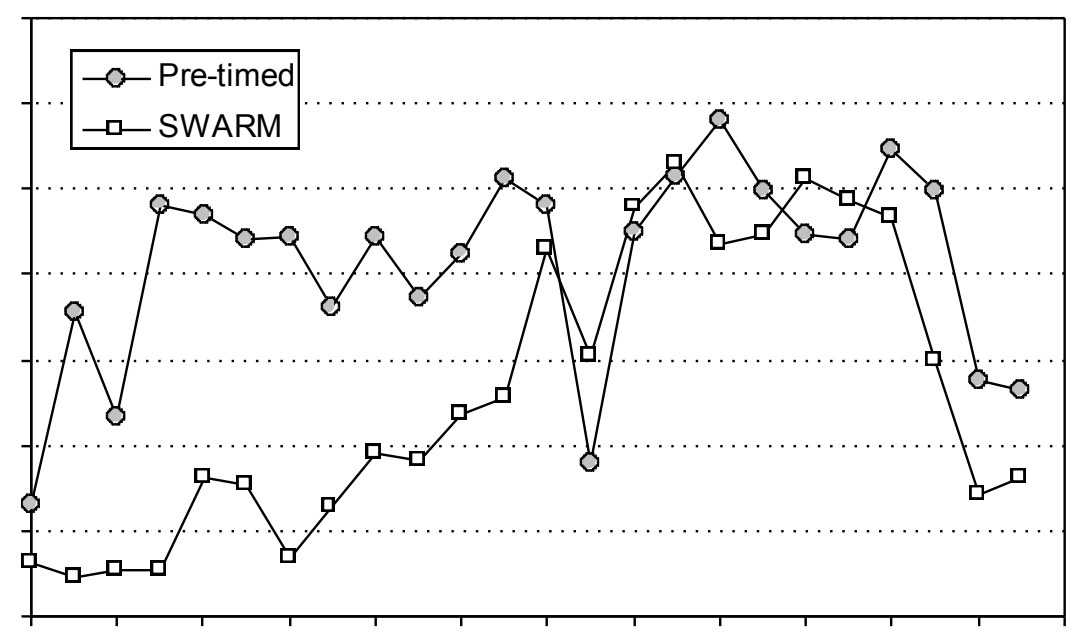

Figure 4.9: Travel time on OR-217 SB on-ramps: Scholls-Ferry Rd.

Both of these figures show that travel times on the on-ramps were lower in general with SWARM. It is estimated that the overall decreases in travel time were $23 \%$ at the BeavertonHillsdale Highway on-ramp and 37\% at the Scholls-Ferry Rd. on-ramp. Large percent decreases in travel time are not surprising since travel times on these two on-ramps are less than 2 minutes). 


\subsection{SUMMARY}

This chapter describes the experimental design for a pilot study to evaluate the benefit of the SWARM strategy as compared to the pre-timed metering strategy. For the selected corridor, data quality and on-ramp conditions were investigated in order to come up with a data collection plan that conformed to our objective given the resources available.

The pilot study was conducted for two weeks, and the changes in freeway conditions were reported. The study found that the vehicle miles traveled (VMT) exhibited a marginal increase under the SWARM operation. However, the total delay on the freeway increased with SWARM, and empirical evidence suggests that this increase resulted from higher metering rates at most of the on-ramps. These higher metering rates under SWARM resulted in lower travel times on several major on-ramps, indicating that the increase in freeway delay was traded with lower onramp delays. However, whether the increase in the total freeway delay was solely caused by the higher merging rates remains an open question since the bottleneck discharge rate could not be measured from the data. Since delays could not be quantified at all on-ramps, due to the limitations on data collection efforts, it was not feasible to analyze the system-wide trade-offs between the freeway and on-ramp delays.

Following the pilot study, the following modifications to the study approach were incorporated into the regional-level study:

- The study duration was increased from one week to two weeks to be help filter out poor data quality, weather, or incidents that affected the comparisons. More days would also allow comparison of similar traffic conditions, rather than comparisons of week averages.

- While the collection of ramp demand and travel times via tubes and video produced good data, it was time consuming to produce. In addition, only a sample of ramp travel times every 5 minutes could be produced. To increase the number of ramps that could be studied and gather information on queue lengths, the Programmable Logic Controller (PLC) approach described in the Methodology chapter was used in the regional study. 


\subsection{REGIONAL STUDY}

Following the pilot study, two corridors were selected for the regional study: I-205 northbound (morning and afternoon peaks) and OR-217 northbound (afternoon peak). To allow comparison of similar traffic conditions each analysis peak period was classified by congestion level. This chapter begins with a description of that methodology.

The results of the two regional corridor studies are then presented. For each corridor, a brief description of the corridor is presented, the effect of SWARM operation on data quality is described, the rationale for removing some days from the evaluation is given, and the results of both mainline performance and ramp performance are given. Finally, the section on each corridor concludes with a discussion of the results. I-205 NB is presented first, followed by OR217 NB.

\subsection{DEFINING CONGESTION LEVELS}

In the pilot study, the comparison was made between average performance measures for the entire peak period for one week. With more data being collected (two weeks instead of one) it was possible to compare SWARM's performance on days with similar levels of congestion for days with sufficient samples. This approach allowed for a comparison of SWARM's ability to deal with a variety of traffic conditions.

There is no formal definition of levels of "congestion" so the approach taken was a blend of criteria and subjective judgment. Use of the Highway Capacity Manual level of service classifications were considered but were deemed too rigorous for what was needed, and thus a less formal approach was adopted. The method used for defining congestion is described in the following paragraphs.

For the regional study corridors (I-205 NB and OR-217 NB), the following fundamental traffic flow relationships were plotted for each station, for each day, and for each analysis period:

- Flow (vehicles per hour (vph), all lanes);

- Density ( occupancy, average across all lanes), shown as a percent; and

- Speed (miles per hour, average across all lanes).

These data were aggregated at the five-minute level. A graphical explanation of the approach is annotated in Figure 5.1. The central portion of this figure shows the expected relationships between flow (volume), speed, and occupancy based on traffic flow theory. Plots of the archived freeway data for one representative day (December 6 2007) for the OR-217 NB at Scholls-Ferry Rd. station are shown in Figure 5.1 as (a) flow (b) speed and (c) occupancy. 
(a)

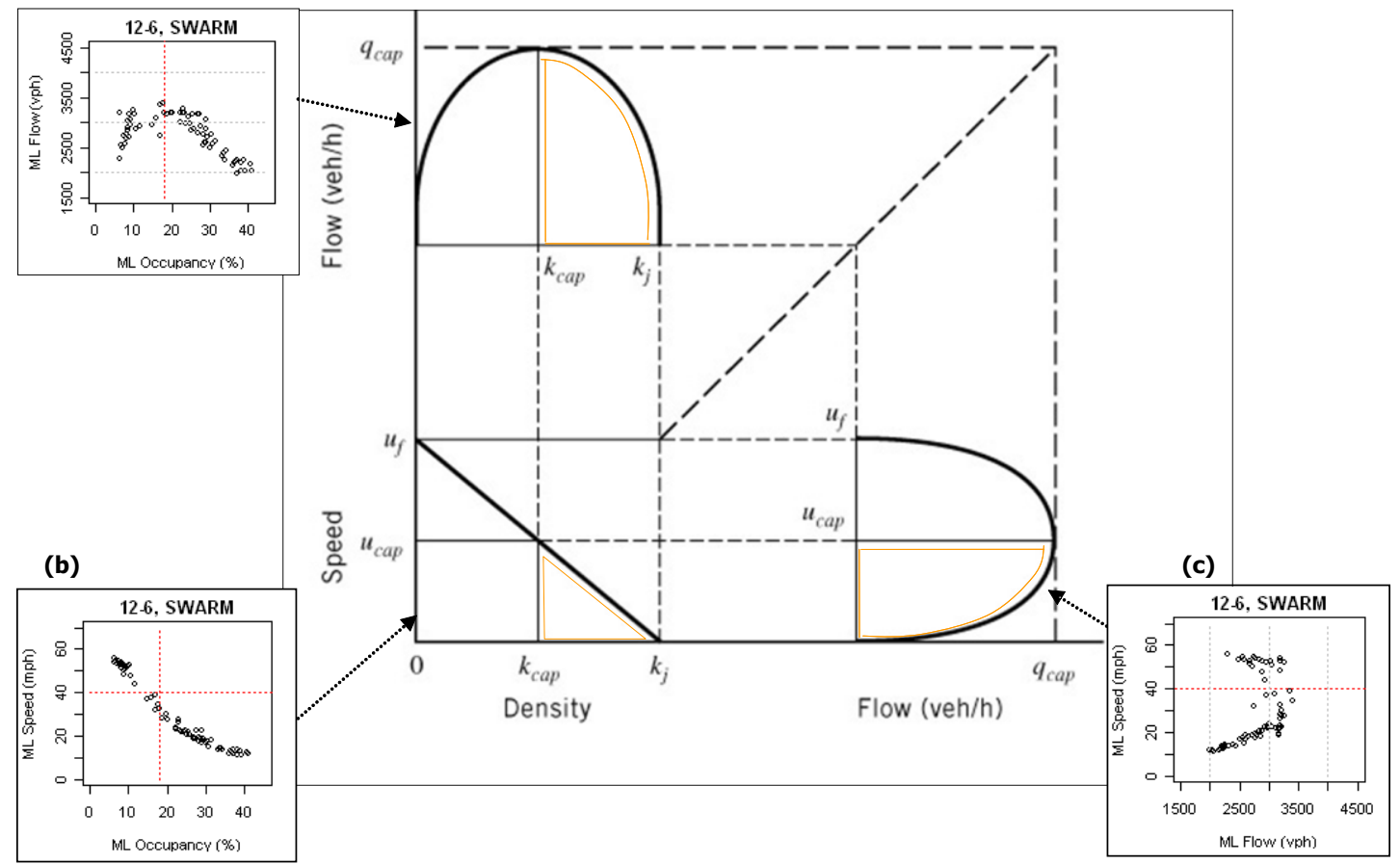

Figure 5.1: Traffic flow fundamental diagram (Source: Mannering and Kilareski, 2004). Individual fundamental diagrams are from OR-217 NB, Scholls-Ferry Road station

Inspection of the plots revealed facility-specific thresholds for each variable that could be used to classify the level of congestion.

In the flow-density ( occupancy) curve (a), data to the right of the peak of the curve at maximum density, $k_{c a p}$, can be considered in the congested regime. Analysis of data for all plots found that on OR-217 NB, congested conditions generally corresponded to occupancy values exceeding $18 \%$ and/or speeds below 35-40 mph. These thresholds are shown in (a) as the dashed vertical line at mainline (ML) occupancy $=18 \%$ and in (b) as the dashed horizontal line at $M L$ Speed $=$ $40 \mathrm{mph}$ ).

Similarly for I-205 NB, analysis of all plots found that congested conditions corresponded to occupancy values exceeding $18 \%$ and/or speeds below $45 \mathrm{mph}$. The plots for all days and stations are located in the online appendices (2-4 and 7-9) companion for this report (located at http://www.oregon.gov/ODOT/TD/TP_RES/ResearchReports.shtml).

Each station was classified based on the number of observed 5-minute periods in a peak period (out of a total number of 48 and 725 minute periods in the morning and afternoon peak, respectively) that were in the congested regime. 
Station classifications included: un-congested, lightly congested, and congested. A station was classified as:

- Un-congested if there was zero or one period with a reading in the congested regime;

- Lightly congested if there were between two and six periods with a reading in the congested regime; or,

- Congested if there were more than six periods with readings in the congested regime.

The plots $(a, b$, and $c)$ in Figure 5.1 show that the Scholls-Ferry station was clearly congested on December 6, 2007 as the vast majority of five-minute readings are in the congested regime.

These station-level estimates were then used to determine corridor-level congestion. Defining congestion over the peak analysis period (four hours) and spatial extent of the corridor required some subjectivity since not all stations exhibit consistent conditions. However, an attempt was made to make the classification as repeatable as possible. The general criteria that were used to define the corridor level congestion varied for I-205 and OR-217 and are shown in Table 5.1. For I-205, the spatial extent of congestion along the study corridor (i.e. number of congested stations on a particular day) was used. For OR-217, the same 3-5 stations were congested on nearly all days, so it was not possible to classify solely based on extent. Rather, the duration of congested conditions at these stations (i.e. number of hours of congested conditions) was used to classify congestion. The number of hours of speeds less than $40 \mathrm{mph}$ was averaged across the five stations.

Table 5.1: Criteria for levels of congestion for corridor

\begin{tabular}{l|l|l}
\hline LEVEL OF CONGESTION & I-205 NB & OR-217 NB \\
\hline Least congested & $<2$ stations & $\begin{array}{l}\text { Average 1-1.5 hours of speeds } \\
\text { less than } 40 \mathrm{mph} \text { at 3-4 } \\
\text { stations }\end{array}$ \\
\hline Moderately congested & $2-3$ stations & $\begin{array}{l}\text { Average } 2-2.5 \text { hours of speeds } \\
\text { less than } 40 \mathrm{mph} \text { at } 4 \text { stations }\end{array}$ \\
\hline Highly congested & $4-7$ stations & $\begin{array}{l}\text { Average } 3 \text { hours of speeds less } \\
\text { than } 40 \text { mph at } 5 \text { stations }\end{array}$ \\
\hline Very highly congested & $8-9$ stations & $\begin{array}{l}\text { Average } 3.5-4 \text { hours of speeds } \\
\text { less than } 40 \text { mph at } 5 \text { stations } \\
\text { (nearly } 6 \text { hours at 3 stations) }\end{array}$ \\
\hline
\end{tabular}

To illustrate the approach, a series of mainline occupancy (\%) vs. flow (vph) diagrams for all stations is shown in Figure 5.2 (a) and a time-space speed contour plot for OR-217 NB for December 6, 2007 (1:00-7:00 PM) is shown in Figure 5.2 (b). The flow-occupancy graphs are as described previously. The time-space speed contour has freeway distance (mi) on the vertical axis and time (hour) on the horizontal axis. The color scale in Figure 5.2 (b) represents average speeds over 20 -sec intervals as estimated from the loop detector data and the ranges of speeds. The corresponding colors are provided in the legend on the right side of each plot. 
(a)
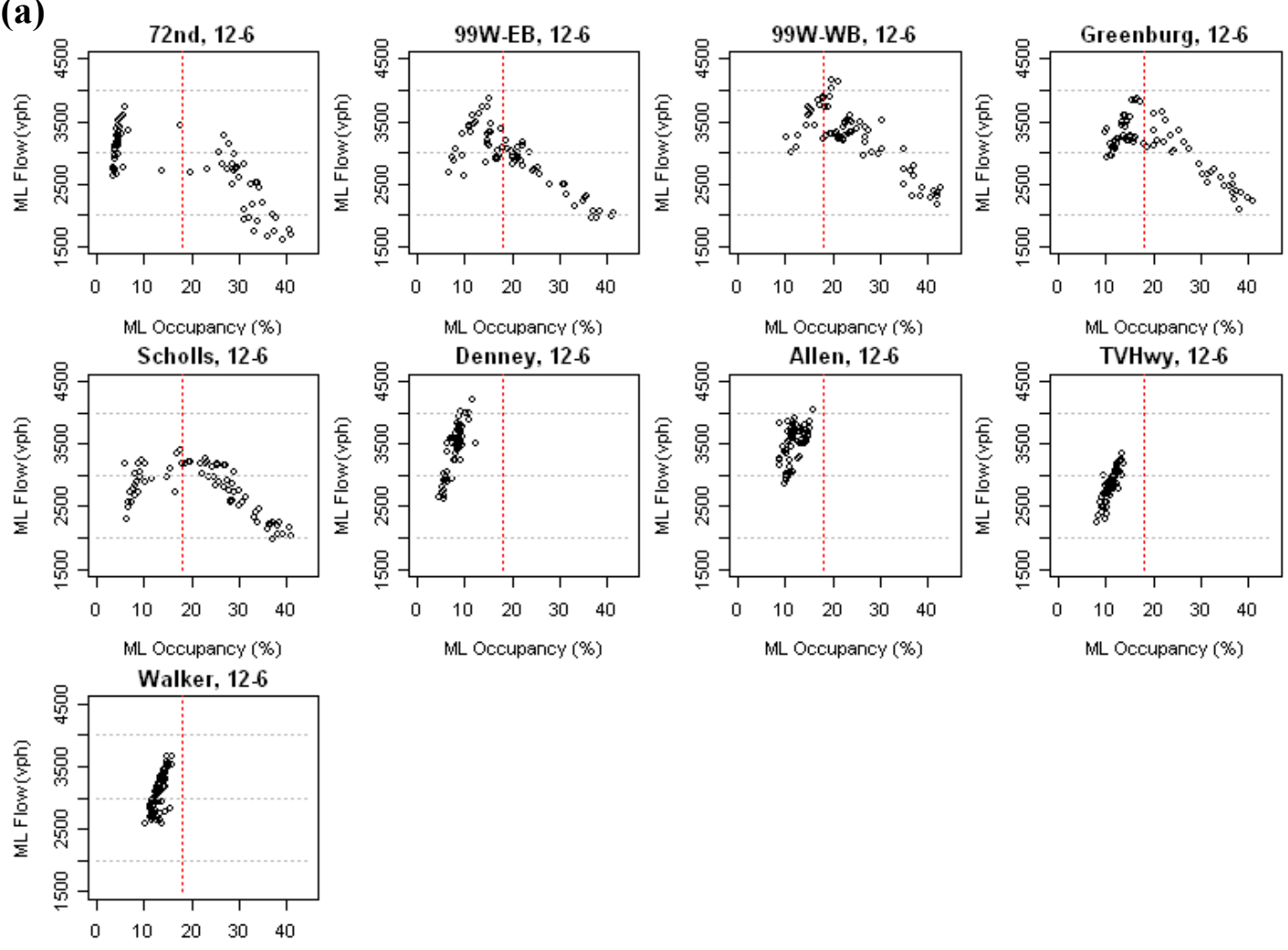

ML Occupancy $(\%)$

\section{(b)}

Speed (mph)

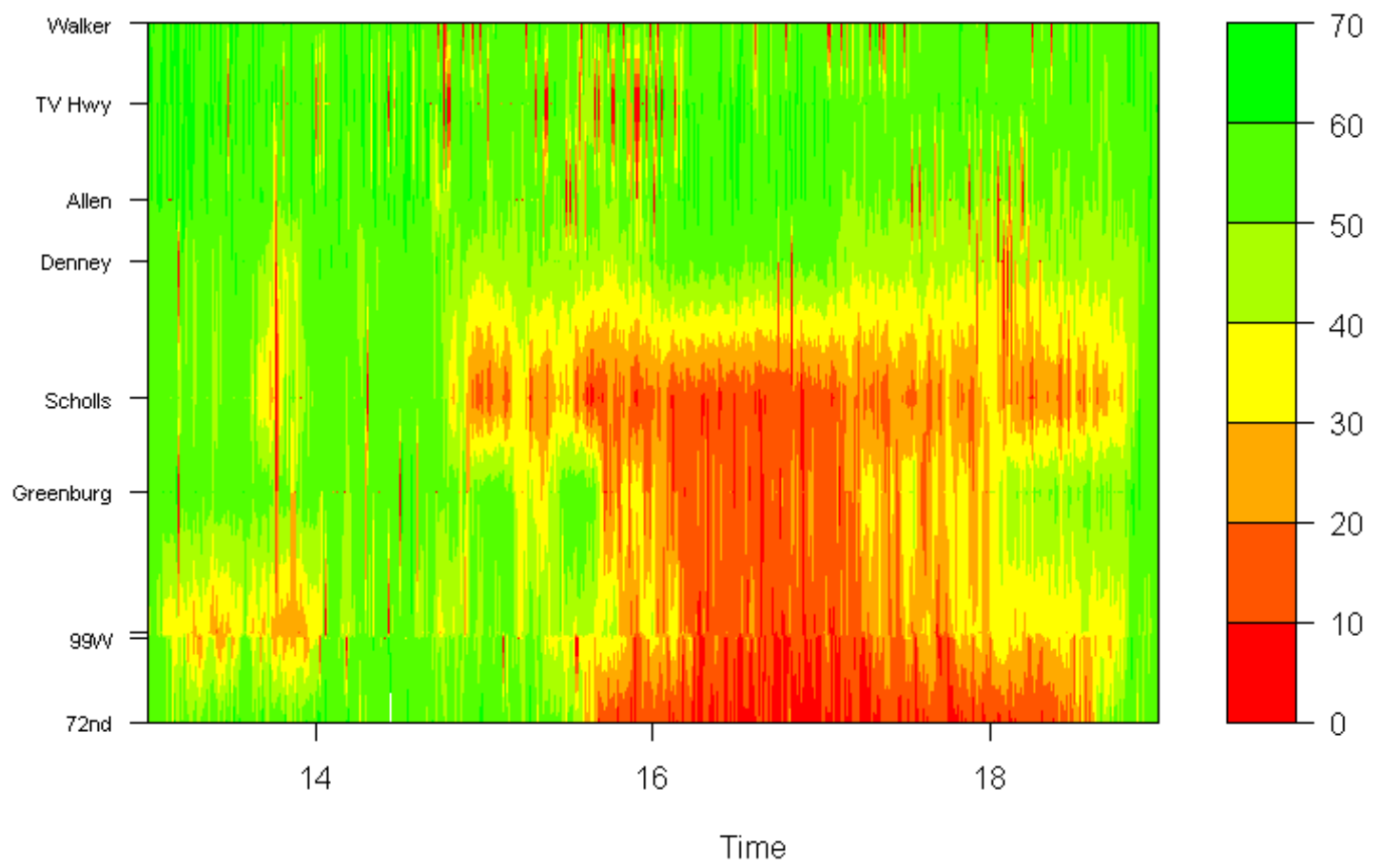

Figure 5.2: Plots of mainline occupancy (\%) vs mainline flow (vph) for all stations (a), and time-space speed contour plot (b), OR-217 NB, December 6, 2007 1:00-7:00 PM 
The flow-occupancy plots clearly show that the first five stations (72nd, 99W EB, 99W WB, Greenburg, and Scholls-Ferry) would be classified as "congested" using this approach (the majority of flow-occupancy data points exceed the $18 \%$ occupancy threshold). The criteria used for OR-217 NB required that the duration of congestion be determined, which could be done using the time-space plot. The red (dark) regions on Figure 5.2 (b) indicate times of low speed which are present at one of the first five stations from nearly 3:00 PM to 6:45 PM. Using these criteria, it was determined that the five stations were congested for a period of 3.75 hours, thus the corridor was defined as "very highly" congested for the December $6^{\text {th }}$ analysis period. Timespace plots for all days are located in the online appendices (1 and 5) in companion to this report.

This procedure was conducted for the remaining days and corridors. The final definition of the level of congestion for each day is shown in Table 5.2. Note that days with data quality, weather, or incidents (explained in Sections 5.2.2 and 5.3.2) were not classified and are shown as blank in the table.

Table 5.2: Summary of congestion levels for pre-timed and SWARM study days

\begin{tabular}{|c|c|c|c|c|c|c|c|c|c|c|c|}
\hline \multicolumn{4}{|c|}{ I-205 NB AM } & \multicolumn{4}{|c|}{ I-205 NB PM } & \multicolumn{4}{|c|}{ OR-217 NB } \\
\hline \multicolumn{2}{|c|}{ PRE-TIMED } & \multicolumn{2}{|c|}{ SWARM } & \multicolumn{2}{|c|}{ PRE-TIMED } & \multicolumn{2}{|c|}{ SWARM } & \multicolumn{2}{|c|}{ PRE-TIMED } & \multicolumn{2}{|c|}{ SWARM } \\
\hline $9 / 24$ & $\begin{array}{l}\text { Moderately } \\
\text { congested }\end{array}$ & $9 / 10$ & & $9 / 24$ & $\begin{array}{l}\text { Moderately } \\
\text { congested }\end{array}$ & $9 / 10$ & $\begin{array}{l}\text { Highly } \\
\text { congested }\end{array}$ & $11 / 5$ & Least & $11 / 26$ & $\begin{array}{l}\text { Moderately } \\
\text { congested }\end{array}$ \\
\hline $9 / 25$ & $\begin{array}{l}\text { Moderately } \\
\text { congested }\end{array}$ & $9 / 11$ & $\begin{array}{l}\text { Moderately } \\
\text { congested }\end{array}$ & $9 / 25$ & $\begin{array}{l}\text { Moderately } \\
\text { congested }\end{array}$ & $9 / 11$ & $\begin{array}{l}\text { Moderately } \\
\text { congested }\end{array}$ & $11 / 6$ & Least & $11 / 27$ & $\begin{array}{l}\text { Moderately } \\
\text { congested }\end{array}$ \\
\hline $9 / 26$ & $\begin{array}{l}\text { Moderately } \\
\text { congested }\end{array}$ & $9 / 12$ & $\begin{array}{l}\text { Moderately } \\
\text { congested }\end{array}$ & $9 / 26$ & & $9 / 12$ & & $11 / 7$ & Least & $11 / 28$ & \\
\hline $9 / 27$ & & $9 / 13$ & & $9 / 27$ & $\begin{array}{l}\text { Moderately } \\
\text { congested }\end{array}$ & $9 / 13$ & & $11 / 8$ & $\begin{array}{l}\text { Moderately } \\
\text { congested }\end{array}$ & $11 / 29$ & $\begin{array}{l}\text { Moderately } \\
\text { congested }\end{array}$ \\
\hline $9 / 28$ & $\begin{array}{l}\text { Moderately } \\
\text { congested }\end{array}$ & $9 / 14$ & & $9 / 28$ & $\begin{array}{l}\text { Very } \\
\text { Highly } \\
\text { congested }\end{array}$ & $9 / 14$ & & $11 / 9$ & High & $11 / 30$ & High \\
\hline $10 / 1$ & $\begin{array}{l}\text { Moderately } \\
\text { congested }\end{array}$ & $9 / 17$ & & $10 / 1$ & $\begin{array}{l}\text { Moderately } \\
\text { congested }\end{array}$ & $9 / 17$ & $\begin{array}{l}\text { Moderately } \\
\text { congested }\end{array}$ & $11 / 12$ & & $12 / 3$ & \\
\hline $10 / 2$ & $\begin{array}{l}\text { Least } \\
\text { Congested }\end{array}$ & $9 / 18$ & & $10 / 2$ & $\begin{array}{l}\text { Least } \\
\text { Congested }\end{array}$ & $9 / 18$ & & $11 / 13$ & $\begin{array}{l}\text { Moderately } \\
\text { congested }\end{array}$ & $12 / 4$ & \\
\hline $10 / 3$ & & $9 / 19$ & $\begin{array}{l}\text { Moderately } \\
\text { congested }\end{array}$ & $10 / 3$ & & $9 / 19$ & $\begin{array}{l}\text { Moderately } \\
\text { congested }\end{array}$ & $11 / 14$ & $\begin{array}{l}\text { Moderately } \\
\text { congested }\end{array}$ & $12 / 5$ & Very High \\
\hline $10 / 4$ & $\begin{array}{l}\text { Highly } \\
\text { congested }\end{array}$ & $9 / 20$ & $\begin{array}{l}\text { Moderately } \\
\text { congested }\end{array}$ & $10 / 4$ & $\begin{array}{l}\text { Highly } \\
\text { congested }\end{array}$ & $9 / 20$ & $\begin{array}{l}\text { Moderately } \\
\text { congested }\end{array}$ & $11 / 15$ & Very High & $12 / 6$ & Very High \\
\hline $10 / 5$ & $\begin{array}{l}\text { Moderately } \\
\text { congested }\end{array}$ & $9 / 21$ & Least & $10 / 5$ & $\begin{array}{l}\text { Highly } \\
\text { congested }\end{array}$ & $9 / 21$ & $\begin{array}{l}\text { Very } \\
\text { Highly } \\
\text { congested }\end{array}$ & $11 / 16$ & & $12 / 7$ & Very High \\
\hline
\end{tabular}




\section{$5.2 \quad \mathrm{I}-205 \mathrm{NB}$}

\subsubsection{Description of Corridor}

I-205 NB is a spur freeway that leaves the I-5 corridor south of the Portland near the city of Wilsonville and returns to I-5 north of Vancouver, Washington (as shown in Figure 1.1). The study area which is from Gladstone (MP 11.05) to Division (MP 19.4) is shown in Figure 5.3. This figure shows the configuration of the highway and the spacing of the nine on-ramps which are all controlled by ramp meters. Mainline loop detector stations are 1.09 miles apart on average. The largest distances between loop detectors are from Gladstone to Clackamas Highway (1.89 miles), Sunnyside to Johnson Creek (1.5 miles), and Johnson Creek to Foster (1.9 miles). SWARM was implemented on this corridor in early December 2005. Construction on the MAX light rail was underway during the study period but did not directly impact northbound freeway operations since most construction was in the southbound direction. Within the fourweek regional study data collection period for I-205 NB, the ramp meters operated under SWARM from September 10 to September 21 and were programmed to run under the pre-timed strategy from September 24 to October 5.

\subsubsection{Typical Congestion Patterns}

I-205 NB from Gladstone to Division has congestion in both the morning and afternoon, allowing both peak periods to be studied. In the AM period, there is generally congestion from Sunnyside to Division which clears after the I-84 interchange near milepost (MP) 21. In the morning peak, the head of a bottleneck may extend beyond the detector at Division. In the afternoon peak, congestion generally extends from the Sunnyside station to well downstream of the Division station. In many cases, the corridor is congested all the way to Washington, at MP 23.41. The described congestion patterns are contained within the study peak periods. Time-space plots for all days are located in the Appendix Online-1 companion to this report.

\subsubsection{Ramp Demand}

As in the pilot study, a characterization of ramp volumes and available storage space was conducted. These data are plotted in Figure 5.4 and Figure 5.5, which show average ramp volume as grey bars plotted on the left axis, and queue storage measured in feet on the right axis for $\mathrm{AM}$ and $\mathrm{PM}$, respectively. The number of lanes on the ramp was taken into consideration in estimating the storage space. These plots were generated from March 2007 data. The plots are not meant to convey queuing problems rather they are intended to show how the volumes and available storage relate. In both the morning and afternoon peaks, the highest volumes are at the Foster, Johnson Creek, and Sunnyside ramps which average from 500 to 900 vehicles per hour (vph) in both AM and PM peak periods. The next busiest ramps (Powell, Lawnfield, Clackamas Hwy, and Division) have moderately heavy traffic volumes averaging about 400 to $500 \mathrm{vph}$ in both peak periods. The available storage at Foster is a potential limitation given the demand volumes. 


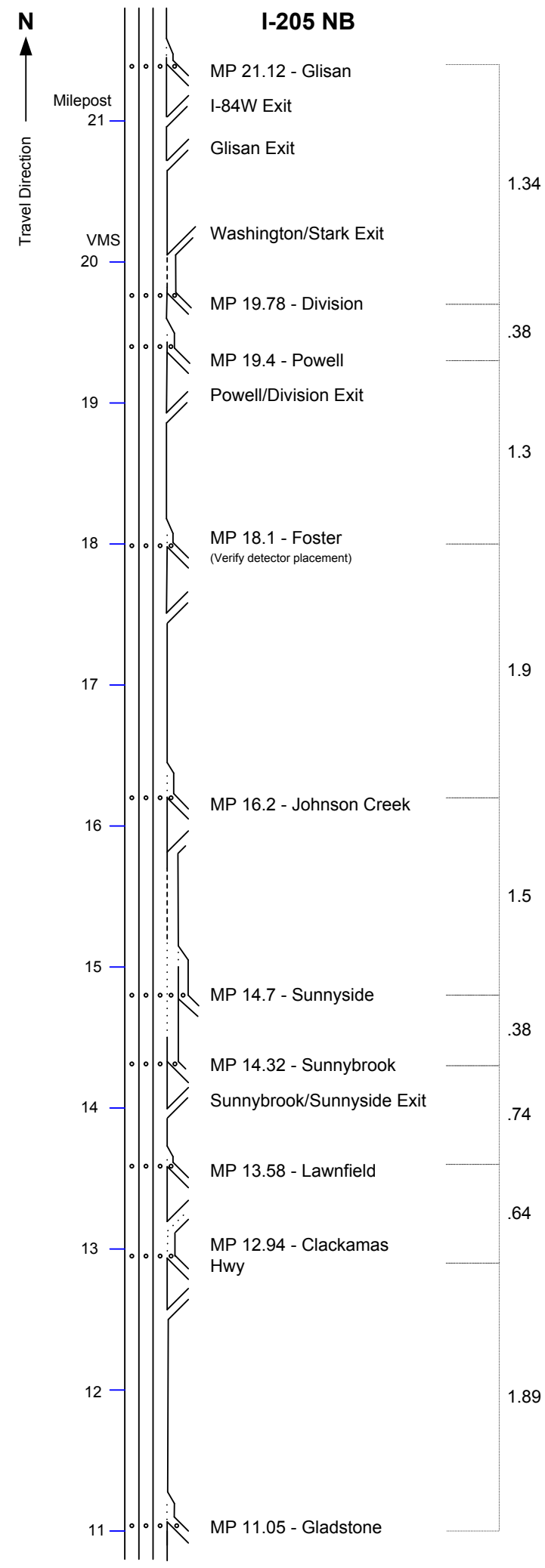

Note: study corridor ends at Division

Figure 5.3: Schematic of I-205 NB 


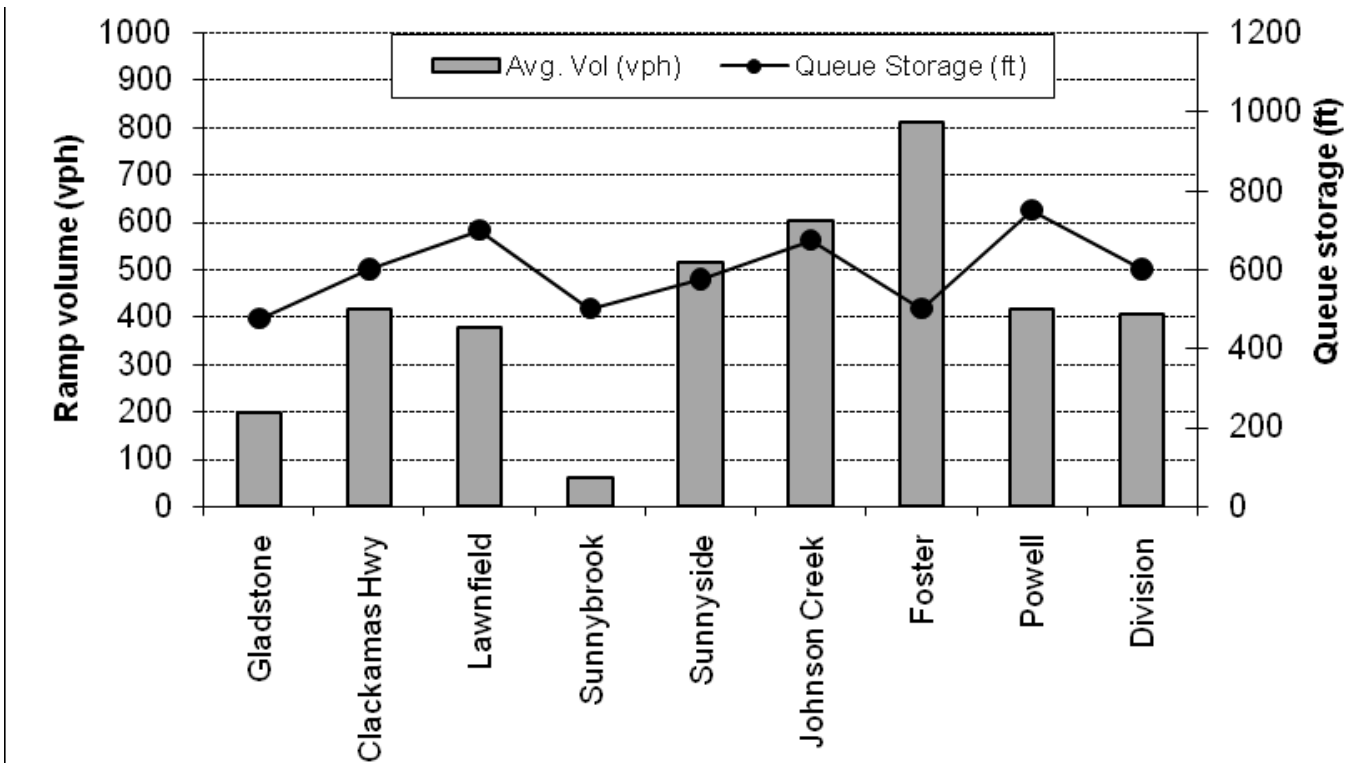

Figure 5.4: Average hourly volume and queue storage on I-205 NB, AM peak, March 2007

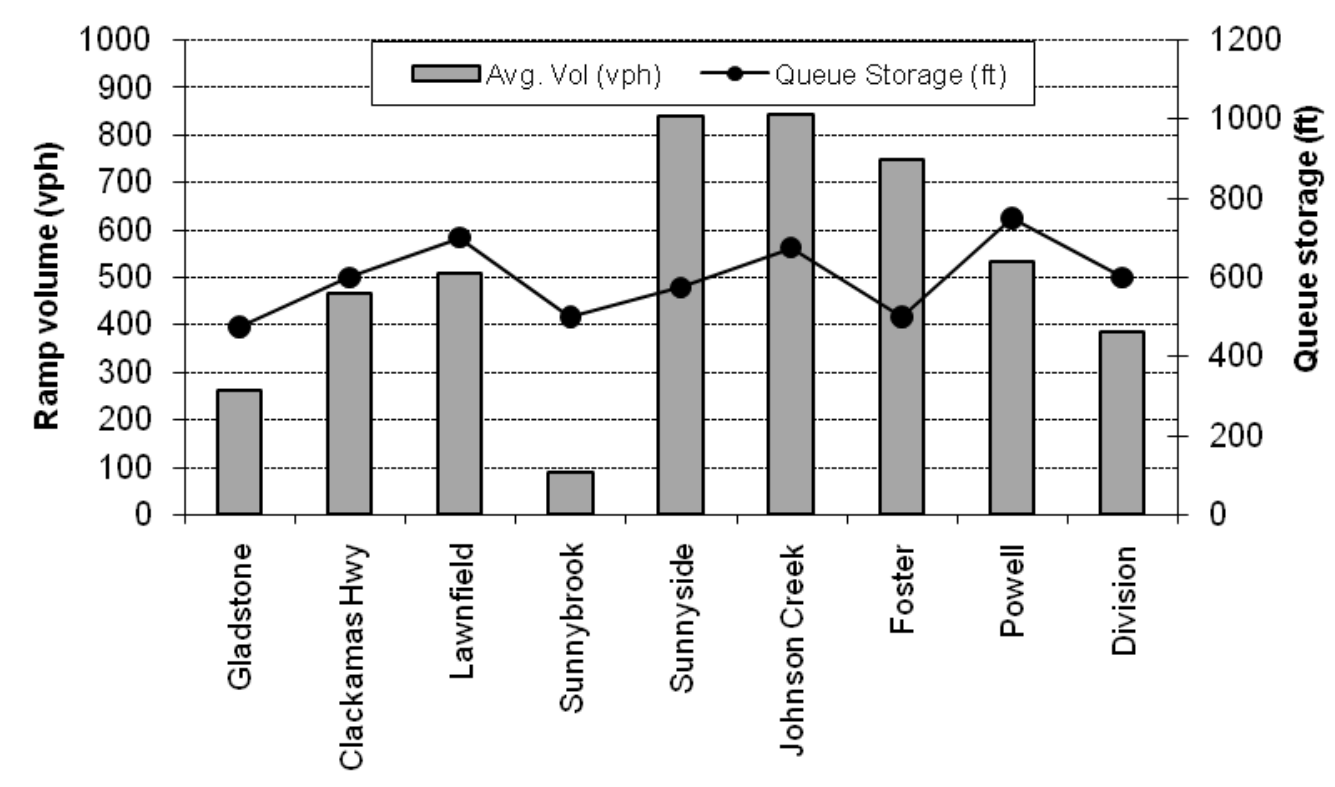

Figure 5.5: Average hourly volume and queue storage on I-205 NB, PM peak, March 2007 


\subsubsection{Excluded Analysis Days}

\subsubsection{Communication Failures}

The data intensive nature of the adaptive metering system requires consistent and accurate data from the system in order to compute an appropriate metering rate (local and global). The system must also send new commands to the controllers frequently. In pre-timed operation, the ATMS polls each ramp controller to obtain each 20 -second data packet. In this case, some of these communication polls "fail" which is reflected in the archived data. In SWARM operation, communication demands on the system are higher and more communication polls fail. The ability of the ATMS to handle the additional data needs of the adaptive system was considered. The communications failure rate apparent from the archived data was compared for the pre-timed and adaptive systems.

To classify the overall impact of SWARM on corridor communications, the percentage of 20-second readings that were missing or corresponded to communication failures on I-205 NB, for each station, were calculated. Figure 5.6 shows the percentage of communication failures in the morning peak hours (6:00-10:00 AM) and Figure 5.7 shows them for the afternoon peak hours (1:00-7:00 PM). Both the pre-timed and SWARM operations are shown. At most ramps, the failure rate was around five percent under the pre-timed strategy. Under SWARM, the failure rate was around 10\%, except for Clackamas Highway, Sunnybrook, and Powell ramps which had significantly higher failure rates.

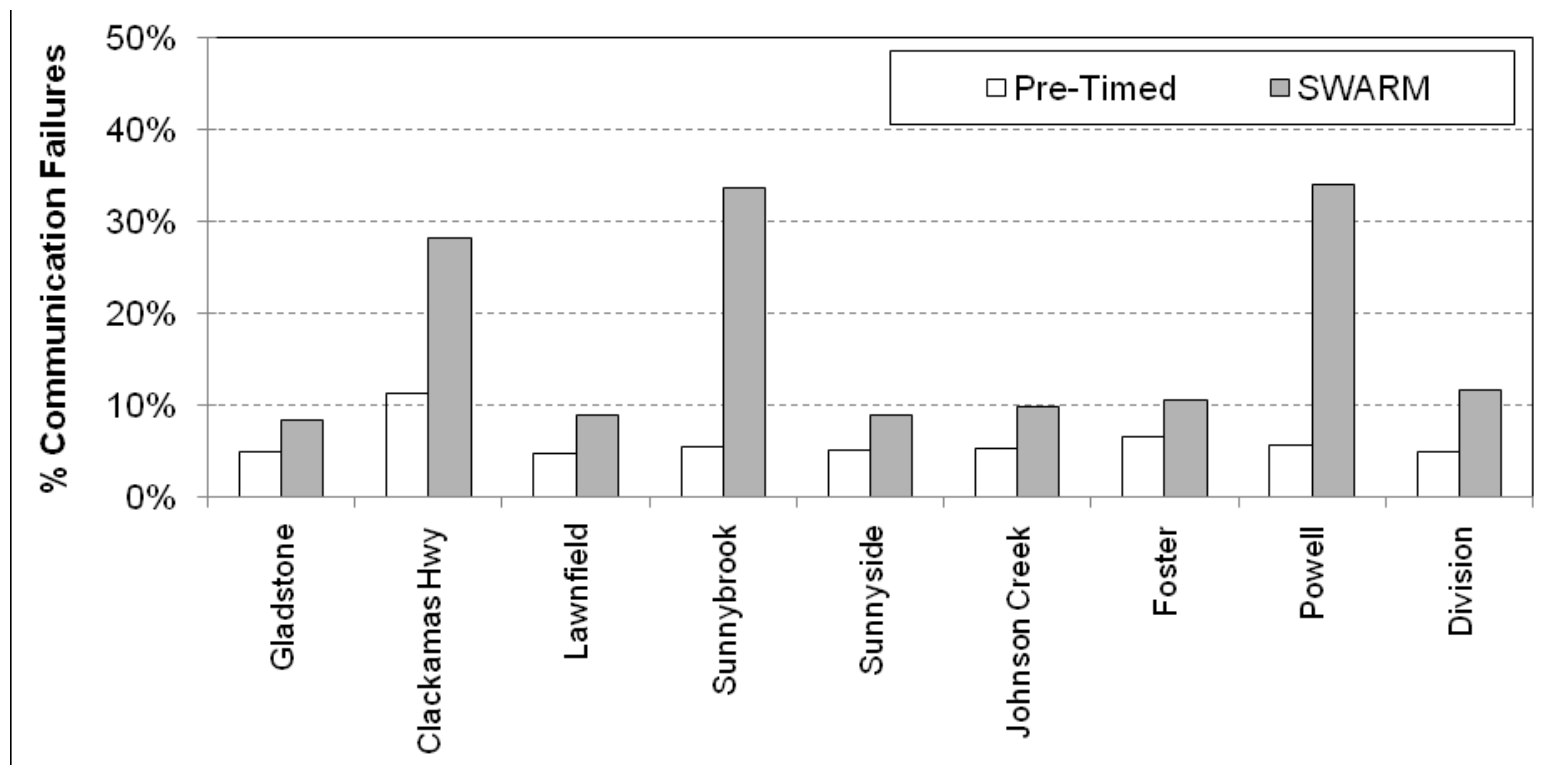

Figure 5.6: Percent communication failures under SWARM and pre-timed operation by station, I-205 NB, AM peak 


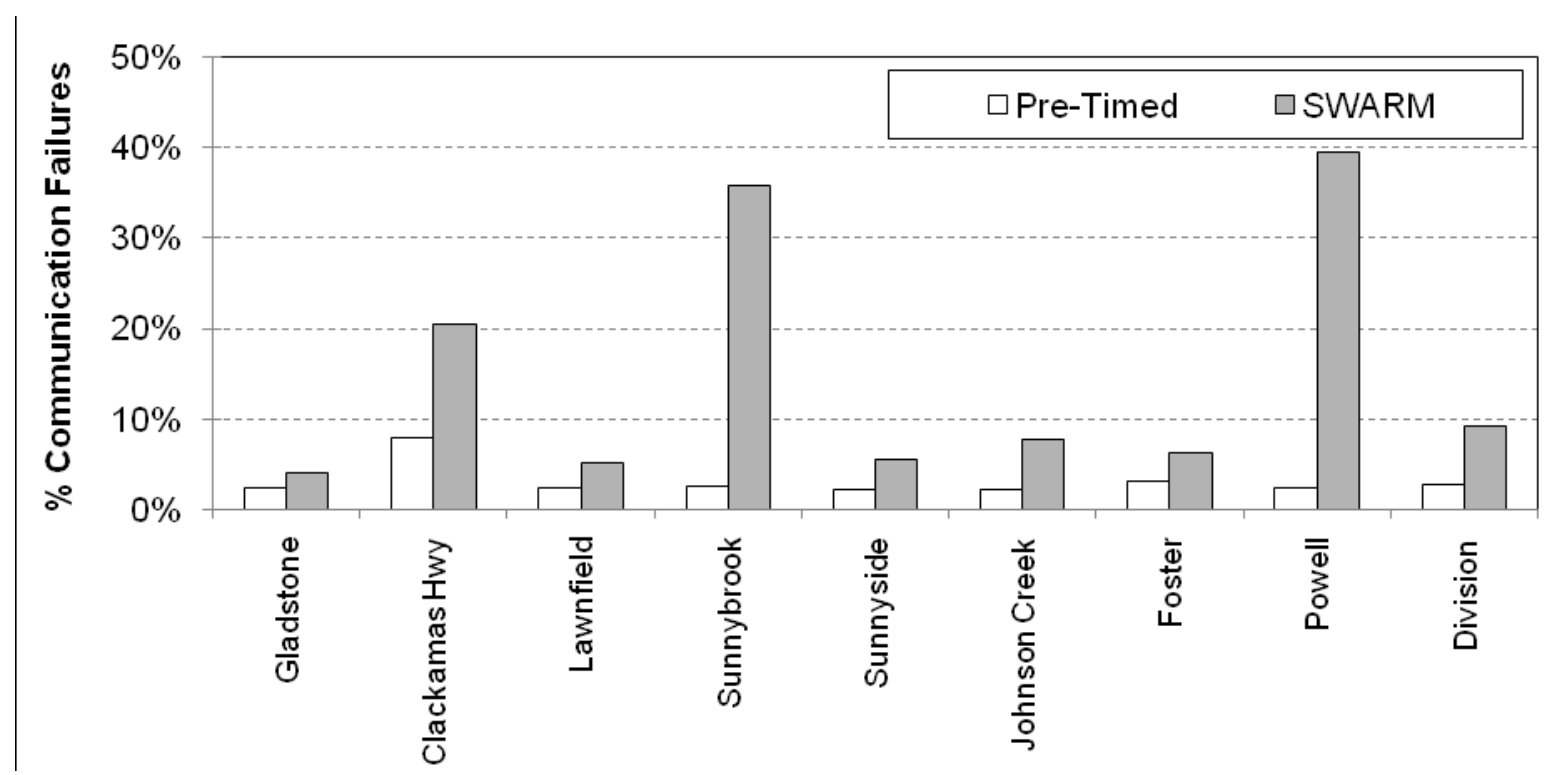

Figure 5.7: Percent communication failures under SWARM and pre-timed operation by station, I-205 NB, PM peak

Because these communication failures inhibited data analysis and are likely indicative of problems for the SWARM system in obtaining accurate data and communicating metering changes to each ramp controller, these error patterns were explored in more detail. The communication failures for each station and each day for the study duration are shown in shown in Table 5.3 for the AM period and Table 5.4 for the PM period. In general, these failures were either: 1) intermittent communication losses, such as one 20-second reading out of three being missing, or 2) failures that occurred on intermittent days but for longer periods of time. The first failure type is less problematic. For SWARM, the built-in data cleaning algorithm should be able to handle these outages and for the analysis it was possible to interpolate missing data. The second type of failure was more problematic for the study, since it was not possible to replace large data gaps. These days would have to be excluded from the study.

Inspection of the data in Table 5.3 and Table 5.4 reveals significant variation in the failure rate on different days in the study period. Analysis periods with more than $10 \%$ of the 20 second readings failing are italicized in the table (these were considered as potential data quality issues). In the pre-timed AM analysis period, only one day (9/27) had significant failures. In the SWARM AM, five days $(9 / 10,9 / 13,9 / 14,9 / 17,9 / 18)$ had significant failures. In the pre-timed PM period, two days had significant outages (9/26 and 10/3), while in the SWARM PM three days $(9 / 13,9 / 14$, and 9/18) had significant failures. All of these days were excluded from the evaluation because of large blocks of missing data. The level of communication failures for the remaining days was tolerable for the analysis.

In the SWARM operation, it is clear that communication failures were much more prevalent than for the pre-timed period. Table 5.3 highlights that the Sunnybrook and Powell stations generally performed adequately in the pre-timed period but had large $(>30 \%)$ failures for all days in the SWARM period. This is true for both the AM and PM periods. The high failure 
rates will probably be corrected if modifications are made to the communication infrastructure.

Table 5.3: Percent communication failures under pre-timed and SWARM by day and station, I-205 NB, 6-10 AM

\begin{tabular}{|c|c|c|c|c|c|c|c|c|c|c|c|}
\hline \multicolumn{12}{|l|}{ PRE-TIMED } \\
\hline STATION & MP & $9-24$ & $9-25$ & $9-26$ & $9-27$ & $9-28$ & $10-1$ & $10-2$ & 10-3 & $10-4$ & $10-5$ \\
\hline Gladstone & 11.05 & $1.7 \%$ & $1.5 \%$ & $2.6 \%$ & $34.7 \%$ & $2.1 \%$ & $1.2 \%$ & $1.7 \%$ & $0.8 \%$ & $1.5 \%$ & $0.7 \%$ \\
\hline Clackamas Hwy & 12.94 & $3.2 \%$ & $1.4 \%$ & $2.6 \%$ & $98.3 \%$ & $0.6 \%$ & $4.2 \%$ & $0.8 \%$ & $0.6 \%$ & $0.8 \%$ & $0.4 \%$ \\
\hline Lawnfield & 13.58 & $1.0 \%$ & $1.5 \%$ & $2.9 \%$ & $34.7 \%$ & $0.8 \%$ & $1.9 \%$ & $1.4 \%$ & $1.1 \%$ & $1.5 \%$ & $1.0 \%$ \\
\hline Sunnybrook & 14.32 & $0.7 \%$ & $2.2 \%$ & $7.9 \%$ & $34.1 \%$ & $0.8 \%$ & $1.4 \%$ & $1.7 \%$ & $2.2 \%$ & $2.6 \%$ & $1.7 \%$ \\
\hline Sunnyside & 14.7 & $1.1 \%$ & $2.1 \%$ & $3.9 \%$ & $34.4 \%$ & $1.0 \%$ & $1.0 \%$ & $1.2 \%$ & $1.5 \%$ & $2.9 \%$ & $2.4 \%$ \\
\hline Johnson Creek & 16.2 & $1.8 \%$ & $1.9 \%$ & $3.9 \%$ & $34.3 \%$ & $1.1 \%$ & $2.8 \%$ & $2.5 \%$ & $1.0 \%$ & $1.5 \%$ & $2.5 \%$ \\
\hline Foster & 18.1 & $13.6 \%$ & $3.1 \%$ & $3.2 \%$ & $34.5 \%$ & $1.4 \%$ & $2.2 \%$ & $1.5 \%$ & $1.8 \%$ & $2.5 \%$ & $1.2 \%$ \\
\hline Powell & 19.4 & $1.4 \%$ & $2.6 \%$ & $9.0 \%$ & $34.3 \%$ & $1.2 \%$ & $1.0 \%$ & $1.2 \%$ & $1.8 \%$ & $2.8 \%$ & $1.5 \%$ \\
\hline Division & 19.78 & $1.4 \%$ & $1.8 \%$ & $3.2 \%$ & $34.5 \%$ & $0.7 \%$ & $1.0 \%$ & $0.8 \%$ & $1.4 \%$ & $1.5 \%$ & $2.4 \%$ \\
\hline SWARM & MP & $9-10$ & $9-11$ & $9-12$ & $9-13$ & $9-14$ & 9-17 & 9-18 & 9-19 & $9-20$ & $9-21$ \\
\hline Gladstone & 11.05 & $31.5 \%$ & $7.8 \%$ & $4.0 \%$ & $4.2 \%$ & $12.3 \%$ & $4.0 \%$ & $6.5 \%$ & $2.4 \%$ & $3.9 \%$ & $6.5 \%$ \\
\hline Clackamas Hwy & 12.94 & $30.8 \%$ & $8.2 \%$ & $4.6 \%$ & $98.9 \%$ & $16.8 \%$ & $66.6 \%$ & $31.9 \%$ & $1.7 \%$ & $13.5 \%$ & $8.3 \%$ \\
\hline Lawnfield & 13.58 & $31.8 \%$ & $7.6 \%$ & $3.7 \%$ & $4.6 \%$ & $19.0 \%$ & $4.3 \%$ & $7.4 \%$ & $2.1 \%$ & $3.3 \%$ & $5.7 \%$ \\
\hline Sunnybrook & 14.32 & $50.3 \%$ & $32.0 \%$ & $27.6 \%$ & $31.6 \%$ & $45.1 \%$ & $31.1 \%$ & $28.7 \%$ & $30.5 \%$ & $29.0 \%$ & $30.5 \%$ \\
\hline Sunnyside & 14.7 & $31.3 \%$ & $10.3 \%$ & $4.6 \%$ & $5.0 \%$ & $18.7 \%$ & $4.6 \%$ & $5.0 \%$ & $1.8 \%$ & $2.9 \%$ & $4.9 \%$ \\
\hline Johnson Creek & 16.2 & $31.5 \%$ & $8.7 \%$ & $6.8 \%$ & $5.7 \%$ & $21.9 \%$ & $4.9 \%$ & $7.1 \%$ & $3.2 \%$ & $3.3 \%$ & $5.1 \%$ \\
\hline Foster & 18.1 & $31.8 \%$ & $11.2 \%$ & $7.4 \%$ & $6.4 \%$ & $14.4 \%$ & $8.0 \%$ & $10.7 \%$ & $4.7 \%$ & $4.4 \%$ & $6.2 \%$ \\
\hline Powell & 19.4 & $43.8 \%$ & $28.0 \%$ & $23.2 \%$ & $34.8 \%$ & $48.0 \%$ & $24.0 \%$ & $32.9 \%$ & $38.0 \%$ & $32.9 \%$ & $34.0 \%$ \\
\hline Division & 19.78 & $34.1 \%$ & $10.1 \%$ & $6.8 \%$ & $5.5 \%$ & $25.0 \%$ & $4.4 \%$ & $9.8 \%$ & $5.7 \%$ & $7.1 \%$ & $8.0 \%$ \\
\hline
\end{tabular}

Table 5.4: Percent communication failures under pre-timed and SWARM by day and station, I-205 NB, 1-7 PM

\begin{tabular}{|c|c|c|c|c|c|c|c|c|c|c|c|}
\hline \multicolumn{12}{|l|}{ PRE-TIMED } \\
\hline STATION & MP & $9-24$ & $9-25$ & $9-26$ & $9-27$ & $9-28$ & 10-1 & 10-2 & 10-3 & $10-4$ & $10-5$ \\
\hline Gladstone & 11.05 & $1.6 \%$ & $1.0 \%$ & $12.9 \%$ & $2.0 \%$ & $0.6 \%$ & $0.5 \%$ & $2.3 \%$ & $0.6 \%$ & $0.9 \%$ & $0.7 \%$ \\
\hline Clackamas Hwy & 12.94 & $2.4 \%$ & $2.7 \%$ & $12.8 \%$ & $4.3 \%$ & $7.3 \%$ & $0.9 \%$ & $2.1 \%$ & $44.9 \%$ & $0.6 \%$ & $0.7 \%$ \\
\hline Lawnfield & 13.58 & $1.2 \%$ & $0.7 \%$ & $13.4 \%$ & $2.0 \%$ & $0.8 \%$ & $0.6 \%$ & $2.5 \%$ & $1.1 \%$ & $1.2 \%$ & $0.6 \%$ \\
\hline Sunnybrook & 14.32 & $1.8 \%$ & $0.7 \%$ & $14.3 \%$ & $1.9 \%$ & $0.9 \%$ & $1.5 \%$ & $2.3 \%$ & $1.0 \%$ & $1.0 \%$ & $1.2 \%$ \\
\hline Sunnyside & 14.7 & $1.6 \%$ & $0.5 \%$ & $13.1 \%$ & $1.8 \%$ & $0.9 \%$ & $0.6 \%$ & $1.5 \%$ & $0.5 \%$ & $1.0 \%$ & $0.6 \%$ \\
\hline Johnson Creek & 16.2 & $1.5 \%$ & $0.9 \%$ & $13.0 \%$ & $1.6 \%$ & $0.9 \%$ & $0.7 \%$ & $1.7 \%$ & $0.8 \%$ & $0.6 \%$ & $0.6 \%$ \\
\hline Foster & 18.1 & $1.6 \%$ & $0.4 \%$ & $12.8 \%$ & $2.2 \%$ & $0.3 \%$ & $1.9 \%$ & $2.6 \%$ & $0.7 \%$ & $7.3 \%$ & $0.8 \%$ \\
\hline Powell & 19.4 & $1.3 \%$ & $0.7 \%$ & $13.1 \%$ & $2.0 \%$ & $1.8 \%$ & $0.9 \%$ & $2.0 \%$ & $0.8 \%$ & $0.6 \%$ & $0.7 \%$ \\
\hline Division & 19.78 & $3.3 \%$ & $0.7 \%$ & $13.1 \%$ & $3.1 \%$ & $1.2 \%$ & $0.7 \%$ & $1.8 \%$ & $1.2 \%$ & $1.9 \%$ & $0.5 \%$ \\
\hline SWARM & MP & $9-10$ & $9-11$ & $9-12$ & $9-13$ & $9-14$ & $9-17$ & $9-18$ & 9-19 & $9-20$ & $9-21$ \\
\hline Gladstone & 11.05 & $3.4 \%$ & $3.8 \%$ & $2.0 \%$ & $2.0 \%$ & $6.1 \%$ & $4.3 \%$ & $4.7 \%$ & $5.2 \%$ & $6.8 \%$ & $1.3 \%$ \\
\hline Clackamas Hwy & 12.94 & $2.6 \%$ & $4.4 \%$ & $1.1 \%$ & $71.5 \%$ & $7.5 \%$ & $2.8 \%$ & $68.9 \%$ & $5.5 \%$ & $38.9 \%$ & $1.7 \%$ \\
\hline Lawnfield & 13.58 & $3.6 \%$ & $6.8 \%$ & $2.7 \%$ & $2.1 \%$ & $8.8 \%$ & $3.3 \%$ & $6.7 \%$ & $5.9 \%$ & $9.4 \%$ & $1.8 \%$ \\
\hline Sunnybrook & 14.32 & $32.6 \%$ & $42.6 \%$ & $35.6 \%$ & $38.3 \%$ & $42.5 \%$ & $26.9 \%$ & $27.0 \%$ & $33.3 \%$ & $39.9 \%$ & $39.3 \%$ \\
\hline Sunnyside & 14.7 & $3.0 \%$ & $7.0 \%$ & $4.3 \%$ & $3.1 \%$ & $9.0 \%$ & $4.3 \%$ & $5.3 \%$ & $7.6 \%$ & $10.9 \%$ & $1.4 \%$ \\
\hline Johnson Creek & 16.2 & $4.5 \%$ & $10.1 \%$ & $2.5 \%$ & $3.0 \%$ & $11.8 \%$ & $8.5 \%$ & $9.9 \%$ & $10.0 \%$ & $14.7 \%$ & $3.0 \%$ \\
\hline Foster & 18.1 & $6.1 \%$ & $6.6 \%$ & $3.6 \%$ & $2.6 \%$ & $11.0 \%$ & $4.9 \%$ & $8.7 \%$ & $6.6 \%$ & $10.6 \%$ & $2.4 \%$ \\
\hline Powell & 19.4 & $37.9 \%$ & $43.4 \%$ & $44.6 \%$ & $43.3 \%$ & $38.8 \%$ & $38.6 \%$ & $41.8 \%$ & $36.7 \%$ & $34.1 \%$ & $35.6 \%$ \\
\hline Division & 19.78 & $10.4 \%$ & $9.7 \%$ & $2.5 \%$ & $4.7 \%$ & $13.0 \%$ & $9.4 \%$ & $11.6 \%$ & $8.0 \%$ & $17.6 \%$ & $4.9 \%$ \\
\hline
\end{tabular}




\subsubsection{Weather and Incidents}

Study days were also analyzed for significant weather and incident issues. These days, as well as days with significant data quality issues, were excluded from the study.

Weather information was taken from the PORTAL database that indicated that there was precipitation on several mornings and afternoons during the study periods (Table $5.5)$.

Table 5.5 Observed weather during study period for I-205 NB

\begin{tabular}{c|c|c|c}
\hline Peak & Date & Time & Precipitation (in) \\
\hline \multirow{3}{*}{ AM } & $10 / 3$ & $7: 00-9: 00 \mathrm{AM}$ & 0.04 \\
\cline { 2 - 4 } & $10 / 4$ & $6: 00-7: 00 \mathrm{AM}$ & 0.01 \\
\hline \multirow{3}{*}{ PM } & $10 / 1$ & $3: 00-4: 00 \mathrm{PM}$ & 0.06 \\
\cline { 2 - 4 } & $10 / 2$ & $4: 00-7: 00 \mathrm{PM}$ & 0.15 \\
\cline { 2 - 4 } & $10 / 3$ & $2: 00-7: 00 \mathrm{PM}$ & 0.03 \\
\cline { 2 - 4 } & $10 / 4$ & $1: 00-2: 00 \mathrm{PM}$ & 0.01 \\
\hline
\end{tabular}

Only the morning precipitation on 10/3 appeared to cause unusual traffic patterns. This day was excluded from the pre-timed period. While more precipitation was observed on $10 / 1$ and 10/2 afternoons than in other time periods, both of these days had relatively light traffic and the precipitation did not appear to significantly affect traffic patterns.

Logs from the ATMS were used to identify incidents that had a significant impact on freeway operations (Table 5.6).

Table 5.6 Inventory of potentially significant incidents occurring during study period for I-205 NB

\begin{tabular}{c|l|l|l|c}
\hline Peak & Date & \multicolumn{1}{|c|}{ Location } & Time & Lanes Effected \\
\hline \multirow{3}{*}{ AM } & $9 / 14$ & at Johnson Creek & $8: 35-9: 31$ AM & 0 \\
\cline { 2 - 5 } & $9 / 19$ & at Powell & $8: 33-9: 29$ AM & 0 \\
\hline \multirow{5}{*}{ PM } & $9 / 10$ & at Lawnfield & $1: 17-2: 12$ PM & 1 \\
\cline { 2 - 5 } & $9 / 12$ & at $92^{\text {nd }}$ & $2: 45-4: 33$ PM & 1 \\
\cline { 2 - 5 } & $9 / 13$ & south of Glisan & $2: 02-2: 57$ PM & 1 \\
\cline { 2 - 5 } & & at Foster & $2: 15-4: 18$ PM & 1 \\
\cline { 2 - 5 } & $9 / 18$ & on the ramp to I-84 & $3: 34-4: 45$ PM & 1 \\
\cline { 2 - 5 } & $9 / 21$ & north of Washington & $2: 33-3: 28$ PM & left lane \\
\cline { 2 - 5 } & $10 / 5$ & north of I-84 & $3: 33-4: 45$ PM & 1 \\
\hline
\end{tabular}

After inspection of the freeway performance, it was concluded that only the incidents on the afternoons of 9/12 and 9/13 in the SWARM period significantly impacted traffic. These afternoons were excluded from the analysis period. 


\subsubsection{Summary of Excluded Analysis Days}

As discussed above and shown in Table 5.7 below, six mornings and five afternoons were excluded from the study due to data quality; one morning was excluded for weather-related reasons, and two afternoons were excluded due to incidents.

Table 5.7: Summary of Excluded Analysis Days for I-205 NB

\begin{tabular}{l|l|l|l|l|l|l|l}
\hline \multicolumn{2}{l|}{ I-205 NB AM } & \multicolumn{2}{l}{ I-205 NB PM } \\
\hline \multicolumn{2}{l|}{ PRE-TIMED } & \multicolumn{2}{l}{ SWARM } & \multicolumn{2}{l}{ PRE-TIMED } & \multicolumn{2}{l}{ SWARM } \\
\hline $9 / 24$ & & $9 / 10$ & Data Quality & $9 / 24$ & & $9 / 10$ & \\
\hline $9 / 25$ & & $9 / 11$ & & $9 / 25$ & & $9 / 11$ & \\
\hline $9 / 26$ & & $9 / 12$ & & $9 / 26$ & Data Quality & $9 / 12$ & Incident \\
\hline $9 / 27$ & Data Quality & $9 / 13$ & Data Quality & $9 / 27$ & & $9 / 13$ & Incident / Data \\
\hline $9 / 28$ & & $9 / 14$ & Data Quality & $9 / 28$ & & $9 / 14$ & Data Quality \\
\hline $10 / 1$ & & $9 / 17$ & Data Quality & $10 / 1$ & & $9 / 17$ & \\
\hline $10 / 2$ & & $9 / 18$ & Data Quality & $10 / 2$ & & $9 / 18$ & Data Quality \\
\hline $10 / 3$ & Weather & $9 / 19$ & & $10 / 3$ & Data Quality & $9 / 19$ & \\
\hline $10 / 4$ & & $9 / 20$ & & $10 / 4$ & & $9 / 20$ & \\
\hline $10 / 5$ & & $9 / 21$ & & $10 / 5$ & & $9 / 21$ & \\
\hline
\end{tabular}

\subsubsection{Morning Peak}

\subsubsection{Mainline Performance}

As described in the Methodology chapter, three primary performance metrics were evaluated for the mainline freeway: Vehicle Miles Traveled (VMT), Vehicle Hours Traveled (VHT), and delay. All three of these metrics are reported as average values and are presented by corridor congestion level, as well as for the total evaluation period. Table 5.8 summarizes the results of the analysis. A total of eight pre-timed days were compared to the five SWARM days. 
Table 5.8: Performance measures overall and by level of congestion, I-205 NB, 6:00-10:00 AM

\begin{tabular}{c|c|c|c|c|c|c}
\hline $\begin{array}{c}\text { AM } \\
\text { PERIOD }\end{array}$ & & $\begin{array}{c}\text { NUMBER } \\
\text { OF } \\
\text { DAYS }\end{array}$ & $\begin{array}{c}\text { VMT } \\
\text { (AVG } \\
\text { DAILY) }\end{array}$ & $\begin{array}{c}\text { VHT } \\
\text { (AVG } \\
\text { DAILY) }\end{array}$ & $\begin{array}{c}\text { AVG } \\
\text { DELAY } \\
\text { (VEH- } \\
\text { HOURS) }\end{array}$ & $\begin{array}{c}\text { DELAY } \\
\text { STANDARD } \\
\text { DEVIATION }\end{array}$ \\
\hline Least & Pre-Timed & 1 & 169,365 & 3,109 & 185 & - \\
Congested & SWARM & 1 & 167,610 & 3,049 & 176 & - \\
& $\%$ Change & - & $-1.04 \%$ & $-1.90 \%$ & $-5.12 \%$ & - \\
\hline Moderately & Pre-Timed & 6 & 168,560 & 3,400 & 470 & 134 \\
Congested & SWARM & 4 & 170,904 & 3,397 & 444 & 115 \\
& $\%$ Change & - & $1.39 \%$ & $-0.09 \%$ & $-5.41 \%$ & $-13.88 \%$ \\
\hline Highly & Pre-Timed & 1 & 169,464 & 3,786 & 814 & - \\
Congested & SWARM & 0 & - & - & - & - \\
& $\%$ Change & - & - & - & - & - \\
\hline \multirow{2}{*}{ Overall } & Pre-Timed & 8 & 168,783 & 3,454 & 477 & 203 \\
AM Period & SWARM & 5 & 170,245 & 3,328 & 391 & 156 \\
& $\%$ Change & - & $0.87 \%$ & $-3.66 \%$ & $-18.14 \%$ & $-23.11 \%$ \\
\hline
\end{tabular}

Overall, the average VMT increased by $0.87 \%$, indicating that the amount of travel remained fairly constant between the SWARM and pre-timed periods. At the same time, mainline VHT decreased by $3.66 \%$ between the two periods. This decrease corresponded with an $18.14 \%$ decrease in mainline delay under SWARM. This decrease, however, was not statistically significant $(p=0.435)$. The standard deviation of the average delay was less under the SWARM operation (overall and for all congestion categories). This indicates that the delay under SWARM was less variable and overall freeway performance was more reliable — a valuable benefit of the SWARM system.

To provide additional insight into the performance measures, study days were classified according to congestion level and compared. This analysis supports, but tempers, the result that SWARM performed better than the pre-timed strategy in the morning peak on I-205 NB: mainline delay averaged about five percent lower excluding a single highly congested day under the pre-timed period.

Least congested - There were one day each in the pre-timed and SWARM periods, and delay was about five percent lower on the SWARM day. In this category, VMT decreased $1.04 \%$, VHT decreased $1.90 \%$ and the average delay decreased $5.12 \%$ under SWARM operations. This difference could not be tested for significance (there is only one day to compare in each category).

Moderately congested - There were six pre-timed days and four SWARM days classified as moderately congested. In this category, VMT increased $1.39 \%$, VHT decreased $0.09 \%$ and the average delay decreased $5.41 \%$ from 470 vehicle-hours to 444 vehicle-hours under SWARM operations. This change was not statistically significant $(p=0.765)$. The standard deviation of the average delay was lower under SWARM. 
Highly congested - Only one pre-timed day was classified as highly congested, with 814 vehicle-hours of delay. This day had significantly more delay than any other day in the study period and heavily influenced the overall evaluation of SWARM performance. Excluding this day from the overall corridor results, there was an improvement of about $5 \%$ under SWARM (rather than the $18 \%$ including this day). While a trace amount of rainfall was recorded early in the morning commute on this day, there did not appear to be a correlation between the time of the rainfall and the onset of congested speeds later in the commute, nor were there other explanatory factors (such as data quality or an incident) to warrant excluding the day from the study.

The same information presented above is shown graphically in Figure 5.8 on the following page, but broken down by station. The clustered bar plots show the difference between mainline delay under the pre-timed strategy (left) and SWARM in the morning peak (right). Stations are listed in the direction of travel, from south, at the bottom of the figure, to north, at the top. The clustered bars represent average delay for each level of congestion, with the number of days in each sample shown in the legend. It is clear from the plots that the majority of delay (and thus improvements from SWARM) are at the Johnson Creek and Foster stations. The figure also clearly highlights the influence of the one highly congested day on the overall corridor results. 

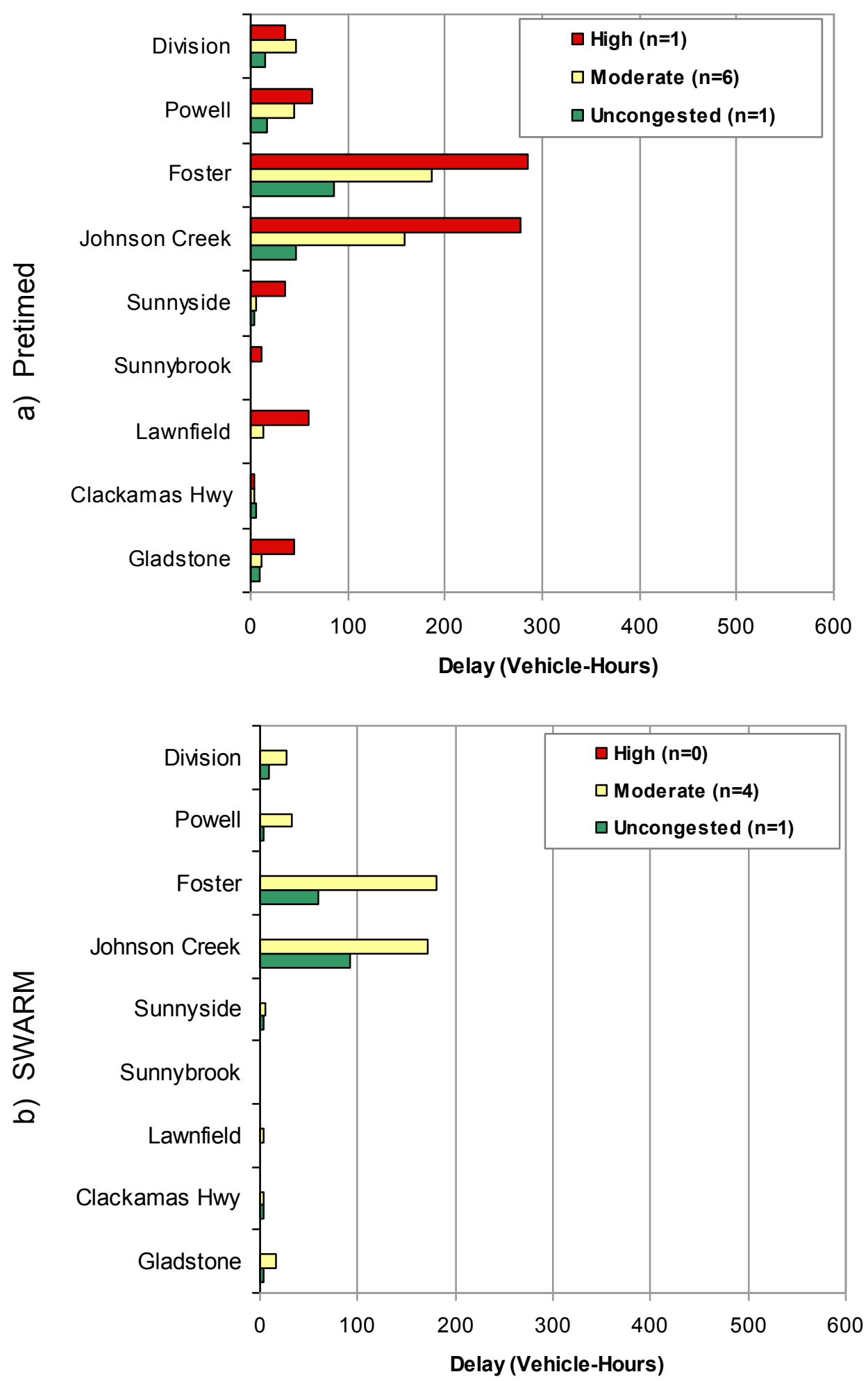

Figure 5.8: Mainline Delay, overall average and average by level of congestion for I-205 NB, Morning Peak, (a) pre-timed (top) and (b) SWARM (bottom). 


\subsubsection{Ramp Performance}

Data on ramp queues and delays at three ramps (Sunnyside, Johnson Creek, and Powell) were to be collected by the Programmable Logic Controllers (PLCs). Unfortunately, a data collection error was not discovered until post-processing of the data began. It is, however, possible to make general inferences on the ramp performance based on ramp (outflow) volume data from the PORTAL system.

Focusing on the time period when metering was active, cumulative vehicle counts at all on-ramps, $N$, were plotted for the morning peak on an oblique time axis in Figure 5.9. In other words, the curves shown in the figure correspond to the quantities, $N-q_{0} *\left(t-t_{0}\right)$, where $q_{0}$ is a background flow (3,600 vph in this case), $t$ is time, and $t_{0}$ is the start time (6:30, in this case). The figure clearly shows that the cumulative curve for SWARM lies above the curve for the pre-timed strategy, and the vertical separation between the two curves increases over time. As in the pilot study, the SWARM strategy consistently admitted higher ramp flows to the freeway. When metering was active, actual ramp demand was not known (meaning vehicles entering the ramp) because of the PLC data collection failure. However, overall mainline demand changed little ( $0.87 \%$ increase). If an assumption is made that ramp demand also changed little, it is likely that ramp delay decreased under SWARM operation (i.e. more vehicles were allowed on the freeway which would equate to less delay for vehicles on the ramps). Decreasing of ramp delay under SWARM is consistent with the findings in the pilot study using the video-based analysis of travel times.

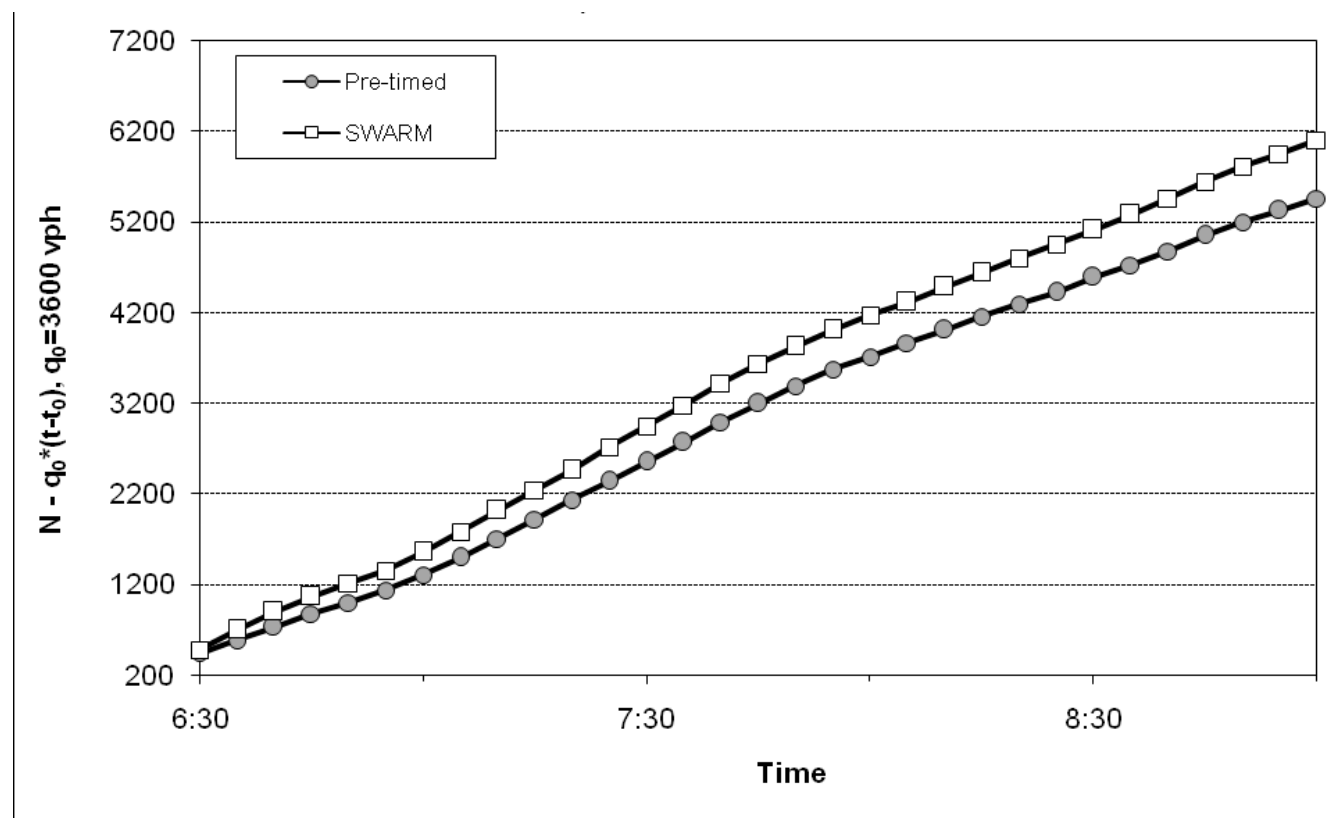

Figure 5.9: Cumulative on-ramp vehicle counts, I-205 NB, 6:30-9:00 AM 
Figure 5.10 shows the average ramp flow in vehicles per hour over the course of the morning peak. With the exception of Powell the flows were higher during SWARM operation.

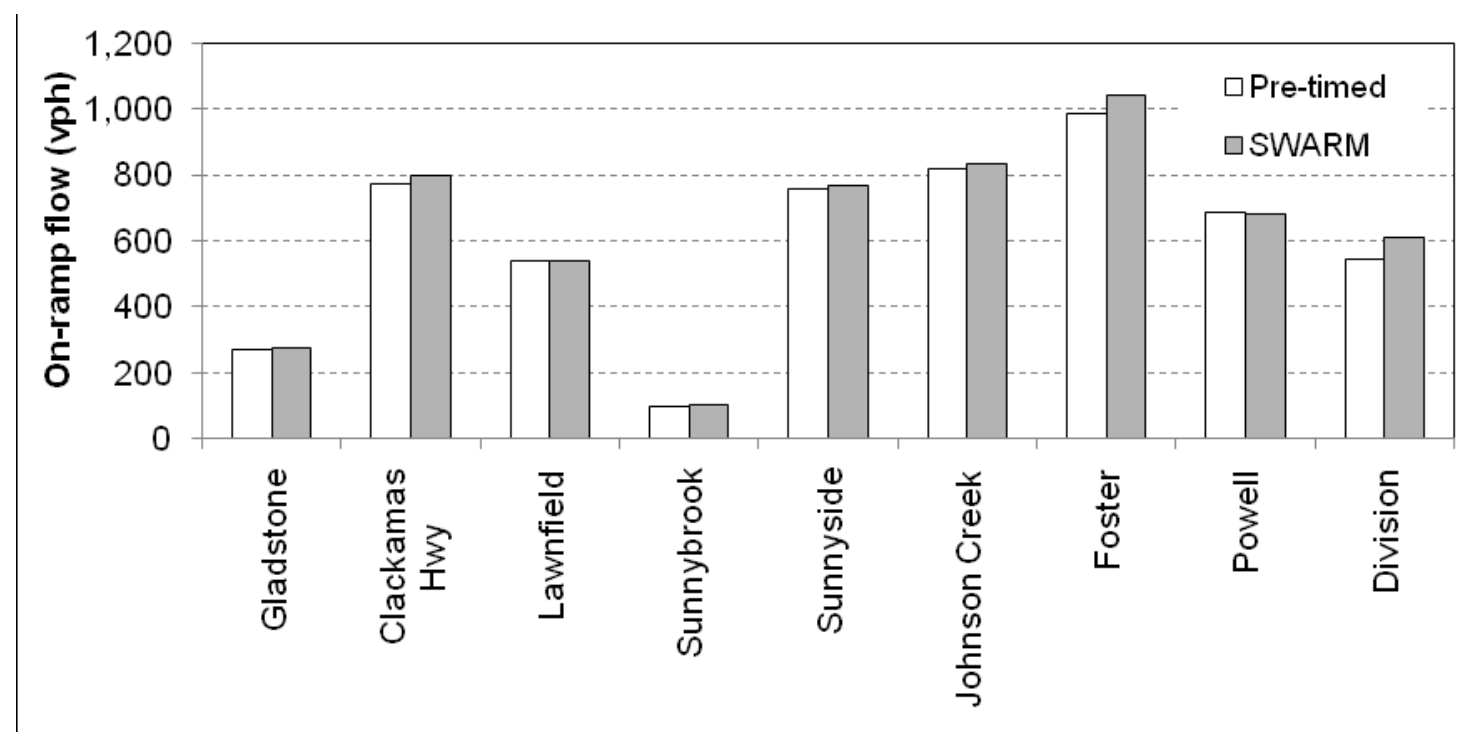

Figure 5.10: Average hourly on-ramp flow, I-205 NB, morning peak, 6:00-10:00 AM

\subsubsection{Afternoon Peak}

\subsubsection{Mainline Performance}

Table 5.9 below lists basic performance measures for the afternoon peak, with overall results in the bottom row of the table. For the entire corridor VMT increased by about $1.63 \%$ while mainline VHT remained nearly unchanged between the SWARM and pretimed periods. Overall, average mainline delay under SWARM decreased by $7.87 \%$. This decrease was not statistically significant $(p=0.896)$. 
Table 5.9: Performance measures overall and by level of congestion, I-205 NB, 1-7 PM.

\begin{tabular}{|c|c|c|c|c|c|c|}
\hline PM PERIOD & & $\begin{array}{c}\text { NUMBER } \\
\text { OF } \\
\text { DAYS }\end{array}$ & $\begin{array}{c}\text { VMT } \\
\text { (AVG } \\
\text { DAILY) }\end{array}$ & $\begin{array}{c}\text { VHT } \\
\text { (AVG } \\
\text { DAILY) }\end{array}$ & $\begin{array}{c}\text { AVG DELAY } \\
\text { (VEH- } \\
\text { HOURS) }\end{array}$ & $\begin{array}{c}\text { DELAY } \\
\text { STANDARD } \\
\text { DEVIATION }\end{array}$ \\
\hline Least Congested & $\begin{array}{r}\text { Pre-Timed } \\
\text { SWARM } \\
\% \text { Change }\end{array}$ & $\begin{array}{l}1 \\
0 \\
-\end{array}$ & $\begin{array}{c}247,775 \\
- \\
-\end{array}$ & $\begin{array}{c}4,409 \\
- \\
-\end{array}$ & $\begin{array}{c}156 \\
- \\
-\end{array}$ & $\begin{array}{l}- \\
- \\
-\end{array}$ \\
\hline $\begin{array}{l}\text { Moderately } \\
\text { Congested }\end{array}$ & $\begin{array}{r}\text { Pre-Timed } \\
\text { SWARM } \\
\% \text { Change }\end{array}$ & $\begin{array}{l}4 \\
4 \\
-\end{array}$ & $\begin{array}{c}254,952 \\
260,524 \\
2.19 \%\end{array}$ & $\begin{array}{l}4,759 \\
4,984 \\
4.71 \%\end{array}$ & $\begin{array}{c}367 \\
476 \\
29.73 \% \\
\end{array}$ & $\begin{array}{c}159 \\
76 \\
-52.54 \%\end{array}$ \\
\hline $\begin{array}{c}\text { Highly } \\
\text { Congested }\end{array}$ & $\begin{array}{r}\text { Pre-Timed } \\
\text { SWARM } \\
\% \text { Change }\end{array}$ & $\begin{array}{l}2 \\
1 \\
-\end{array}$ & $\begin{array}{c}264,642 \\
250,177 \\
-5.47 \%\end{array}$ & $\begin{array}{c}5,736 \\
5,356 \\
-6.64 \%\end{array}$ & $\begin{array}{c}1,111 \\
1,002 \\
-9.76 \%\end{array}$ & $\begin{array}{c}21 \\
- \\
-\end{array}$ \\
\hline $\begin{array}{l}\text { Very Highly } \\
\text { Congested }\end{array}$ & $\begin{array}{r}\text { Pre-Timed } \\
\text { SWARM } \\
\% \text { Change }\end{array}$ & $\begin{array}{l}1 \\
1 \\
-\end{array}$ & $\begin{array}{c}249,704 \\
267,714 \\
7.21 \%\end{array}$ & $\begin{array}{c}8,235 \\
7,087 \\
-13.95 \%\end{array}$ & $\begin{array}{c}3,775 \\
2,358 \\
-37.52 \%\end{array}$ & $\begin{array}{l}- \\
- \\
-\end{array}$ \\
\hline $\begin{array}{c}\text { Overall } \\
\text { PM Period }\end{array}$ & $\begin{array}{r}\text { Pre-Timed } \\
\text { SWARM } \\
\% \text { Change }\end{array}$ & $\begin{array}{l}8 \\
6 \\
-\end{array}$ & $\begin{array}{c}255,821 \\
259,998 \\
1.63 \%\end{array}$ & $\begin{array}{c}5,394 \\
5,396 \\
0.03 \%\end{array}$ & $\begin{array}{c}953 \\
878 \\
-7.87 \%\end{array}$ & $\begin{array}{c}1,201 \\
757 \\
-36.92 \%\end{array}$ \\
\hline
\end{tabular}

Classifying the study days according to the level of congestion revealed a mixed picture of SWARM's performance:

- Least congested - One pre-timed day was classified as least congested but there were no comparable days for comparison under the SWARM system. However, the inclusion of this day in the "moderately congested" category would only have increased the disparity in mainline delay between the SWARM and pretimed strategies.

- Moderately congested - Four days each under SWARM operation and the pretimed strategy were classified as moderately congested. For these days, average VMT increased $2.19 \%$, VHT increased $4.71 \%$ and the average delay increased $29.73 \%$ from 367 vehicle-hours to 476 vehicle-hours under SWARM operation. This change was not statistically significant $(p=0.262)$. Two such days are compared in more detail in the discussion section below. Note however, that the standard deviation of the delay is significantly less under SWARM.

- Highly congested - There were two highly congested days in the pre-timed period versus one day in the SWARM period. On these days, mainline delay decreased $9.76 \%$ percent under SWARM, compared to the pre-timed strategy. This difference could not be tested for significance.

- Very highly congested - There was one very highly congested day under the pretimed strategy and one under SWARM. Comparing these days, SWARM operation resulted in $37.52 \%$ lower average delay than the pre-timed strategy. There was a $7.21 \%$ increase in VMT and a $13.95 \%$ decrease in VHT. This difference could not be tested for significance. 
The same information is presented graphically in Figure 5.11 by station. The clustered bar plots show the difference between mainline delay under the pre-timed strategy (left) and SWARM (right). Stations are listed in the direction of travel, from south, at the bottom of the figure, to north, at the top. The clustered bars represent average delay for each level of congestion, with the number of days in each sample shown in the legend. It is clear from the plots that the majority of delay (and thus improvements from SWARM) are at the Sunnyside, Johnson Creek, and Foster stations.
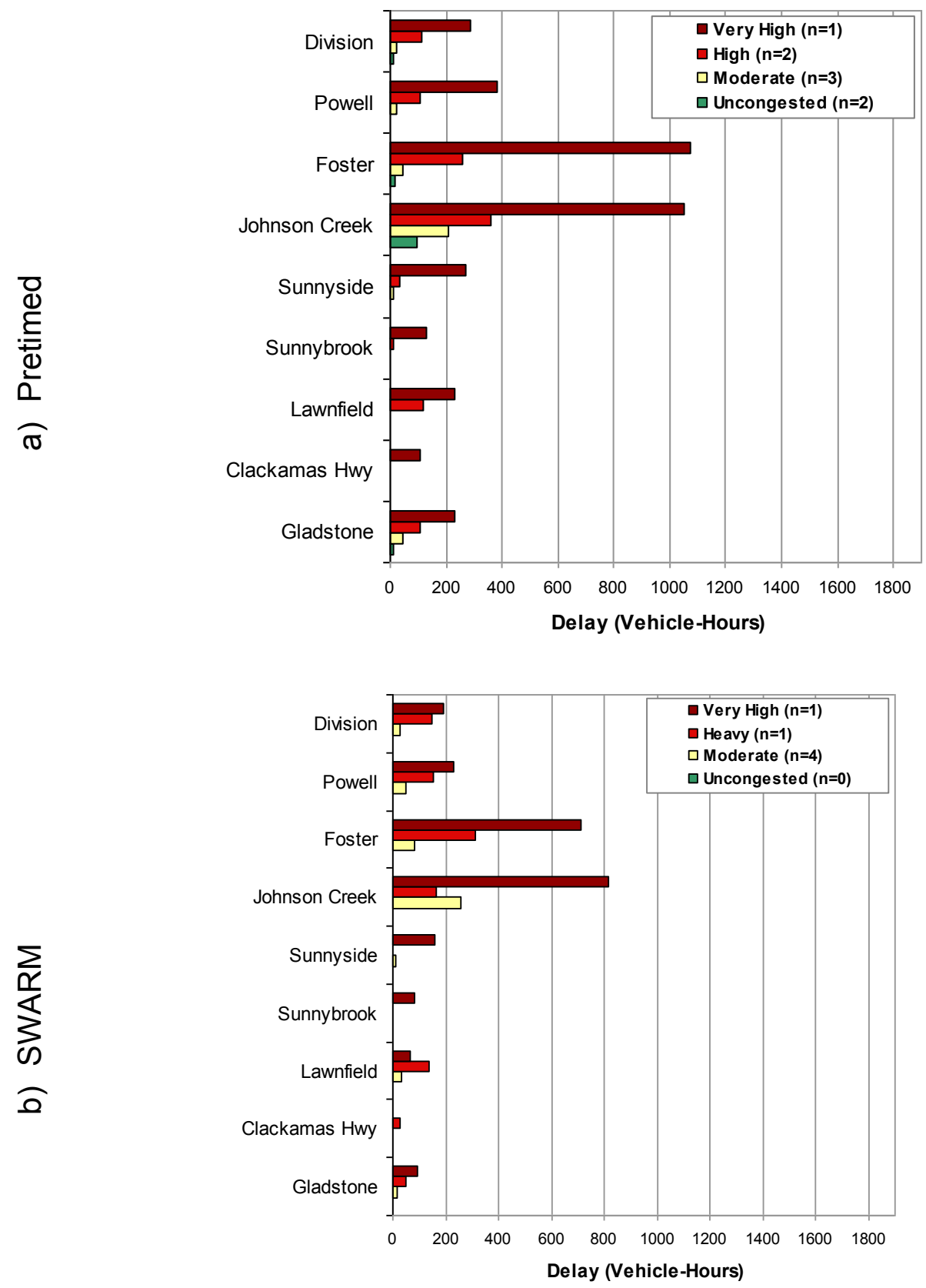

Figure 5.11: Mainline delay showing overall average and averages by level of congestion for I-205 NB during the afternoon peak for (a) pre-timed (top) and (b) SWARM (bottom). 


\subsubsection{Ramp Performance}

Data on ramp queues and delays at three ramps (Sunnyside, Johnson Creek, and Powell) was to be collected by the Programmable Logic Controllers (PLCs). Unfortunately, a data collection error was not discovered until post-processing of the data began. It is, however, possible to make general inferences on the ramp performance based on ramp (outflow) volume data from the PORTAL system. Focusing on the time period when metering was active, cumulative vehicle counts at all on-ramps, $N$, were plotted on an oblique time axis in Figure 5.12. In other words, the curves shown in the figure correspond to the quantities, $N-q_{0} *\left(t-t_{0}\right)$, where $q_{0}$ is a background flow $(3,600 \mathrm{vph}$ in this case), $t$ is time, and $t_{0}$ is the start time (6:30 AM and 14:30/2:30 PM, respectively, in this case). As in the morning, the cumulative curve for SWARM lies above the curve for the pre-timed strategy, and the vertical separation between the two curves increases over time. As in the pilot study, the SWARM strategy consistently admitted higher ramp flows to the freeway. When metering was active, actual ramp demand was not known because of the PLC data collection failure. As in the morning, overall mainline demand changed little in the afternoon ( $1.63 \%$ increase). If an assumption is made that ramp demand also changed little, it is likely that ramp delay decreased under SWARM operation (i.e. more vehicles were allowed on the freeway which would equate to less delay for vehicles on the ramps). Decreased ramp delay under SWARM is consistent with the findings in the pilot study using the video-based analysis of travel times.

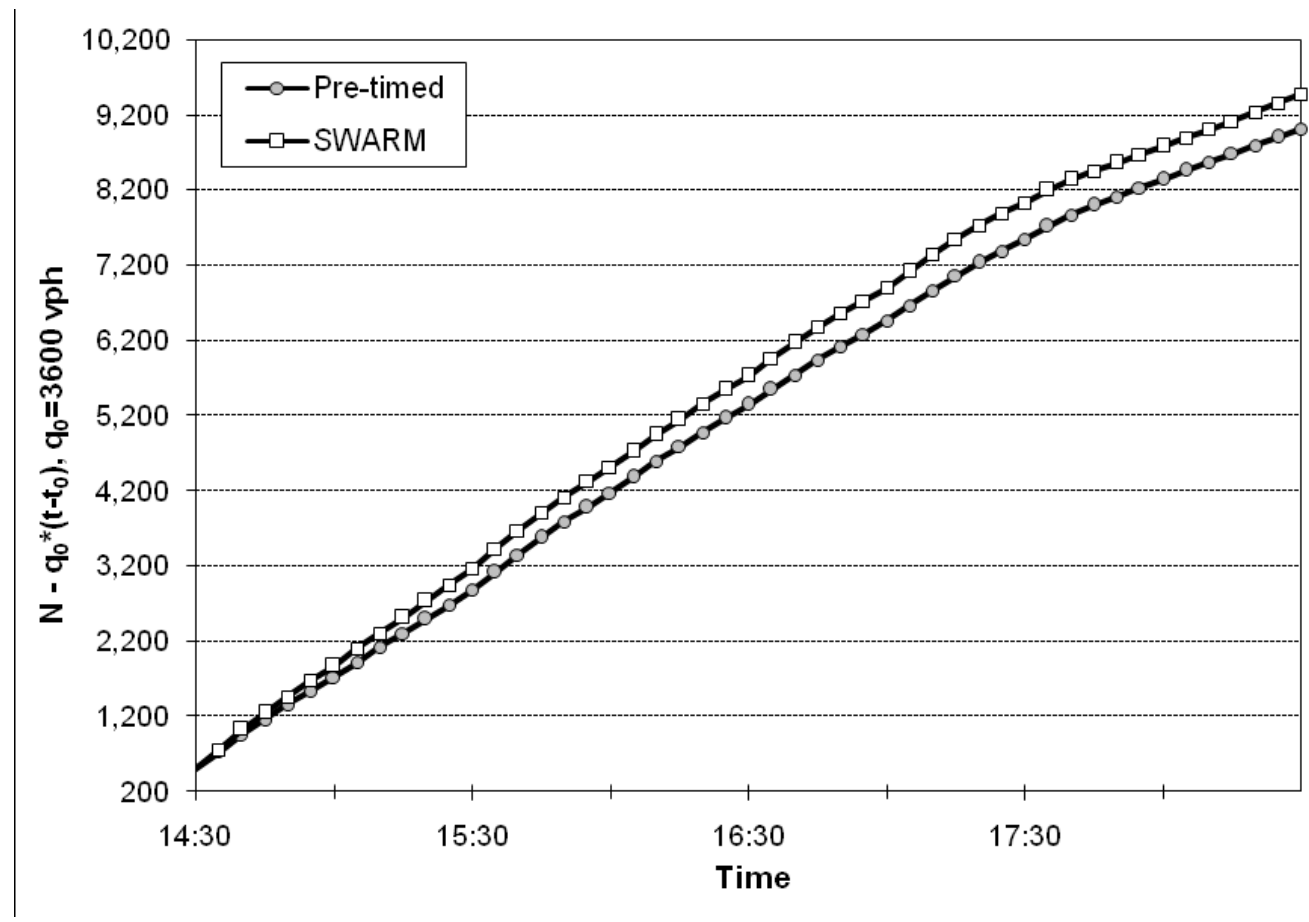

Figure 5.12: Cumulative on-ramp vehicle counts, I-205 NB, 14:30/2:30-18:30/6:30 PM 
Figure 5.13 shows the average ramp flow in vehicles per hour over the course of the afternoon peak. With the exception of Lawnfield, Sunnyside, and Powell, the flows are higher during SWARM operation.

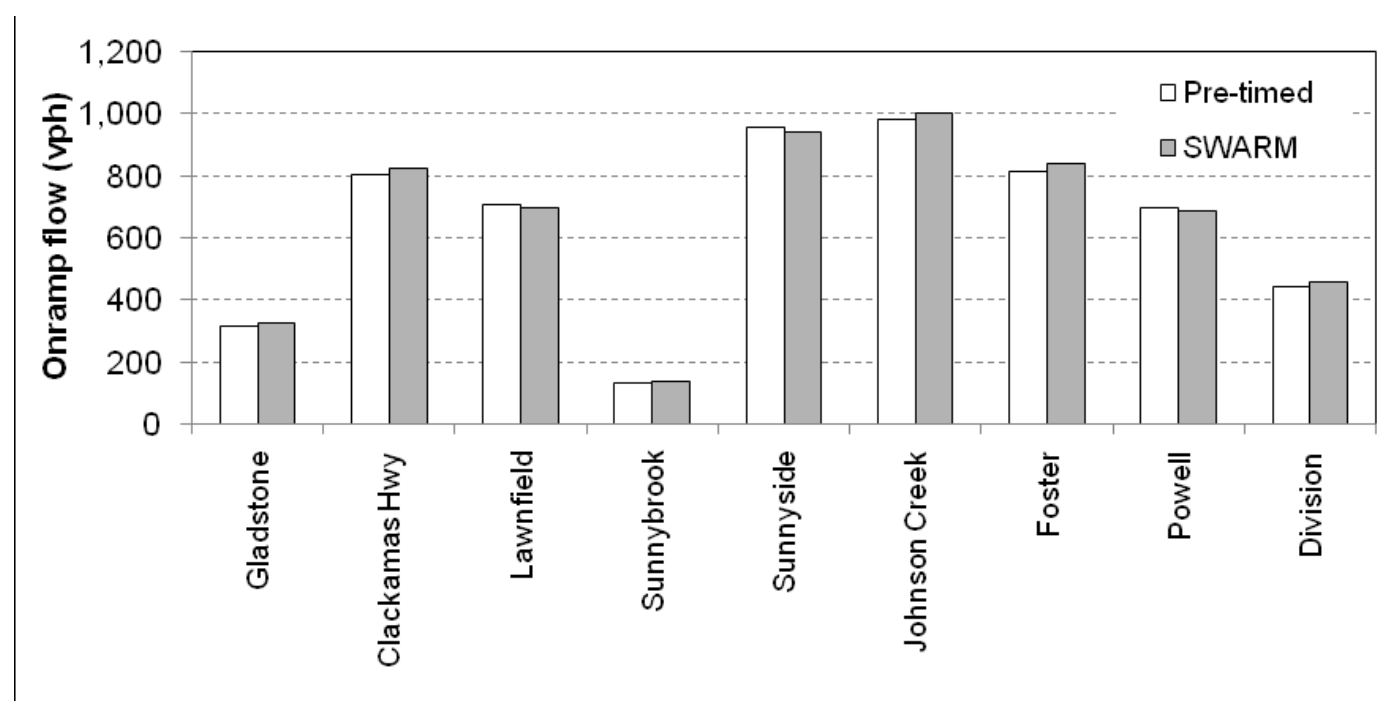

Figure 5.13: Average hourly on-ramp flow, I-205 NB, afternoon peak, 1:00-7:00 PM

\subsubsection{Discussion}

To investigate the results discussed in the previous sections, a number of additional plots were generated. In general, it appears that SWARM operation resulted in lower mainline delay for the morning peak. Figure 5.14 shows the changes in average delay in the time-space plane. In the plots, green colors indicate better SWARM performance while red colors reveal locations where pre-timed metering performed better. The color-key legend corresponds to the difference in average delay between SWARM and pre-timed. The figure illustrates that there were major improvements for SWARM operation at the Johnson Creek, Foster, and Powell stations between 8:00 $\mathrm{AM}$ and 9:00 $\mathrm{AM}$, centered at approximately 8:45 $\mathrm{AM}$ (noted by the brightest green color). The largest improvement was associated with the Foster station. 


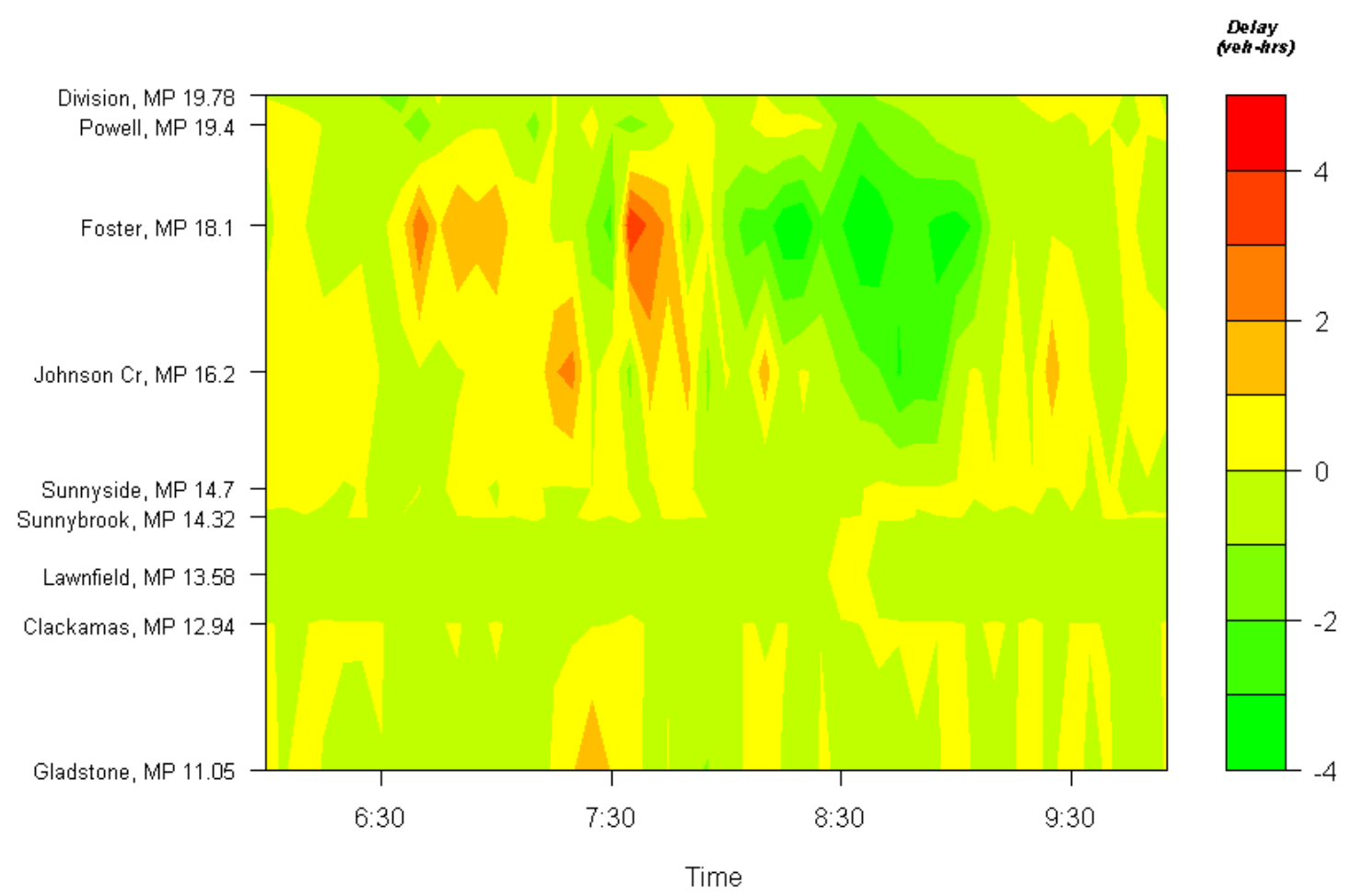

Figure 5.14: Changes in delay under SWARM in time-space plane, I-205 NB, AM peak

Performance by severity of congestion is discussed in the following subsections.

\subsubsection{SWARM Performance on Moderately Congested Days}

Figure 5.15 contains two plots for both pre-timed and SWARM operation of similar moderately congested days at the Foster Road station showing (in order from the top of the plot) the mainline speed (mph) (plotted on the secondary $y$-axis), the mainline flow (vph), and the ramp inflow (vph) from 6:00-10:00 AM. In color, these lines are orange (speed), blue (mainline flow) and red (ramp inflow). 

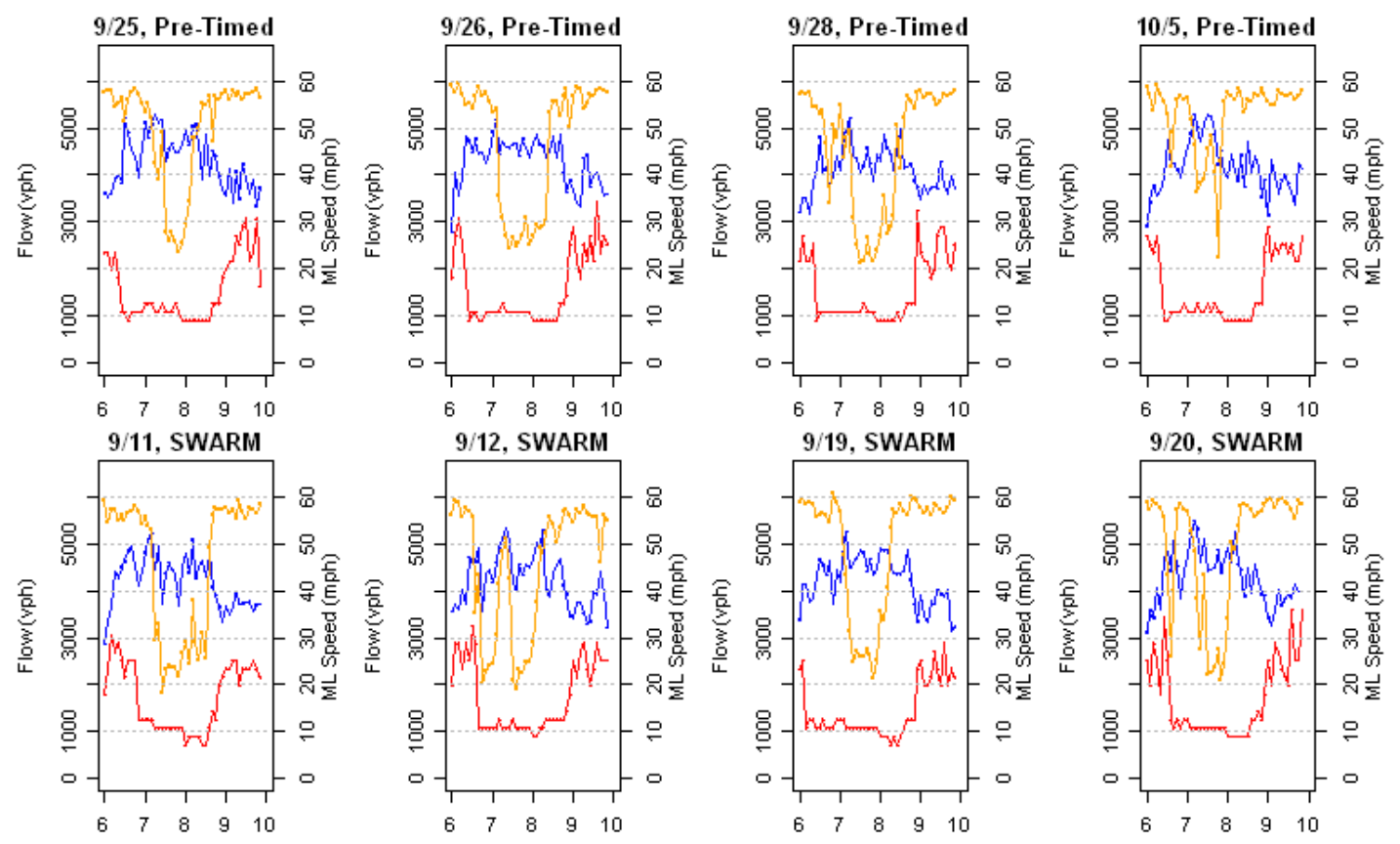

Figure 5.15: Plots for Foster Road showing mainline flow (vph), ramp flow (vph) and mainline speed (mph) over time with meter activations

Inspection of the ramp inflow line (bottom, red) reveals that on the pre-timed day (10/3) there was a significant surge in ramp flow after the meters were turned off at 9:00 AM (the pre-timed metering rate changes from 1,200 to 1,440 vph at 8:45 AM). While neither the SWARM metering rate nor the activation times are known for the Foster station, it appears that the SWARM does not allow the ramp flows to surge (or rise as sharply). Though not shown here, these patterns are consistent for all moderately congested days at the Foster station (similar plots for all stations and all days are included in the Appendix Online-1).

It appears that SWARM's ability to respond to conditions and keep metering active resulted in improved mainline performance. Interestingly, the same area had worse performance in the SWARM period from approximately 7:30 AM to 7:45 AM. As will be highlighted in the next section, this is most likely associated with the higher metering rates under the SWARM operation during most meter-eligible times.

SWARM performance under moderately congested conditions in the afternoon peak was less conclusive. Overall, average corridor delay decreased but moderately congested days saw a significant increase $(29.73 \%)$ in mainline delay under SWARM. This is of key interest since ramp metering can provide the most benefit prior to complete breakdown of the corridor and moderately congested days are the most common (four out of eight days pre-timed and four out of six days in the AM and PM periods). Figure 5.16 shows the changes in corridor average delay for the moderately 
congested days (four in pre-timed, four in SWARM) in the time-space plane for the afternoon peak. The increase in delay was concentrated in two areas: Johnson Creek to Powell between 3:45 PM and 4:30 PM and Clackamas to Lawnfield before 3:30 PM and after 5:30 PM. It is interesting to note that while the entire time period (1:00-7:00 PM) experienced an increase in delay under SWARM, this increase was neither systematic nor corridor-wide - there were many time-space periods that benefited from SWARM operation. In any event, the two areas that contributed to the delay are explored in more detail in the following subsections.

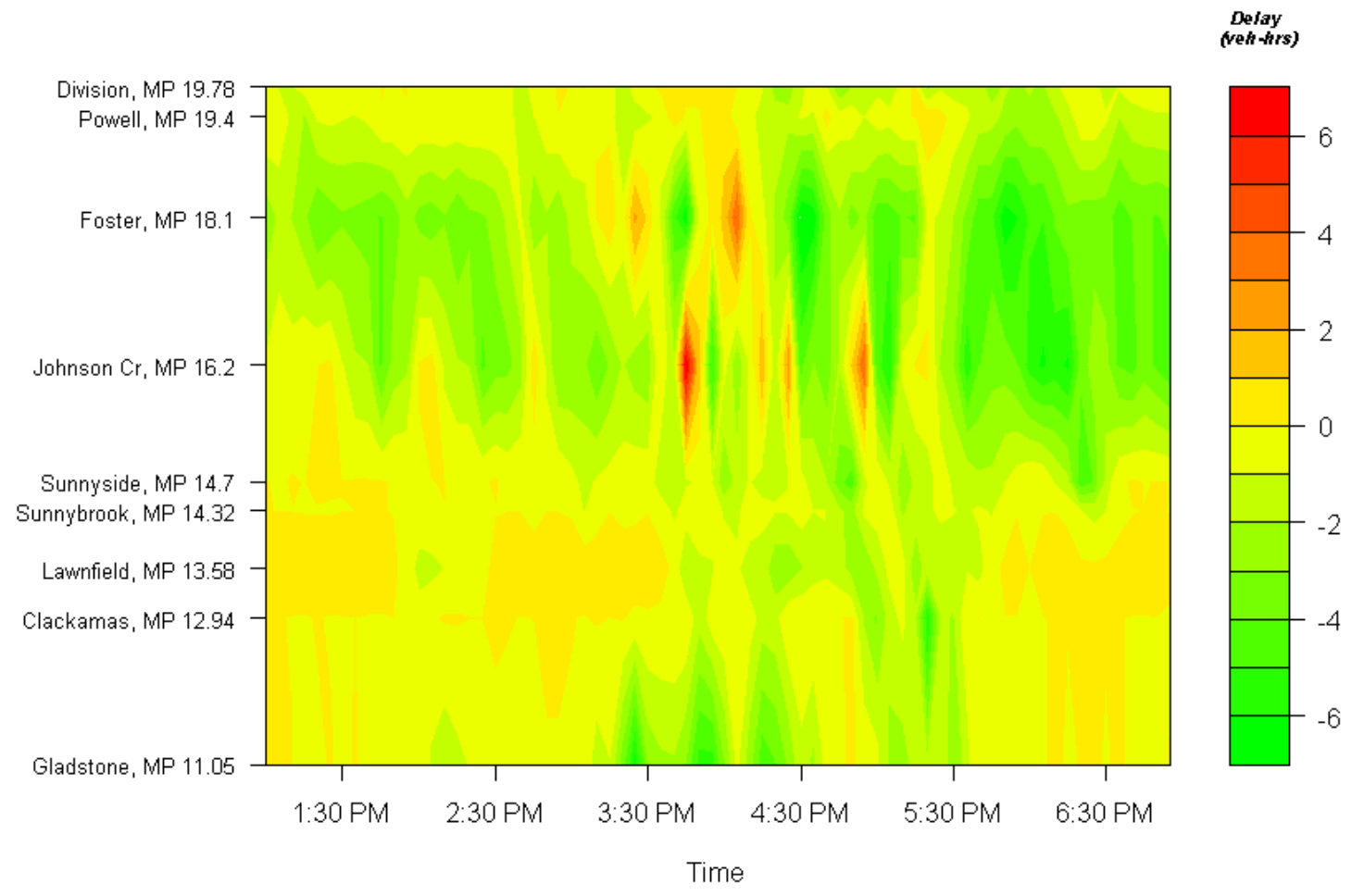

Figure 5.16: Changes in moderately congested delay under SWARM in time-space plane, I-205NB, 1:00-7:00 PM

\subsection{Johnson Creek to Powell}

Figure 5.17 represents mainline flow (vph), ramp flow (vph) and mainline speed (mph) over a period of two days (9/17/2007 and 10/1/2007) for comparison, with meter activations at Sunnyside, Johnson Creek, and Foster. Pre-timed operation is shown on the top; SWARM operation, on the bottom row. Vertical dashed lines in the figure indicate the meter on and off times as recorded by the PLCs or the pretimed ramp meter times (note that SWARM on-off times are not available at Foster). 


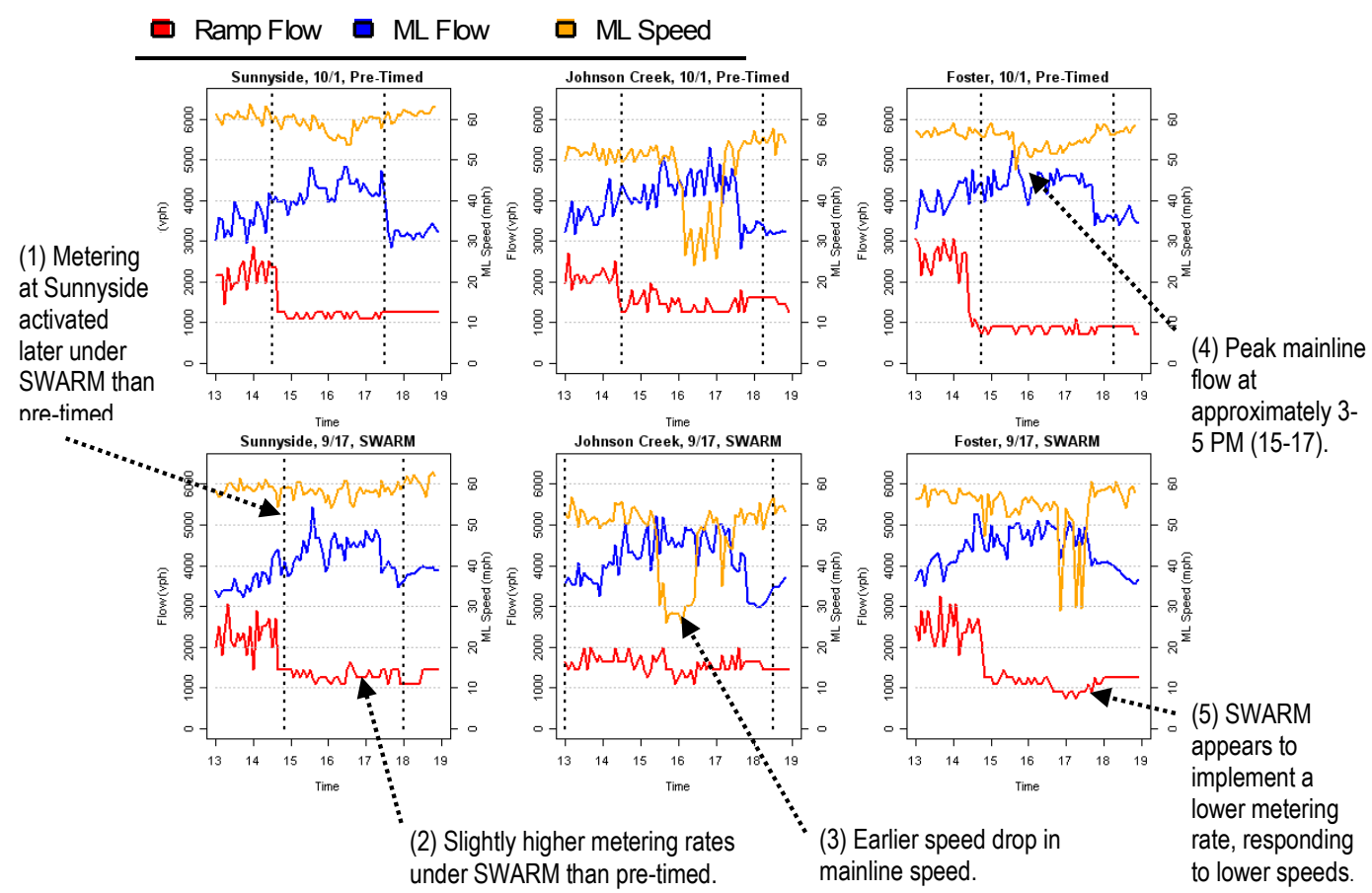

Figure 5.17. Annotated plots of mainline flow (vph), ramp flow (vph) and mainline speed (mph) over time with meter activations, Sunnyside, Johnson Creek, Foster, 9/17/2007 and 10/1/2007

The following points are annotated on the figure:

1. At Sunnyside, SWARM metering (shown by the dashed vertical line) starts later than under the pre-timed strategy. It can be seen that SWARM does activate as soon as allowed (13:00/1:00 PM) at the busiest station (Johnson Creek).

2. When metering does start at Sunnyside, SWARM implements a slightly higher metering rate than pre-timed. This higher metering rate (evidenced by the higher volumes (bottom red line) is consistent for all stations.

3. While it is difficult to attribute the exact cause as related to metering, the mainline speed drops occur much earlier at the Johnson Creek station under SWARM despite the earlier start of metering.

As shown in all plots, the mainline volume peak is in the 3:00-5:00 PM time period. The adaptive nature of the system is evident, as SWARM, in response to mainline speed reduction, implements a lower metering rate at the Foster station on 9/17 at approximately 16:30/4:30 PM.

One possible explanation for the increased delay under SWARM on these moderately congested days is that the higher SWARM metering rates initiate a flow breakdown as mainline volumes begin to peak. This is supported in the timespace plane in Figure 5.16, where the largest delay increase (red) is at 4:00 PM 
for the Sunnyside, Johnson Creek and Foster stations. It is the understanding of the research team that SWARM can implement any metering rate up to the maximum pre-timed rate. It appears that SWARM's selection of a higher rate is a key contributor to the increased delay. This is supported by the cumulative ramp flow plots in Figure 5.12. Because the system does not log its desired metering rate, it is not known if communication failures are preventing SWARM from implementing its desired rate. However, as shown in annotation (5) in Figure 5.17 , there is some observed evidence that the system was adaptive to local conditions.

\subsection{Clackamas to Lawnfield}

Figure 5.18 plots mainline flow (vph), ramp flow (vph) and mainline speed (mph) over time for the Clackamas Hwy station on the same days as Johnson Creek to Powell, 9/17/2007 and 10/1/2007.
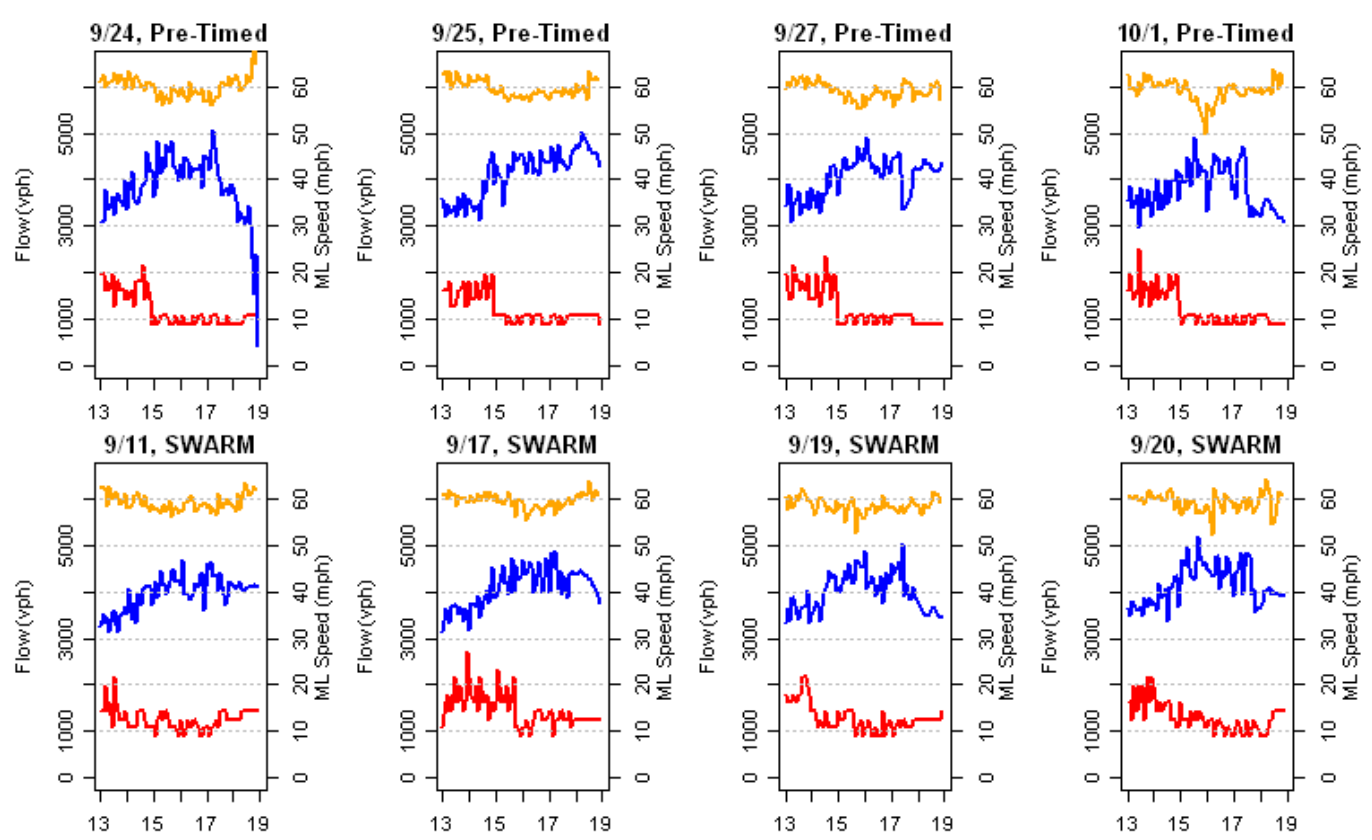

Figure 5.18: Plots of mainline flow (vph), ramp flow (vph) and mainline speed (mph) over time with meter activations, Clackamas Hwy

While SWARM meter activations were not known, it was apparent that metering started about one hour later on 9/17 as compared to 10/1 (by inspection of the drop of the ramp flow [red] line). When metering did start, it was again at a higher rate than the pre-timed condition. Inspection of the remaining plots for the Clackamas and Lawnfield stations generally reveal the same trend (though on some days meter start times appeared comparable, SWARM rates were always higher). This occasional later start and higher metering rate would appear to contribute to the increased delay at these stations. 


\subsubsection{SWARM Performance on Very Highly Congested Days}

On the highly congested and very highly congested days SWARM operation resulted in less average corridor delay $(9.76 \%$ and $37.52 \%)$ than the pre-timed operation. Figure 5.19 shows the changes in corridor average delay for the highly congested and very highly congested days ( 3 in pre-timed, 2 in SWARM) in the time-space plane for the afternoon peak. Note that the scale of this plot is much different than the previous two in that the color scale ranges from a change in vehicle-hours of delay of - 30 to 30 vehiclehours. In the time-space plot in Figure 5.19, the time periods with better SWARM performance (green) again concentrated at the Johnson Creek to Powell ramps, though this time is slightly later in the afternoon at about 5:15 PM. Unlike the moderately congested days, the improvement under SWARM appears to be corridor-wide for these very highly congested days.

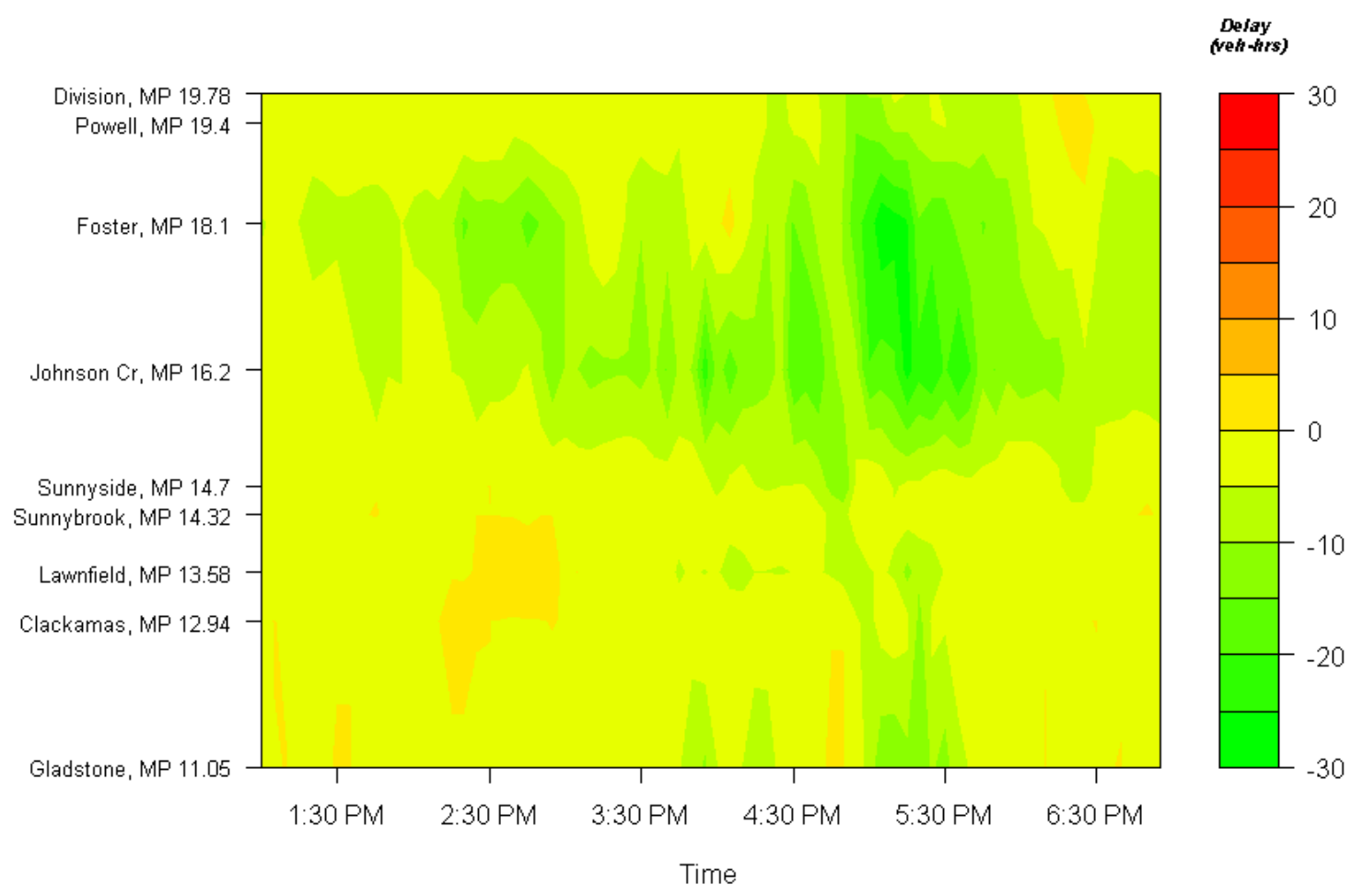

Figure 5.19: Changes in highly and very highly congested delay days under SWARM in time-space plane, I-205NB, PM peak

To explore this better performance, similar plots for the three stations comparing two very highly congested days are shown in Figure 5.20. 

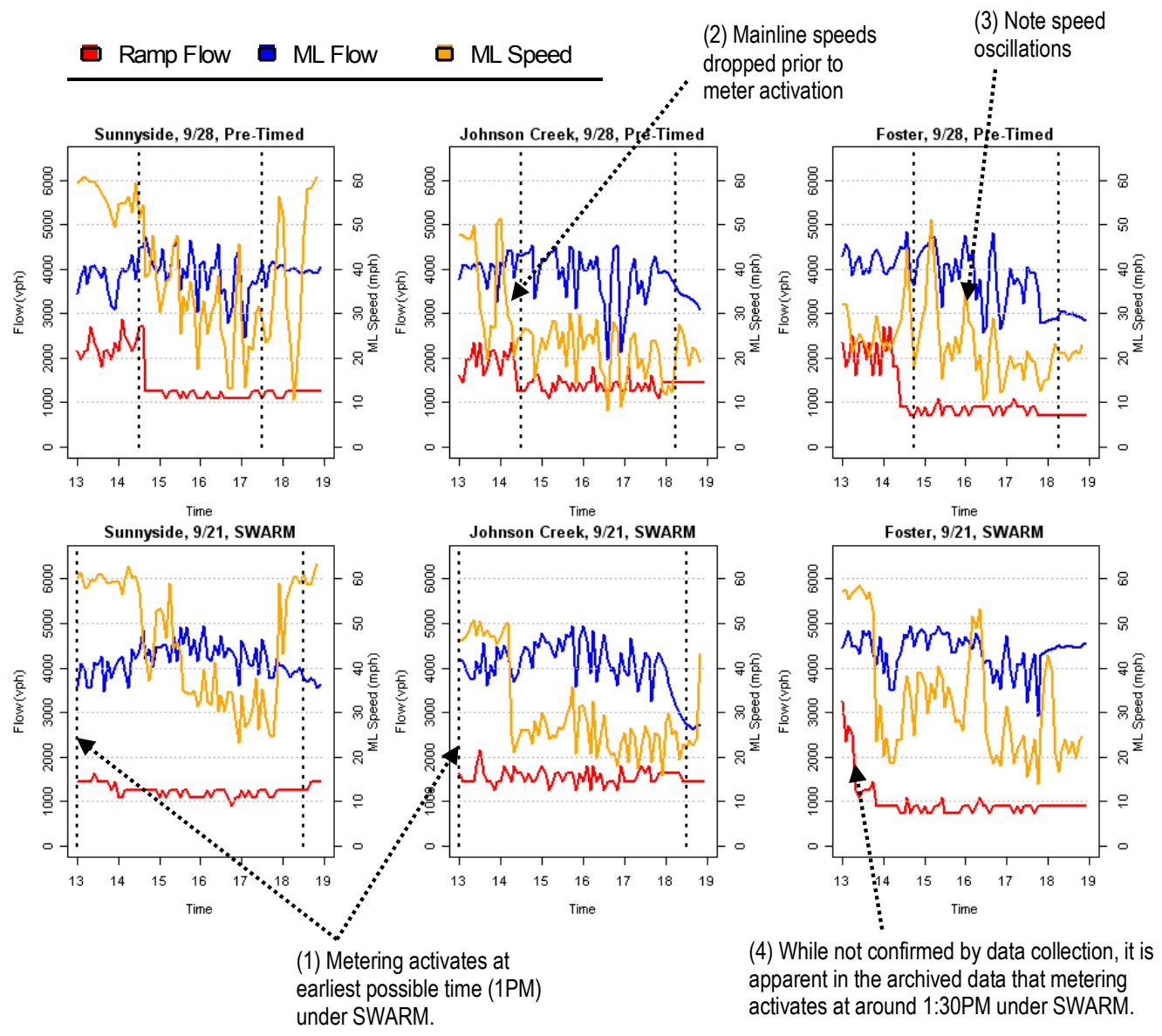

Figure 5.20: Plots of mainline flow (vph), ramp flow (vph) and mainline speed (mph) over time with meter activations, Sunnyside, Johnson Creek, Foster, 9/28/2007 and 9/21/2007

The following points are annotated on the figure:

1. At Sunnyside and Johnson Creek, SWARM activates as early as allowed (13:00/1:00 PM). While the metering rate is slightly higher than the pre-timed situation, the adaptive situation was (in this case) able to respond and delay the onset of the mainline speed drop. Also, note that the pre-timed meters deactivate while congestion is still present at the Powell ramp, perhaps delaying the queue clearance and increasing the length of congestion.

2. At Johnson Creek in the pre-timed operation, it is clear on this highly congested day that mainline speed drops well before metering starts.

3. While difficult to draw conclusions, comparison of the mainline speed over time appears to indicate fewer oscillations in the SWARM period, particularly for the Sunnyside and Johnson Creek stations (less so at Foster). This implies more stable operations (better reliability). On September 28, congestion reaches the Sunnyside station at about the same time $\sim 15: 30 / 3: 30$ PM but the mainline speed is much less variable. 
These observations are the basis for the conclusion that SWARM's earlier activation time, on the highly congested and very highly congested days, was able to offset higher metering rates and decrease mainline delay.

\subsection{OR-217 NB}

\subsubsection{Description of Corridor}

OR-217 NB was the second regional study corridor to be evaluated. OR-217 northbound is a 7mile freeway that diverges from I-5N/S, intersects with Highways 99W (Pacific Hwy), 210 (Scholls-Ferry Rd.), 8 (Canyon Rd./Tualatin Valley Highway), and 10 (Beaverton-Hillsdale Hwy), and finally merges onto US-26 (see Figure 1.1). The freeway has various lane configurations, but in the study area, is generally two lanes, as shown in the corridor schematic in Figure 5.21. The schematic shows that the corridor contains 9 on-ramps, all of which are controlled by ramp meters. The average locations of loop detectors are 0.75 miles apart (minimum of 0.05 miles between $99 \mathrm{~W}$ EB and WB and maximum of 1.2 miles from $99 \mathrm{~W}$ WB to Greenburg). SWARM was implemented on this corridor in late November 2005. The ramp meters operated under the SWARM system from November 5 to November 16 and were programmed to run under the pre-timed strategy from November 26 to December 7. Only the afternoon peak was studied.

\subsubsection{Typical Congestion Patterns}

OR-217 NB is congested during the afternoon peak period. Congestion generally persists from the start of the highway near the I-5 and Kruse Way unmetered merge (upstream of the 72nd Ave. merge at MP 6.61) through the lane drops and additions to the Denney Ave off-ramp. This queue often propagates upstream onto I-5 NB (over the fly-over ramp). Downstream of Denney, the corridor generally has limited congestion. Plots of reported mainline speeds in the time-space plane are available for all study days in the Appendix Online-6. 


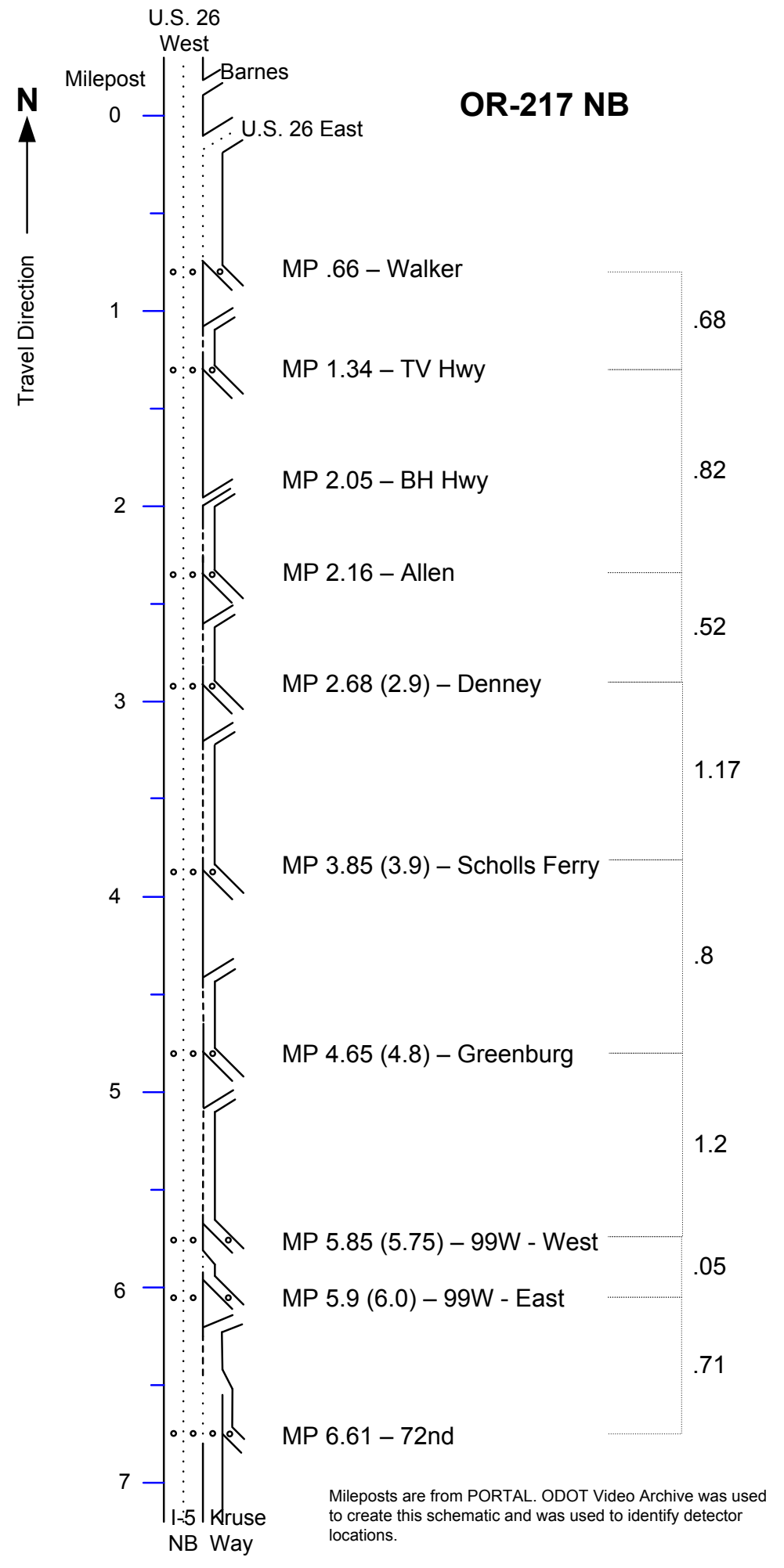

Figure 5.21: Schematic of OR-217 NB 


\subsubsection{Ramp Demand}

As in the pilot study, a characterization of ramp volumes and available storage space was conducted. These data are plotted in Figure 5.22 which shows average ramp volume as grey bars plotted on the left axis and queue storage measured in feet on the right axis for AM and PM, respectively. The queue storage space was provided by the Oregon Department of Transportation (ODOT). The number of lanes on the ramp was taken into consideration in estimating the storage space. These plots were generated from March 2007 data. The busiest ramps during the PM peak are 99W (WB), Scholls-Ferry, and TV Highway (split diamond interchange with B-H Highway) with average volumes of between 900 and 1,700 vehicles per hour (vph) during this period, followed by Allen - the next busiest, with $600 \mathrm{vph}$. Scholls-Ferry is one of the busiest on-ramps and has limited storage.

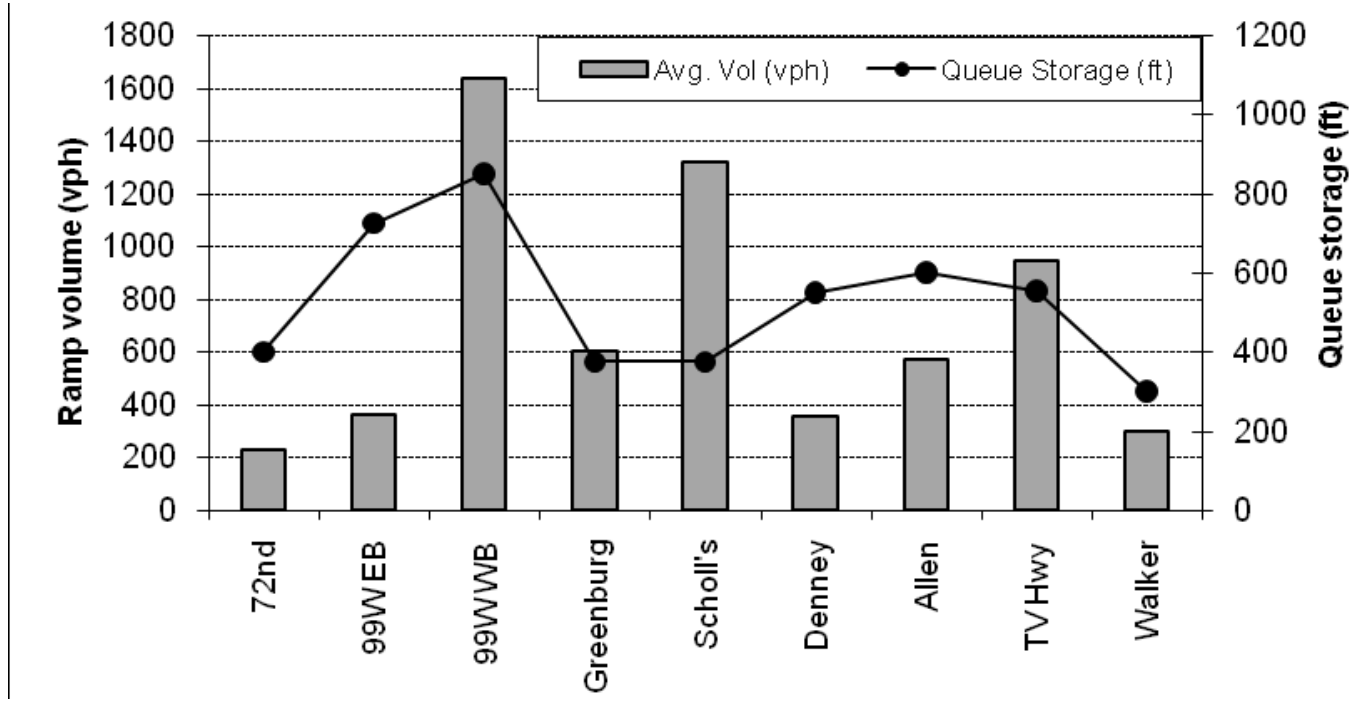

Figure 5.22: Average hourly volume and queue storage on OR-217 NB, March 2007, PM peak

\subsubsection{Excluded Analysis Days}

\subsubsection{Communication Failures}

In general, communication failures and data quality were much less of a problem for the OR-217 corridor than on I-205. Figure 5.23 below shows the communication failure rate by station. However, the data still reveals the effect of the SWARM operation on data quality. On OR-217, the communication failure rate under the pre-timed strategy was about one percent, except at Walker, which was about five percent. Under the SWARM strategy, the overall communication failure rate was about $10 \%$, except at $72 \mathrm{nd}$, which was less than five percent. 


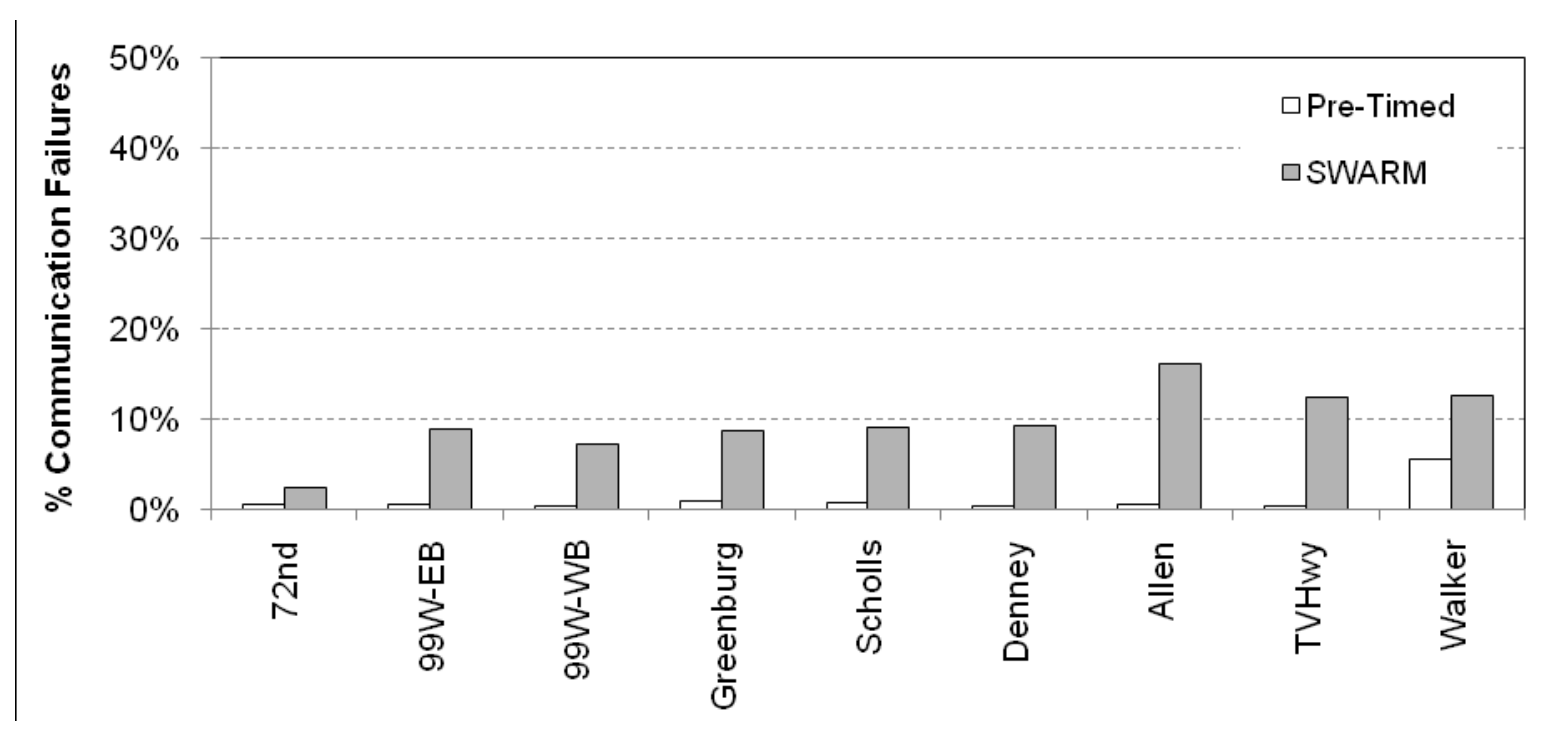

Figure 5.23: Percent communication failures under SWARM and pre-timed operation by station, OR-217 NB, PM peak.

The communication errors are reported by day and ramp in Table 5.10. Analysis periods with more than $10 \%$ of the 20 -second readings failing are italicized in the table which indicates that these were considered to be potential data quality issues.

Table 5.10: Communication Failures, OR-217 NB

\begin{tabular}{|c|c|c|c|c|c|c|c|c|c|c|c|}
\hline \multicolumn{12}{|c|}{ PRE-TIMED } \\
\hline STATION & MP & $11-5$ & 11-6 & 11-7 & 11-8 & 11-9 & 11-12 & 11-13 & 11-14 & 11-15 & 11-16 \\
\hline 72 nd & 12.94 & $0.6 \%$ & $0.2 \%$ & $0.4 \%$ & $1.4 \%$ & $0.8 \%$ & $0.6 \%$ & $0.1 \%$ & $0.8 \%$ & $0.2 \%$ & $0.5 \%$ \\
\hline 99W-EB & 13.58 & $0.4 \%$ & $0.6 \%$ & $0.6 \%$ & $1.1 \%$ & $0.4 \%$ & $0.4 \%$ & $0.2 \%$ & $1.3 \%$ & $0.9 \%$ & $0.5 \%$ \\
\hline 99W-WB & 14.32 & $0.4 \%$ & $0.3 \%$ & $0.3 \%$ & $0.2 \%$ & $0.3 \%$ & $0.6 \%$ & $0.2 \%$ & $0.2 \%$ & $0.7 \%$ & $0.5 \%$ \\
\hline Greenburg & 14.7 & $1.9 \%$ & $0.6 \%$ & $0.1 \%$ & $1.0 \%$ & $2.0 \%$ & $0.6 \%$ & $0.8 \%$ & $1.3 \%$ & $0.9 \%$ & $0.1 \%$ \\
\hline Scholls-Ferry & 16.2 & $0.2 \%$ & $0.6 \%$ & $0.8 \%$ & $0.6 \%$ & $0.2 \%$ & $0.6 \%$ & $1.1 \%$ & $0.6 \%$ & $1.6 \%$ & $0.4 \%$ \\
\hline Denney & 18.1 & $0.1 \%$ & $1.2 \%$ & $0.2 \%$ & $0.2 \%$ & $0.6 \%$ & $0.4 \%$ & $0.0 \%$ & $0.4 \%$ & $0.3 \%$ & $0.6 \%$ \\
\hline Allen & 19.4 & $0.6 \%$ & $0.6 \%$ & $0.6 \%$ & $0.5 \%$ & $0.3 \%$ & $0.2 \%$ & $0.3 \%$ & $1.0 \%$ & $0.6 \%$ & $0.1 \%$ \\
\hline TV Hwy & 19.78 & $0.3 \%$ & $1.2 \%$ & $0.5 \%$ & $0.2 \%$ & $0.1 \%$ & $0.2 \%$ & $0.4 \%$ & $0.4 \%$ & $0.6 \%$ & $0.6 \%$ \\
\hline Walker & 21.12 & $0.3 \%$ & $0.6 \%$ & $0.1 \%$ & $1.8 \%$ & $0.5 \%$ & $50.0 \%$ & $0.1 \%$ & $0.6 \%$ & $0.5 \%$ & $0.6 \%$ \\
\hline \multicolumn{12}{|c|}{ SWARM } \\
\hline STATION & MP & $11-26$ & $11-27$ & $11-28$ & 11-29 & 11-30 & $12-3$ & $12-4$ & $12-5$ & $12-6$ & $12-7$ \\
\hline 72 nd & 12.94 & $0.6 \%$ & $1.4 \%$ & $0.5 \%$ & $0.5 \%$ & $1.0 \%$ & $16.4 \%$ & $1.9 \%$ & $1.1 \%$ & $0.6 \%$ & $0.0 \%$ \\
\hline 99W-EB & 13.58 & $4.6 \%$ & $3.6 \%$ & $2.6 \%$ & $5.8 \%$ & $3.8 \%$ & $17.0 \%$ & $45.5 \%$ & $2.1 \%$ & $1.5 \%$ & $2.6 \%$ \\
\hline 99W-WB & 14.32 & $3.0 \%$ & $2.1 \%$ & $0.9 \%$ & $0.9 \%$ & $2.7 \%$ & $16.6 \%$ & $43.8 \%$ & $0.6 \%$ & $1.0 \%$ & $0.8 \%$ \\
\hline Greenburg & 14.7 & $2.9 \%$ & $2.5 \%$ & $2.4 \%$ & $3.8 \%$ & $4.1 \%$ & $17.0 \%$ & $47.6 \%$ & $1.5 \%$ & $2.4 \%$ & $3.3 \%$ \\
\hline Scholls-Ferry & 16.2 & $2.5 \%$ & $2.7 \%$ & $1.9 \%$ & $4.4 \%$ & $3.9 \%$ & $23.6 \%$ & $45.2 \%$ & $0.8 \%$ & $1.4 \%$ & $4.1 \%$ \\
\hline Denney & 18.1 & $3.9 \%$ & $0.6 \%$ & $2.5 \%$ & $2.2 \%$ & $4.4 \%$ & $27.9 \%$ & $44.9 \%$ & $1.6 \%$ & $1.9 \%$ & $3.4 \%$ \\
\hline Allen & 19.4 & $5.4 \%$ & $6.2 \%$ & $4.5 \%$ & $3.8 \%$ & $8.4 \%$ & $68.1 \%$ & $46.2 \%$ & $5.3 \%$ & $4.2 \%$ & $9.2 \%$ \\
\hline TVHwy & 19.78 & $8.1 \%$ & $4.1 \%$ & $7.5 \%$ & $6.8 \%$ & $8.8 \%$ & $21.3 \%$ & $45.9 \%$ & $6.0 \%$ & $7.5 \%$ & $8.5 \%$ \\
\hline Walker & 21.12 & $7.7 \%$ & $7.3 \%$ & $8.2 \%$ & $8.2 \%$ & $7.4 \%$ & $17.7 \%$ & $47.6 \%$ & $5.6 \%$ & $7.4 \%$ & $8.0 \%$ \\
\hline
\end{tabular}


Two days (12/3 and 12/4) had high rates of communication failures under SWARM. Excluding these days, the average failure rate was less than five percent at all ramps south of and including Denney, and between 5-7.5\% at the ramps north of Denney. Moreover, there were no other days with greater than a $10 \%$ failure rate. The two days with a rate greater than $10 \%, 12 / 3$ and $12 / 4$, were the only SWARM days excluded from the sample for data quality reasons. One day, 11/12, was excluded from the pre-timed sample due to a data quality failure at Walker.

The data qualities are in strong contrast to those reported on I-205. The errors on OR$217 \mathrm{NB}$, however, are comparable to the values in the pilot study on OR-217 SB. It is apparent that the communication errors are higher at the north end of the corridor during SWARM operation (Walker, TV Hwy/B-H Highway, Allen and Denney). This is most likely related to the way the ramp controllers are connected in drops, with SWARM communication demands exacerbating communication problems with some controllers. It is worth noting that between the pilot and the regional study, a paving project on OR217 in 2007 included new loops and maintenance of the detector infrastructure. This resulted in improved data quality (i.e. reported speed readings from some stations) but not improvements in communication.

\subsubsection{Weather and Incidents}

In addition to data quality, study days were analyzed for significant weather and incidents. Table 5.11 summarizes the days precipitation was recorded.

Table 5.11: Observed weather during study period for OR-217 NB

\begin{tabular}{c|c|c|c}
\hline Peak & Date & Time & Precipitation (in) \\
\hline \multirow{5}{*}{} & $11 / 5$ & $2-3$ PM & 0.01 \\
\cline { 2 - 4 } & $11 / 9$ & $1-4$ PM & 0.02 \\
\cline { 2 - 4 } & $11 / 12$ & $1-4$ PM & 0.03 \\
\cline { 2 - 4 } & $11 / 15$ & $5-7$ PM & 0.05 \\
\cline { 2 - 4 } & $11 / 16$ & $1-7$ PM & 0.27 \\
\cline { 2 - 4 } & $11 / 26$ & $4-7$ PM & 0.28 \\
\cline { 2 - 4 } & $11 / 27$ & $3-7$ PM & 0.06 \\
\cline { 2 - 4 } & $11 / 28$ & $1-7$ PM & 0.33 \\
\cline { 2 - 4 } & $11 / 29$ & $6-7$ PM & 0.02 \\
\cline { 2 - 4 } & $12 / 3$ & $1-7$ PM & 0.48 \\
\cline { 2 - 4 } & $12 / 5$ & $2-6$ PM & 0.06 \\
\hline
\end{tabular}

As in the I-205 evaluation, traffic conditions were evaluated to determine if weather appeared to play a significant role in congestion. Three days were excluded from the analysis: $11 / 16,11 / 28$, and $12 / 3$. Since the significant rainfall ( 0.28 inches) on $11 / 26$ did not have a clear impact on traffic conditions; it was not excluded. 
Logs from the ATMS were used to identify incidents that had a significant impact on freeway operations (Table 5.12). None of these incidents was deemed significant enough to exclude any analysis days.

Table 5.12: Inventory of potentially significant incidents occurring during study period for OR-217 NB

\begin{tabular}{c|l|l|l|c}
\hline Peak & Date & Location & Time & Lanes Effected \\
\hline \multirow{5}{*}{ PM } & $11 / 13$ & Scholls-Ferry & $18: 31-18: 34$ & 0 \\
\cline { 2 - 5 } & $11 / 26$ & ramp to US26 & $17: 45-17: 47$ & Right lane \\
\cline { 2 - 5 } & $11 / 27$ & Barnes & $17: 59-18: 30$ & Right lane \\
\cline { 2 - 5 } & $11 / 28$ & at Hall & $15: 08-15: 16$ & Right lane \\
\cline { 2 - 5 } & $11 / 30$ & at Walker & $13: 35-13: 59$ & 0 \\
\cline { 2 - 5 } & & at 99W & $18: 48-19: 15$ & right shoulder \\
\cline { 2 - 5 } & $12 / 3$ & Denney/Allen & $18: 30-20: 12$ & right shoulder \\
\hline
\end{tabular}

\subsubsection{Summary of Excluded Analysis Days}

As shown in Table 5.13, one pre-timed day and two SWARM days were excluded from the study due to data quality issues (one of these afternoons was also excluded due to weather).

Table 5.13: Summary of Exclusion Analysis Days, OR-217 NB

\begin{tabular}{l|l||l|l}
\hline \multicolumn{2}{l||}{ PRE-TIMED } & \multicolumn{2}{|l}{ SWARM } \\
\hline $11 / 5$ & & $11 / 26$ & \\
\hline $11 / 6$ & & $11 / 27$ & \\
\hline $11 / 7$ & & $11 / 28$ & Weather \\
\hline $11 / 8$ & & $11 / 29$ & \\
\hline $11 / 9$ & & $11 / 30$ & \\
\hline $11 / 12$ & Data Quality & $12 / 3$ & Data Quality, Weather \\
\hline $11 / 13$ & & $12 / 4$ & Data Quality \\
\hline $11 / 14$ & & $12 / 5$ & \\
\hline $11 / 15$ & & $12 / 6$ & \\
\hline $11 / 16$ & Weather & $12 / 7$ & \\
\hline
\end{tabular}

\subsubsection{Mainline Performance}

As described in the methodology chapter, three primary performance metrics were evaluated for the mainline freeway: Vehicle Miles Traveled (VMT), Vehicle Hours Traveled (VHT), and Delay. All three of these metrics are reported as average daily values and are presented by corridor congestion level, as well as the total evaluation period. Table 5.14 summarizes the results of the analysis. 
Table 5.14: Performance measures overall and by level of congestion, OR-217 NB, 1:00-7:00 PM

\begin{tabular}{|c|c|c|c|c|c|c|}
\hline PM PERIOD & & $\begin{array}{l}\text { NUMBER OF } \\
\text { DAYS }\end{array}$ & $\begin{array}{c}\text { VMT } \\
\text { (AVG DAILY) }\end{array}$ & $\begin{array}{c}\text { VHT } \\
\text { (AVG } \\
\text { DAILY) }\end{array}$ & $\begin{array}{l}\text { AVG DELAY } \\
\text { (VEH-HOURS) }\end{array}$ & $\begin{array}{c}\text { DELAY } \\
\text { STANDARD } \\
\text { DEVIATION }\end{array}$ \\
\hline \multirow{3}{*}{ Least Congested } & Pre-Timed & 3 & 129,454 & 2,754 & 478 & 65 \\
\hline & SWARM & 0 & - & - & - & - \\
\hline & $\%$ Change & - & - & - & - & - \\
\hline \multirow{3}{*}{$\begin{array}{l}\text { Moderately } \\
\text { Congested }\end{array}$} & Pre-Timed & 3 & 130,991 & 2,933 & 618 & 31 \\
\hline & SWARM & 3 & 125,053 & 3,029 & 802 & 14 \\
\hline & $\%$ Change & - & $-4.53 \%$ & $3.26 \%$ & $29.85 \%$ & $-54.14 \%$ \\
\hline \multirow{3}{*}{ Highly Congested } & Pre-Timed & 1 & 133,821 & 3,395 & 1,006 & - \\
\hline & SWARM & 1 & 130,203 & 3,284 & 960 & - \\
\hline & $\%$ Change & - & $-2.70 \%$ & $-3.26 \%$ & $-4.61 \%$ & - \\
\hline \multirow{3}{*}{$\begin{array}{l}\text { Very Highly } \\
\text { Congested }\end{array}$} & Pre-Timed & 1 & 127,696 & 3,424 & 1,156 & - \\
\hline & SWARM & 3 & 125,173 & 3,583 & 1,341 & 130 \\
\hline & $\%$ Change & - & $-1.98 \%$ & $4.63 \%$ & $15.99 \%$ & - \\
\hline \multirow{3}{*}{$\begin{array}{c}\text { Overall } \\
\text { PM Period }\end{array}$} & Pre-Timed & 8 & 130,357 & 2,985 & 681 & 261 \\
\hline & SWARM & 7 & 126,339 & 3,303 & 1,056 & 283 \\
\hline & $\%$ Change & - & $-3.08 \%$ & $10.64 \%$ & $54.97 \%$ & $8.42 \%$ \\
\hline
\end{tabular}

Overall, in the afternoon peak VMT decreased 3.08\% while mainline VHT increased by $10.64 \%$ in the SWARM period, compared to the pre-timed period. The average mainline delay increased by $54.95 \%$ (375 vehicle-hours); this increase was statistically significant $(p=0.02)$. The results by congestion level revealed that SWARM operations resulted in more mainline delay for all days, except for the highly congested days. The results by congestion level of congestion were:

- Least congested - There were three days classified at this congestion level in the pretimed operation, however there were no comparable days under SWARM.

- Moderately congested - There were three days in each mode classified as moderately congested. For these days, average VMT decreased $4.53 \%$, average VHT increased $3.26 \%$ and the average delay increased $29.85 \%$ from 618 vehicle-hours to 802 vehiclehours under SWARM operations. The increase in delay was comparable to the increase in the I-205 PM for this congestion level (29.73\%) and was statistically significant $(p=0.001)$.

- Highly congested - There was only one day in each operation that was highly congested. Comparing these two days, average VMT decreased 2.70\%, average VHT decreased $3.26 \%$ and the average delay decreased $4.61 \%$ under SWARM, as compared to pretimed operation. This difference could not be tested for significance.

- Very highly congested - There was one "very highly" congested day under the pre-timed strategy and three under SWARM. Comparing the pre-timed operation to SWARM, average VMT decreased $1.98 \%$, VHT increased $3.26 \%$ and the average delay increased $15.99 \%$ over pre-timed. This difference could not be tested for significance.

Figure 5.24 below shows the difference between mainline delay under the pre-timed strategy (left) and SWARM (right) in the afternoon peak on OR-217 NB. Stations are listed in the direction of travel from south, at the bottom of the figure, to north, at the top. The other bars represent average delay for each level of congestion, with the number of days in each sample shown in the legend. 

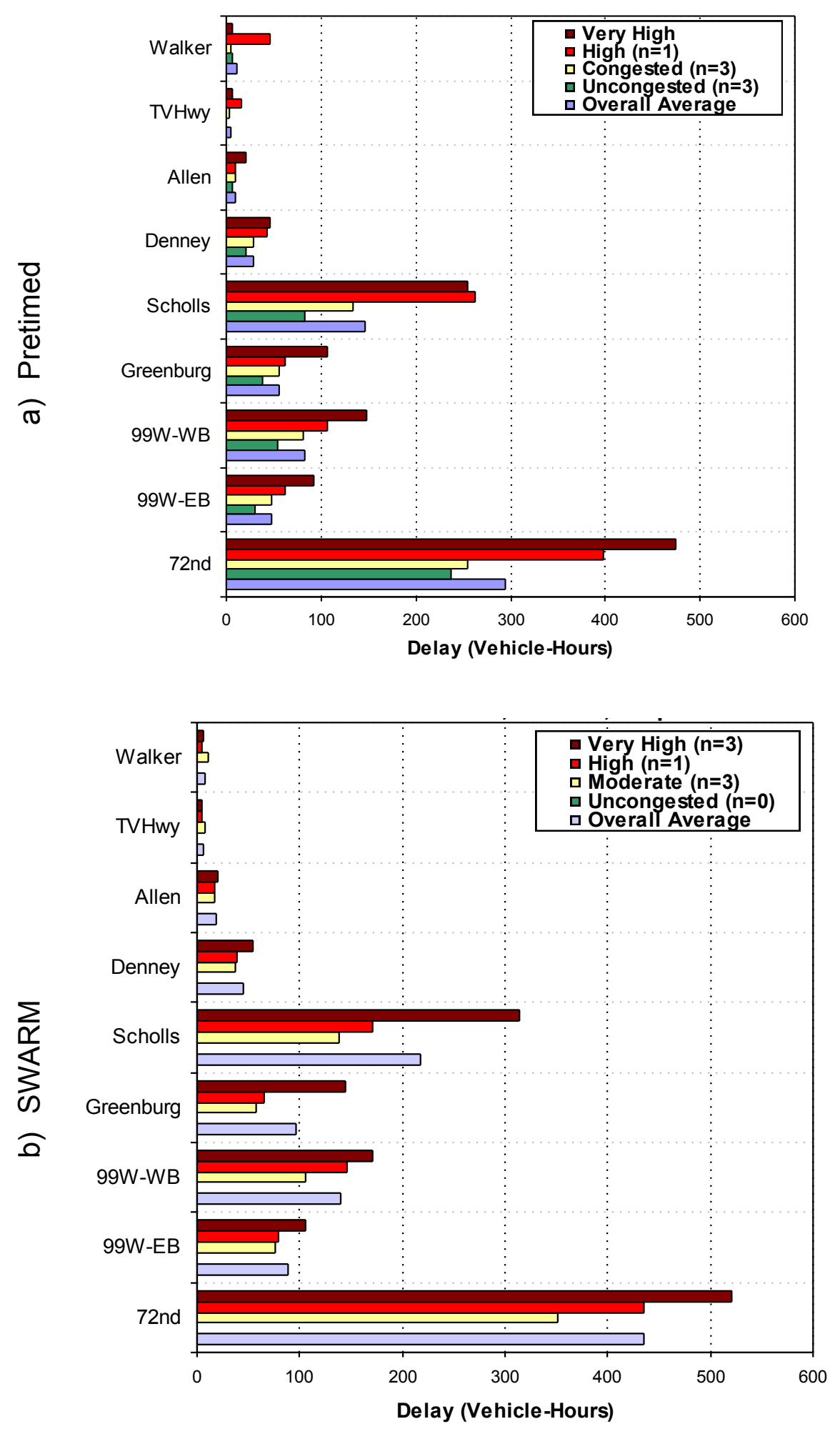

Figure 5.24: Mainline Delay, overall average and average by level of congestion for OR-217 NB, Afternoon Peak, (a) Pre-Timed (top) and (b) SWARM (bottom). 


\subsubsection{Ramp Performance}

Consistent with the other corridors, SWARM allowed more vehicles on the freeway. Figure 5.25 shows the cumulative vehicle counts at all on-ramps, $N$, plotted on an oblique time axis. In other words, the curves shown in the figure correspond to the quantities, $N-q_{0} *\left(t-t_{0}\right)$, where $q_{0}$ is a background flow (3600 vph in this case), $t$ is time, and $t_{0}$ is the start time (14:30/2:30 PM in this case).

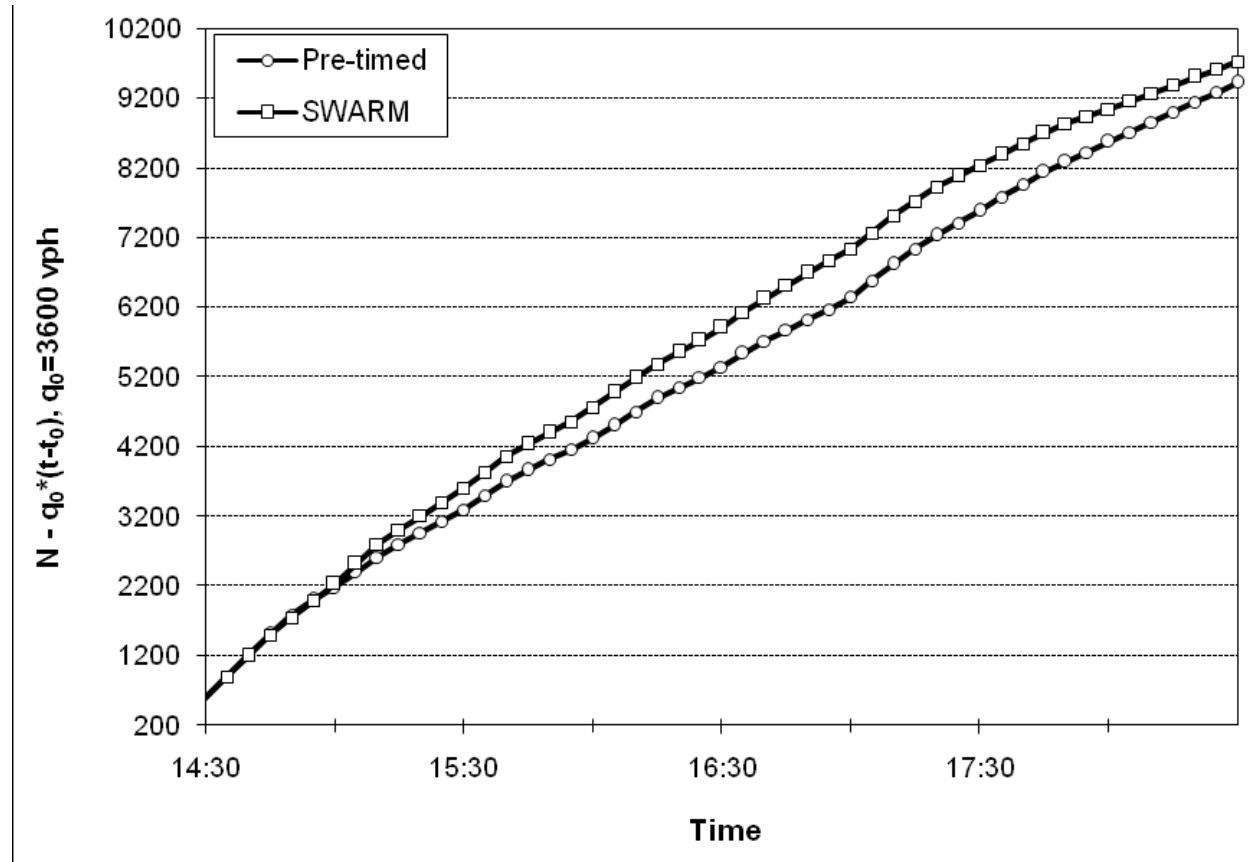

Figure 5.25: Cumulative on-ramp vehicle counts, OR-217 NB, afternoon peak

As shown in Figure 5.26, with the exception of the 99W ramps and Walker, each ramp allowed more vehicles on the freeway. The Greenburg and Scholls-Ferry ramps had the greatest increase in average flow.

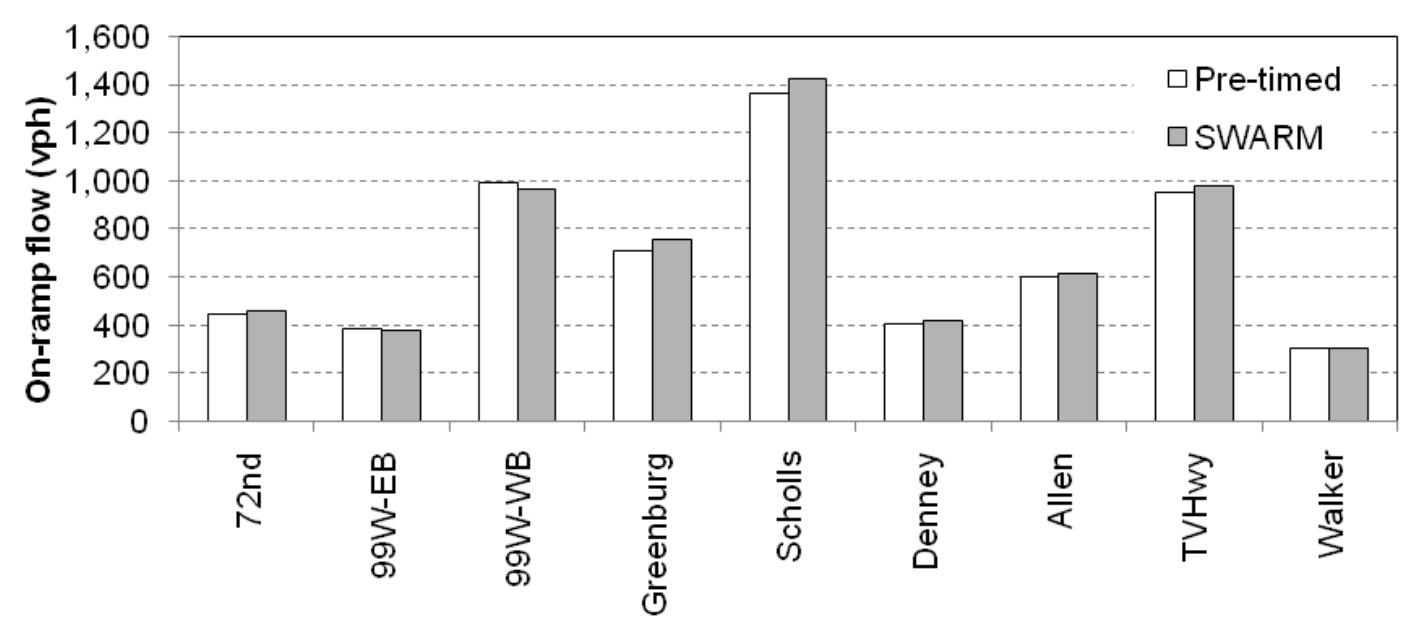

Figure 5.26: Average hourly on-ramp flow, OR-217 NB, afternoon period, 1:00-7:00 PM 


\subsubsection{Discussion}

In general, SWARM operation resulted in increased average delay for the OR-217 corridor. Figure 5.27 shows the changes in average delay in the time-space plane. In the plots, green colors indicate better SWARM performance, while red colors reveal locations where pre-timed metering performed better.

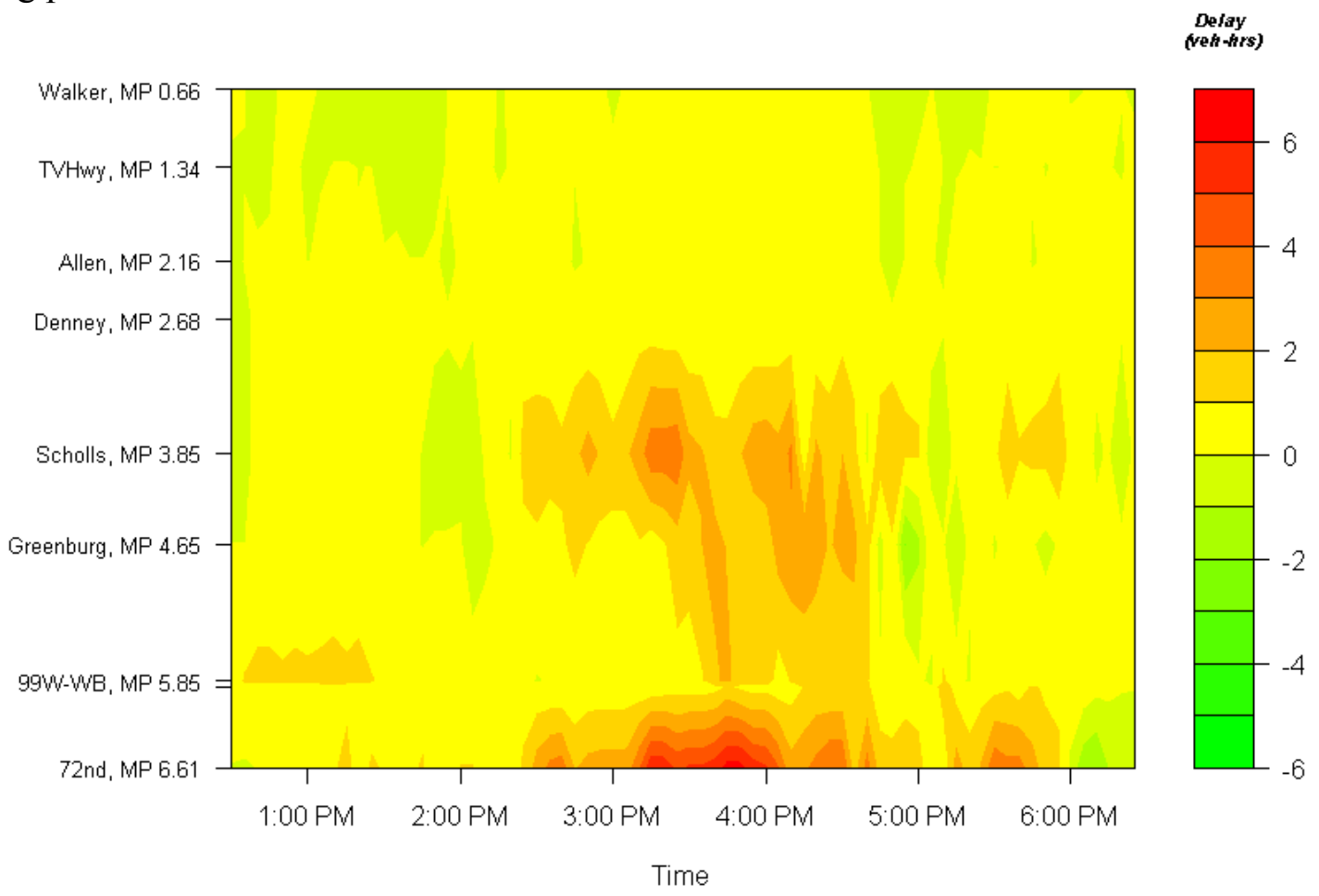

Figure 5.27: Changes in delay under SWARM in time-space plane, OR-217NB, PM peak

The figure clearly shows that unlike I-205 NB, where there were few periods and locations where SWARM performed better, nearly the entire plane is yellow, orange or red, indicating that the decreased performance was corridor wide. As shown in the bar plots in Figure 5.24 and the time-space plot, the majority of delay increases occur upstream of the Denney station (which corresponds to a location of an auxiliary lane drop). The largest increase in delay was near the 72 nd station which is the location where the unmetered merge with I-5SB/Kruse Way occurs. A secondary concentration of delay was around Greenburg and Scholls-Ferry - which were shown in Figure 5.26 to have the largest increase in pre-timed to SWARM on-ramp flows.

\subsubsection{SWARM Performance on Very Highly Congested Days}

Possible reasons for decreased performance were explored for the OR-217 corridor using two very highly congested days. Similar to the figure presented in Section 5.2.5.1.1, Figure 5.28 plots mainline flow (vph), ramp flow (vph) and mainline speed (mph), over a period of 2 days (11/15/2007 and 12/7/2007) for comparison, with meter 
activations at 72nd, 99W WB, and Greenburg. Pre-timed operation is shown on the top, and SWARM operation on the bottom row. Vertical dashed lines indicate the meter on and off times as recorded by the PLCs or the pre-timed ramp meter times. (Note that SWARM on-off times are not available at $72^{\text {nd }}$.)

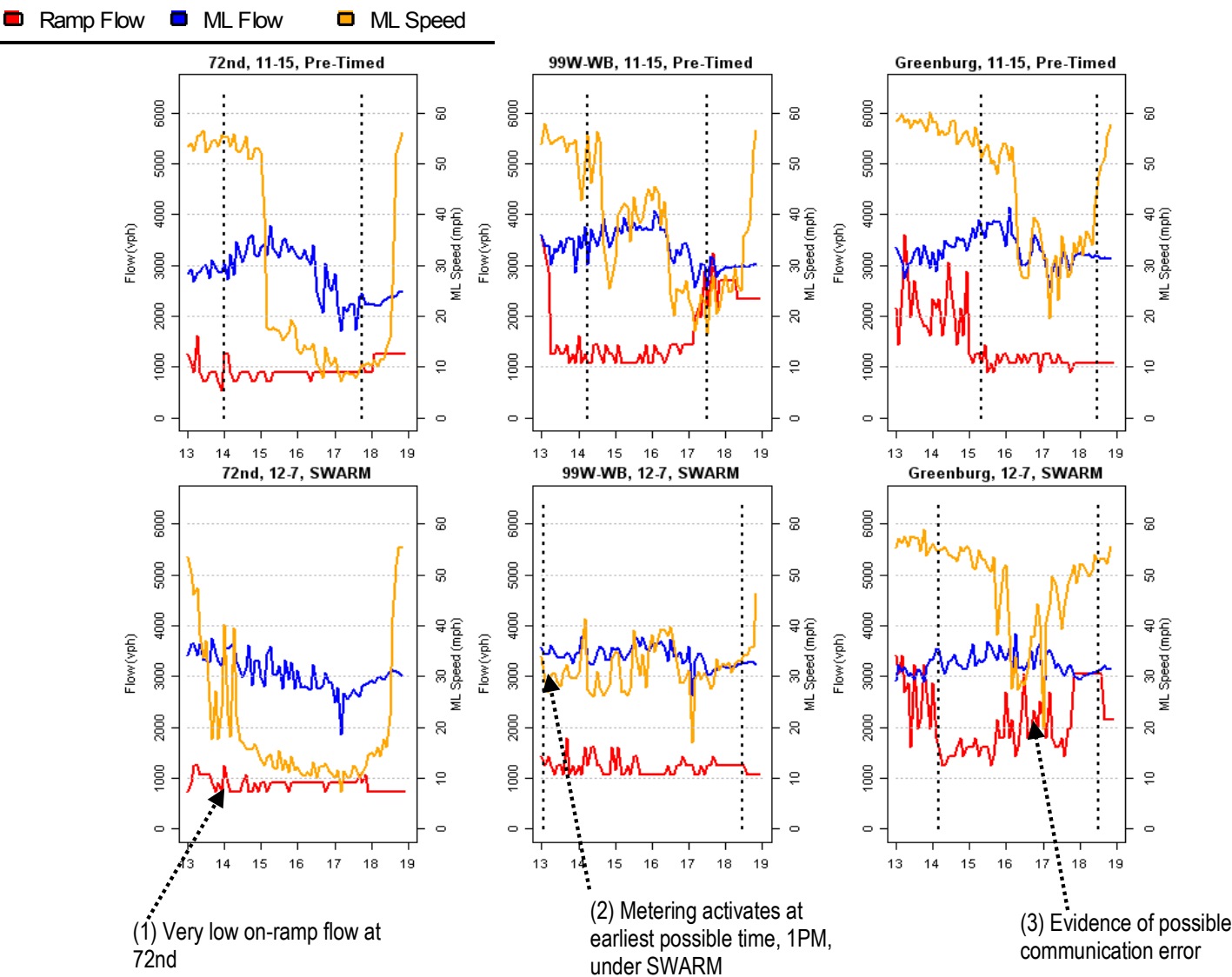

Figure 5.28: Plots of mainline flow (vph), ramp flow (vph) and mainline speed (mph) over time with meter activations, 11/15/2007 and 12/7/2007

The following points are annotated on the figure:

1. At 72nd, the ramp flow volumes are generally the lowest in the corridor (as shown in Figure 5.28). While the largest delay is near this station, it is clearly not because of any difference in SWARM metering.

2. Downstream at $99 \mathrm{~W} \mathrm{WB}, \mathrm{SWARM}$ metering does activate (shown by the dashed vertical line) as soon as allowed (13:00/1:00 PM) and before the pre-timed metering activation, however by this time the mainline speed had already dropped, indicating congested flows. 
3. At the Greenburg station, the observed ramp metering rate appears much higher and variable than one might expect. One possible explanation might be that communication problems inhibit SWARM from appropriately changing the metering rate at this station. There is evidence that this occurs for other stations but it is not systematic.

In summary, the primary reasons for the decreased performance on OR-217 are less clear than on I-205 NB, though they are certainly related to SWARM's higher metering rates. The physical bottleneck at the 72nd/I-5-Kruse Way merge appears to play an important role in the significant increase in congestion. One hypothesis is that as SWARM allows more vehicles at the downstream ramps, congestion at $72 \mathrm{nd} / \mathrm{I}-5$-Kruse Way is increased which exacerbates the bottleneck at this merge. 


\subsection{CONCLUSIONS AND RECOMMENDATIONS}

Portland's original ramp metering strategy employed a pre-timed approach that determined the days and times that the meters were active as well as each ramp's metering rate, based on limited analysis of historical patterns. With the development of a robust freeway surveillance and communication system, the deployment of a traffic-responsive metering approach became possible. In May 2005, the System-Wide Adaptive Ramp Metering (SWARM) system was implemented in stages in the Portland metropolitan area and is currently operational on all corridors except for I-405.

While the SWARM system is designed to be more effective than the pre-timed ramp metering strategy, the true benefits of the new system, as deployed in Oregon, had not been quantified prior to this study. The objective of this research was to compare selected freeway and ramp performance metrics between the existing pre-timed operation and the SWARM operating mode. To accomplish this, data were obtained from existing surveillance and communications infrastructures and supplemental sources. Archived traffic sensor data was the primary data source used to evaluate the system-wide impact of the SWARM system. This data source was made possible via the Portland Oregon Regional Transportation Archive Listing (PORTAL).

Pre-timed meter operation and SWARM meter operation were compared on the OR-217 and I205 corridors. The study selected two morning and two afternoon peak periods for analysis. The following sections summarize the conclusions about SWARM performance and communications issues. Recommendations are included at the end of each section.

\subsection{SWARM PERFORMANCE}

\subsubsection{Conclusions}

The evaluation research revealed that the operation of the SWARM system, as currently configured in the Portland metropolitan region, produces mixed results when comparing the selected performance metrics to pre-timed operation. A summary of the performance metrics is presented in Table 6.1.

\subsubsection{OR-217}

For the OR-217 corridors, SWARM operation resulted in increased mainline delay, increased variability in delay, and possible decreased on-ramp delays due to higher metering rates at most of the on-ramps.

The pilot study on southbound OR-217 found that the while VMT exhibited a marginal increase $(+0.4 \%)$ under the SWARM operation, total delay on the freeway increased $34.9 \%$. This increase was not statistically significant $(p=0.421)$. 
Table 6.1: Summary of Performance Measures

\begin{tabular}{|c|c|c|c|c|c|c|c|}
\hline \multirow[b]{2}{*}{ Corridor } & \multirow[b]{2}{*}{ Congestion Level } & \multirow[b]{2}{*}{$\begin{array}{l}\text { Days Pre- } \\
\text { Timed-Days } \\
\text { Swarm }\end{array}$} & \multicolumn{5}{|c|}{ Percent Change from Pretimed to SWARM Operations } \\
\hline & & & VMT & VHT & $\begin{array}{c}\text { Delay } \\
\text { (veh-hours) }\end{array}$ & P-Value & $\begin{array}{c}\text { St. Dev. } \\
\text { Delay }\end{array}$ \\
\hline OR-217 SB AM & Overall & $4-5$ & +0.4 & +8.6 & +34.9 & 0.421 & +18.0 \\
\hline \multirow{5}{*}{ OR-217 NB PM } & Least Congested & $3-0$ & - & - & - & - & - \\
\hline & $\begin{array}{l}\text { Moderately } \\
\text { Congested }\end{array}$ & $3-3$ & -4.3 & +3.3 & +29.8 & 0.001 & -54.1 \\
\hline & Highly Congested & $1-1$ & -2.7 & -3.3 & -4.6 & - & - \\
\hline & $\begin{array}{l}\text { Very Highly } \\
\text { Congested }\end{array}$ & $1-3$ & -2.0 & +4.6 & +16.0 & - & - \\
\hline & Overall & $8-7$ & -3.1 & +10.6 & +55.0 & 0.02 & +8.4 \\
\hline \multirow{4}{*}{ I-205 NB AM } & Least Congested & $1-1$ & -1.0 & -1.9 & -5.1 & - & - \\
\hline & $\begin{array}{l}\text { Moderately } \\
\text { Congested }\end{array}$ & $6-4$ & +1.4 & -0.1 & -5.4 & 0.765 & -13.88 \\
\hline & $\begin{array}{l}\text { Highly } \\
\text { Congested }\end{array}$ & $1-0$ & - & - & - & - & - \\
\hline & Overall & $8-5$ & +0.9 & -3.7 & -18.1 & 0.435 & -23.1 \\
\hline \multirow{5}{*}{ I-205 NB PM } & Least Congested & $1-0$ & - & - & - & - & - \\
\hline & $\begin{array}{l}\text { Moderately } \\
\text { Congested }\end{array}$ & $4-4$ & +2.2 & +4.7 & +29.7 & 0.262 & -52.5 \\
\hline & $\begin{array}{l}\text { Highly } \\
\text { Congested }\end{array}$ & $2-1$ & -5.5 & -6.6 & -9.8 & - & - \\
\hline & $\begin{array}{l}\text { Very Highly } \\
\text { Congested }\end{array}$ & $1-1$ & +7.2 & -14.0 & -37.5 & - & - \\
\hline & Overall & $8-6$ & +1.6 & +0.03 & -7.9 & 0.896 & -36.9 \\
\hline
\end{tabular}

In the pilot study, higher metering rates under SWARM resulted in lower travel times on several major on-ramps, indicating that the increase in freeway delay was traded against lower on-ramp delay.

In the regional study, the northbound afternoon VMT marginally decreased (-3.08\%), while delay increased by 55\% (375 vehicle-hours); this increase was statistically significant $(p=0.02)$. In addition, the standard deviation of the average delay increased $(+8.4 \%)$. This implies that the delay under SWARM was more variable, and freeway performance less reliable.

Although only one day of data showing highly congested conditions could be compared, SWARM operation on the northbound corridor, resulted in $4.6 \%$ less delay than pretimed operation. In addition, on moderately congested days in this corridor, the standard deviation of the average delay was $54.1 \%$ less (despite an increase in overall delay).

For the northbound corridor, the physical bottleneck at the 72nd/I-5/Kruse Way merge appeared to play an important role in the significant increase in congestion. Whether the increase in the total freeway delay was solely caused by the higher merging rates remains an open question since the bottleneck discharge rates could not be measured from the data. 


\subsubsection{I-205}

For the I-205 northbound corridor, SWARM operation appeared to result in decreased mainline delay, decreased variability in the delay, and possible decrease in on-ramp delays.

In the morning peak, the average VMT increased by $0.87 \%$, indicating that the amount of travel remained fairly constant between the SWARM and pre-timed periods. At the same time, mainline delay decrease corresponded to an $18.1 \%$ decrease in mainline delay under SWARM. This decrease, however, was not statistically significant ( $p=$ 0.435). This decrease includes one very congested (unusual) day during the pre-timed period; when removing this day the change between pre-timed and SWARM was approximately $5 \%$ and is probably more indicative of the SWARM improvement.

In the afternoon peak, the VMT increased by about $1.6 \%$ while average mainline delay under SWARM decreased by $7.9 \%$. This decrease was not statistically significant ( $p=$ 0.896 ). The standard deviation of the average delay was $23.1 \%$ less for the morning peak under SWARM and 36.9\% less for the afternoon peak under the SWARM operation than under the pre-timed operation. This implies that the delay under SWARM was less variable and freeway performance more reliable.

\subsubsection{Comparison of Results}

The empirical evidence suggests that SWARM operation resulted in higher metering rates at most of the on-ramps on both OR-217 and I-205. On I-205, unlike on OR-217, these higher metering rates appear to have been offset by SWARM's earlier activation time on the highly congested and very highly congested days. The higher metering rates did appear to contribute to localized congestion at some stations during some periods. In addition, there is empirical evidence that SWARM's ability to respond dynamically to conditions resulted in improved mainline performance. The primary reason for better performance in the morning peak on I-205 was associated with longer duration of metering times at the busiest ramps. There are other examples where the empirical data reveal SWARM responding to localized congestion.

However, because of the data communication failures and the lack of ramp demand data, a complete black and white conclusion is not yet possible. If an assumption is made that ramp demand changes correspond to VMT changes, it is likely that ramp delay decreased under SWARM operation (i.e. more vehicles were allowed on the freeway which would equate to lower delay for vehicles on the ramps). This was verified in the pilot study but not in the regional studies.

The contrasting results for SWARM performance between the two freeway corridors can partially be explained by the general differences between the two facilities. OR-217 is a relatively short freeway ( 7 miles) bounded on both ends by freeway-to-freeway (system) interchanges. The ramp spacing is generally short ( 0.75 mile average) and the freeway contains numerous auxiliary lane drops and adds. In the afternoon, the unmetered merge with Kruse Way and I-5 NB traffic results in recurrent congestion. 
The I-205 study corridor is unbounded, has greater ramp spacing (1.07 mile average), and maintains three through lanes. Only one auxiliary lane add/drop is present. Peak flows per mainline lane are generally higher on OR-217 than I-205. For the 99W WB, Greenburg, and Scholls-Ferry detector stations the average flow per lane in the afternoon analysis period was $1,470,1,660$, and $1,720 \mathrm{vph}$, respectively. For the Sunnyside, Johnson Creek, and Foster stations the average flow per lane was 1,320, 1,370 , and 1,440 , respectively. The higher per lane flows combined with less desirable geometry on OR-217 may explain why higher metering rates on OR-217 produced significant increases in mainline delay.

The higher metering rates observed under SWARM are partially explained by the system configuration. When ODOT implemented SWARM in 2005 and 2006, it anticipated that SWARM would admit fewer vehicles to the freeway, consistent with evaluations of SWARM in Southern California (Caltrans 2005, Pham et al. 2002). In setting up the SWARM system, ODOT conservatively used the highest metering rate under the pre-timed system to set SWARM's upper threshold, in order to gain confidence in the system and to prevent vehicles from backing up onto city arterials. There was also evidence of communication and data challenges (discussed in the following section) that may have hampered SWARM's desired operation.

Unfortunately, the SWARM system as implemented by ODOT, does not currently log meter start times, metering rates, or desired metering rates, so comparison of SWARM's desired operation and actual operation cannot be performed at this time.

\subsubsection{Recommendations}

One of the intentions of this project was to encourage ongoing evaluation and continuous improvement of the ramp metering system, and in general the overall freeway management system. Therefore, in close consultation with the Technical Advisory Committee, the results of this study led to the following recommendations:

- Explore more conservative maximum metering rates for SWARM and other settings to optimize implementation. The results of this study indicate that, contrary to initial expectations, SWARM let more vehicles onto the freeway than the pre-timed system. The SWARM parameters that distribute the volume reduction (or excess if local density is smaller than the required density) to upstream on-ramps based on demand, queue storage, etc. of each on-ramp should also be revaluated.

- Given that there appears to be a significant benefit to SWARM's earlier activations on a highly congested days, ODOT should consider removing mid-day constraints on meter operation.

- The current system logs neither meter activations nor rates. Incorporating additional logging capabilities into the SWARM system would make it easier to evaluate system operations on an on-going automated basis. In addition, ODOT should incorporate vehicle counts from the ramp queue loop detectors in the ATMS. These metering rates could be compared with vehicle flows at on-ramps to verify that the rates are properly received by the on-ramp controller. For an on-going evaluation of the ramp meter system, 
these data are critical. To aid ODOT staff in continuous monitoring of the ramp meter performance a "Using Portal Data to Monitor The Ramp Metering System" is included in Appendix A-2.

- In general, installation of additional detectors (especially in locations of recurrent congestion) would assist in evaluation efforts, have potential benefits for the SWARM system, and complement other ODOT initiatives, such as travel time calculation.

Recommendations about placement of these loops are outside the scope of this evaluation and should be the focus of future research.

\subsection{COMMUNICATION SYSTEM}

\subsubsection{Conclusions}

The performance of any adaptive ramp metering system is dependent on the underlying communications infrastructure. While adequate for the pre-timed system, it appears that the communication infrastructure as configured during this evaluation has presented challenges for system operations that were not anticipated prior to SWARM implementation or this evaluation. Data quality issues impacted the research team's ability to study SWARM operation; even with an increase in the study length from one week each for pre-timed and SWARM operation in the pilot study to two weeks each in the regional study. Communication failures reduced the sample size of SWARM days suitable for study and limited the team's ability to compare similar days.

Communications failures are also indicative of problems for the SWARM system's ability to control freeway and ramp operations. SWARM polls data from ramps and issues commands to ramp controllers every 20 seconds. The data intensive nature of the adaptive system contributed to an increase in communications failures, which inhibited the system's ability to receive data about freeway and ramp operations. This could have impacted SWARM's ability to compute an appropriate metering rate (local and global) and to send new commands to the controllers.

Concurrent with this study, ODOT discovered an issue where SWARM commands are queued and not received by the ramp controllers in a timely manner. The system is not able to complete sending of the commands to all controllers within a 20 second period. This issue affects SWARM's ability to adjust metering operations in response to freeway conditions. The uncovering of this issue was an unintended but valuable outcome of this research.

\subsubsection{Recommendations}

The work done in this study and the results produced lead to the following recommendations:

- Implementation of SWARM revealed that problems with ATMS infrastructure which contributed to communication failures and hampered SWARM's ability to fully function. Maintenance of detectors, communications, and other infrastructure should be prioritized. 
- ODOT should continue to work toward resolving issues with queuing of SWARM commands. This issue affects SWARM's ability to adjust metering operations in response to freeway conditions. If ODOT is able to resolve issues with queuing of SWARM commands and communications infrastructure, it would potentially allow SWARM's full benefits to be realized.

- The corridor studies allowed us to identify specific stations which ODOT could target for further analysis and possible improvement of the communications infrastructure. It is the understanding of the research team that controllers are connected in groups or "drops". It is possible that stations exhibiting high rates of post SWARM communication failures need to be separated on a different communication drop. There are likely some other physical improvements that could be made.

- I-205 NB at Glisan and Clackamas Highway exhibited significant failures for sustained periods while the Powell and Sunnybrook stations were characterized by intermittent failures. The communications at these ramps should be investigated. 


\subsection{REFERENCES}

R. L. Bertini, M. W. Rose, A. M. El-Geneidy, A. Eder, M. Leal, S. Malik, S. Tantiyanugulchai, and T. Yin (2004), "Using Archived Data to Measure Operational Benefits of ITS Investments: Ramp Meters,” Final Report prepared for the Oregon Department of Transportation.

K. Bogenberger, H. Keller, and S. Ritchie (2001), “Adaptive Fuzzy Systems for Traffic Responsive and Coordinated Ramp Metering”, Research Report UCI-ITS-WP-01-8, Institute of Transportation Studies, University of California, Irvine.

K. Bogenberger and A. May (1999), "Advanced Coordinated Traffic Responsive Ramp Metering Strategies”, California PATH Working Paper UCB-ITS-PWP-99-19.

California Department of Transportation (CalTrans), District 7 (2005), "Ramp Meter Development Plan".

Cambridge Systematics (2001), Mn/DOT Ramp Metering Study Final Report.

M. Cassidy and J. Rudjanakanoknad (2006), "Increasing Capacity of an Isolated Merge by Metering its On-ramp. Transportation Research B, 39(10), pp. 896-913.

M. J. Cassidy (2003), "Freeway On-ramp metering, delay savings, and diverge Bottleneck", Transportation Research Record 1856, TRB, Washington D.C., pp. 1-5.

M. J. Cassidy and J.R. Windover (1995), "Methodology for assessing dynamics of freeway traffic flow". Transportation Research Record 1484, 73-79.

Diakaki, C., Papageorgiou, M., and McLean, T. (2000), "Integrated traffic-responsive urban corridor control strategy in Glasgow, Scotland - application and evaluation", Transportation Research Record 1856, TRB, Washington D.C., pp. 101-111.

Haj-Salem, H., and Papageorgiou, M. (1995), "Ramp metering impact on urban corridor traffic: field results", Transportation Research, Vol. 29A, pp. 303-319.

Haj-Salem, H., Poirier, P., Heylliard, J., and Peynaud, J. (2001), “ALINEA: a local traffic responsive strategy for ramp metering: field results on A6 Motorway in Paris", IEEE Intelligent Transportation Systems Conference Proceedings - Oakland (CA).

R. Horowitz, A. May, A. Skabardonis, P. Varaiya, M. Zhang, G. Gomes, L. Muñoz, X. Sun, and D. Sun (2005), "Design, Field Implementation and Evaluation of Adaptive Ramp Metering Algorithms", UCB-ITS-PRR-2005-2, California PATH Research Report, University of California, Berkeley. 
J. Hourdakis and P.G. Michalopoulos (2002), "Evaluation of Ramp Control Effectiveness in Two Twin Cities Freeways. Transportation Research Board 81st Annual Meeting, Washington, D.C.

L. Jacobsen, K. Henry, and O. Mahyar (1989), "Real-Time Metering Algorithm for Centralized Control”, Transportation Research Record 1232.

A. Kotsialos, M. Papageorgiou, and F. Middelham (2005), "Local and Optimal Coordinated Ramp Metering for Freeway Networks", Journal of Intelligent Transportation Systems, 9(4), pp. 187-203.

A. Kotsialos and M. Papageorgiou (2004), "Efficiency and Equity Properties of Freeway Network-wide Ramp Metering with AMOC", Transportation Research C, 12, pp. 401-420.

E. Kwon, S. Nanduri, R. Lau, and J. Aswegan (2001), "Comparative Analysis of Operational Algorithms for Coordinated Ramp Metering”. Transportation Research Board Annual Meeting, Washington, D.C.

D. Levinson and L. Zhang (2006), "Ramp Meters on Trial: Evidence from the Twin Cities Metering Holiday". Transportation Research A, 40(10), pp. 810-828

D. Levinson, L. Zhang, S. Das, and A. Sheikh (2002), "Ramp Meters on Trial: Evidence from the Twin Cities Ramp Meters Shut-off”. Transportation Research Board 81 st Annual Meeting, Washington, D.C.

L. Lipp, L. Corcoran, and G. Hickman (1991), "Benefits of Central Computer Control for the Denver Ramp Metering System”, Transportation Research Record 1320

F.L. Mannering, and W. Kilareski. Principles of Highway Engineering and Traffic Analysis, 3rd ed., Wiley. 2004

C.A. MacCarley, S.P. Mattingly, M.G. McNally, D. Mezger, and J.E. Moore II (2002), "Field Operational Test of Integrated Freeway Ramp Metering/Arterial Adaptive Signal Control Lessons Learned in Irvine, California", Transportation Research Record 1811,

J.C. Munoz. and C.F. Daganzo (2002), "Fingerprinting traffic from static freeway sensors". Cooperative Transportation Dynamics 1, 1-11.

G. Paesani, J. Kerr, P. Perovich, and E. Khosravi (1997), "System Wide Adaptive Ramp Metering In Southern California”, ITS America 7th Annual Meeting, June 1997,

M. Papageorgiou and A. Kotsialos (2002), "Freeway Ramp Metering: An Overview", IEEE Transactions on Intelligent Transportation Systems, Vol. 3(4)

H. Pham, et al. (2002), "SWARM Study Final Report on W/B Foothill Freeway (W/B LA-210)", Research Report to California Department of Transportation, 
J. Rudjanakanoknad (2005), "Increasing Freeway Merge Capacity Through On-Ramp Metering”, Ph.D. Thesis, University of California, Berkeley.

J. Rudjanakanoknad and M. Cassidy (2006), "Traffic Responsive Ramp Metering to Increase Merge Bottleneck Capacity", 85th Annual Meeting of Transportation Research Board, Washington, D.C.

J. Scariza (2003) Evaluation of Coordinated and Local Ramp Metering Algorithms using Microscopic Traffic Simulation. M.S. Thesis. Massachusetts Institute of Technology,

Y. Stephanedes (1994), "Implementation of on-line Zone Control Strategies for optimal Ramp Metering in the Minneapolis Ring Road", 7th International Conference on Road Traffic Monitoring and Control.

C. Taylor and D. Meldrum (1998), "Fuzzy Ramp Metering - Design Overview and Simulation Results", Transportation Research Record 1634.

L. Zhang and D. Levinson (2004), "Optimal Freeway Ramp Control Without Origin-Destination Information”, Transportation Research B 38(10), pp 869-887.

M. Zhang, T. Kim, X. Nie, W. Jin, L. Chu, and W. Recker (2001), "Evaluation of On-ramp Control Algorithms", California PATH Research Report UCB-ITS-PRR-2001-36. 



\section{APPENDIX A: \\ SELECTED TIME-SPACE SPEED CONTOUR}



Programmable logic controllers (PLCs) were installed at several key ramps with the assistance of the City of Portland and used to capture additional data about ramp operations that are not otherwise logged. The data include the activation and deactivation of metering (Figures A-1.1 through A-1.6). Blue lines represent the duration of metering activation at three ramps: Sunnyside, Johnson Creek, and Powell (from bottom). The purple dots represent the fixed metering on/off times under the pre-timed system.

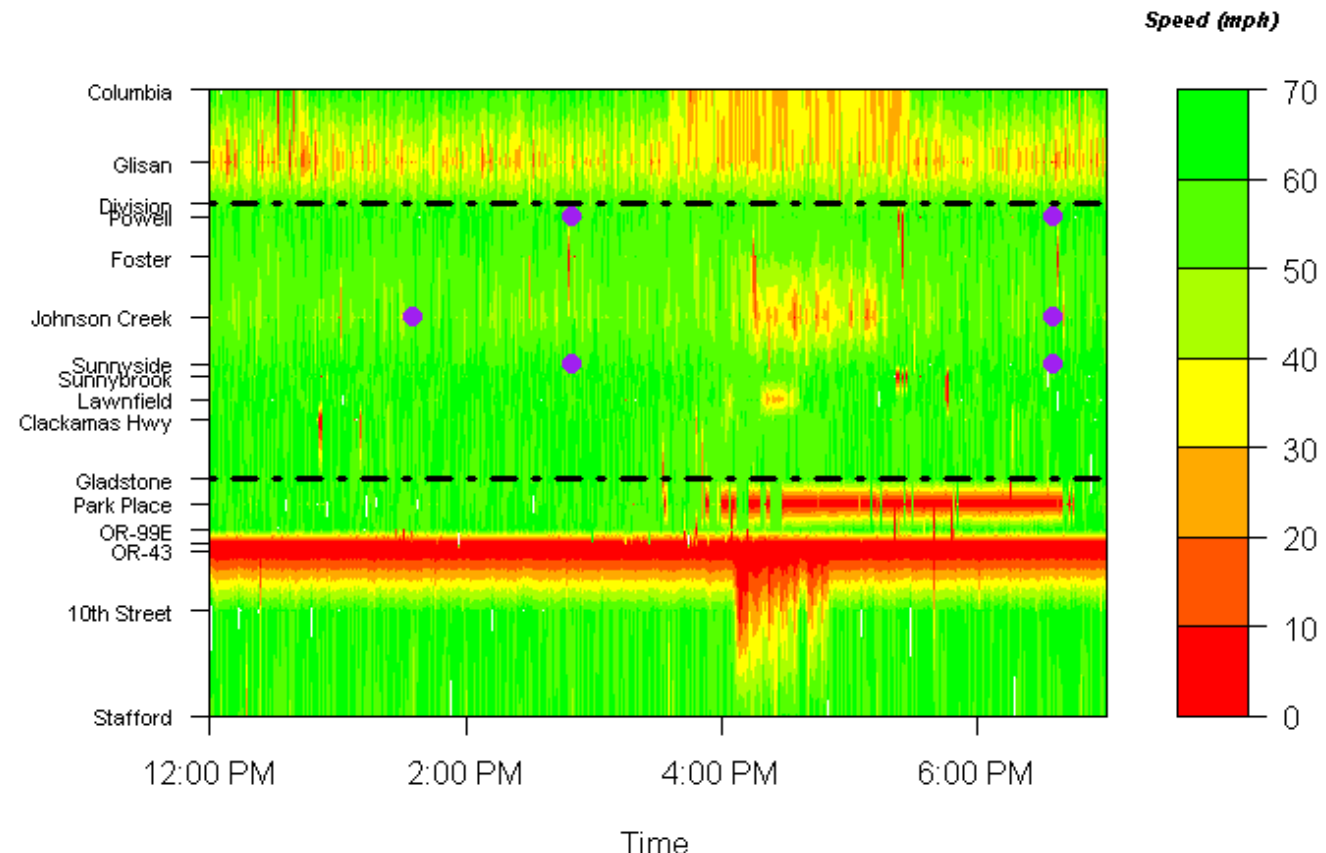

Figure A-1.1: Reported mainline speeds in the time-space plane, October 1, 2007, I-205 NB (pre-timed)

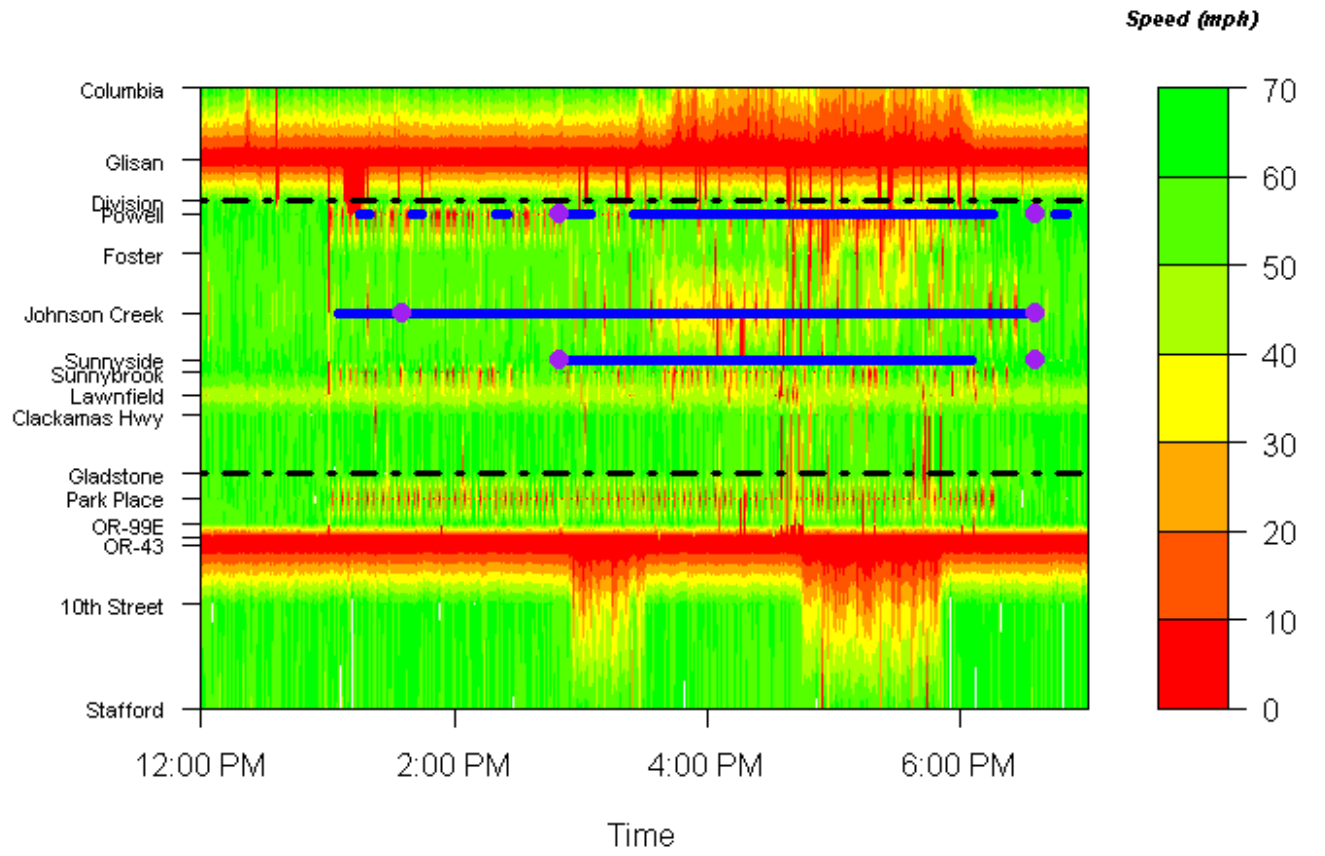

Figure A-1.2: Reported mainline speeds in the time-space plane, September 17, 2007, I-205 NB (SWARM) 
Speed (mph)

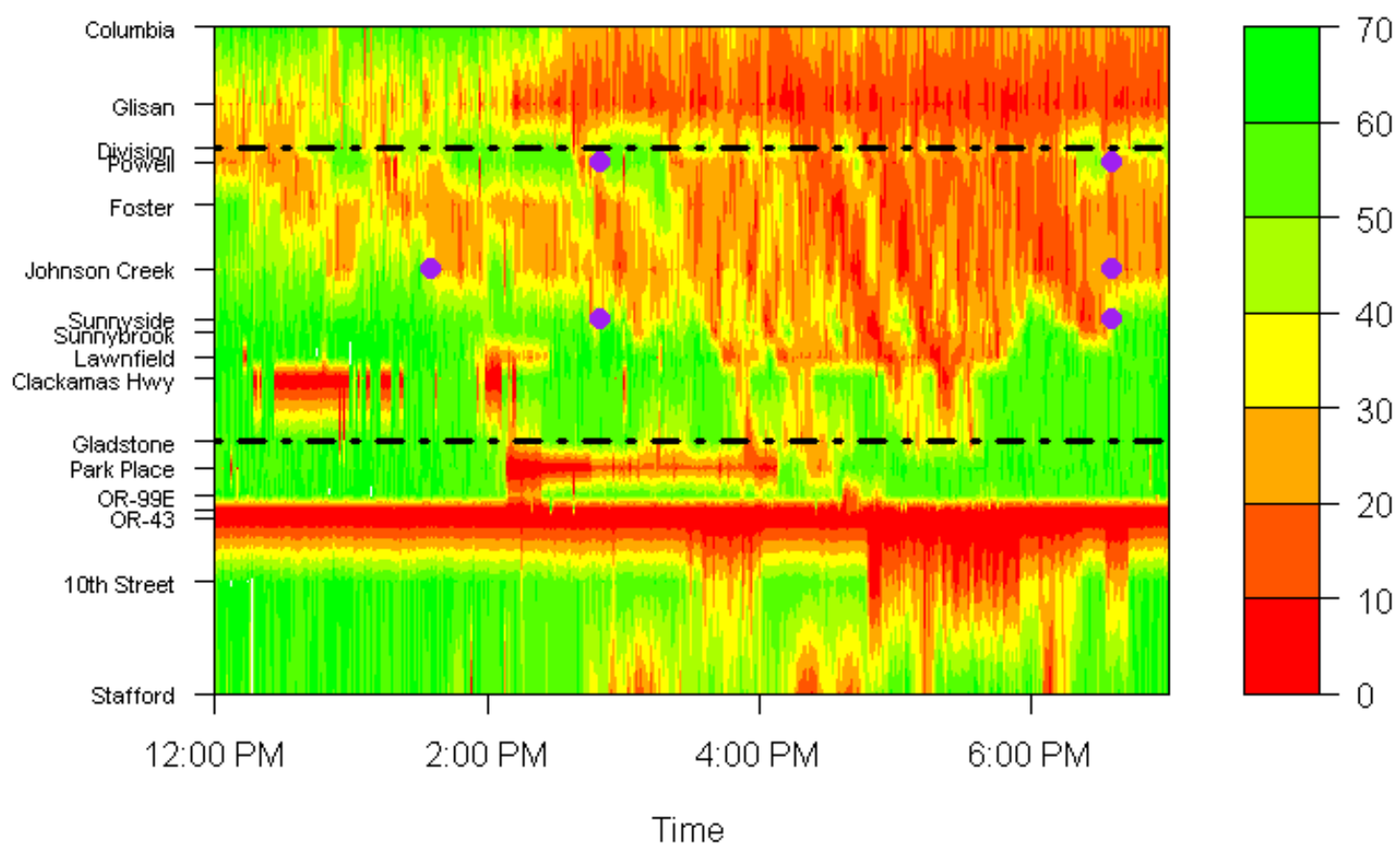

Figure A-1.3: Reported mainline speeds in the time-space plane, September 28, 2007, I-205 NB (pre-timed)

Speed (mph)

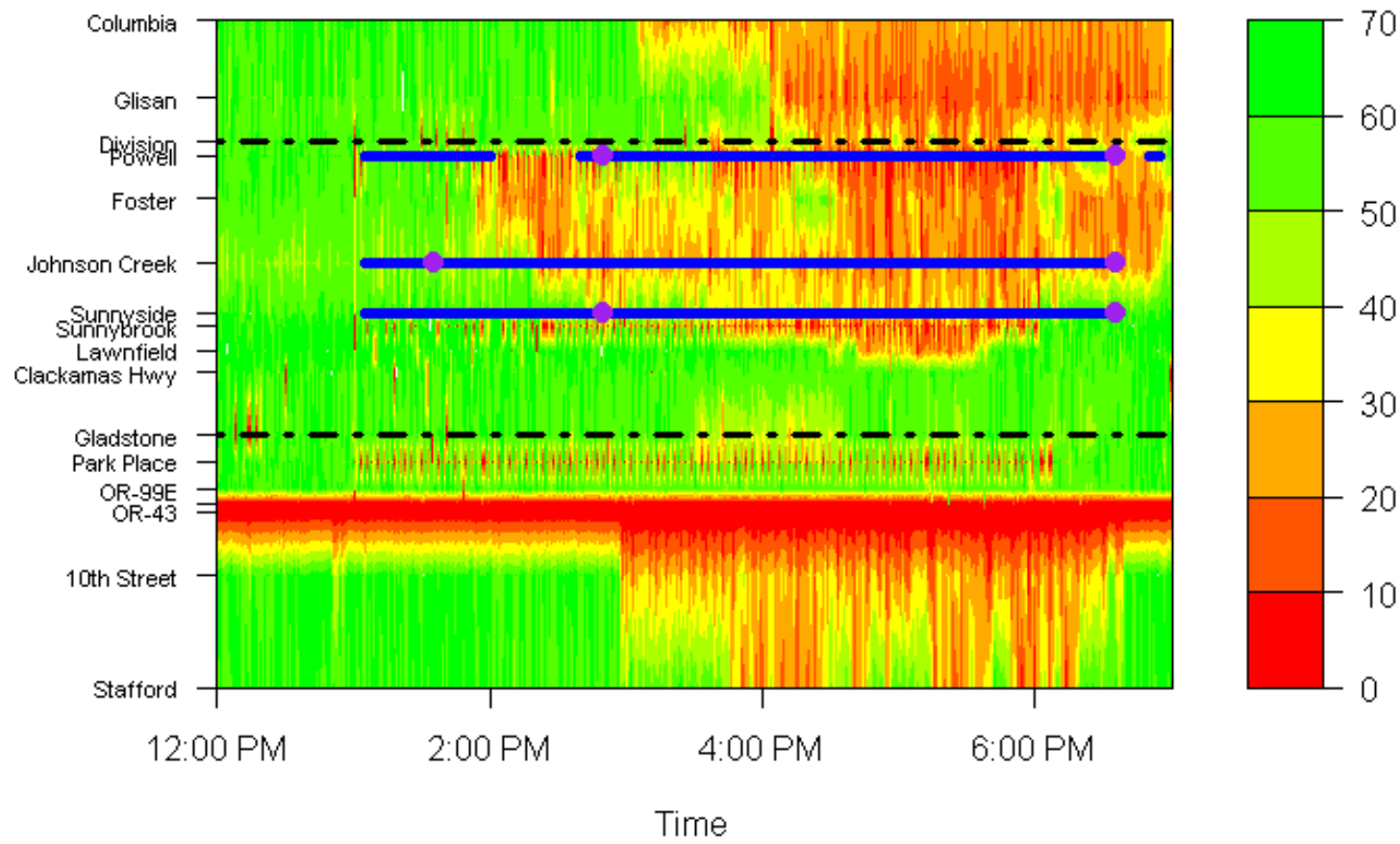

Figure A-1.4: Reported mainline speeds in the time-space plane, September 21, 2007, I-205 NB (SWARM) 
Speed (mph)

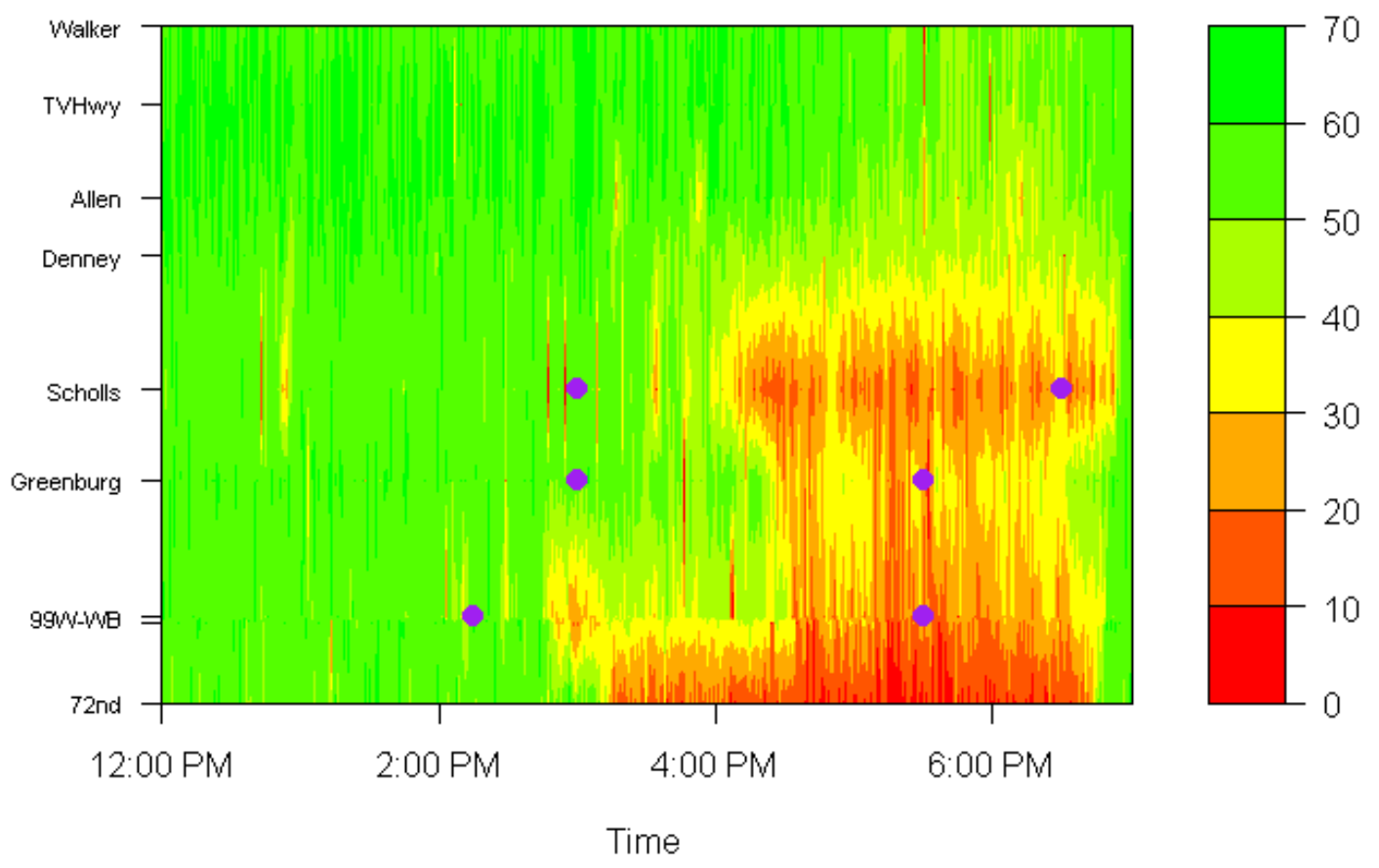

Figure A-1.5: Reported mainline speeds in the time-space plane, November 15, 2007, OR-217 NB (pre-timed)

Speed $(m p h)$

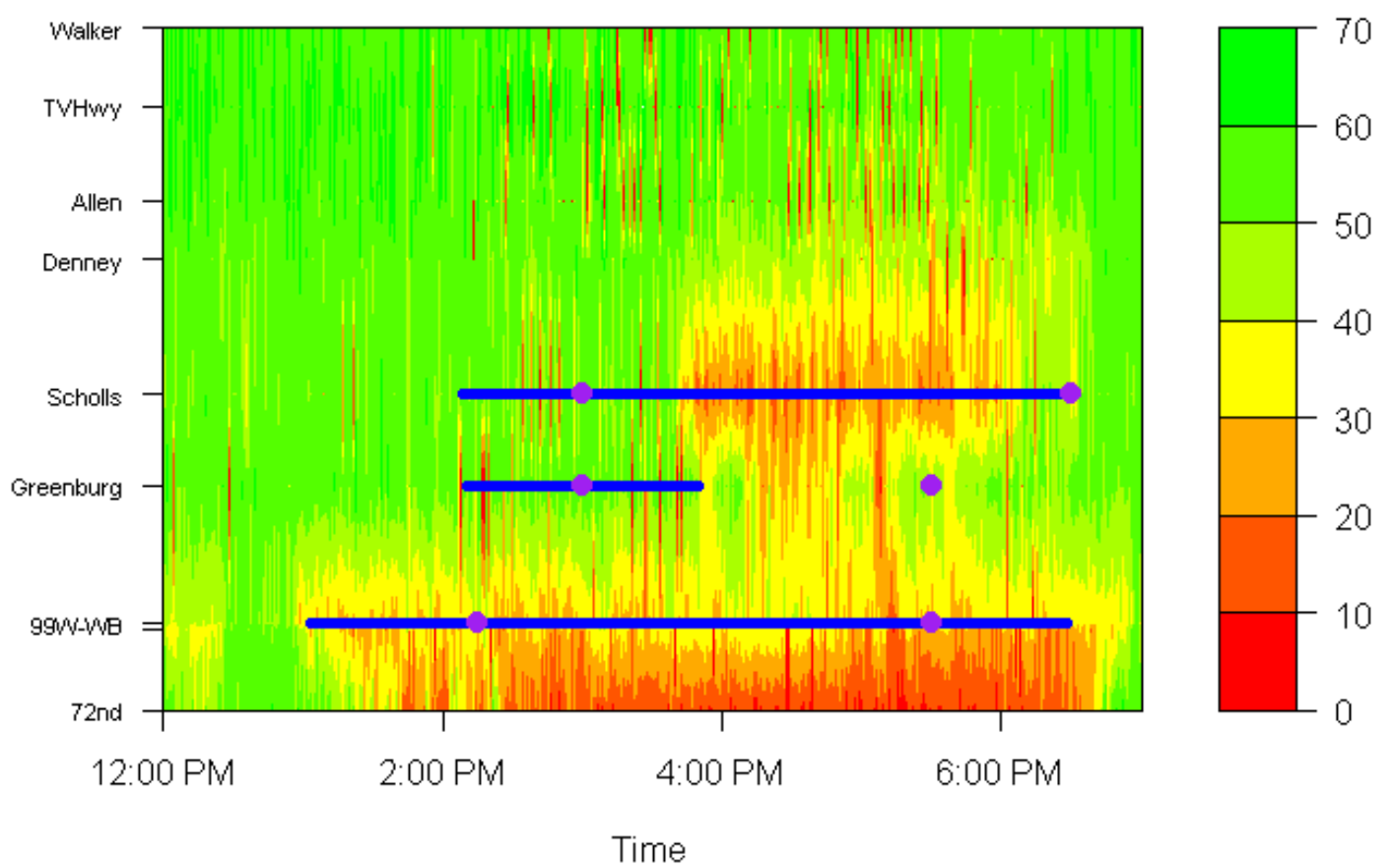

Figure A-1.6: Reported mainline speeds in the time-space plane, December 7, 2007, OR-217 NB (SWARM) 



\section{APPENDIX B: \\ USING PORTAL DATA TO MONITOR THE RAMP METERING SYSTEM}





\section{APPENDIX B: TABLE OF CONTENTS}

B-1 MONITORING RAMP METER COMMUNICATIONS …...................................... B-1

B-1.1 PORTAL: DATA FIDELITY FEATURE ........................................................ B-1

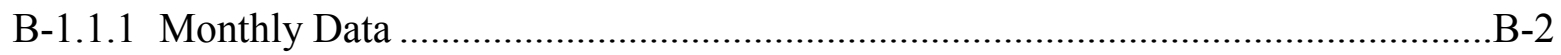

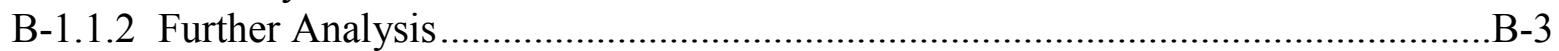

B-2 CONDUCTING A BEFORE AND AFTER STUDY ............................................ B-5

B-2.1 BASIC PORTAL TOOLS …………………........................................... B

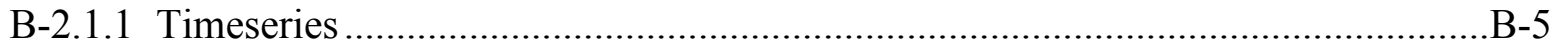

B-2.2 ELIMINATING DATA DUE TO COMMUNICATIONS FAILURES,

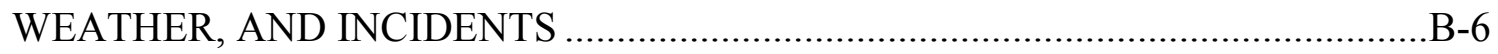

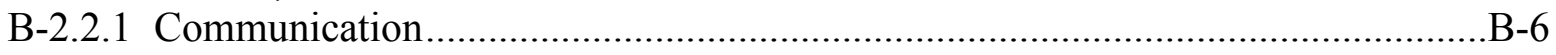

B-2.2.2 Incidents .............................................................................................

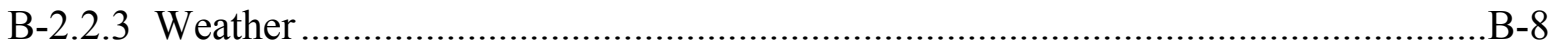

B-2.3 DETERMINING COMPARABLE DAYS .................................................. B-10

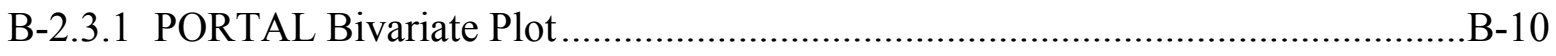

B-2.3.2 Classifying Freeway Conditions …………..................................................

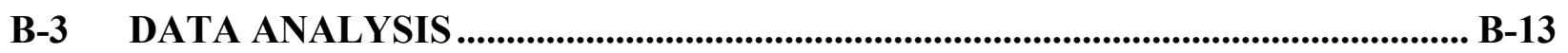

B-3.1 SPACE TIME PLOTS …………………………………………………. B-13

B-3.2 MAINLINE SPEED, RAMP VOLUME, AND MAINLINE FLOW ...................... B-15

B-3.2.1 Creating Timeseries Line Plots in PORTAL …………………………...........

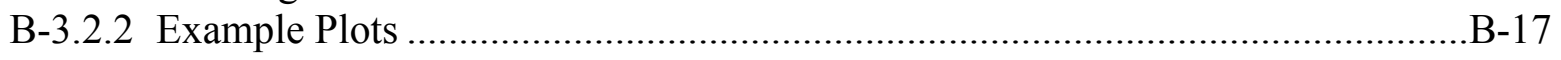

\section{APPENDIX B: LIST OF TABLES}

Table B-1.2: I-205 NB, 9/13/2007, selected stations from PORTAL daily data fidelity report, sorted by milepost and lane number.

Table B-2.1: Selected incidents from PORTAL Timeseries feature, I-205 NB, September $13,2007$.

Table B-3.1: Specifying quantity and lane for plot type.

\section{APPENDIX B: LIST OF FIGURES}

Figure B-1.1: PORTAL Data Fidelity feature, I-205 NB, 9/13/2007. B-1

Figure B-1.2: Percent good data, aggregated by time of day, for September 2007, Glisan

St. Station, I-205 NB.

Figure B-1.3: Percent good data, aggregated by time of day, for September 13, 2007,

Powell St. Station, I-205 NB. B-4

Figure B-2.1: PORTAL Timeseries function, I-205 NB, 9/13/2007 ……………….................

Figure B-2.2: Time-space plot with incidents shown, for I-5 NB, 5/17/2007 …….....................

Figure B-2.3: Example of PORTAL hourly weather chart, I-205 NB, 10/3/2007 ………............-9

Figure B-2.4: Daily Weather plot, October 2007 .................................................................. 
Figure B-2.5: Flow-Occupancy Fundamental Diagram, I-205 NB, Johnson Creek, October 2, 2007, 6-10 am

Figure B-2.6: Flow-Occupancy Fundamental Diagram, I-205 NB, Johnson Creek, October 5, 2007, 6-10 am

Figure B-2.7: Flow-Occupancy Fundamental Diagram, I-205 NB, Johnson Creek, October 4, 2007, 6-10 am

Figure B-2.8: Speed-Flow fundamental diagrams, I-205 NB, Johnson Creek, 6-10 am, for October 2, 5, and 4, 2007

Figure B-3.1: Speed Space-Time Plot, I-205 NB, October 5, 2007, between Gladstone (MP 11.05) and Division (MP 19.78)

Figure B-3.2: Delay Space-Time Plot, I-205 NB, October 5, 2007, between Gladstone (MP 11.05) and Division (MP 19.78)

Figure B-3.3: PORTAL Timeseries feature, used to create line plots for individual stations

Figure B-3.4: Plots of (a) flow for all lanes, (b) mainline speed, (c) 5-minute on-ramp volume, (d) hourly on-ramp volume, and (e) 20-second on-ramp volume. I-205 NB, Johnson Creek station, October 5, 2007, 6-10 am. 
This appendix outlines the use of the Portland Transportation Archive Listing (PORTAL) for monitoring the ramp metering system. ${ }^{2}$ The appendix assumes a PORTAL login account, which can be requested on the website, and some basic familiarity with PORTAL. The information provided in this appendix is current at the time of publication but PORTAL is a dynamic webbased tools and some options may change.

\section{B-1 MONITORING RAMP METER COMMUNICATIONS}

The quality of data from freeway loop detectors is critical both to the operation of the freeway ramp metering system as well as to conducting a study of system operations.

\section{B-1.1 PORTAL: DATA FIDELITY FEATURE}

PORTAL's data fidelity feature will allow you to download information on the quality of data received from loop detectors on the Portland freeway system. Figure B-1.1 below shows a display of a daily data fidelity report for I-205 NB.

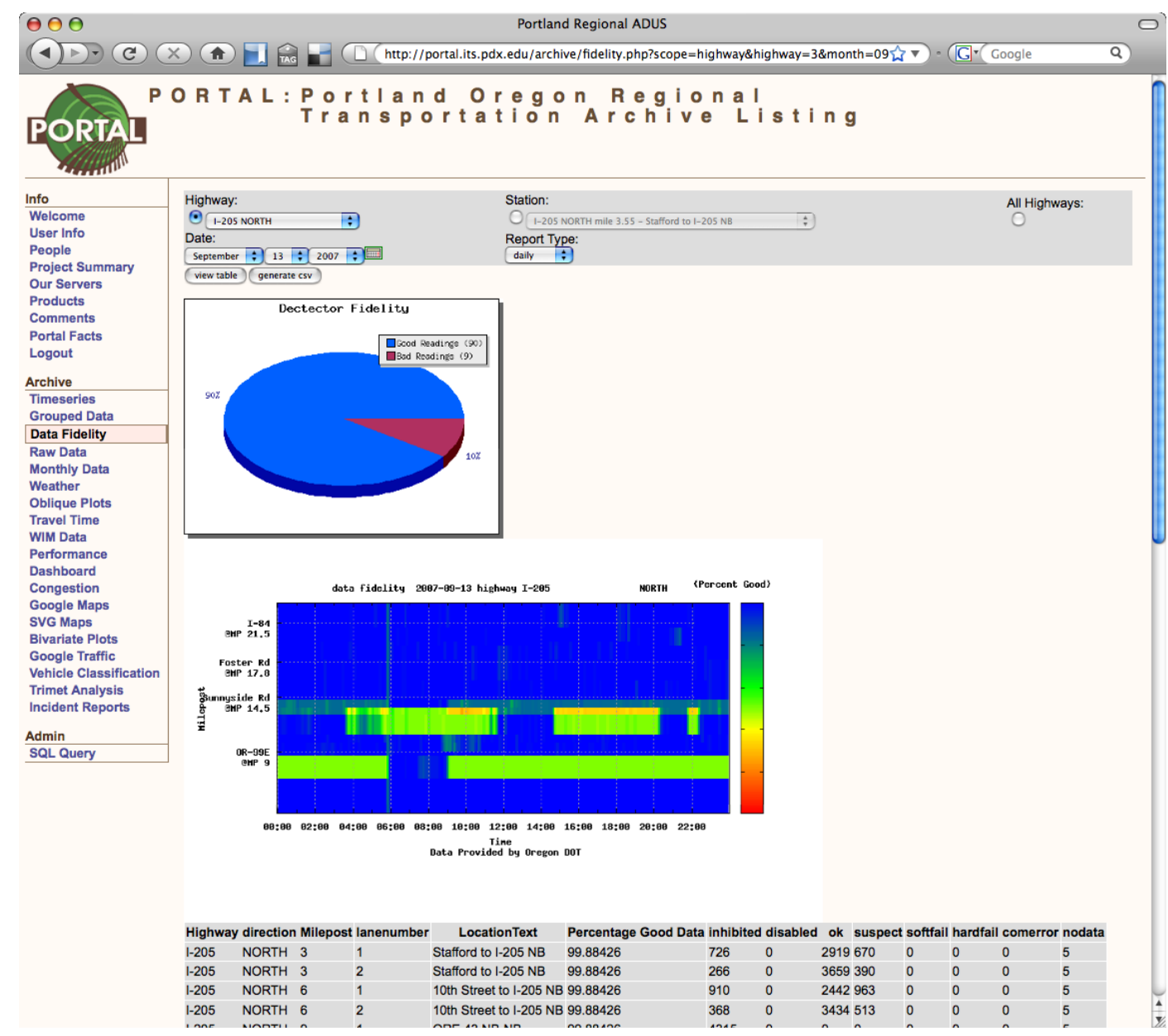

Figure B-1.1: PORTAL Data Fidelity feature, I-205 NB, 9/13/2007

\footnotetext{
${ }^{2}$ http://portal.its.pdx.edu
} 
To use the data fidelity feature:

1. Select a Highway, individual Station, or the All Highways checkbox.

2. Select the Report Type, either Daily or Monthly. A monthly report will be most useful for periodic monitoring of loop detector data fidelity and identifying stations or individual detectors that are potentially problematic. A daily report will be most useful for detailed analysis of the issues uncovered in monthly data.

3. Click View Table to display the data in your web browser or Generate CSV to download a comma-delimited file.

\section{B-1.1.1 Monthly Data}

Monthly fidelity data will allow you to identify chronic detector problems, although more detailed analysis would be necessary to more fully assess loop detector data issues and/or identify intermittent problems.

While the data fidelity page shows summary charts, viewing the resulting data table is most useful. The data table is typically sorted by the percentage of "good" data, as shown in Table B1.1. The table shows all detectors from I-205 NB in September 2007, where less than $90 \%$ of the received 20 -second data packets were determined to be "good."

Table B-1.1: I-205 NB, detectors with less than 90\% "good" data from PORTAL monthly data fidelity report, sorted by percentage of "good" readings

\begin{tabular}{|c|c|c|c|c|c|c|c|c|c|c|c|c|}
\hline $\begin{array}{c}\text { Row } \\
\#\end{array}$ & $\begin{array}{l}\text { Mile } \\
\text { post }\end{array}$ & $\begin{array}{c}\text { Lane } \\
\#\end{array}$ & Location text & $\begin{array}{c}\% \\
\text { Good }\end{array}$ & $\begin{array}{c}\text { In- } \\
\text { hibited }\end{array}$ & $\begin{array}{c}\text { Dis- } \\
\text { abled }\end{array}$ & ok & suspect & $\begin{array}{l}\text { Soft } \\
\text { fail }\end{array}$ & $\begin{array}{c}\text { Hard } \\
\text { fail }\end{array}$ & $\begin{array}{l}\text { Com } \\
\text { error }\end{array}$ & $\begin{array}{c}\text { No } \\
\text { data }\end{array}$ \\
\hline 1 & 8.8 & 2 & ORE 43 SB-NB & 7.1 & 25 & 0 & 0 & 9129 & 3520 & 110348 & 6123 & 455 \\
\hline 2 & 8.8 & 1 & ORE 43 SB-NB & 7.1 & 25 & 0 & 0 & 9129 & 3520 & 110348 & 6123 & 455 \\
\hline 3 & 13.58 & 2 & Lawnfield NB & 62.3 & 7442 & 0 & 58351 & 14903 & 3219 & 40442 & 4788 & 455 \\
\hline 4 & 21.12 & 1 & I-205 NB at Glisan & 83.3 & 1679 & 0 & 49299 & 56993 & 0 & 0 & 21174 & 455 \\
\hline 5 & 21.12 & 2 & I-205 NB at Glisan & 83.3 & 911 & 0 & 54353 & 52707 & 0 & 0 & 21174 & 455 \\
\hline 6 & 21.12 & 3 & I-205 NB at Glisan & 83.3 & 4800 & 0 & 76041 & 27130 & 0 & 0 & 21174 & 455 \\
\hline 7 & 12.94 & 1 & Clackamas Hwy NB & 84.7 & 28806 & 0 & 66538 & 14433 & 0 & 0 & 19368 & 455 \\
\hline 8 & 12.94 & 2 & Clackamas Hwy NB & 84.7 & 13228 & 0 & 86052 & 10497 & 0 & 0 & 19368 & 455 \\
\hline 9 & 12.94 & 3 & Clackamas Hwy NB & 84.7 & 14076 & 0 & 84046 & 11655 & 0 & 0 & 19368 & 455 \\
\hline
\end{tabular}

Note that the data fidelity report currently does not display data for the on-ramp loop detector, which would be shown as lane number 0

For Table B-1.1 (above), a "Row \#" column was added to aid in discussing the following points:

- In rows $1 \& 2$, it can be seen that both mainline detectors at milepost 8.8 appear to be in a failure state, with no "OK" readings over the entire month.

- In row 3, the lane 2 mainline detector at Lawnfield $\mathrm{Rd}$. appears to have a communication issue. Note that examination of September 2008 data shows that this detector remains problematic (57\% "good" data packets).

- In rows 4-6 and 7-9, all mainline detectors at Glisan St. and Clackamas Hwy NB, respectively, appear to have compromised data quality. 


\section{B-1.1.2 Further Analysis}

The PORTAL daily data fidelity report could be a next step in confirming the monthly results using data that is aggregated for a specific day within the month. The example shown in Table B shows all the detectors for three of the problem stations identified in the monthly fidelity report shown in Table B-1.2, on the previous page.

Table B-1.2: I-205 NB, 9/13/2007, selected stations from PORTAL daily data fidelity report, sorted by milepost and lane number

\begin{tabular}{c|c|c|c|c|c|c|c|c|c|c|c|c}
\hline $\begin{array}{c}\text { Row } \\
\#\end{array}$ & $\begin{array}{c}\text { Mile } \\
\text { post }\end{array}$ & $\begin{array}{c}\text { Lane } \\
\#\end{array}$ & Location text & $\begin{array}{c}\% \\
\text { Good }\end{array}$ & $\begin{array}{c}\text { In- } \\
\text { hibited }\end{array}$ & $\begin{array}{c}\text { Dis- } \\
\text { abled }\end{array}$ & ok & suspect & $\begin{array}{c}\text { Soft } \\
\text { fail }\end{array}$ & $\begin{array}{c}\text { Hard } \\
\text { fail }\end{array}$ & $\begin{array}{c}\text { Com } \\
\text { error }\end{array}$ & $\begin{array}{c}\text { No } \\
\text { data }\end{array}$ \\
\hline 1 & 12.94 & 1 & Clackamas Hwy NB & 44.4 & 823 & 0 & 891 & 203 & 0 & 0 & 2398 & 5 \\
\hline 2 & 12.94 & 2 & Clackamas Hwy NB & 44.4 & 439 & 0 & 1266 & 212 & 0 & 0 & 2398 & 5 \\
\hline 3 & 12.94 & 3 & Clackamas Hwy NB & 44.4 & 428 & 0 & 1268 & 221 & 0 & 0 & 2398 & 5 \\
\hline 4 & 13.58 & 1 & Lawnfield NB & 98.2 & 1026 & 0 & 2632 & 583 & 0 & 0 & 74 & 5 \\
\hline 5 & 13.58 & 2 & Lawnfield NB & 13.6 & 50 & 0 & 0 & 539 & 240 & 3412 & 74 & 5 \\
\hline 6 & 13.58 & 3 & Lawnfield NB & 98.2 & 370 & 0 & 3388 & 483 & 0 & 0 & 74 & 5 \\
\hline 7 & 21.12 & 1 & I-205 NB at Glisan & 99.6 & 37 & 0 & 1172 & 3093 & 0 & 0 & 13 & 5 \\
\hline 8 & 21.12 & 2 & I-205 NB at Glisan & 99.6 & 19 & 0 & 859 & 3424 & 0 & 0 & 13 & 5 \\
\hline 9 & 21.12 & 3 & I-205 NB at Glisan & 99.6 & 153 & 0 & 2677 & 1472 & 0 & 0 & 13 & 5 \\
\hline
\end{tabular}

For Table B-1.2 (above), a "Row \#" column was added to aid in discussing the following points:

- In rows $1-3$, only about $44 \%$ of 20 -second data packets received from each mainline detector at Clackmas Highway NB were classified as "good."

- In rows 4-6, the lane 2 detector at Lawnfield appears to be problematic, while the lane 1 \& lane 3 detectors appear to be operating satisfactorily.

- On this particular day (9/13/2007), data quality was good (>99\%) at Glisan St. This, however, contrasts with the entire month, which was at about $85 \%$, indicating that the problem may lie with the overall communications infrastructure serving that station, as opposed to its physical detector infrastructure.

Examination of data fidelity, over the course of a day, can allow for a better assessment of the problem. This can be done by running the data fidelity report for a specific station, either monthly or daily. Figure B-1.2 (on the following page) shows an example of a daily plot from Clackamas Hwy NB on September 13, 2007, where significant communications failures occurred in both morning and afternoon periods. 


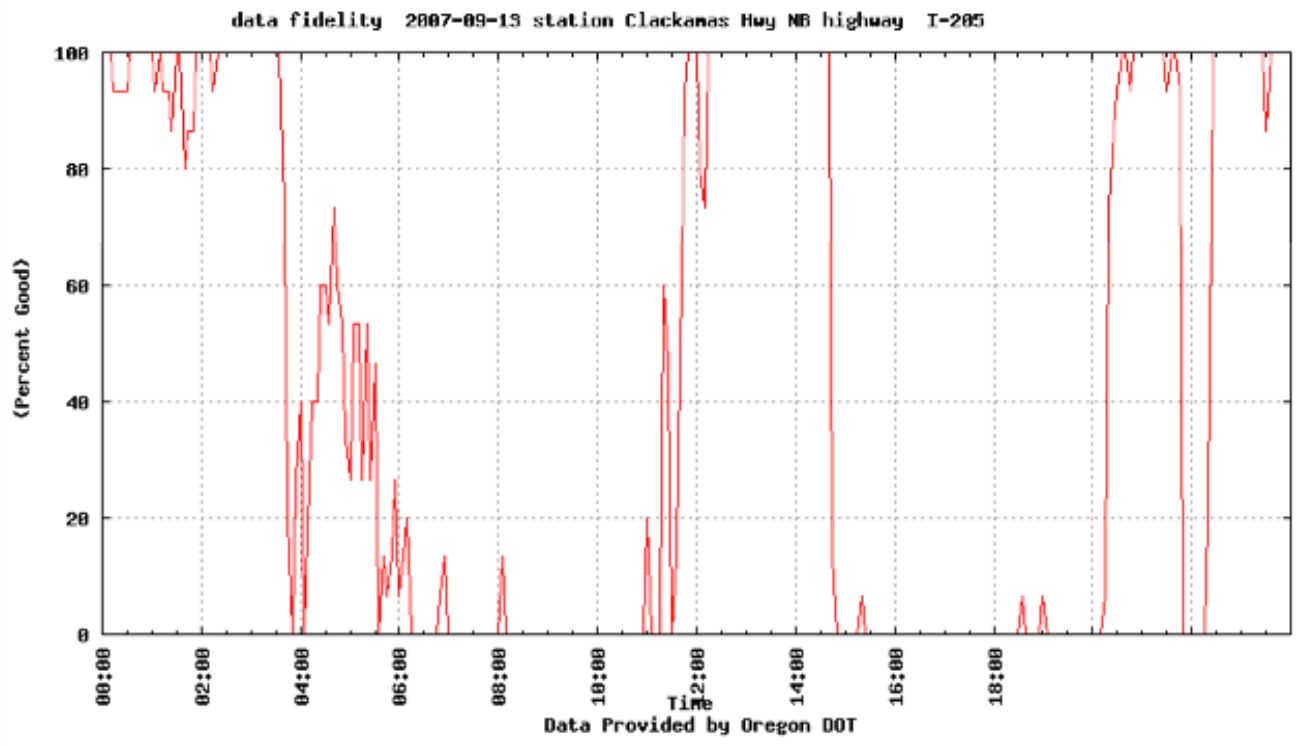

Figure B-1.2: Percent good data, aggregated by time of day, for September 2007, Glisan St. Station, I-205 NB

Significant gaps in data, such as the ones shown in Figure B-1.2 (above), provide justification for excluding a particular day from a study, as it would clearly be impossible to interpolate between data points.

A similar chart from the PORTAL daily data fidelity report, for Powell Blvd. on the same day (September 13, 2007), illustrates intermittent failures throughout a day that are typical for this station (Figure B-1.3). It is generally possible to interpolate between these relatively short gaps in data.

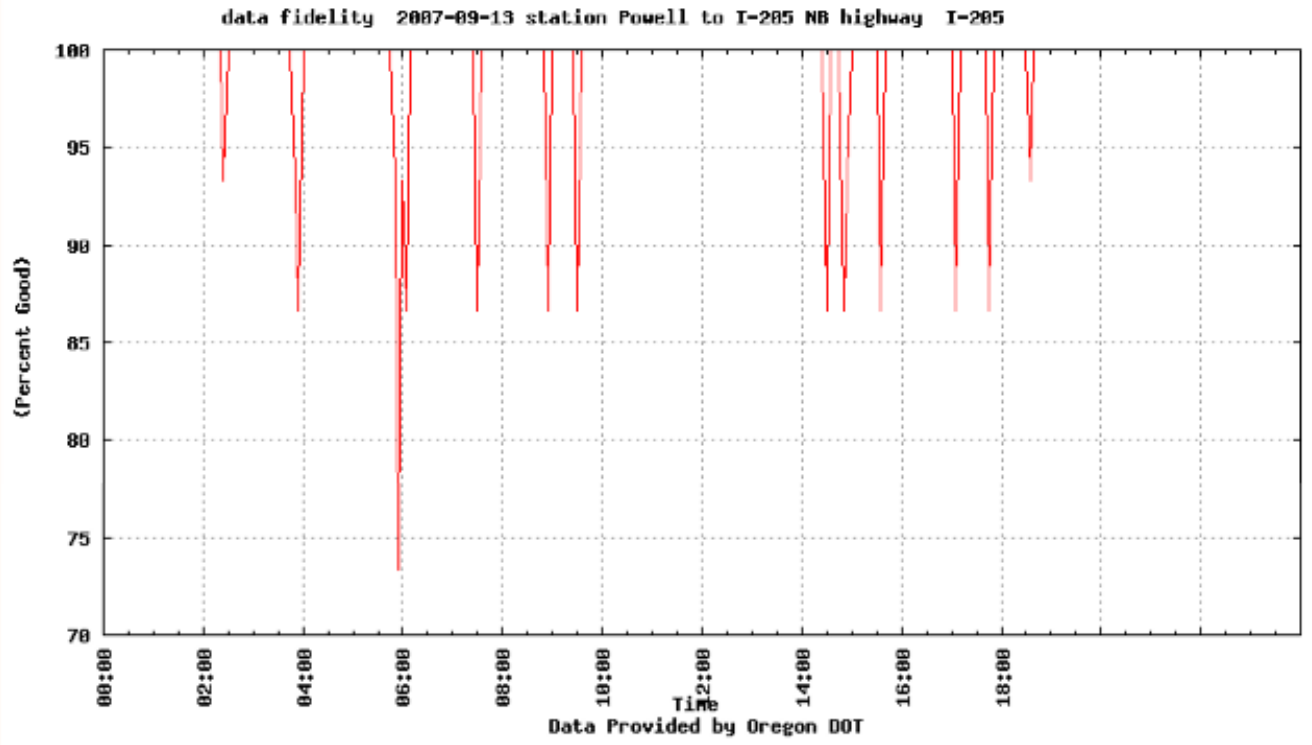

Figure B-1.3: Percent good data, aggregated by time of day, for September 13, 2007, Powell St. Station, I-205 NB 
Finally, it should also be noted that ODOT staff has access to the ATMS system which can provide the most detailed reporting and systemic analysis of data quality issues.

\section{B-2 CONDUCTING A BEFORE AND AFTER STUDY}

\section{B-2.1 BASIC PORTAL TOOLS}

\section{B-2.1.1 Timeseries}

The PORTAL Timeseries feature creates space-time plots of multiple metrics useful in conducting a study of freeway performance, including volume, speed, occupancy, vehicle miles traveled (VMT), vehicle hours traveled (VHT), travel time, and delay. In addition, it provides an interface to tabular data and data on communications failures, weather, and incidents for which a study would need to account (Figure B-2.1).

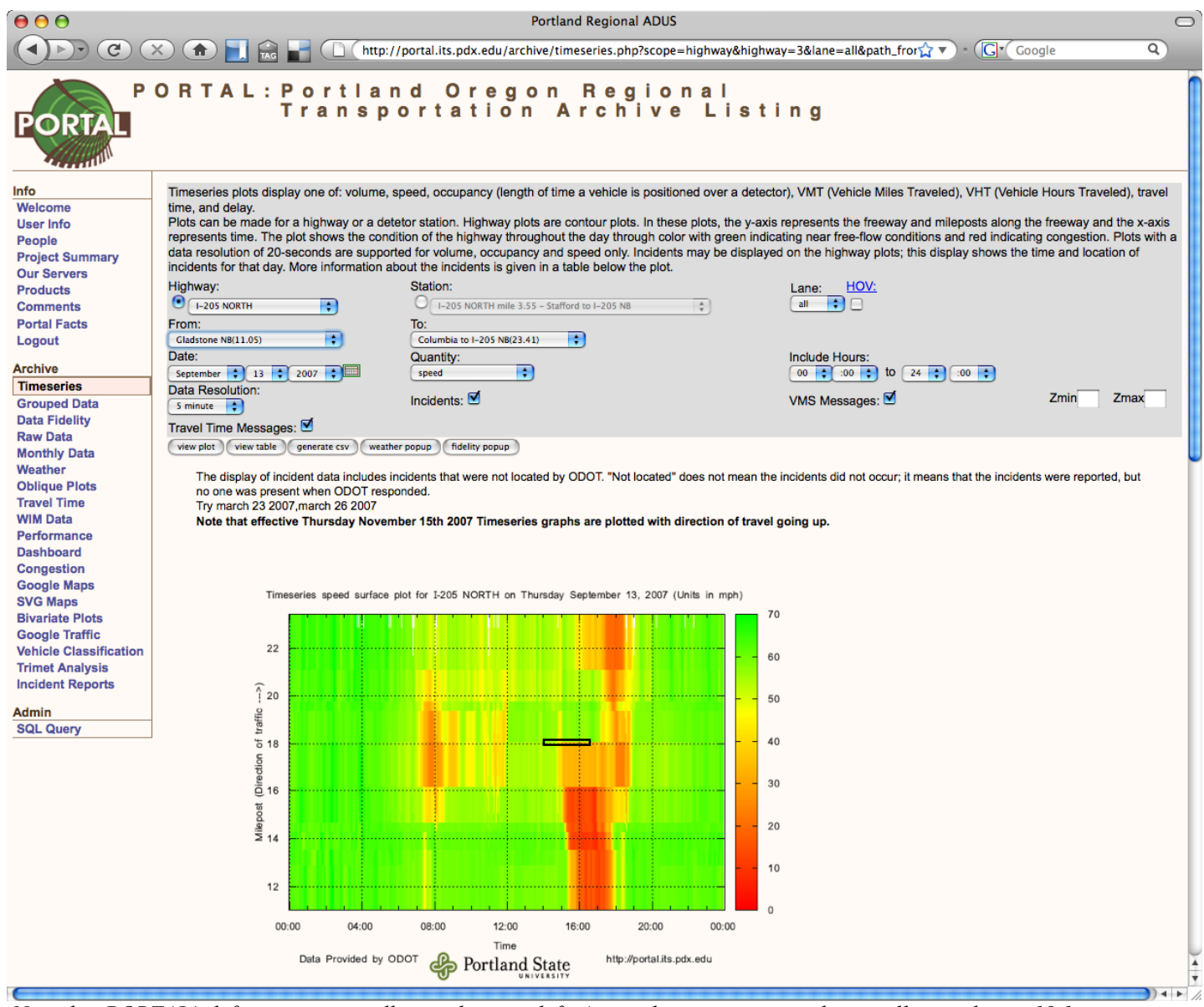

Note that PORTAL's left navigation toolbar is shown at left. An incident was annotated manually at milepost 18.1

Figure B-2.1: PORTAL Timeseries function, I-205 NB, 9/13/2007 
The steps for using the PORTAL Timeseries feature are described as follows:

1. Select a "Highway" or a particular "Station." If you are not working with an entire corridor, you can limit the plot to a range of stations, i.e. 'From' and 'To.'

2. Select the "Lane:" all lanes, a particular lane (the lowest number corresponds to the rightmost lane), or the on-ramp.

3. Select a "Date."

4. Choose a "Quantity." Choices are volume, speed, occupancy, VMT, VHT, travel time and delay.

5. Select a "Data Resolution" of 1 hour, 15 minutes, 5 minutes, or 20 seconds. The data will be aggregated at this interval and your choice will determine the number of records returned.

6. Click the "Incidents" checkbox to see a table of incidents. You can also display variable message sign (VMS) and travel time messages.

7. Click "View Plot" to see a graph, "View Table" to see data displayed in a table, or "Generate CSV" to download a comma-delimited file.

\section{B-2.2 ELIMINATING DATA DUE TO COMMUNICATIONS FAILURES, WEATHER, AND INCIDENTS}

\section{B-2.2.1 Communication}

An earlier section of this appendix (Section B-1) discussed the use of PORTAL to identify data quality issues. In addition to the overall data fidelity report discussed in the earlier section, a Data Fidelity Popup button is available from the Timeseries feature.

\section{B-2.2.2 Incidents}

Incident data logged by ODOT dispatchers is available directly to ODOT staff. It is also loaded into the PORTAL archive and aggregate statistics are available in monthly incident reports. Incident data for a particular corridor or day can be viewed by checking the Incident checkbox when using the PORTAL Timeseries feature as shown in Figure B-2.1 on the previous page. Data shown in this figure was excerpted for Table B-2.1 (on the next page). 
Table B-2.1: Selected incidents from PORTAL Timeseries feature, I-205 NB, September 13, 2007

\begin{tabular}{|c|c|c|c|c|c|c|c|c|c|}
\hline ID & $\begin{array}{c}\text { Primary } \\
\text { Route }\end{array}$ & Location & $\begin{array}{c}\text { Number } \\
\text { of } \\
\text { Lanes } \\
\text { Affected }\end{array}$ & $\begin{array}{l}\text { Start Time } \\
\text { (hh:mm:ss) }\end{array}$ & $\begin{array}{l}\text { Duration } \\
\text { (min) }\end{array}$ & $\begin{array}{l}\text { Incident } \\
\text { Type }\end{array}$ & $\begin{array}{l}\text { Affected } \\
\text { Lanes }\end{array}$ & Hazmat & $\begin{array}{c}\text { Number } \\
\text { of } \\
\text { Fatalities }\end{array}$ \\
\hline 778811 & I-205 (GLENN JACKSON BR) & I-205 (GLENN JACKSON BR) Northbound At MID SPAN & 0 & $13: 54: 19$ & 55 & Stall & Right Shoulder r & rno & 0 \\
\hline 778948 & $1-205$ & I-205 Northbound At $10 \mathrm{TH}$ & 1 & $18: 20: 37$ & 55 & Stall & Left Shoulder & no & 0 \\
\hline 778509 & $1-205$ & I-205 Northbound At AIRPORT WAY & 0 & 04:58:18 & 55 & Stall & None & no & 0 \\
\hline 778648 & $1-205$ & 1-205 Northbound At STAFFORD & 0 & 08:39:08 & 55 & Stall & All Lanes & no & 0 \\
\hline 778748 & $1-205$ & I-205 Northbound GLISAN & 0 & $11: 35: 31$ & 55 & Stall & Right Shoulder & no & 0 \\
\hline 778529 & $1-205$ & 1-205 Northbound MP 5.5 & 0 & $05: 10: 28$ & 55 & Stall & Right Shoulder $\mathrm{r}$ & no & 0 \\
\hline 778811 & I-205 (GLENN JACKSON BR) & 1-205 (GLENN JACKSON BR) Northbound At MID SPAN & 0 & $13: 54: 19$ & 55 & Stall & Right Shoulder & no & 0 \\
\hline 778948 & $1-205$ & I-205 Northbound At $10 \mathrm{TH}$ & 1 & $18: 20: 37$ & 55 & Stall & Left Shoulder & no & 0 \\
\hline 778509 & $1-205$ & I-205 Northbound At AIRPORT WAY & 0 & $04: 58: 18$ & 55 & Stall & None & no & 0 \\
\hline 778648 & $1-205$ & I-205 Northbound At STAFFORD & 0 & 08:39:08 & 55 & Stall & All Lanes & no & 0 \\
\hline 778748 & $1-205$ & I-205 Northbound GLISAN & 0 & $11: 35: 31$ & 55 & Stall & Right Shoulder $\mathrm{r}$ & no & 0 \\
\hline 778529 & $1-205$ & 1-205 Northbound MP 5.5 & 0 & $05: 10: 28$ & 55 & Stall & Right Shoulder r & no & 0 \\
\hline 778508 & $1-205$ & 1-205 Northbound HWY 213 & 0 & $04: 54: 54$ & 55 & Debris & Left Lanes & no & 0 \\
\hline 778593 & $1-205$ & I-205 Northbound GLENN JACKSON BRIDGE & 0 & 07:02:57 & 55 & Debris & All Lanes & no & 0 \\
\hline 778508 & $1-205$ & 1-205 Northbound HWY 213 & 0 & $04: 54: 54$ & 55 & Debris & Left Lanes & no & 0 \\
\hline 778593 & $1-205$ & I-205 Northbound GLENN JACKSON BRIDGE & 0 & 07:02:57 & 55 & Debris & All Lanes & no & 0 \\
\hline 778828 & $1-205$ & 1-205 Northbound At FOSTER & 1 & $14: 15: 43$ & 123 & Crash & Left Lanes & no & 0 \\
\hline 778828 & $1-205$ & 1-205 Northbound At FOSTER & 1 & $14: 15: 43$ & 123 & Crash & Left Lanes & no & 0 \\
\hline
\end{tabular}

An incident at Foster (Milepost 18.1), lasting over two hours and affecting one of the left lanes, is shown in the last line in the table. Congestion resulting from the incident can be seen in the space-time speed plot in Figure B-2.1, which was manually annotated to show the incident's location and duration.

It should be noted that incidents that have been located to a milepost in the incident data will automatically be displayed on a space-time plot. Using a semi-automated process, incidents were more comprehensively located as a proof-of-concept for selected corridors and time periods, such as I-5 for incidents occurring in 2007. An example is shown in Figure B-2.2 on the next page. 
Timeseries speed surface plot for I-5 NORTH on Thursday May 17, 2007 (Units in mph)

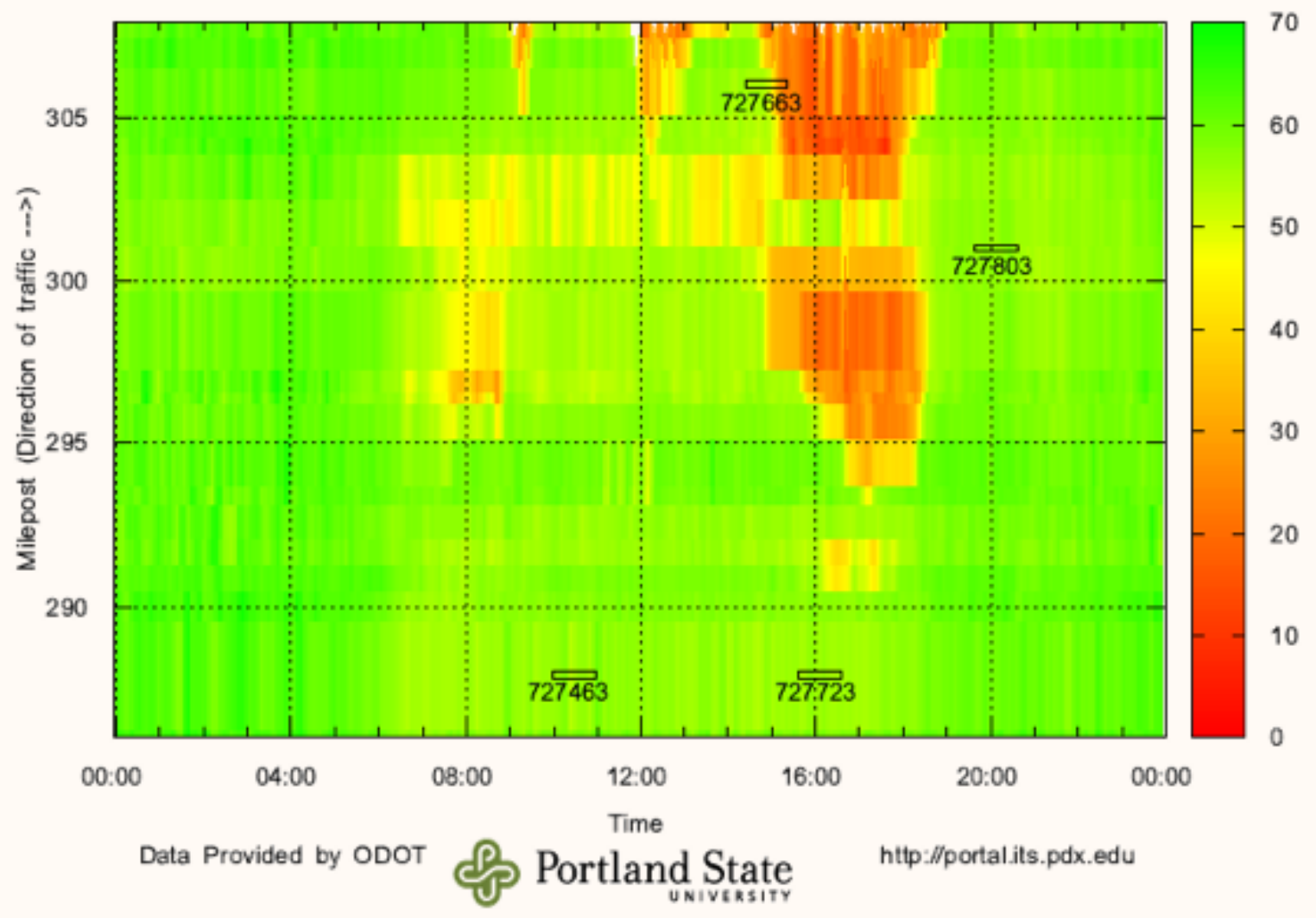

Figure B-2.2: Time-space plot with incidents shown, for I-5 NB, 5/17/2007

\section{B-2.2.3 Weather}

From the PORTAL timeseries plot web page (see Figure B-2.1), you can click "Weather Popup" to see a graph of rainfall and temperature. The graph shown in Figure B-2.3 on the following page can also be generated using the PORTAL Weather feature's Daily data type. Both interfaces allow tabular data to be viewed or downloaded. 


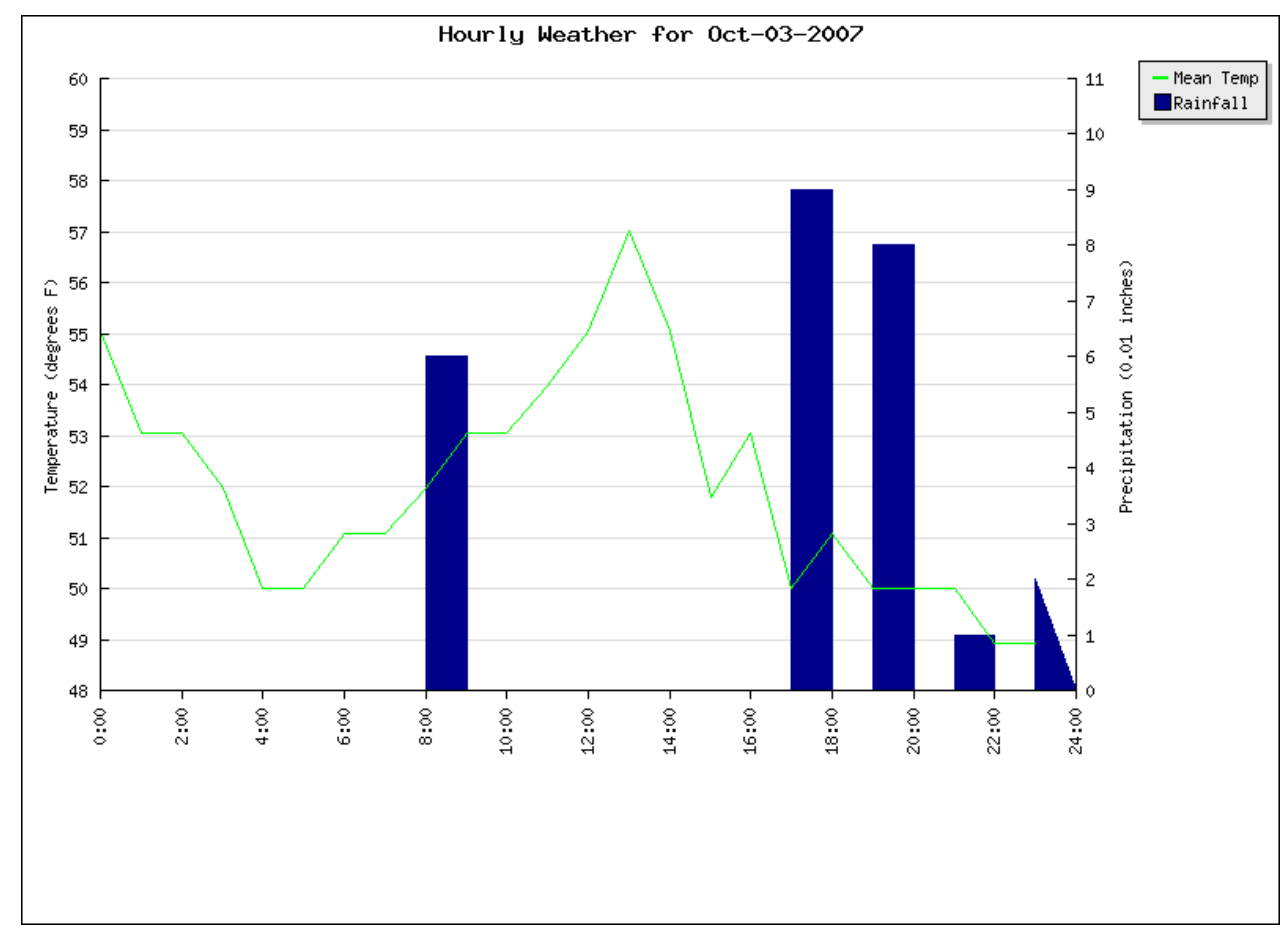

Figure B-2.3: Example of PORTAL hourly weather chart, I-205 NB, 10/3/2007

Using the Weather feature, it is also possible to view weather data for an entire month (Figure B2.4).

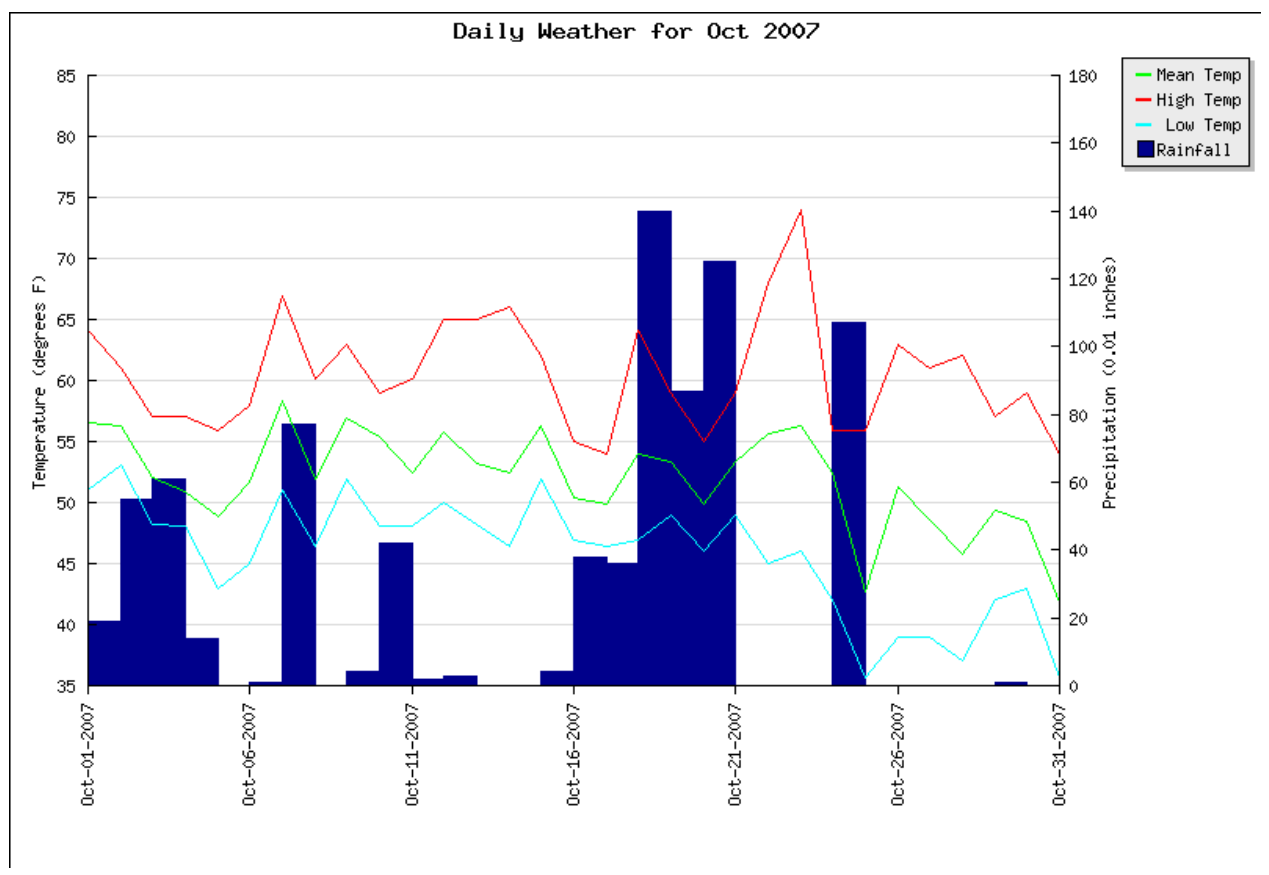

Figure B-2.4: Daily Weather plot, October 2007 


\section{B-2.3 DETERMINING COMPARABLE DAYS}

Traffic flow fundamental diagrams can be used to classify freeway performance on different days and categorize days of like traffic conditions for further analysis. Figure 5.1 in the main body of the report illustrates the relationships between flow and occupancy, speed and occupancy, and speed and flow. The following subsection of this appendix describes the use of Bivariate Plots in PORTAL to classify freeway performance.

\section{B-2.3.1 PORTAL Bivariate Plot}

PORTAL's Bivariate Plot feature can be used to construct fundamental traffic flow diagrams for stations along Portland freeways. The example in Figure B-2.5 on the following page demonstrates use of bivariate plots for occupancy and flow for the Johnson Creek station on I$205 \mathrm{NB}$, for the morning peak period on October 2, 2007. It was produced using the following steps:

1. Select "Bivariate Plots" from PORTAL's left navigation bar.

2. Set the $\mathrm{X}$-axis to "Occupancy" and the $\mathrm{Y}$-axis to "Flow."

3. Select "Johnson Creek (MP 16.2)" as the station.

4. Set the date to "October 2, 2007."

5. Include "All lanes."

6. Set the hours to be included to the morning peak period: 06:00 to 10:00. These correspond to SWARM's hours of operation on I-205 NB. For the afternoon peak period, SWARM operates between 13:00 and 19:00 on I-205 NB (this may vary by freeway).

7. Click "View Plot." 


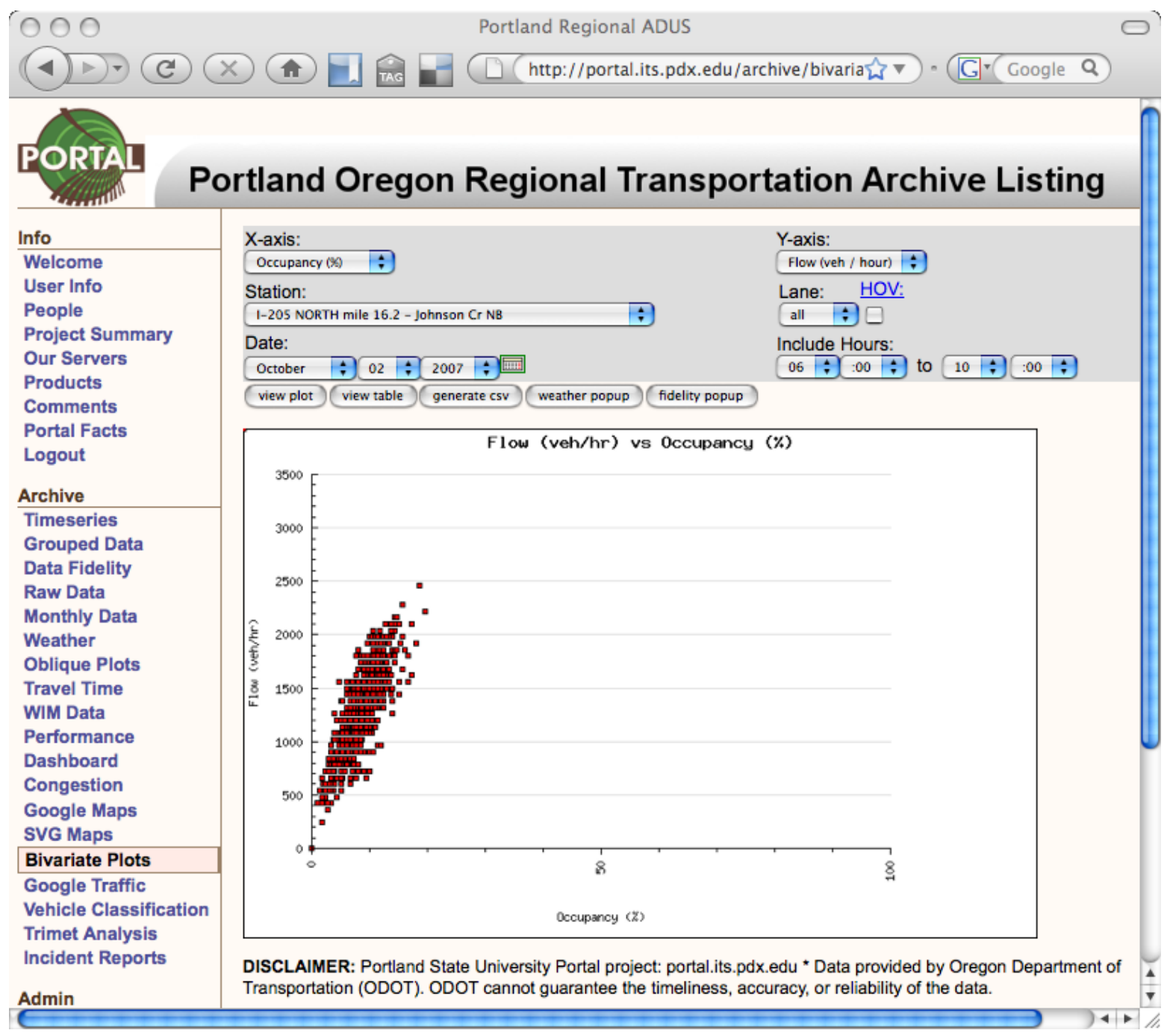

Figure B-2.5: Flow-Occupancy Fundamental Diagram, I-205 NB, Johnson Creek, October 2, 2007, 6-10 am

\section{B-2.3.2 Classifying Freeway Conditions}

The Flow-Occupancy plot in Figure B-2.5 (above) shows relatively un-congested conditions on October 2, 2007 from 6-10 am. Occupancy never exceeded 20\% during this time period. In contrast, the plot for October 5, 2007, in Figure B-2.6 on the following page, illustrates the presence of congested conditions: there are a number of data points where occupancy exceeded $20 \%$ and where vehicle flows decreased with occupancy. More precisely, the plots in Figure B2.6 and Figure B-2.7 show that occupancy of approximately $18 \%$ differentiates congested and un-congested conditions. 


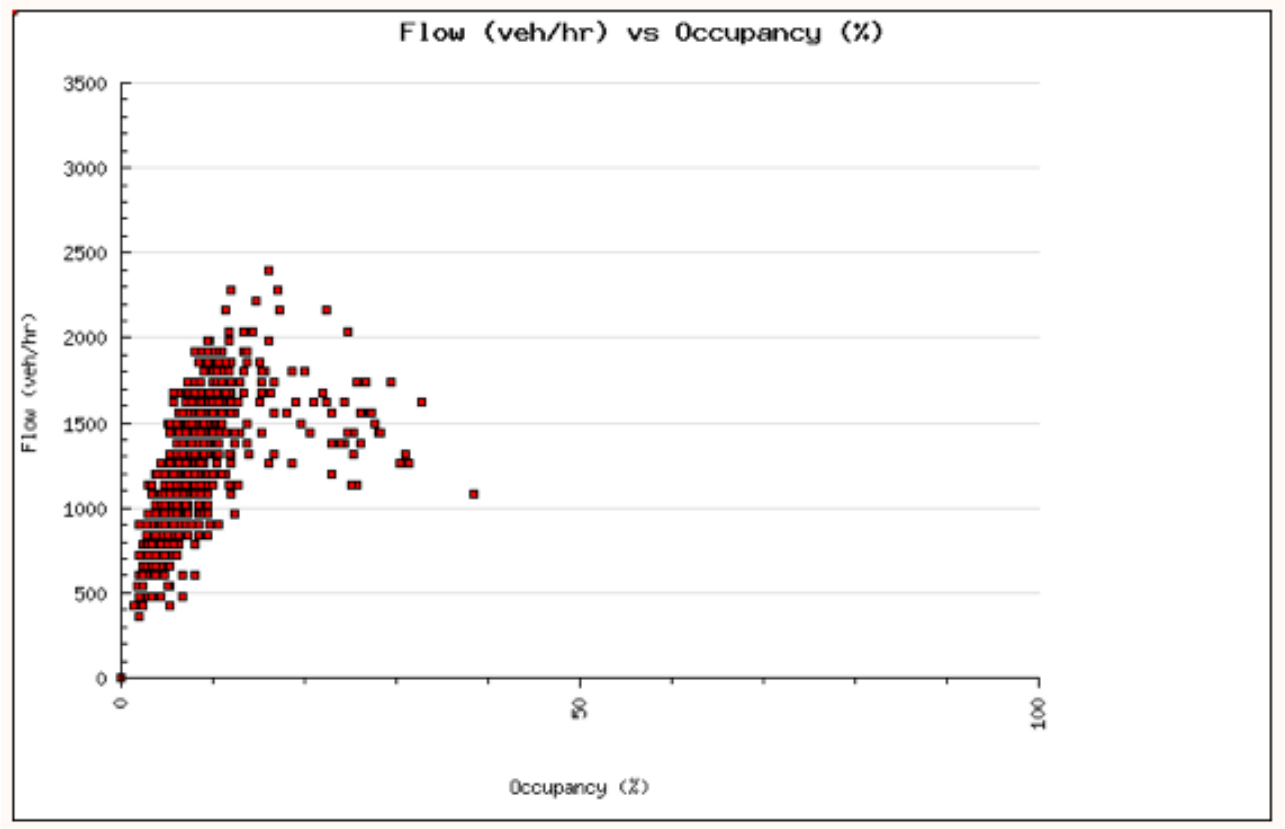

Figure B-2.6: Flow-Occupancy Fundamental Diagram, I-205 NB, Johnson Creek, October 5, 2007, 6-10 am

The plot in Figure B-2.7 below illustrates a higher level and duration of congestion on October 4, 2007. In comparison to October 5 , there are significantly more data points with occupancy greater than $18 \%$ and occupancy exceeds $40 \%$ for a number of data points.

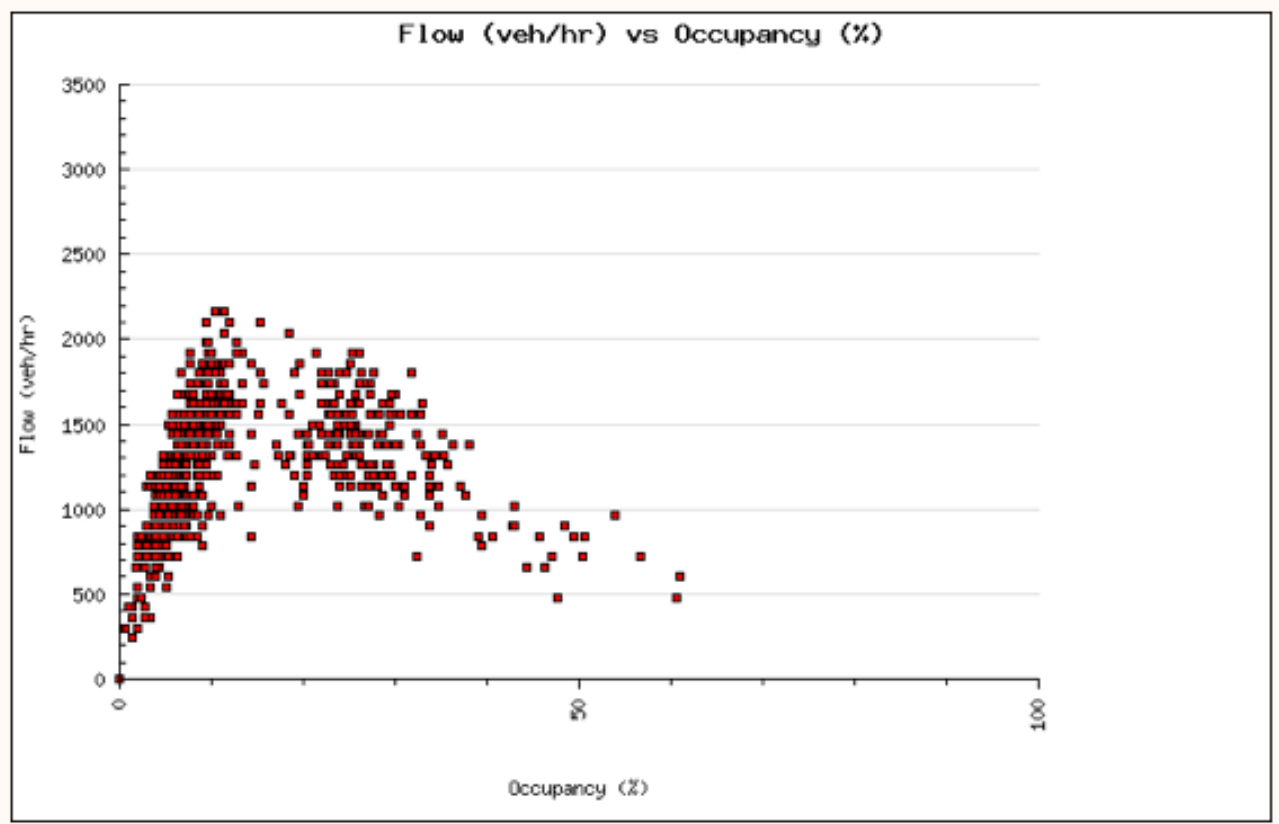

Figure B-2.7: Flow-Occupancy Fundamental Diagram, I-205 NB, Johnson Creek, October 4, 2007, 6-10 am 
To complement the Flow-Occupancy diagrams shown on the previous page, the panels in Figure B-2.8 (below) show plots of Speed (Velocity) and Flow for the Johnson Creek station on I-205 NB. Panel (a) shows October 2, 2007, the day of relatively un-congested conditions. In Panel (b), a larger number of data points fall below $35 \mathrm{mph}$ on October 5. Panel (c) shows lower speeds and flow on October 4.

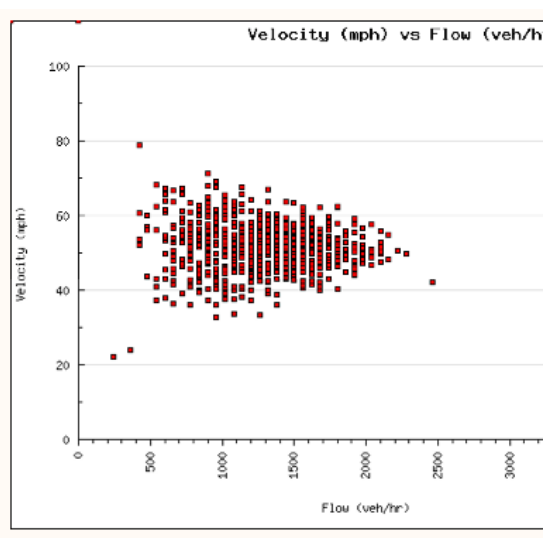

(a) October 2, 2007

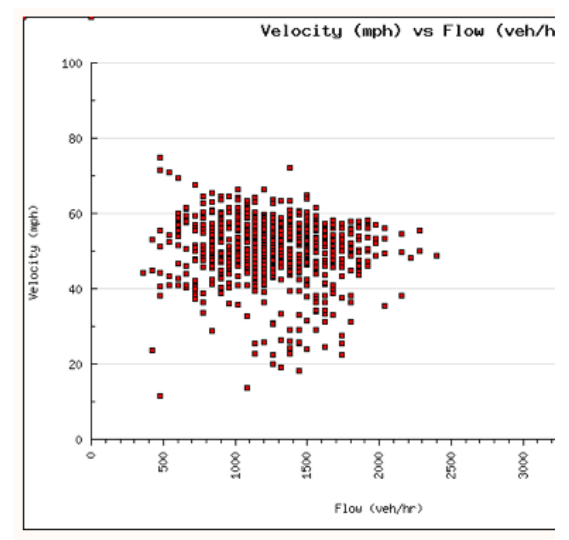

(b) October 5, 2007

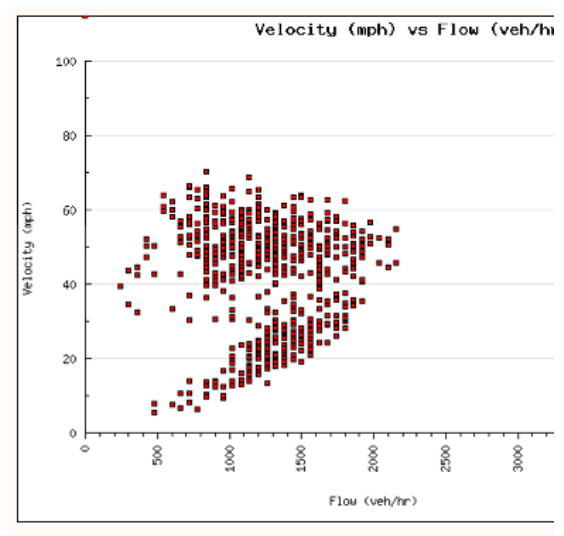

(c) October 4, 2007

Figure B-2.8: Speed-Flow fundamental diagrams, I-205 NB, Johnson Creek, 6-10 am, for October 2, 5, and 4, 2007

\section{B-3 DATA ANALYSIS}

This section demonstrates the use of space-time plots to examine freeway performance across a corridor and line plots to look at a particular freeway station in greater depth.

\section{B-3.1 SPACE TIME PLOTS}

A space-time plot is useful for showing the magnitude of a quantity across space and time. Please refer to Section B-0 (b-2.1 Basic Portal Tools) in this appendix for detail on creating space-time plots using the PORTAL Timeseries feature, such as the one shown in Figure B-3.1 on the following page. This plot shows freeway speed on I-205 NB between the Gladstone and Division stations, from 6 am to $8 \mathrm{pm}$. 


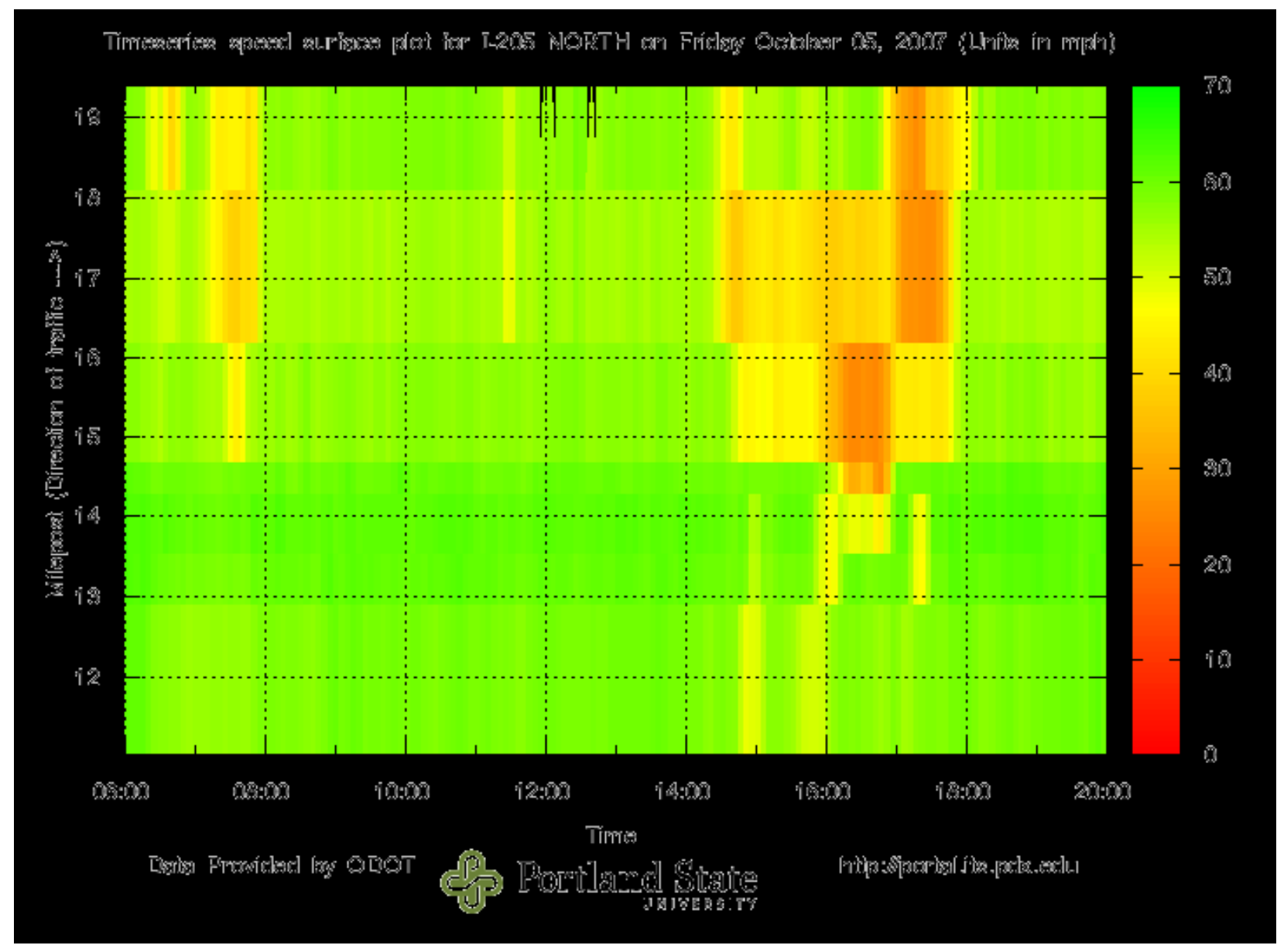

Figure B-3.1: Speed Space-Time Plot, I-205 NB, October 5, 2007, between Gladstone (MP 11.05) and Division (MP 19.78)

In Figure B-3.1 (above) the darker/red-orange colors denote lower speeds. Moderate morning congestion can be seen both north and south of Foster Road (MP 18.1) and propagating upstream to at least the Johnson Creek (MP 16.2) station. Congested speeds are not present as far south as Sunnyside Rd. (MP 14.32). The plot also shows heavier afternoon congestion from about 2:45 pm to $6 \mathrm{pm}$.

Delay is another quantity that can be displayed on a space-time plot, measured in vehicle-hours of delay (relative to free-flow speeds). In Figure B-3.2 on the following page, lighter/orangeyellow colors indicate greater amounts of delay and present in the regions of congested speeds shown in the previous figure. 


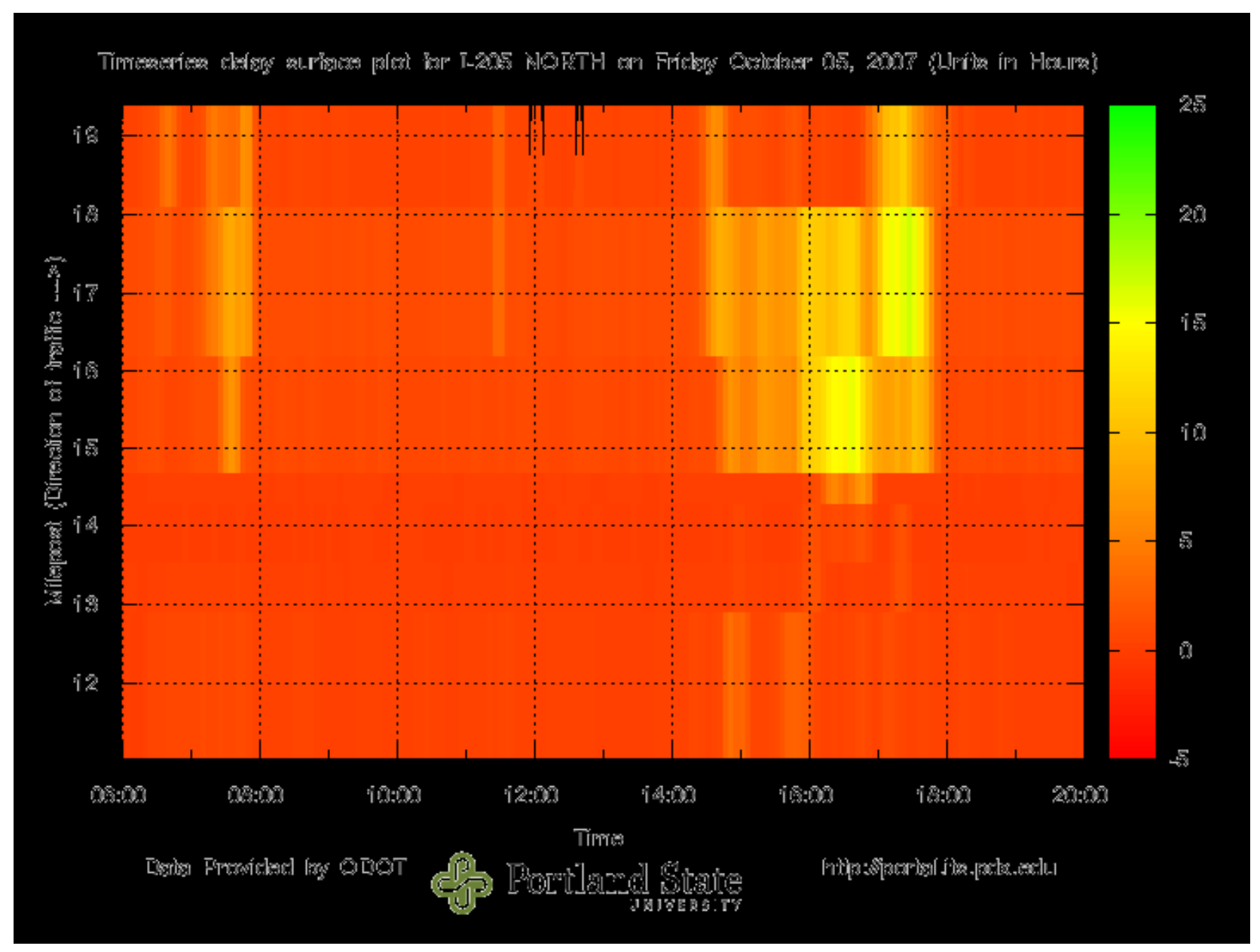

Figure B-3.2: Delay Space-Time Plot, I-205 NB, October 5, 2007, between Gladstone (MP 11.05) and Division (MP 19.78)

Data from the Timeseries function can also be viewed in tabular form for more fine-grained analysis. It is possible to do so both within the web browser (View Table) or to download the data as a "zipped" comma-delimited (CSV) file such as for use with Microsoft Excel (Generate CSV). Volume, occupancy, VMT, VHT, travel time and delay are available in addition to speed.

\section{B-3.2 MAINLINE SPEED, RAMP VOLUME, AND MAINLINE FLOW}

Plots of mainline speed and flow and on-ramp volume are useful in correlating mainline freeway performance with on-ramp activity and metering rates. They may be useful in conducting more in-depth analysis of stations or congested regions identified on a space-time plot. This subsection demonstrates the use of PORTAL to create such plots and provides several examples. 


\section{B-3.2.1 Creating Timeseries Line Plots in PORTAL}

The Timeseries feature in PORTAL can be used to create line plots for individual stations. Line plots are generated when a station is selected as opposed to an entire freeway corridor. The steps below demonstrate how to create different types of plots using the Timeseries feature shown in Figure B-3.3.

1. Select the "Timeseries" feature from PORTAL's left navigation bar.

2. Select a particular "Station," e.g. Johnson Creek on I-205 NB.

3. Select a "Date," e.g. October 5, 2007

4. Select the "Data Resolution," e.g. 5 minute.

5. Specify "Quantity" and "Lane" as shown in the Table B-3.1 (below) for each type of plot. When plotting ramp volume, specify an appropriate maximum value for the Y-axis (Ymax), e.g. 100 in Panel (c) of Figure B-3.4 in subsection B-3.2.2. Ramp volume refers to vehicle counts at the "Pass" loop detectors just downstream from the metering lights. Also note that "All Lanes" does not include the ramp.

Table B-3.1: Specifying quantity and lane for plot type

\begin{tabular}{c|c|c|c}
\hline Plot Type & Quantity & Lane & Ymax \\
\hline Ramp Volume & Volume & Ramp & e.g. 100 \\
\hline Mainline Flow & Volume & All & N/A \\
\hline Mainline Speed & Speed & All & N/A \\
\hline
\end{tabular}

6. If desired, specify a time interval (include "Hours"), e.g. use 6-10 am to correspond to SWARM's morning hours of operation (or 1-7 pm in the afternoon).

7. Click "View Plot."

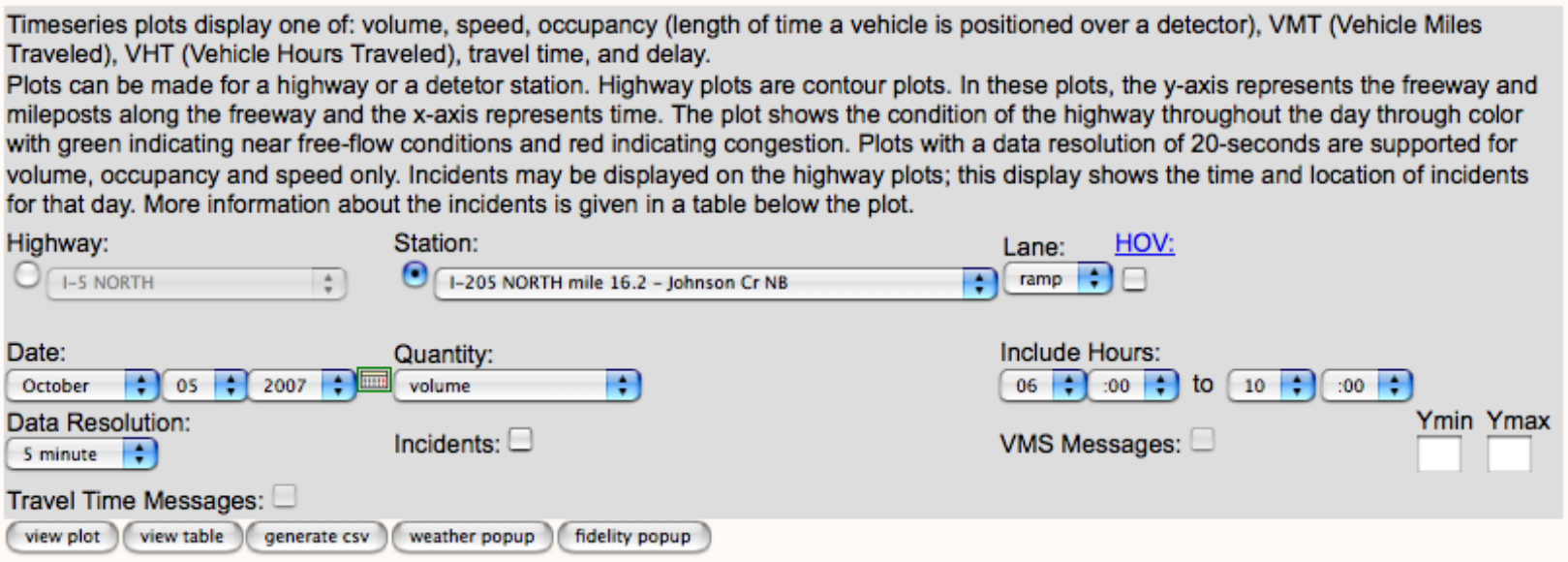

Figure B-3.3: PORTAL Timeseries feature, used to create line plots for individual stations 


\section{B-3.2.2 Example Plots}

The plots below (Figure B-3.4) demonstrate use of the Timeseries feature to create plots of freeway and on-ramp performance for the Johnson Creek station on I-205 NB on October 5, 2007, from 6-10 am. Several observations are noted to the left of the plots.

\section{(a) Mainline Speed (miles/hr)}

Mainline speeds began to drop at about 7:25 am, shortly after mainline flow reached a maximum of about 1,600 vehicles per lane per hour (Panel B).

\section{(b) Mainline Flow (vehicles/lane/hr)}

Note: there are three lanes at Johnson Creek Blvd.

\section{(c) Ramp Volume (vehicles/5-min)}

This plot shows ramp volume per 5-minute period.

On-ramp volume was about 95 vehicles per 5 minute period (about 18 vehicles per minute) at 7:10 am. Between about 7:35 and 7:55 there was a decrease in the number of vehicles entering the freeway.

Note: a Ymax of 100 was specified when creating the plot.
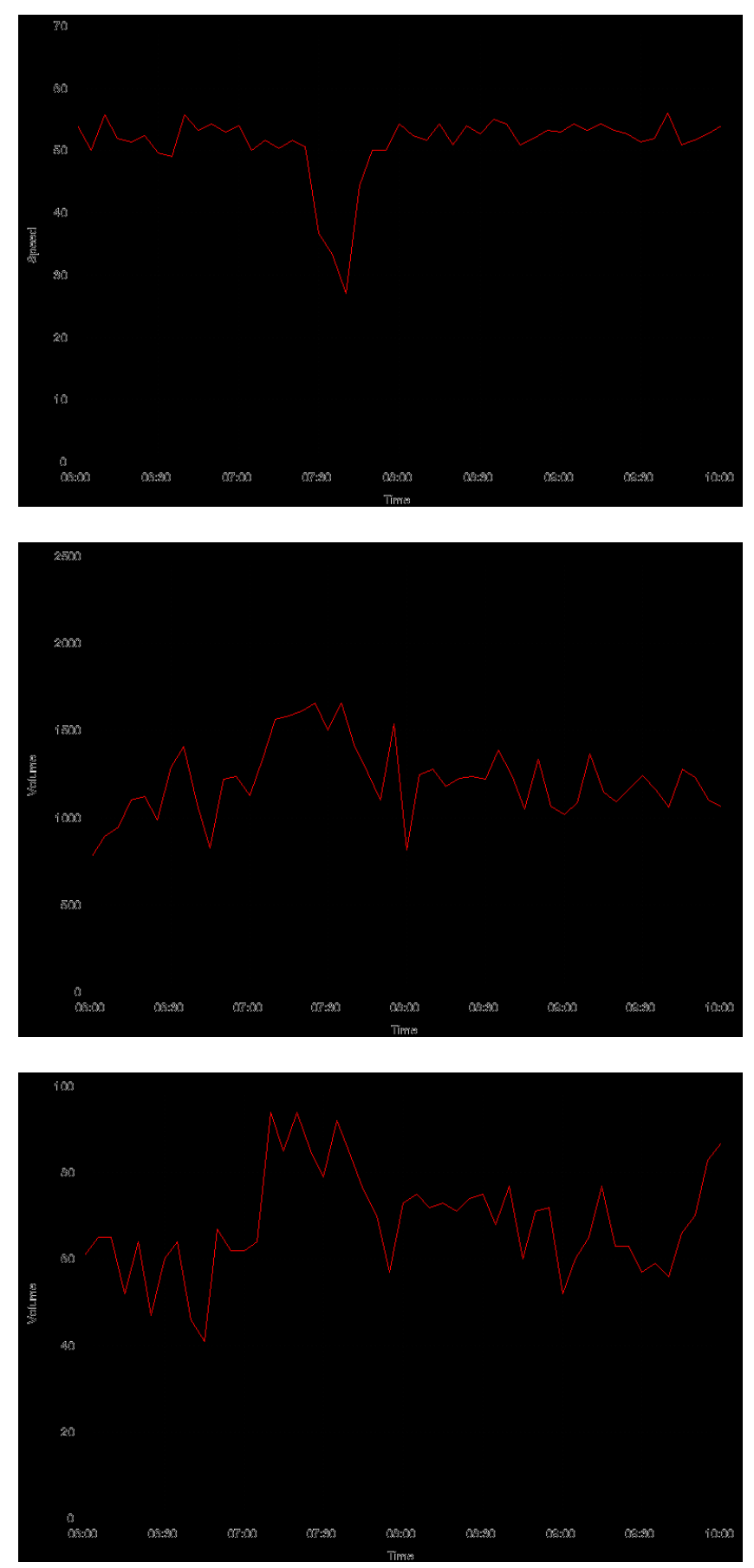


\section{(d) Ramp Volume (vehicles/hour)}

This plot shows an hourly ramp volume, obtained using a data resolution of 1-hour. The average ramp volume of about 800 vehicles per hour in the morning peak compares to the maximum 5-minute volume of approximately 95 vehicles shown in Panel (c).
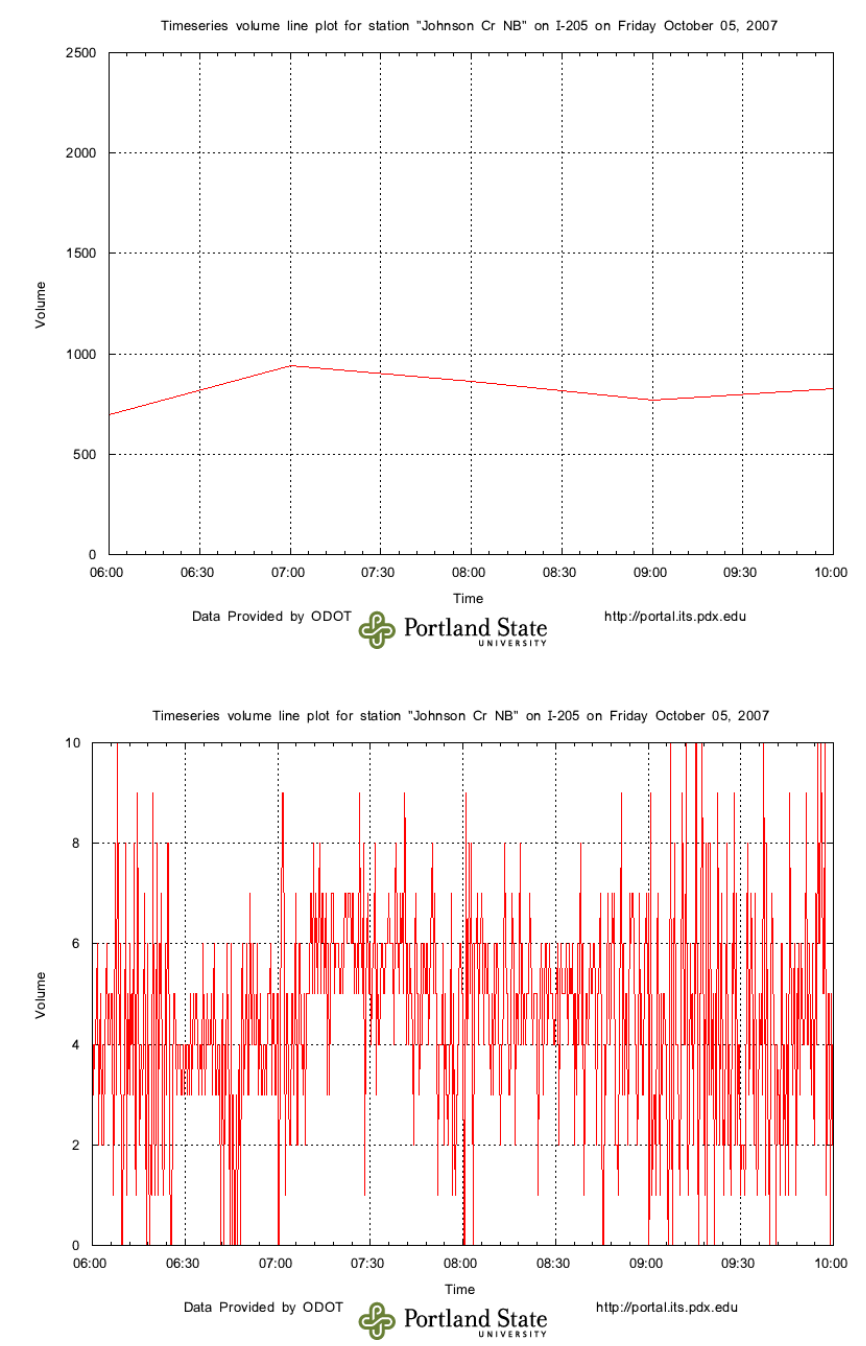

\section{(e) Ramp Volume (vehicles/20-seconds)}

This plot shows ramp volume per 20-second time interval for more fine-grained analysis.

Note that on October 5, 2007 the ramp metering system was operating in a pre-timed mode for study purposes, however ODOT personnel can determine the actual metering rate in real time from the ATMS (traffic management system) and compare it to the volumes obtained from the loop detectors.

Data resolution was set to 20 seconds and Ymax was set to 10 .$$
\text { was set to } 10 \text {. }
$$

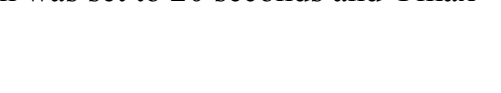

Figure B-3.4: Plots of (a) flow for all lanes, (b) mainline speed, (c) 5-minute on-ramp volume, (d) hourly on-ramp volume, and (e) 20-second on-ramp volume. I-205 NB, Johnson Creek station, October 5, 2007, 6-10 am

As stated in the introduction to this appendix, the information provided above is current at the time of publication but PORTAL is a dynamic web-based tools and some options may change. To request a PORTAL account, go to the website http://portal.its.pdx.edu. 